\title{
ALEXANDRIUM CATENELLA CYST DYNAMICS IN A COASTAL EMBAYMENT: TEMPERATURE DEPENDENCE OF DORMANCY, GERMINATION, AND BLOOM INITIATION
}

\author{
By \\ Alexis Dal Fischer \\ B.A., Wellesley College, 2010 \\ Submitted in partial fulfillment of the requirements for the degree of \\ Doctor of Philosophy \\ at the \\ MASSACHUSETTS INSTITUTE OF TECHNOLOGY \\ and the \\ WOODS HOLE OCEANOGRAPHIC INSTITUTION
}

June 2017

(C) 2017 Alexis Dal Fischer

All rights reserved.

The author hereby grants to MIT and WHOI permission to reproduce and to distribute publicly paper and electronic copies of this thesis document in whole or in part in any medium now known or hereafter created.

Signature of Author

Joint Program in Oceanography / Applied Ocean Science and Engineering Massachusetts Institute of Technology and Woods Hole Oceanographic Institution May 26, 2017

Certified by

Dr. Donald M. Anderson Thesis Supervisor

Accepted by

Dr. Ann M. Tarrant Chair, Joint Committee for Biological Oceanography Woods Hole Oceanographic Institution 


\section{Contents}

Acknowledgements

Abstract

CHAPTER 1 Introduction

CHAPTER 2 Cold exposure controls the duration of dormancy in cysts of the toxic dinoflagellate, Alexandrium catenella

CHAPTER 3 Field emergence and laboratory germination of cysts of the toxic dinoflagellate Alexandrium catenella in response to vernal warming

CHAPTER 4 Temperature modulation of dormancy transitions, germination, and division as a determinant of Alexandrium catenella bloom initiation

CHAPTER 5 Summary and conclusion

APPENDIX The persistence of Alexandrium catenella cyst seedbeds in Nauset Marsh
5 


\section{Acknowledgements}

These past six years have been an incredible journey, both scientifically and personally. But it would not have been possible without the support and collaboration of many people and groups. It takes a village to produce a thesis.

I am deeply grateful for the funding provided through the Woods Hole Center for Oceans and Human Health by National Science Foundation (OCE-0430724 and OCE-0911031) and the National Institute of Environmental Health Sciences (1P50-ES01274201 and 1P01ES021923). This work was also supported by student awards from the Woods Hole Oceanographic Institution (WHOI) Ocean Ventures Fund and from the Friends of Cape Cod National Seashore. I am indebted to the NOAA Center for Sponsored Coastal Ocean Research, the AMGEN Scholars U.S. Program, the MIT Student Assistance Fund, the MIT Graduate Student Council, the WHOI Biology Department, and the WHOI Academic Program Office for granting me conference travel funds that have afforded me numerous opportunities to see the world, while taking my science to the next level.

None of this would have been possible without the talents and enthusiasm of my advisor, Don Anderson. He afforded me incredible intellectual freedom, financial security, and opportunities that simply would not have been possible in another group. I feel privileged to have worked on dormancy and germination of Alexandrium cysts in a shallow estuary on Cape Cod - the very topic that launched his career a number of years ago. This made Don perfect at playing devil's advocate whenever I would present a new experiment or conceptual model. I can remember so many times walking into his office to ask him with a quick question, only to emerge two hours later with even more questions. I look forward to continuing to unravel the mysteries of dinoflagellate cysts with him, and more long chats over good wine.

Michael Brosnahan was my lighthouse in the final foggy years of my thesis. He is an extraordinary mentor, and friend, who somehow always found time to talk science with me. His future students will be lucky to have someone who cares so much. I am grateful to him for always pushing me to follow the research question, rather than be limited by a particular method. I am also indebted to him for guiding me through the revisions of my first manuscript - it was not pretty but I certainly learned a lot!

My thesis committee, Dave Ralston, Ed Delong, Matt Johnson, and Chris Gobler, were remarkably supportive, sharing their knowledge, insights, and connections with me. I am especially grateful to Dave, who through fielding numerous questions about modeling and MATLAB, undoubtedly helped make me a better oceanographer. Special thanks to the chair of my committee, Heidi Sosik, who guided me and several other students through the writing of a scientific review paper.

Thanks to the many people who have shared the lab with me - it's always been a friendly and fun place to work. I am especially indebted to Dave Kulis, the MacGyver in Chief, who makes 
the lab run like a well-oiled machine. I have learned most of my field and lab techniques from Dave, and he's was always ready to step in and help. Therefore, I'm terrified what a lab situation will be like without him. Thanks to my officemate and partner in crime Katie Pitz for keeping me sane and embarking on so many shenanigans with me. I won't forget our post-work swims at Stoney Beach, our amazing Alfred Hitchcock's "The Birds" Halloween costume, or hiking the Milford Track in New Zealand. I'm grateful to my "east coast mom", Judy Kleindinst, for her support, so many great chats, and excellent cooking adventures. Thanks to Bruce Keafer for showing me the way with large-scale cyst surveys and field endeavors. Thanks also to Finn Correia for putting up with my crazy and for making field and lab work look easy.

I'm grateful to the WHOI scientific community for always make me feel welcome. Special thanks to Sam Laney, Ann Tarrant, Stace Beaulieu, Mike Neubert, Dennis McGillicuddy, Mark Hahn, and Andy Solow for stimulating discussions and for their support. I'm lucky to have had such wonderful, brilliant people in my biology cohort ( \pm 1 year) - Eleanor Bors, Harriet Alexander, Jenny Panlilio, Megan May, Julie van der Hoop, Emily Brownlee, Kristin HunterCevera, and Nicolas Macfarlane - each of whom I have learned so much from and I know will go on to be highly successful in their JP afterlives.

I've been blessed to undergo much of my graduate school experience while sharing a house with close friends. Winn Johnson and Oscar Sosa - my Cambridge housemates and fellow classmates in the C-MORE Microbial Oceanography summer course in Hawaii - offered me understanding and kindness in our first year in the Joint Program. In Woods Hole, I was lucky enough to live with Alice Alpert, Ben Linhoff, and occasional honorary-housemate Eleanor Bors for a number of years. Our door was constantly open to a continual onslaught of dinner parties, bonfires, costumed dance parties, and holiday cookie baking paries. From carrying each other through those difficult times that one goes through when completing a thesis, to celebrating the good times, our experiences have have shaped my journey in more ways than I can describe.

Finally, thanks to my family for believing in me this whole time. I'm grateful to my sister Lauren for keeping me grounded and reminding me that a world exists beyond Woods Hole. Thanks to my parents for immersing me in the magic of science and the natural environment from a young age. You've inspired me endlessly. I love you all. 


\title{
ALEXANDRIUM CATENELLA CYST DYNAMICS IN A COASTAL EMBAYMENT: TEMPERATURE DEPENDENCE OF DORMANCY, GERMINATION, AND BLOOM INITIATION
}

\author{
By Alexis Dal Fischer
}

Submitted to the MIT-WHOI Joint Program in Oceanography and Applied Ocean Science and Engineering on April 28, 2017 in partial fulfillment of the requirements for the degree of Doctor of Philosophy in Biological Oceanography

\begin{abstract}
Blooms of the dinoflagellate Alexandrium catenella cause paralytic shellfish poisoning syndrome and present an expanding public health threat. They are inoculated through the germination of benthic cysts, a process regulated by internal and environmental factors, most importantly temperature. Less understood is the effect of temperature conditioning on cyst dormancy cycling, which inhibits germination for long periods. This thesis characterizes the temperaturedependence of both dormancy and germination in natural $A$. catenella cyst populations from Nauset Marsh (Cape Cod, MA, USA), a small estuarine embayment, and relates these processes to the phenology of blooms there. Through laboratory germination assays, it is shown that dormant $A$. catenella cysts require a quantifiable amount of chilling to exit dormancy and attain quiescence (i.e. become germinable). A series of experiments compares germination rates of quiescent cysts across a range of temperatures through laboratory experiments and field incubations of raw sediment using plankton emergence traps (PETs). Emergence rates of $A$. catenella germlings measured by PETs increased linearly with temperature and were comparable to germination under constant laboratory conditions. Total emergence fluxes were much lower than expected, suggesting that germination occurs in a much shallower layer of sediments than typically assumed. The results are synthesized to develop a temperature-dependent model to examine the sensitivity of $A$. catenella bloom phenology to dormancy-breaking by winter chilling. Notably, the chilling-alleviated dormancy model accurately predicted the timing of quiescence (January) and the variable bloom phenology from multiple blooms in Nauset. Once cysts became quiescent and began to germinate, however, temperatures were typically too cold for growth to exceed losses so there was a several-week lag until bloom development. Years with warmer winters and springs had shorter lag periods and thus significantly earlier blooms. Ecologically, dormancy-breaking by a chilling threshold is advantageous because it prevents the mismatch between conditions that are favorable for germination but not for the formation of large blooms. Synchronized germination after winter chilling also promotes promotes efficient conversion from the cyst seedbed to the spring bloom inoculum. The dormancy mechanism characterized here may be present in other cyst-forming dinoflagellates, but there is likely plasticity that reflects the temperature regime of each habitat.
\end{abstract}

Thesis Supervisor:

Dr. Donald M. Anderson

Senior Scientist, Woods Hole Oceanographic Institution 


\section{Chapter 1}

\section{Introduction}

\section{The phenomenon of annual rhythmicity}

Many organisms that inhabit seasonally changing environments have evolved specific behavioral and life cycle strategies that adapt them to annual fluctuations of biologically significant forcings. This is seen in the clustering of biological activities at times of the year when they are most likely to be successful. In temperate regions, the conditions of the spring, summer, and fall are exploited by many organisms for growth and reproduction. During winter, some species adapt to severe environmental conditions by reducing metabolic activity into a state of dormancy, diapause, or hibernation, while others avoid these conditions entirely by migrating to more favorable climates. Annual biological rhythms are most clearly expressed in organisms inhabiting temperate and arctic regions, where seasonal differences in environmental conditions are most pronounced. In such regions, many of the environmental factors relevant for an organism vary in regular annual fashion, and thus can be exploited as a proximal cue. Ambient temperature and photoperiod (the light fraction of the 24-h day) are both proximate factors used by many mid- and high-latitude species ranging from plants to insects, to fish and algae (e.g. Hoar 1969; Lofts 1974; Saunders 1976; Gwinner 1986).

The focus of this thesis is the seasonal strategy employed by many dinoflagellate species - the dormant resting cyst stage - and how it responds to environmental temperature cues. In the introductory chapter that follows, I will review the current state of knowledge concerning dinoflagellate cysts with a focus on Alexandrium catenella, a causative organism of paralytic shellfish poisoning, and the control of germination and its relationship with bloom phenology.

\section{Dinoflagellate cysts}

Dinoflagellates are ecologically diverse, eukaryotic organisms that comprise one of the major groups of phytoplankton. Because some species of dinoflagellates are associated with harmful algal blooms (HABs), their complex life cycle has been studied intensely. The life cycle of more 
than $10 \%$ of the approximately 2000 known marine dinoflagellate species includes a non-motile, benthic cyst stage (Bravo and Figueroa 2014) that is morphologically distinct from its vegetative counterparts. Cysts play an important ecological role because they can survive extended periods when environmental conditions are unfavorable, and then germinate to become planktonic swimming stages once conditions become favorable again (e.g. Wall 1971; Dale 1983). Evolutionarily, the need to adapt to short-term environmental fluctuations and seasonality is thought to have driven the development of this life stage. Dinoflagellates have two types of cysts. Pellicle cysts are formed asexually (Bravo et al. 2010) when motile vegetative cells are exposed to unfavorable conditions such as a sudden change of temperature or salinity (Anderson and Wall 1978; Dale 1983). When conditions become favorable again, pellicle cysts quickly transform back into vegetative cells. In contrast, resting cysts are produced sexually, become dormant, and can persist in the sediments for several decades or more (Keafer et al. 1992; Miyazono et al. 2012; Feifel et al. 2012). The latter type of cysts are the subject of this thesis.

During a bloom and often as it is ending, resting cysts form and remain in the bottom sediments until some germinate, inoculating subsequent blooms. In many dinoflagellate species, bloom inoculation is inhibited immediately after a bloom and during certain periods of the year because of cyst dormancy (Dale 1983). Dormancy is an internal state that impedes germination under otherwise adequate environmental conditions. This is a common definition that is also used for the seeds and bulbs of higher plants (e.g. Bewley et al. 2013). Once the barrier imposed by dormancy is broken, cysts remain in an internal resting state, termed quiescence, until external factors are favorable for germination. Temperature is considered a primary regulatory factor and must be within an optimal range for germination to occur (e.g. Huber and Nipkow 1923; Anderson and Morel 1979; Bravo and Anderson 1994). Oxygen is a requirement for germination in all species that have been examined thus far (Anderson and Keafer 1987; Rengefors and Anderson 1998; Kremp and Anderson 2000). For many species, the lack of light reduces the germination rate (Anderson et al. 1987; Cannon 1993; Rengefors and Anderson 1998), but for a few species, the presence of light is an absolute requirement for germination (Binder and Anderson 1986; Anderson et al. 1987; Rengefors and Anderson 1998). 
There are two distinct types of dormancy and they can be distinguished by their timing within the lifetime of dinoflagellate cysts. The first, termed mandatory dormancy, occurs immediately after cysts are formed and is associated with physiological maturation. It can last from several weeks to months and only occurs once in a cyst's lifetime (e.g. Pfiester 1977; Anderson 1980; Pfiester and Anderson 1987; Perez et al. 1998). The second type, simply termed dormancy, occurs in mature cysts that are otherwise competent to germinate, and thus controls when cysts can germinate seasonally. Although mandatory dormancy is relatively well-characterized in dinoflagellates (e.g. Anderson and Morel 1979), the regulation of dormancy in mature cysts is less understood. The majority of our understanding of dormancy in mature cysts derives from investigations with the genus Alexandrium because it includes the largest number of toxic species associated with HABs.

\section{Alexandrium species}

The dinoflagellate genus Alexandrium is comprised of more than thirty morphologically defined species. At least half of these are known to be toxic or have otherwise harmful effects (Anderson et al. 2012). Alexandrium produces three different families of known toxins - including saxitoxins, spirolides, and goniodomins. The most significant of these in terms of impacts are saxitoxins, a class of neurotoxins that selectively block sodium ion channels in animals. Human consumption of shellfish and fish contaminated with these toxins cause intoxication and death from paralytic shellfish poisoning (PSP). PSP is the most geographically widespread of HABrelated shellfish poisoning syndromes (e.g. Hallegraeff 1993; Anderson et al. 2012). The impacts of outbreaks can include loss of wild and cultured seafood resources, impairment of tourism and recreational activities, alterations of marine trophic structure, and death of marine mammals, fish, and seabirds. Thus, a major goal in Alexandrium research has been to identify the physiological and ecological mechanisms underlying the timing and biogeography of blooms.

The majority of PSP outbreaks have been caused by the A. tamarense species complex, which is comprised of the morphotypes A. tamarense and A. catenella ( $=$ A. fundyense ${ }^{1}$ ) (Cembella 1998). The overall appearance of each morphotypes is highly similar and is distinguished mainly by

\footnotetext{
${ }^{1}$ Alexandrium catenella and A. fundyense are conspecific, and "catenella" was determined by the Nomenclature Committee for Algae to have nomenclatural priority (Prud'homme van Reine 2017).
} 
chain-forming ability, cell shape, and the presence or absence of a ventral pore between plates 1' and 4' (Balech 1995). The morphotypes were long considered to be valid species, but several phylogenetic analyses have demonstrated that morphology is not a good indicator of evolutionary relationships within the A. tamarense complex (Scholin et al. 1995; Higman et al. 2001; John et al. 2003; Lilly et al. 2007) - thus, invalidating the use of morphotype names as species descriptors. Using a collection of clones from all six temperate continents, Lilly et al. (2007) described five distinct ribosomal clades, designated Groups I-V, that strongly correlated with their clones region of origin. Notably, each of the clades included representatives of the tamarense, fundyense, and catenella morphotypes. Two of the clades produced saxitoxin and/or its congeners (Group I and IV), while the other three clades were nontoxic. Both the topology of the ribosomal phylogeny and their geographic separation demonstrated that the five clades were distinct, cryptic species (Lilly et al. 2007). This thesis focuses on the toxic blooms formed by $A$. catenella (Group I).

\section{Role of resting cysts in Alexandrium catenella population dynamics}

Two types of hydrographic systems are commonly associated with A. catenella blooms: (1) open coastal waters with widespread blooms; and (2) shallow, restricted embayments with localized blooms (Anderson 1998). The seasonality of blooms in both habitats is caused by life history transformations between mature cysts in the sediment and vegetative cells in the water column blooms (Anderson 1998). Once vegetative cells enter the water column following cyst germination, they begin to divide asexually via binary fission to produce a bloom. Net growth of a population is significantly affected by a variety of chemical and physical factors, most importantly nutrients, circulation, and stratification, as well as biological loss processes (e.g. grazers, parasites, mortality). At the end of the bloom, vegetative growth ceases and the cells undergo sexual reproduction (Anderson et al. 1985; Pfiester and Anderson 1987; Brosnahan et al. 2015). Gametes are formed that fuse to form swimming zygotes (planozygotes) that ultimately become dormant resting cysts. These life cycle transitions of $A$. catenella are summarized in Fig. 1.

Until germination, resting cysts remain in the benthos, in accumulations commonly referred to as "seedbeds". Cyst seedbeds can be localized, but also widespread and dispersed, thus a discrete 
seedbed does not necessarily provide the germination inoculum in some habitats (Anderson et al. 2012). In both estuarine systems (Crespo et al. 2011) and in deeper coastal waters (Anderson et al. 2014), discrete cyst seedbeds have been shown to provide the inoculum for $A$. catenella blooms. For example, Nauset Marsh estuary on Cape Cod has three localized seedbeds at the extreme ends of the complex network of channels and kettle ponds that each host independent, localized A. catenella blooms (Crespo et al. 2011). Linkages between localized cyst seedbeds and bloom initiation are most commonly reported in shallow sites like lagoons, harbors, and estuaries. However, this lack of similar observation in open coastal waters could simply reflect the difficulty and financial cost of large-scale mapping; large studies have documented cyst accumulations stretching hundreds of kilometers along the shore (Anderson et al. 2012). A key example are the offshore A. catenella cyst accumulations in the Gulf of Maine (GOM) that are linked to the initiation of an annual, widespread coastal bloom (Anderson et al. 2005; 2014).

Excystment dynamics are determined by the interplay between internal and external controls on dormancy and quiescence (summarized in Fig. 1). However, the mechanism of regulation differs among A. catenella habitats. The seasonality of the open coastal blooms of A. catenella in the GOM is a direct result of timed germination of cysts in deep offshore seedbeds. There, dormancy transitions of mature cysts are regulated by an endogenous annual rhythm which restricts quiescence to a discrete interval in the spring and early summer - thus germination can only occur at these times (Anderson and Keafer 1987; Matrai et al. 2005). This fixed germination interval is ecologically advantageous for cysts in deep seedbeds because they lack exposure to strong seasonal signals that mark the onset of conditions favorable for blooms in the overlying euphotic waters. In contrast, for $A$. catenella cysts in shallow embayments, germination timing is thought to be controlled to a much greater extent by environmental temperatures, which appear to synchronize germination with the onset of favorable growth conditions in spring (Anderson 1998; Rathaille and Raine 2011). The underlying mechanism by which environmental temperature regulates this germination seasonality is unknown. A consequence of the lack of heat capacity in shallow coastal waters and estuaries is that they respond to interannual variation in temperature. Thus, understanding the mechanism underlying A. catenella germination seasonality in these shallow habitats is of considerable importance to both dinoflagellate ecophysiology and to predictions of how this species may respond to climate change. 
Temperature conditioning experiments using dinoflagellate cysts can provide insights into this mechanism. Specifically, cold conditioning has been shown to alleviate cyst dormancy in several species of dinoflagellates. Stosch found that extended periods of cold treatment at $3^{\circ} \mathrm{C}$ both improved the viability and reduced the incubation period required for excystment of Ceratium (1967), Gymnodinium, and Woloszynskia (1973) species. More recently, after conditioning dormant Alexandrium pseudogonyaulax cysts at $7^{\circ} \mathrm{C}$ for $40-100$ days, Montresor and Marino (1996) reported more synchronous germination. These independent studies suggest that $A$. catenella could use the cue of winter temperature conditioning to synchronize its germination with favorable growth conditions in the spring. In fact, many terrestrial plant seeds and bulbs have a "chilling requirement" that must be fulfilled before dormancy is released and germination and bud break can occur. Chilling in this context is a period of low but above freezing temperatures that synchronize growth and reproduction with the onset of favorable environmental conditions in spring or summer (e.g. Vegis 1964; Karssen 1982; Vleeshouwers et al. 1995; Bewley et al. 2013). Winter dormancy in plants is induced by cold temperatures, short photoperiod, or both, and released by the accumulated effects of chilling temperatures (e.g. Arora et al. 2003; Horvath et al. 2003; Rohde and Bhalerao 2007). Therefore, the chilling requirement of terrestrial plants presents a plausible mechanism by which $A$. catenella cysts could quantify the passing of winter, thereby ensuring germination occurs afterwards. This hypothetical mechanism is explored in this thesis.

\section{The size of the cyst germination inoculum}

Our knowledge of dinoflagellate cyst ecophysiology stems predominantly from laboratory studies using constant temperatures, oxygen, and irradiance - all of which are highly variable and not always at favorable levels in the natural benthos. A commonly used methodology isolates individual cysts from natural populations, incubates them under various conditions, and assesses germination from an empty cyst or presence of a swimming cell (e.g., Anderson 1980; Anderson and Keafer 1987). Another typical approach creates resuspended slurries from natural sediments and assesses germination from the cysts remaining after different durations of incubation (e.g. Anderson et al. 2005). A key problem with these traditional laboratory approaches is that measurements of cyst 'germination' are not necessarily the same as 
'emergence'. After excystment, germling cells (planomeiocytes) may temporarily reside in the sediments and perhaps even divide there before cells emerge from the sediment particles and detritus into the overlying water column, but the extent of this behavior is unknown at present (Fig. 1).

In natural systems, water temperatures vary on daily and monthly scales, whereas laboratory experiments use constant temperatures. Oxygen is required for Alexandrium germination (Anderson et al., 1987; Kremp and Anderson, 2000; Rengefors and Anderson, 1998) so it can only proceed in oxygenated sediment layers, the thickness of which varies across habitats. In contrast, laboratory conditions are oxygen replete. Lastly, light is not essential, but it expedites the germination rate of Alexandrium species (Anderson et al. 1987; Bravo and Anderson 1994; Anderson et al. 2005; Genovesi et al. 2009; Vahtera et al. 2014). Light penetration to the natural benthos varies depending on depth and turbidity, whereas laboratory studies use constant levels of irradiance. Given these differences, germination rate and extent measured under laboratory conditions may be different in the natural benthos.

New techniques have considerably advanced our ability to measure the in situ emergence flux. The most sophisticated are the plankton emergence trap (PET) chambers designed by Ishikawa et al. (2007), which were deployed on the seafloor of Ago Bay, Japan to measure the emergence flux of $A$. catenella (2014). Each PET chamber consists of a base cylinder plugged with natural sediment and a top cylinder covered by a $10 \mu \mathrm{m}$ mesh to keep the plankton inside but allow water exchange with the in situ environment. Natsuike (2017) measured the emergence flux of $A$. catenella and A. pacificum in Kesennuma Bay, Japan by deploying sediment core tubes containing filtered seawater that were capped. The objective of both of these studies was to document the seasonality of the in situ emergence flux, so sampling vessels were deployed every 2- to 6-weeks for 24-hr intervals over the course of at least a year. The maximum emergence rates were $0.05 \%$ day $^{-1}$ for $A$. catenella and $0.04 \%$ day $^{-1}$ for $A$. pacificum in Kesennuma Bay (Natsuike et al. 2017), and $0.15 \%$ day $^{-1}$ and $0.34 \%$ day $^{-1}$ for $A$. catenella in Ago Bay (Ishikawa et al. 2014). With these maximum germination rates and typical cyst concentrations in surface sediments in Kesennuma Bay and Ago Bay, a 6-week season would result in only a fraction of cysts in the top centimeter of sediment germinating. To accurately estimate the size of the 
emergence flux and the relationship between emergence rates and seasonal temperature, high frequency measurements using these in situ methods are needed. Further, these measurements would allow us to determine if laboratory germination measurements are representative of the emergence flux.

\section{Summary}

The overarching goal of this thesis is to determine the mechanism by which temperature regulates the seasonality of $A$. catenella cyst germination and emergence flux in an estuarine embayment, and how those dynamics relate to bloom initiation. To address these subjects, studies were carried out in Nauset Marsh on Cape Cod (MA, USA), a site that hosts annual, localized A. catenella blooms that cause near-annual shellfishing closures due to PSP. In Chapter 2, a laboratory germination assay was used to determine when natural cyst populations in Nauset are dormant and quiescent. The natural dormancy rhythm informed the timing of cyst collections for a series of experiments to determine how cysts respond to and quantify the severity of winter. A. catenella cysts in Nauset were discovered to require a quantifiable amount of chilling to exit dormancy and become quiescent. In Chapter 3 , a series of experiments compared germination rates of quiescent cysts across a range of temperatures through laboratory experiments and field incubations of raw sediment using plankton emergence traps (PETs). Emergence rates of $A$. catenella germlings measured by PETs increased linearly with temperature and were comparable to germination under constant laboratory conditions. Total emergence fluxes were much lower than expected, suggesting that germination occurs in a much shallower layer of surface sediments than typically assumed. In Chapter 4 , a temperature-dependent model was developed to examine the sensitivity of A. catenella bloom phenology to dormancy-breaking by winter chilling. Model bloom predictions were evaluated against observations of $A$. catenella over eight bloom years (2009-2016), during which winter and spring temperatures varied considerably $\left( \pm 2.0^{\circ} \mathrm{C}\right)$ from climatological averages. The chilling-alleviated dormancy parameterization from Chapter 2 was shown to accurately predict the breaking of dormancy and onset of quiescence (January) and the variable bloom phenology from multiple independent blooms in Nauset. Once cysts became quiescent, temperatures were typically too cold to support high rates of division so there was a several-week lag until bloom initiation. Years with warmer winters and springs had shorter lag periods and thus significantly earlier blooms, even though it took longer to achieve 
the chilling requirement to break dormancy. These findings are significant ecologically because they demonstrate mechanistically how A. catenella in Nauset, and perhaps many other dinoflagellates, use a chilling requirement to match excystment timing to their environment, thereby maximizing bloom potential in different temperature regimes and habitats. In the Appendix, multi-year observations of the temporal variability of two A. catenella cyst seedbeds in Nauset are presented and the key gain and loss processes affecting the persistence the cyst seedbed are considered. Finally, I summarize the findings of this thesis, draw overall conclusions, and suggest future research endeavors in Chapter 5. 


\section{REFERENCES}

Anderson, D. M. 1980. Effects of Temperature Conditioning on Development and Germination of Gonyaulax tamarensis (Dinophyceae) Hypnozygotes. Journal of Phycology 16: 166-172.

Anderson, D. M. 1998. Physiology and Bloom Dynamics of Toxic Alexandrium Species, with Emphasis on Life Cycle Transitions, p. 29-48. In D.M. Anderson, A.D. Cembella, and G.M. Hallegraeff [eds.], Physiological Ecology of Harmful Algal Blooms. NATO ASI Series. NATO ASI Series.

Anderson, D. M., and B. Keafer. 1987. An endogenous annual clock in the toxic marine dinoflagellate Gonyaulax tamarensis. Nature 325: 616-617.

Anderson, D. M., and D. Wall. 1978. Potential Importance of Benthic Cysts of Gonyaulax tamarensis and G. excavata in Initiating Toxic Dinoflagellate Blooms. Journal of Phycology 14: $224-234$.

Anderson, D. M., and F. M. M. Morel. 1979. The Seeding of two Red Tide Blooms by the Germination of Benthic Gonyaulax tamarensis Hypnocysts. Estuarine and Coastal Marine Science 8: 279-293. doi:10.1016/0302-3524(79)90098-7

Anderson, D. M., B. A. Keafer, J. L. Kleindinst, and others. 2014. Alexandrium fundyense cysts in the Gulf of Maine: Long-term time series of abundance and distribution, and linkages to past and future blooms. Deep-Sea Research Part II 1-21. doi:10.1016/j.dsr2.2013.10.002

Anderson, D. M., C. A. Stock, B. Keafer, and others. 2005. Alexandrium fundyense cyst dynamics in the Gulf of Maine. Deep Sea Research II 52: 2522-2542.

doi:10.1016/j.dsr2.2005.06.014

Anderson, D. M., C. D. Taylor, and E. V. Armbrust. 1987. The effects of darkness and anaerobiosis on dinoflagellate cyst germination. Limnology and Oceanography 32: 340-351.

Anderson, D. M., D. W. Coats, and M. A. Tyler. 1985. Encystment of the dinoflagellate Gyrodinium uncatenum: Temperature and Nutrient Effects. 1-7.

Anderson, D. M., T. J. Alpermann, A. D. Cembella, Y. Collos, E. Masseret, and M. Montresor. 2012. The globally distributed genus Alexandrium: Multifaceted roles in marine ecosystems and impacts on human health. Harmful Algae 14: 10-35. doi:10.1016/j.hal.2011.10.012

Arora, R., L. J. Rowland, and K. Tanino. 2003. Induction and release of bud dormancy in woody perennials: a science comes of age. HortScience.

Balech, E. 1995. The genus Alexandrium Halim (Dinoflagellata).

Bewley, D. J., K. J. Bradford, H. Hilhorst, and H. Nonogaki. 2013. Seeds: Physiology of Development, Germination and Dormancy, 3rd ed. Springer.

Binder, B. J., and D. M. Anderson. 1986. Green light-mediated photomorphogenesis in a dinoflagellate resting cyst. Nature 322: 659-661. doi:10.1038/322659a0

Bravo, I., and D. M. Anderson. 1994. The effects of temperature, growth medium and darkness on excystment and growth of the toxic dinoflagellate Gymnodinium catenatum from northwest Spain. Journal of Plankton Research 16: 513-525. doi:10.1093/plankt/16.5.513 
Bravo, I., and R. Figueroa. 2014. Towards an Ecological Understanding of Dinoflagellate Cyst Functions. Microorganisms 2: 11-32. doi:10.3390/microorganisms2010011

Bravo, I., R. I. Figueroa, E. Garces, S. Fraga, and A. Massanet. 2010. The intricacies of dinoflagellate pellicle cysts: The example of Alexandrium minutum cysts from a bloomrecurrent area (Bay of Baiona, NW Spain). Deep-Sea Research Part II 57: 166-174. doi:10.1016/j.dsr2.2009.09.003

Brosnahan, M. L., L. V. Suárez, D. K. Ralston, and others. 2015. Rapid growth and concerted sexual transitions by a bloom of the harmful dinoflagellate Alexandrium fundyense (Dinophyceae). Limnology and Oceanography 60: 2059-2078. doi:10.1002/lno.10155

Cannon, J. 1993. Germination of the toxic dinoflagellate, Alexandrium minutum from sediments of the Port River, South Australia, p. 103-112. In T. Smayda and Y. Shimizu [eds.], Toxic Phytoplankton Blooms in the Sea.

Cembella, A. D. 1998. Ecophysiology and metabolism of paralytic shellfish toxins in marine microalgae, p. 381-403. In D.M. Anderson, A.D. Cembella, and G.M. Hallegraeff [eds.], Physiological Ecology of Harmful Algal Blooms. NATO ASI Series. Springer-Verlag.

Crespo, B. G., B. A. Keafer, D. K. Ralston, H. Lind, D. Farber, and D. M. Anderson. 2011. Dynamics of Alexandrium fundyense blooms and shellfish toxicity in the Nauset Marsh System of Cape Cod (Massachusetts, USA). Harmful Algae 12: 26-38. doi:10.1016/j.hal.2011.08.009

Dale, B. 1983. Dinoflagellate Resting Cysts, p. 69-136. In G.A. Fryxell [ed.], Survival Strategies of the Algae. Survival strategies of the algae.

Feifel, K. M., S. K. Moore, and R. A. Horner. 2012. An Alexandrium Spp. Cyst Record from Sequim Bay, Washington State, USA, and its Relation to Past Climate Variability. Journal of Phycology 48: 550-558. doi:10.1111/j.1529-8817.2012.01175.x

Genovesi, B., M. Laabir, E. Masseret, A. Vaquer, and D. Grzebyk. 2009. Dormancy and germination features in resting cysts of Alexandrium tamarense species complex (Dinophyceae) can facilitate bloom formation in a shallow lagoon (Thau, southern France). Journal of Plankton Research 31: 1209-1224. doi:10.1093/plankt/fbp066

Gwinner, E. 1986. Circannual Rhythms: Endogenous Annual Clocks in the Organization of Seasonal Processes, W. Burggren, S. Ishii, K. Johansen, H. Langer, G. Neuweiler, and D.J. Randell [eds.]. Springer-Verlag.

Hallegraeff, G. M. 1993. A review of harmful algal blooms and their apparent increase. Phycologia 32: 79-99.

Higman, W. A., D. M. Stone, and J. M. Lewis. 2001. Sequence comparisons of toxic and nontoxic Alexandrium tamarense (Dinophyceae) isolates from UK waters. Phycologia 40: 256262. doi:10.2216/i0031-8884-40-3-256.1

Hoar, W. S. 1969. Reproduction, p. 1-72. In W.S. Hoar and D.J. Randell [eds.], Fish physiology.

Horvath, D. P., J. V. Anderson, W. S. Chao, and M. E. Foley. 2003. Knowing when to grow: signals regulating bud dormancy. Trends in Plant Science 8: 534-540. doi:10.1016/j.tplants.2003.09.013 
Huber, G., and F. Nipkow. 1923. Experimentelle Untersuchungen über die Entwicklung und form bildung von Ceratium hirundinella O. F. Müller. Flora 116: 114-215.

Ishikawa, A., M. Hattori, and I. Imai. 2007. Development of the "plankton emergence trap/chamber (PET Chamber)," a new sampling device to collect in situ germinating cells from cysts of microalgae in surface sediments of coastal waters. Harmful Algae 6: 301-307. doi:10.1016/j.hal.2006.04.005

Ishikawa, A., M. Hattori, K. I. Ishii, D. M. Kulis, D. M. Anderson, and I. Imai. 2014. In situ dynamics of cyst and vegetative cell populations of the toxic dinoflagellate Alexandrium catenella in Ago Bay, central Japan. Journal of Plankton Research 36: 1333-1343. doi: 10.1093/plankt/fbu048

John, U., A. Cembella, C. Hummert, M. Elbrächter, R. Groben, and L. Medlin. 2003. Discrimination of the toxigenic dinoflagellates Alexandrium tamarense and A. ostenfeldii in co-occurring natural populations from Scottish coastal waters. European Journal of Phycology 38: 25-40. doi:10.1080/0967026031000096227

Karssen, C. M. 1982. Seasonal patterns of dormancy in weed seeds, p. 243-270. In A.A. Khan [ed.], The physiology and biochemistry of seed development, dormancy and germination.

Keafer, B. A., K. O. Buesseler, and D. M. Anderson. 1992. Burial of living dinoflagellate cysts in estuarine and nearshore sediments. Marine Micropaleontology 20: 147-161. doi:10.1016/0377-8398(92)90004-4

Kremp, A., and D. M. Anderson. 2000. Factors regulating germination of resting cysts of the spring bloom dinoflagellate Scrippsiella hangoei from the northern Baltic Sea. Journal of Plankton Research 22: 1311-1327. doi:10.1093/plankt/22.7.1311

Lilly, E. L., K. M. Halanych, and D. M. Anderson. 2007. Species boundaries and global biogeography of the Alexandrium tamarense complex (Dinophyceae). Journal of Phycology 43: 1329-1338. doi:10.1111/j.1529-8817.2007.00420.x

Lofts, B. 1974. Reproduction, p. 107-218. In B. Lofts [ed.], Physiology of the amphibia.

Matrai, P., B. Thompson, and M. Keller. 2005. Circannual excystment of resting cysts of Alexandrium spp. from eastern Gulf of Maine populations. Deep Sea Research Part II 52: 2560-2568. doi:10.1016/j.dsr2.2005.06.013

Miyazono, A., S. Nagai, I. Kudo, and K. Tanizawa. 2012. Viability of Alexandrium tamarense cysts in the sediment of Funka Bay, Hokkaido, Japan: Over a hundred year survival times for cysts. Harmful Algae 16: 81-88. doi:10.1016/j.hal.2012.02.001

Montresor, M., and D. Marino. 1996. Modulating effect of cold-dark storage on excystment in Alexandrium pseudogonyaulax (Dinophyceae). Marine Biology 127: 55-60. doi:10.1007/BF00993643

Natsuike, M., K. Yokoyama, G. Nishitani, Y. Yamada, I. Yoshinaga, and A. Ishikawa. 2017. Germination fluctuation of toxic Alexandrium fundyense and A. pacificum cysts and the relationship with bloom occurrences in Kesennuma Bay, Japan. Harmful Algae 62: 52-59. doi:10.1016/j.hal.2016.11.018

Perez, C. C., S. Roy, M. Levasseur, and D. M. Anderson. 1998. Control of germination of Alexandrium tamarense (Dinophyceae) cysts from the lower St. Lawrence Estuary (Canada). 
Journal of Phycology 34: 242-249. doi:10.1046/j.1529-8817.1998.340242.x

Pfiester, L. A. 1977. Sexual reproduction of Peridinium gatuense (Dinophyceae). Journal of Phycology 13: 92-95.

Pfiester, L. A., and D. M. Anderson. 1987. Dinoflagellate Reproduction, p. 611-648. In F.J.R. Taylor [ed.], The Biology of Dinoflagellates.

Prud'homme van Reine, W. 2017. Report of the Nomenclature Committee for Algae: 15. Taxon 66: 191-192. doi:10.12705/661.16

Rathaille, A. N., and R. Raine. 2011. Seasonality in the excystment of Alexandrium minutum and Alexandrium tamarense in Irish coastal waters. Harmful Algae 10: 629-635. doi:10.1016/j.hal.2011.04.015

Rengefors, K., and D. M. Anderson. 1998. Environmental and endogenous regulation of cyst germination in two freshwater dinoflagellates. Journal of Phycology 34: 568-577.

Rohde, A., and R. P. Bhalerao. 2007. Plant dormancy in the perennial context. Trends in Plant Science 12: 217-223. doi:10.1016/j.tplants.2007.03.012

Saunders, D. S. 1976. Insect Clocks, Pergamon.

Scholin, C. A., G. M. Hallegraeff, and D. M. Anderson. 1995. Molecular evolution of the Alexandrium tamarense "species complex" (Dinophyceae): dispersal in the North American and West Pacific regions. Phycologia 34: 472-485.

Stosch, H. A., von. 1967. Haptophyceae, p. 646-656. In W. Ruhland [ed.], Encyclopedia of Plant Physiology. Gottingen and Heidelberg.

Stosch, H. A., von. 1973. Observations on vegetative reproduction and sexual life cycles of two freshwater dinoflagellates, Gymondinium pseudopalustre Schiller and Woloszynskia apiculata sp. nov. British Phycological Journal 8: 105-134. doi:10.1080/00071617300650141

Vahtera, E., B. G. Crespo, D. J. McGillicuddy, K. Olli, and D. M. Anderson. 2014. Alexandrium fundyense cyst viability and germling survival in light vs. dark at a constant low temperature. Deep-Sea Research Part II 103: 112-119. doi:10.1016/j.dsr2.2013.05.010

Vegis, A. 1964. Dormancy in higher plants. Annual Review of Plant Physiology 15: 185-224. doi:10.1146/annurev.pp.15.060164.001153

Vleeshouwers, L. M., H. J. Bouwmeester, and C. M. Karssen. 1995. Redefining seed dormancy: an attempt to integrate physiology and ecology. The Journal of Ecology 83: 1031-1037. doi: $10.2307 / 2261184$

Wall, D. 1971. Biological problems concerning fossilizable dinoflagellates. Geoscience and Man 3: 1-15. doi:10.1080/00721395.1971.9989704 


\section{FIGURES}

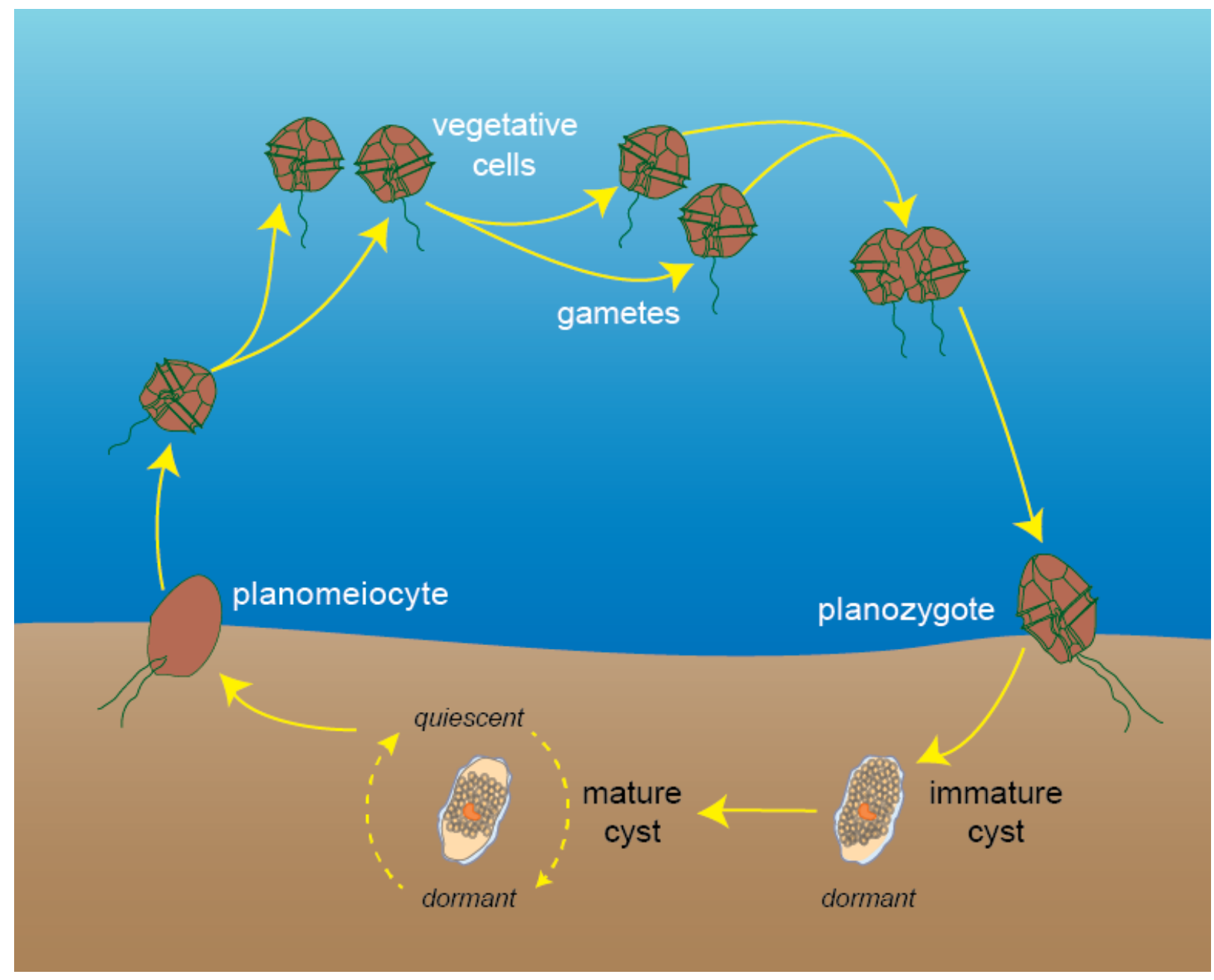

Fig. 1. Life cycle diagram of $A$. catenella. 


\title{
Chapter 2
}

\section{Cold exposure controls the duration of dormancy in cysts of the toxic dinoflagellate, Alexandrium catenella}

\begin{abstract}
Many cyst-forming dinoflagellates optimize excystment timing to avoid environmental extremes like winter cold, enabling them to exploit favorable periods for bloom development. This study quantifies how cysts of Alexandrium catenella, a species that causes paralytic shellfish poisoning (PSP), use the environmental cue of winter chilling to delay germination until more favorable conditions in the spring. The temperature and duration of cold storage were varied to characterize their influence on dormancy transitions in cysts collected from natural sediments. Results demonstrate that $A$. catenella cysts: (1) quantitatively respond to chilling; and (2) need to surpass a chilling threshold to transition from dormancy to quiescence. These findings are significant because they elucidate a mechanism by which $A$. catenella, and perhaps many other cyst-forming dinoflagellates, match excystment timing to their environment, thereby maximizing bloom potential in different temperature regimes and habitats. Consequences of this mechanism are explored over the life cycle of individual cysts in the Nauset Marsh system, a shallow, inshore habitat that experiences near-annual shellfishing closures due to PSP. Temperature seasonality in Nauset is considerable $\left(-2-27^{\circ} \mathrm{C}\right)$, suggesting that there is a buffer between the onset of quiescence and bloom development, which would make the timing of blooms more resilient to weather and climate variability.
\end{abstract}

\section{INTRODUCTION}

The phenology of phytoplankton blooms - i.e., the timing of their development, peak, and termination - is often seasonal. At higher latitudes this is a direct consequence of large variations 
in temperature and photoperiod that directly impact species' progression through their annual life cycles. Therefore, many phytoplankton have evolved specific behavioral and life-cycle strategies for surviving periods of seasonally-induced stress and exploiting periods that are more advantageous for growth and reproduction ( $\mathrm{Ji}$ et al. 2010). One strategy that is especially common among dinoflagellate species is the formation of resting cysts. Dinoflagellate cysts have been shown to survive extended periods of unfavorable environmental conditions, then germinate to become planktonic swimming stages once conditions become favorable again (Wall 1971; Dale 1983). During a bloom and often as it is ending, resting cysts form and remain in the bottom sediments until some germinate, inoculating subsequent blooms.

In many species, bloom inoculation is inhibited immediately after a bloom and during certain periods of the year because of cyst dormancy. It is useful to review the terminology of dormancy (Fig. 1), clearly distinguishing between the internal and external factors that control it and the ability of cysts to germinate. Borrowing from the terminology used for seeds of higher plants (e.g. Bewley et al. 2013), I define cyst dormancy as an internal state that impedes germination under otherwise adequate environmental conditions. Once the barrier imposed by dormancy is broken, cysts remain in an internal resting state, termed quiescence, until external factors are favorable for germination. Temperature is considered a primary regulatory factor and must be within an optimal range for germination to occur (e.g. Huber and Nipkow 1923; Anderson and Morel 1979; Bravo and Anderson 1994). Oxygen is a requirement for germination in all dinoflagellate species that have been examined thus far (Anderson and Keafer 1987; Rengefors and Anderson 1998; Kremp and Anderson 2000). Light enhances the germination rate (Anderson et al. 1987; Cannon 1993; Rengefors and Anderson 1998), but it is not a germination requirement for many species, with a few exceptions (Binder and Anderson 1986; Anderson et al. 1987; Rengefors and Anderson 1998).

There are two distinct types of dormancy and they can be distinguished by their timing within the lifetime of dinoflagellate cysts. The first, termed mandatory dormancy, occurs immediately after cysts are formed and is associated with physiological maturation. It can last from several weeks to months and only occurs once in a cyst's lifetime (e.g. Pfiester 1977; Anderson 1980; Pfiester and Anderson 1987; Perez et al. 1998). The second type, simply termed dormancy, occurs in 
mature cysts that are otherwise competent to germinate, and thus controls when cysts can germinate seasonally. Although mandatory dormancy is relatively well-characterized in dinoflagellates (e.g. Anderson and Morel 1979), the regulation of dormancy in mature cysts is less understood. Because many dinoflagellates are harmful algal bloom (HAB) species, there is a practical need for a quantitative understanding of these environmental controls so that the timing of blooms can be better predicted.

The dormancy exhibited by mature cysts has been extensively studied in Alexandrium catenella (=A. fundyense $\left.e^{1}\right)$ a toxic species that is endemic to North and South America (John et al. 2014), due to the significant ecological, economic, and public health impacts of its blooms. Saxitoxin produced by these cells causes paralytic shellfish poisoning (PSP) in temperate and subarctic coastal areas worldwide (Anderson et al. 2012). Within deep "seedbed" areas of the Gulf of Maine (GOM), dormancy-quiescence transitions have been shown to be regulated by an endogenous annual clock (Anderson and Keafer 1987; Matrai et al. 2005). This behavior releases mature cysts from dormancy in the absence of strong seasonal signals that mark the onset of conditions favorable for blooms in overlying euphotic waters, far from where cysts lie on the bottom. In contrast, within shallow areas, germination timing is thought to be controlled to a much greater extent by environmental temperatures, which appear to synchronize germination with the onset of favorable growth conditions in spring (Anderson 1998; Rathaille and Raine 2011). This study investigates how seasonal environmental temperatures determine the timing of dormancy-quiescence transitions and cause $A$. catenella germination to coincide with the onset of favorable conditions within a shallow temperate estuary.

Winter cooling has long been thought to alleviate dormancy in dinoflagellate cysts, but a quantitative or mechanistic explanation has been lacking (Anderson 1998; Rathaille and Raine 2011). Stosch found that extended periods of cold treatment at $3^{\circ} \mathrm{C}$ both improved the viability and reduced the incubation period required for excystment of Ceratium (1967), Gymnodinium, and Woloszynskia (1973) species. In another study, Montresor and Marino (1996) reported more synchronous germination after conditioning Alexandrium pseudogonyaulax cysts at $7^{\circ} \mathrm{C}$ for 40

\footnotetext{
${ }^{1}$ Alexandrium catenella and A. fundyense are conspecific, and "catenella" was determined to have nomenclatural priority (Prud'homme van Reine 2017).
} 
100 days. These findings suggest that the underlying mechanism regulating cyst germinability may be similar to the chilling requirements that have been documented for many terrestrial plants. Chilling in this context is a period of low but above freezing temperatures that synchronize growth and reproduction with the onset of favorable environmental conditions in spring or summer (e.g. Vegis 1964; Karssen 1982; Vleeshouwers et al. 1995; Bewley et al. 2013). Winter dormancy in plants is induced by cold temperatures, short photoperiod, or both, and released by the accumulated effects of chilling temperatures (e.g. Arora et al. 2003; Horvath et al. 2003; Rohde and Bhalerao 2007). If its chilling requirement is not met, a dormant seed or bud will not exit dormancy during spring and therefore cannot germinate or bud break, respectively. One of the goals of this study was therefore to determine if Alexandrium cysts have a similar chilling requirement to exit dormancy, and if so, to determine how this requirement regulates germination in the context of environmental temperature fluctuations.

The study's overall objective was to characterize the role of winter chilling in the ecophysiology of A. catenella cysts. Cyst ecophysiology includes the perception of environmental factors and how they are translated into internal signals that ultimately determine if and when germination occurs. Here, I present the results of a series of cyst incubations that apply different cold storage temperatures to naturally-formed A. catenella cysts and demonstrate that dormancy can only be broken after cysts have fulfilled a well-defined chilling requirement. Further, the implications of this physiological mechanism are explored, and a conceptual model is proposed that links dormancy transitions between shallow and deep water $A$. catenella cyst populations.

\section{METHODS}

\section{Study site}

The Nauset Marsh system is a shallow estuary consisting of tidal channels within a central marsh area that connect three drowned kettle ponds - Mill Pond, Salt Pond, and Town Cove - each of which hosts independent, localized populations of A. catenella (Crespo et al. 2011; Ralston et al. 2015). Localization of blooms within the ponds occurs through an interaction between the swimming behavior of the $A$. catenella cells, stratification within the ponds, and the shallow 
central marsh area which acts as a sill that blocks passage of cells from one pond to the other (Anderson et al. 1983; Anderson and Stolzenbach 1985; Ralston et al. 2015) In turn, retention promotes the local deposition of cysts that then inoculate new blooms each spring, leading to PSP shellfishing closures on a near-annual basis. An exception occurred during the second year of this study (2014) when no toxicity was recorded within Nauset through a weekly monitoring program that is overseen by the Massachusetts Division of Marine Fisheries. Cysts used in this study's germination experiments were collected from Roberts Cove, an area that is located immediately outside the inlet of Mill Pond. This site was selected due to its accessibility and high mean concentrations of $A$. catenella cysts in its surficial sediment (typically $>10^{3} \mathrm{cysts}^{-}$ ${ }^{3}$ ). Temperature at this location was monitored for the duration of the study by a moored, internally-recording HOBO logger (Onset Computer Corporation).

\section{Assessment of the seasonal dormancy status of natural cyst populations}

Throughout this study, the dormancy state of the Nauset cyst seedbed was assessed through monthly sediment collections and germination tests in the laboratory. All cysts collected for this purpose were obtained from intertidal sediment within Roberts Cove, an area immediately outside of Mill Pond in the southern branch of the Nauset estuary. Collections began in July 2013 and continued through June 2015. Each month, a hand corer was used to collect an undisturbed sediment core that was transported back to the laboratory for extrusion and sediment processing. All cores had a light-colored, oxygenated surface layer of a few millimeters overlaying anoxic sediment, which was identified by its black coloration and odor. During transportation, sediment cores were kept upright in a bucket filled with water maintained at the ambient temperature of Roberts Cove.

Once in the laboratory, headwater from each core was carefully aspirated before extrusion of sediment. To target the cysts deposited from the most recent bloom, the surface $1 \mathrm{~cm}$ layer of sediment was sub-sampled and placed into a beaker. This sediment was sonicated using a Branson Sonifier 250 at a constant $40 \mathrm{~W}$ output for $1 \mathrm{~min}$ and sieved to yield a disaggregated 20$100 \mu \mathrm{m}$ size fraction (Anderson et al. 2003). Next, cysts were separated from same size particles with higher specific densities using density cushion centrifugation as described by Schwinghamer (1991). Because A. catenella cysts range in densities from $\sim 1.15$ to $1.30 \mathrm{~g} \mathrm{~cm}^{-3}$, 
heavy solutions of colloidal silica were adjusted to $1.40 \mathrm{~g} \mathrm{~cm}^{-3}$ through addition of sucrose to ensure near-complete retention of cysts at the cushion interface. Round-bottom step gradient tubes were centrifuged for $15 \mathrm{~min}$ at $200 \mathrm{rcf}$, and then cysts and other organic material were removed from the cushion interface and overlaying suspension by Pasteur pipette. Cysts and other light debris were then concentrated and thoroughly rinsed with filtered seawater over a 20 $\mu \mathrm{m}$ sieve. Sieve contents were then backwashed into a Sedgewick-Rafter counting chamber from which cysts could be easily identified and isolated under a Zeiss Axioskop upright microscope.

For each monthly dormancy test, approximately 30 healthy-looking cysts (starch granules present, golden to brown coloration) were individually isolated by micropipette and subjected to conditions known to induce rapid germination of quiescent cysts. Isolated cysts were placed in wells of a 96-well tissue culture plate, each pre-loaded with $200 \mu \mathrm{L}$ of f/2 medium (Guillard and Ryther 1962). The plates were then sealed to limit evaporative loss of medium and incubated at $15^{\circ} \mathrm{C}$ on a $14: 10 \mathrm{~h} \mathrm{~L}: \mathrm{D}$ cycle $\left(250 \mu \mathrm{mol} \mathrm{m} \mathrm{m}^{-1}\right.$ photon flux density). Individual cysts were checked for germination on a weekly basis using an inverted Olympus IX-70 microscope. If the germination percentage of total cysts after the first week was less than $50 \%$, the majority of the cyst seedbed was deemed dormant, and if the germination percentage exceeded $50 \%$, the majority of the cyst seedbed was deemed quiescent. According to this criterion, the cyst seedbed was found to be quiescent in the winter and spring months (January-May), and dormant in the summer and autumn months (June-December) in both 2014 and 2015 (Fig. 2).

\section{Cold storage experiment}

A cyst germination assay was designed to examine the effect of winter chilling on dormancybreaking in natural cyst populations (Fig. 3). Sediment cores containing cysts were collected from Nauset on 04 October because environmental temperatures are cooling and the majority of the cyst seedbed is dormant at this time (Fig. 2). To assess the effect of chilling on cyst cohorts of different ages, cysts were collected in both 2013 and 2014 (Fig. 2). The majority of cysts in these collections were presumably formed in May 2013 following a major "red-water" $A$. catenella bloom in Roberts Cove because there was no significant bloom or cyst formation in 2014 (A. Fischer, unpublished). This indicates that cysts collected in 2013 were dormant from the time of their formation in May through their collection in October. In contrast, the cysts 
collected in October 2014 were a year older, so they had experienced an additional cycle of summer-autumn dormancy.

For both collections, six undisturbed sediment cores were collected and processed following the procedure detailed in the seasonal dormancy status experiment above. After the $1 \mathrm{~cm}$ layer was subsampled, the sediment was combined with anoxic, cyst-free sediment from $>15 \mathrm{~cm}$ depth in a 1:1 ratio to prevent oxygen contamination. Exposure to oxygen and light was minimized by following procedures outlined by Anderson (1987). To ensure anoxic conditions, this mixture was dispensed into $5 \mathrm{~mL}$ amber, crimp-top, glass vials and when no headspace remained, vials were sealed and buried in the remaining anoxic sediment from the cores. To examine the effect of winter chilling on dormancy, each of the four 2-L glass containers was stored at a different cold temperature. The 2013-collected cysts were stored at $2{ }^{\circ} \mathrm{C}$ and $6^{\circ} \mathrm{C}$, and the 2014-collected cysts were stored at $4^{\circ} \mathrm{C}$ and $8^{\circ} \mathrm{C}$. The ability of cysts from both collections to germinate without chilling was also tested by incubating them at the ambient water temperature $\left(18^{\circ} \mathrm{C}\right)$ and monitoring their germination for 7 weeks.

Biweekly for the first 6 months of cold storage (October-March), cysts were removed from each storage temperature in order to test their germinability (Fig. 2). Single vials were removed from each cold storage container under a red light to prevent stimulation of remaining cysts (Binder and Anderson 1986) and special care was taken to maintain all contents at their given cold storage temperature. Vial contents were sonicated according to the previously detailed methods. For each biweekly dormancy test, approximately 30 healthy-looking cysts were isolated and subjected to the same favorable $15^{\circ} \mathrm{C}$ conditions as detailed in the methods above. Cysts were monitored for germination a total of seven weeks. Results from these dormancy tests were expressed as $G$, the cumulative fraction of total cysts germinated at each weekly check and $G_{\max }$, the total fraction germinated at the end of seven weeks.

At the outset of these experiments it was not known whether cyst survival might differ between cold storage temperatures. In order to test for a temperature effect, values of $G_{\max }$ were compared between cold storage treatments. Initial assessments also showed that only longer-chilled cohorts from each storage treatment germinated readily. Therefore, $G_{\max }$ comparisons considered only 
tests from cohorts that reached at least $85 \%$ of the highest $G_{\max }$ of a given cold storage treatment (demarcated by open circles in Fig. 4). This subset of cohorts was then compared by one-way ANOVA. To account for storage temperature based differences in $G_{\max }$ among the cohorts, I calculate the term $G^{*}$ from $G$ :

$$
G^{*}=\frac{\mathrm{G}}{\overline{\mathrm{G}}_{\max }}
$$

where $\bar{G}_{\text {max }}$ is the mean of $G_{\max }$ values derived from the subset of cohorts considered ( $>85 \%$ $\left.G_{\max }\right)$. The effect of this normalization was to make the range of germinability across all of the cold storage treatments range from 0 to $\sim 100 \%$. From the $G^{*}$ time-series, I also calculated $G^{*}{ }_{50}$ for each temperature treatment, the point in cold storage time at which cyst cohorts attained a $G^{*}$ of $50 \%$ within the first week of the germination assay.

\section{Chilling-unit calculation}

Chilling-units $(C U)$, a measurement of winter severity commonly used in horticulture studies, were evaluated as a means to collapse the germination variability between the $2,4,6$, and $8^{\circ} \mathrm{C}$ cold storage treatments. A common, simple model was applied that assigns one $C U$ for each degree below $T_{\max }$, a temperature below which an organism perceives chilling (e.g. Luedeling et al. 2009; Penfield and Springthorpe 2012). Daily chilling-units were thus calculated for the average daily temperature $\left(T_{i}\right)$ that cysts experienced during cold storage using the following formula:

$$
C U(t)=\Delta t \sum_{i=t o}^{t}\left\{\begin{array}{ccc}
T_{\max }-T_{i} & \text { if } & T_{\max } \geq T_{i} \geq 0 \\
0 & \text { if otherwise }
\end{array}\right.
$$

Calculation of chilling-units required estimation of a $T_{\max }$ that is specific to $A$. catenella cysts. To accomplish this, chilling-units from the start date of each cold storage experiment were

calculated for $T_{\max }$ values from 2 to $30^{\circ} \mathrm{C}$. Then, for each value of $T_{\max }$, the chilling-units associated with the $G^{*}$ after one week of incubation (from all four temperature treatments) were fit to a sigmoid curve and $T_{\max }$ was chosen by optimizing goodness of fit. Sigmoidal responses 
are commonly observed in terrestrial plant studies and reflect the normally-distributed variance of germination times among cysts in the experimental populations.

In order to test the significance of $C U$-based reductions in variability across the four cold storage temperature treatments, the following statistical model was devised. The null hypothesis $\left(H_{o}\right)$ was that the cold storage temperature had no effect on $G^{*}{ }_{50}$ timing and was evaluated against the alternative hypothesis $\left(H_{l}\right)$ that there was an effect. Under $H_{o}$, the timing of the $G^{*}{ }_{50}$ is not mediated by the temperature of chilling and the difference among treatments reflects variability due to other untested factors. If $H_{l}$ is true, the variation in the number of $C U$ s needed to attain $G^{*}{ }_{50}$ for each temperature treatment is small relative to a distribution constructed under $H_{0}$, i.e. with the assumption that storage temperature does not affect the $C U$ variance. Our data consist of the $G^{*} 50$ periods (in days) for each treatment $\left(d_{j}, \mathrm{j}=2,4,6,8^{\circ} \mathrm{C}\right)$ and the corresponding number of $C U \mathrm{~s}\left(c_{j}\left(d_{j}\right), \mathrm{j}=2,4,6,8^{\circ} \mathrm{C}\right)$ accumulated through each cold-storage experiment. The observed range of $C U$ required to reach $G^{*}{ }_{50}$ in each temperature and storage duration combination was used as a test statistic and significance was evaluated against a distribution constructed under the assumption of no temperature effect (from $H_{o}$ ). This distribution was approximated by reassigning the values of $d_{j}\left(d_{2}{ }^{*}, d_{4} *, d_{6}{ }^{*}, d_{8} *\right.$ of $\left.d_{2}, d_{4}, d_{6}, d_{8}\right)$, forming the quantities $c_{2}\left(d_{2} *\right)$, $c_{4}\left(d_{4}^{*}\right), c_{6}\left(d_{6} *\right), c_{8}\left(d_{8} *\right)$, and then determining the resulting ranges of $C U$ for each combination.

To compare our cold storage treatments to the natural chilling that cysts experienced during the same time period in Nauset, chilling-units were calculated from bottom water temperature records collected at Roberts Cove. Calculations applied a start date in late May in 2013 and 2014, which coincides with the typical timing of new cyst formation within Nauset.

\section{RESULTS}

\section{Cysts were quiescent from January through May in Nauset}

To examine the dormancy status of the in situ cyst seedbed, A. catenella cysts were routinely sampled monthly for two years (July 2013 - June 2015) and their germinability after one week of incubation under optimal conditions was assessed. Cysts exceeded 50\% cumulative germination 
within the first week of incubation from January through May (grey shading, Fig. 2) in 2014 and 2015, indicating that the majority of the cyst seedbed was quiescent in the winter and spring. In contrast, less than $17 \%$ germination was observed from June through November, indicating that the majority of the cyst seedbed was dormant during the summer and winter. Some interannual variability in the onset of quiescence was observed. Cyst cohorts from January exhibited 73\% cumulative germination in 2014 , but only $48 \%$ in 2015 . This would indicate that the Nauset cyst seedbed experienced quiescence slightly earlier in 2014 than 2015. Importantly, the age of cysts in the second half of these dormancy observations was one year older because all cysts were formed in May 2013. This demonstrates that natural populations, regardless of their age, cycle synchronously from dormancy to quiescence on an annual basis. The primary focus of this paper is the transition from dormancy to quiescence, although the reverse will also be discussed.

\section{Duration of cold storage affects the onset of quiescence}

A minimum of 40 days of cold conditioning was required for cysts to begin to germinate in the dormancy assay (i.e. removal from cold storage and incubation under optimal conditions for one week prior to germination assessment) (Fig. 4). In contrast, cyst cohorts from the same 2013 and 2014 October collections in Nauset that were incubated under optimal conditions immediately after collection (thus without cold storage), failed to germinate. The extent of germination $\left(G_{\max }\right)$ increased monotonically with increasing time in cold storage. For example, after 10, 67, and 190 days of cold storage, the $G_{\max }$ of cysts stored at $2{ }^{\circ} \mathrm{C}$ increased from $0 \%$, to $63 \%$, to $77 \%$, respectively (Fig. 4).

The $\bar{G}_{\max }$, the mean maximum percent germination after seven weeks of incubation, varied across cold-storage temperatures, which reflects differences in cyst viability (Fig. 4). Across all cold-storage experiments, non-germinating cysts often appeared blackened and/or showed green autofluorescence at the conclusion of dormancy tests, both indicators of cyst death (Tang and Dobbs 2007). Cyst cohorts from the $6^{\circ} \mathrm{C}$ treatments reached the highest $\bar{G}_{\max }$ of $94 \%$ (SD $=$ 0.023). This was followed by the $4^{\circ} \mathrm{C}$ treatment $(83 \%, S D=0.018)$, the $2^{\circ} \mathrm{C}$ treatment $(77.4 \%$, $S D=0.018)$, and the $8^{\circ} \mathrm{C}$ treatment $(68.0 \%, S D=0.020)$. A one-way ANOVA comparison of these values showed a significant effect of temperature $\left(F=3,14, p<1 \times 10^{-6}\right.$; Fig. 5). A post hoc Tukey test revealed that cyst cohorts in the $6^{\circ} \mathrm{C}$ treatment had a significantly higher $\bar{G}_{\max }$ 
than any of the other treatments $(\mathrm{p}<0.05)$. In all subsequent analyses, differences in viability across the storage temperatures were accounted for by normalizing germination measurements using $G^{*}$ (Equation 1; Fig. 6).

\section{Chilling collapses the variability among cold storage treatments}

The breaking of dormancy for the majority of a cyst population is demarcated as when $50 \%$ cumulative normalized germination is attained after one week of incubation under optimal conditions $\left(G^{*}{ }_{50}\right)$. The colder the treatment, the faster that dormancy was broken, or $G^{*}{ }_{50}$ was reached: after 67 days at $2^{\circ} \mathrm{C}$, after 87 days at $4^{\circ} \mathrm{C}$, after 93 days at $6^{\circ} \mathrm{C}$, and after 108 days at $8^{\circ} \mathrm{C}$ (Fig. 6). This variability of the dormancy duration among the different cold storage temperature treatments was collapsed using chilling-units calculated with a $T_{\max }$ specific to $A$. catenella populations from Nauset.

$T_{\max }$ is the threshold temperature below which chilling is sensed and it varies by organism. In assessments of the complete dataset and across a range of $T_{\max }$ from 2 to $30^{\circ} \mathrm{C}$, goodness of fit to sigmoidal response curves increased with increasing values of $T_{\max }$ up to $15^{\circ} \mathrm{C}\left(\mathrm{r}^{2}=0.99\right.$; Figs. 7 and 8 ). Above $15^{\circ} \mathrm{C}$, measures of fit are similar to $T_{\max }=15^{\circ} \mathrm{C}$ but are no longer ordered according to their relative temperatures, just as would be expected for temperatures exceeding the true value of $T_{\max }$ under the constraints provided by our experimental design and $C U$ formulation (Figs. 7 and 8). Therefore, I conclude that $T_{\max }$ is approximately $15^{\circ} \mathrm{C}$, and this value was used in all subsequent $C U$ calculations including the statistical assessment of $C U$ as an approach to collapse variability between cold-storage treatments.

Using $15^{\circ} \mathrm{C}$ as the value of $T_{\max }$, dormancy was broken for a small number of cysts upon attainment of approximately $500 \mathrm{CU}$, the equivalent of 6 weeks at $4^{\circ} \mathrm{C}$ (Fig. 8b). A better indicator of the population-level response to chilling is the $G^{*}{ }_{50}$, and this occurred at approximately $800 C U$ and ranged from 756 to $957 C U$ among the different temperature treatments. No permutation of the cold temperature assignments yielded a value less than that observed for the actual experimental data, indicating a significant collapse in the variability through $C U$ scaling $(p<0.05)$. Both the 2013-collected cyst samples $\left(2^{\circ} \mathrm{C}\right.$ and $6^{\circ} \mathrm{C}$ treatments $)$ and the 2014-collected cyst samples $\left(4^{\circ} \mathrm{C}\right.$ and $8^{\circ} \mathrm{C}$ treatments) required a similar amount of chilling to transition from dormancy to quiescence. This is remarkable given that both collections 
had different chilling histories prior to this experiment. Both cyst collections were presumed to be formed following the 2013 bloom in Nauset in May, thus the 2013-collected cysts had not experienced natural winter chilling, whereas the 2014-collected cysts had (Fig. 2). In other words, the chilling that the 2014-collected cysts accumulated during winter in Nauset was not retained.

Data from all four experiments were combined to examine the response of cysts first to the accumulation of $C U$, then heating in the dormancy test phase of these experiments (Fig. 9). Though a limited number of cysts germinated at $C U$ accumulations less than 500, these tests always yield values of $G^{*}$ less than $18 \%$. Cyst cohorts with 500 to $800 C U$ reached $G^{*}$ of $50 \%$, but did so slowly (always requiring at least 2 weeks of incubation at $15^{\circ} \mathrm{C}$ ). In contrast, all cyst cohorts with over $800 \mathrm{CU}$ attained $G^{*}$ of $>50 \%$ within the first week of incubation and beyond $1200 \mathrm{CU}$, attained $G^{*}$ of $100 \%$.

\section{Winter chilling in Nauset}

Annual temperatures in Nauset from October 2013 to 2015 ranged from -2 to $28^{\circ} \mathrm{C}$ (Fig. 10). The average temperature from 01 December to 01 May was $5.4^{\circ} \mathrm{C}(S D=3.3)$ in $2013-2014$ and $4.0^{\circ} \mathrm{C}(S D=3.0)$ in $2014-2015$. These temperatures roughly align with the 6 and $4^{\circ} \mathrm{C}$ treatments that cysts experienced in this study; they are also the temperatures that yielded the highest $\bar{G}_{\max }$ (Fig. 5). These results are reported with the caveat that $G$ is a measure of viability after an appearance-based selection process; cysts that were darkened or green autofluorescent at the time of removal from cold storage were not isolated for dormancy tests. Unfortunately, the relative abundance of dead cysts was not quantified and therefore causes of mortality in field populations is not addressed in the present work.

Natural chilling (given a $T_{\max }$ of $15^{\circ} \mathrm{C}$ ) in Nauset did not begin to accumulate until late October, approximately five months after cyst formation (in 2013) and the start of the chilling-unit calculation in May (Fig. 10). Because experimental cysts were collected the first week of October, the onset of experimental chilling would have been three weeks earlier than natural chilling. The total chilling calculated over an entire year in Nauset was $1674 C U$ and $1985 C U$ in 2013-2014 and 2014-2015, respectively, which is within range of the $2000 C U$ maximum exposure in this study. This with a chilling requirement of $800 \mathrm{CU}$, natural $\mathrm{A}$. catenella cyst 
populations would have transitioned from dormancy to quiescence by late January in both 2014 and 2015.

\section{DISCUSSION}

It is unexpected that the duration of dormancy in mature cysts is shortened through exposure to cold temperatures. This inverse relationship between temperature and the rate of transition to quiescence is opposite to that of most other physiological rates including cell division, new cyst maturation, and germination, all of which are slower at lower temperatures. Here, a series of experiments are described in which mature cysts were stored under a range of cold treatments $(2$, 4,6 , and $8^{\circ} \mathrm{C}$ ), removed after different periods, and transferred to favorable germination conditions to assess their dormancy state. The results demonstrate, for the first time, that the cyst stage of a dinoflagellate: (1) quantitatively responds to chilling; and (2) needs to surpass a chilling threshold to transition from dormancy to quiescence. These findings are significant because they elucidate how temperature conditioning of $A$. catenella cysts could modulate germination in a given year or habitat. Incorporating this response into existing predictive models of blooms where environmental cues drive germination timing will improve bloom forecasting, especially in the context of species biogeography, local weather phenomena, and climate change. Results from these experiments also suggest a way that temperature may regulate dormancy-quiescence cycling within populations that have been described as being under control of an endogenous annual germination rhythm (Anderson and Keafer 1987). These new insights into the modulation of dormancy-quiescence transitions by chilling are detailed below.

\section{$T_{\max }$ and the chilling requirement are important physiological parameters}

The simple chilling-unit model presented here is able to predict the timing of germination with considerable precision by scaling the amount of chilling accumulated by cysts subjected to different cold temperatures. Integral to it are two physiological parameters, the first of which, $T_{\max }$, determines when, and to what degree, cysts register cold exposure (Fig. 7). For the $A$. catenella cysts collected from Nauset, the $T_{\max }$ is $\sim 15^{\circ} \mathrm{C}$, a temperature that is significant in other 
aspects of this species' physiology and ecology. Growth of vegetative $A$. catenella cells is typically maximal in laboratory cultures at $15^{\circ} \mathrm{C}$ and this is also the upper limit of water temperatures in which this species occurs in Nauset (Ralston et al. 2014). Furthermore, it is the temperature at which germination proceeds most rapidly once quiescence has been attained (Anderson et al. 2005).

The second physiological parameter is the chilling requirement, which, when calculated using $T_{\max }=15^{\circ} \mathrm{C}$ for the cysts in this study, was $800 \mathrm{CU}$. Upon exposure to $800 \mathrm{CU}$ and above, at least $50 \%$ of viable cysts germinated within the first week of incubation under optimal conditions, thus demonstrating that the majority of the cohort was quiescent (Fig. 9). Beyond $1200 \mathrm{CU}$, $100 \%$ germination of viable cysts within the first week of incubation was always reached. In sharp contrast, cyst cohorts that received between 500 and $800 C U$ required at least 2-weeks and up to the full 7-week test period to achieve 50\% germination of viable cysts. Below $500 \mathrm{CU}$, very few cysts germinated. Thus, for Nauset $A$. catenella cysts, $800 C U$ is a true chilling requirement, as it must be met for rapid and complete germination to occur.

Characterization of both the $T_{\max }$ and chilling requirement parameters are needed for other populations of $A$. catenella in order to assess the extent to which these findings can be generalized globally, or instead are region- or population- specific. For instance, do populations living in habitats that seldom if ever exceed $15^{\circ} \mathrm{C}$ share the same $T_{\max }$ of $15^{\circ} \mathrm{C}$ as those in Nauset? Likewise, is there plasticity in the chilling requirement among populations of $A$. catenella, a species that occurs in all temperate oceans worldwide? If so, variations in these parameters will undoubtedly be informative for understanding the role of chilling in this organism's ecology and its ability to colonize widely varying habitats.

Whether or not these specific parameters are similar among A. catenella populations globally, dormancy control by chilling is certainly one of several physiological and environmental factors that determine the occurrence of $A$. catenella blooms. Past observations of enhanced germination of other dinoflagellate cysts following exposure to chilling temperatures (Stosch 1967; 1973; Montresor and Marino 1996) suggest that dormancy is regulated similarly in these species, and likely in many others. The precise parameterizations of their $T_{\max }$ and chilling requirements will 
have similar implications for these species' ecology and will likely provide further insights into species succession patterns.

\section{Nullification of chilling in Nauset}

Though dormancy was the initial state of all cysts used in the cold storage experiments, the number of times that cysts had previously experienced dormancy differed (Fig. 3). In our analysis, the assumption was made that the vast majority of cysts used in these experiments were produced in May 2013 upon termination of a large A. catenella bloom (peak concentration on the order of $10^{5}$ cells $\mathrm{L}^{-1}$ ). This is because cells were not observed in Nauset until a small bloom occurred during the spring of 2014 (peak concentration on the order of $10^{3}$ cells $\mathrm{L}^{-1}$ ), and no significant cyst formation was observed this year (A. Fischer, unpublished). The dormancy status

of those cysts that remained in Nauset through the winter, spring and summer of 2014 is inferred from the germinability observed from monthly collections. The first dormancy period of these cysts concluded in January 2014 , when $73 \%$ germinated within one week of incubation at $15^{\circ} \mathrm{C}$ (Fig. 3). Continued monthly observations recorded high germination percentages until June 2014, when the cysts re-entered dormancy and remained in this second dormancy through the time of their collection. Given the different temperature histories of the 2013- and 2014-collected cysts, the congruence between the two sets of cold storage experiments is both surprising and fortuitous as it reveals several new aspects of dormancy-quiescence cycling.

Within the framework of the chilling model, the 2013-collected cysts were an ideal test population because from the time of their formation to collection, they never experienced chilling (i.e., Nauset water temperatures never fell below $T_{\max }=15^{\circ} \mathrm{C}$ between May and October 2013; Fig. 3). Therefore, comparison of the 2 and $6^{\circ} \mathrm{C}$ experiments was expected to provide a true estimate of the chilling requirement of the $A$. catenella population in Nauset. On the other hand, one might have expected the 2014-collected cysts, which had previously experienced chilling during the 2013-2014 winter (Figs. 3 and 10), to attain quiescence more rapidly in response to laboratory cold storage. As this was not observed, the in situ conditioning experienced by the 2014-collected cysts had apparently nullified any residual chilling by the time of their collection in October 2014. 
Another aspect of these experiments that was initially uncertain was whether the type of dormancy exhibited by the 2013-collected cysts was comparable to that of the 2014-collected cysts, or was associated with mandatory dormancy from the maturation process (Fig. 1). To distinguish between these two dormancy types, I propose the term "recurrent dormancy" to characterize the former which is only exhibited by fully mature cysts and, unlike mandatory dormancy, can occur many times within a single cyst's lifetime. This type of regulation has been compared to secondary dormancy in the seeds of terrestrial plants, which is the induction (and reinduction) of dormancy in response to unfavorable environmental conditions (Anderson and Keafer 1987; Matrai et al. 2005; Rathaille and Raine 2011; Moore et al. 2015). Although both of these types of dormancy are used to describe mature seeds or cysts, secondary dormancy is different because it can only be induced by environmental factors, whereas recurrent dormancy might be induced by internal and/or environmental factors.

A prime example of recurrent dormancy behavior is that of $A$. catenella cysts from deep water habitats in the GOM, which have been described as being under the control of an endogenous circannual rhythm (Anderson and Keafer 1987; Matrai et al. 2005). In effect, these cysts repeatedly cycle through the states of dormancy and quiescence even when maintained in constant darkness and at a constant cold temperature. The cysts collected in October 2014 from Nauset used in the 4 and $8^{\circ} \mathrm{C}$ experiments were similar in that they uniquely had attained quiescence in situ, then reverted back to dormancy by the time of their collection in October 2014 (Fig. 3). The type of dormancy experienced by the 2013-collected cysts was less clear. These cysts never attained quiescence in situ prior to their use in cold storage experiments and subsequent sampling of Robert's Cove cysts showed that they remained dormant until January. Were they in mandatory dormancy or recurrent dormancy at the start of these experiments?

Prior assessments of the duration of mandatory dormancy provide a valuable point of reference. Anderson (1980) showed that the mandatory dormancy period of A. catenella cysts from Perch Pond (another shallow Cape Cod embayment) is $1-4$ months and is shortest at warmer temperatures (when tested at $22^{\circ} \mathrm{C}$ versus $4^{\circ} \mathrm{C}$ ). Therefore, the mandatory dormancy period of the 2013-collected cysts was likely short due to the warm summertime temperatures they experienced in Nauset (Fig. 3). It is almost certain then that mandatory dormancy was completed 
in less than the 5 months between these cysts' formation and their collection in October. The lack of any observed quiescence through this period further suggests that an initial state of quiescence is not required for recurrent dormancy to be initiated; instead, cysts may enter recurrent dormancy either from quiescence or directly from mandatory dormancy (which is reflected in the conceptual model shown in Fig. 1).

Another question that can be addressed by considering the temperature histories of the once and 2014-collected cysts is: What factor(s) induce cysts to enter recurrent dormancy? Because both collections were experiencing recurrent dormancy, summertime conditions in Nauset were likely responsible. Water temperatures in Nauset always exceed $18.5^{\circ} \mathrm{C}$ from mid-June through midSeptember, a temperature that is known to inhibit A. catenella excystment (Anderson and Rengefors 2006; Fig. 10). Here, I further propose that these high temperatures induced recurrent dormancy.

If the observed failure of these cysts to germinate was due to simple inhibition by unfavorably warm summer temperatures, placing cysts taken from Nauset in July-October 2013 into optimal incubation conditions $\left(15^{\circ} \mathrm{C}\right.$, oxygen, and light) should have resulted in high rates of germination. Instead, germination rates were consistently $<6 \%$ (Fig. 3). It appears that exposure to persistent warm conditions nullified any accrued chilling from exposure to the 2013-2014 winter, and simultaneously caused these cysts to enter recurrent dormancy. Further experiments are needed to determine what duration of exposure to temperatures exceeding $18.5^{\circ} \mathrm{C}$ are needed to induce recurrent dormancy and the relationship to nullification of accumulated chilling.

The chilling response ( $T_{\max }$ and the chilling requirement) of other cyst populations is of obvious interest. To establish this, two aspects of our experimental design must be replicated: (1) an initial state of recurrent dormancy, and (2) nullification of any residual chilling. Cysts for these experiments were collected at a time of year when both of these challenges were met through natural conditioning. However, A. catenella cysts occur worldwide in habitats with milder seasonality than Nauset, many of which have temperatures constrained within the favorable window for germination $\left(2-18.5^{\circ} \mathrm{C}\right.$; Anderson and Rengefors 2006). Thus, temperatures may never be so unfavorable in these milder habitats that they induce recurrent dormancy and there 
may always be residual accumulated chilling. The temperature history of the 2014-collected cysts provides a useful roadmap that could be applied to these future chilling experiments. To send these cysts into a state of recurrent dormancy, a collection of cysts might be initially warmed to temperatures $>18.5^{\circ} \mathrm{C}$. By transferring cohorts of the warmed population to $15^{\circ} \mathrm{C}$, the transition to recurrent dormancy could be monitored until complete for the population as a whole. Then, cyst cohorts could be exposed to temperatures $<T_{\max }$ to investigate the chilling response as detailed in this study.

\section{Temperature determines the length of dormancy}

One of the more puzzling aspects of dormancy regulation by A. catenella cysts has been the apparent conflict between the behavior of deep water and shallow, inshore populations.

Dormancy-quiescence transitions by cyst populations lying in the deep areas of the GOM have an endogenous circannual rhythmicity that causes quiescence to coincide with spring when conditions in overlying euphotic waters are favorable for blooms (Anderson and Keafer 1987; Matrai et al. 2005). Such endogenous rhythmicity is advantageous in these deep habitats because seasonal temperature variability at depth is greatly dampened relative to euphotic waters where blooms develop. In contrast, rhythmicity appears to be muted or absent in A. catenella cysts collected from shallow, inshore habitats in Puget Sound, WA (Moore et al. 2015) and Cork Harbour, Ireland (Rathaille and Raine 2011), leading to the hypothesis that these populations employ an alternate, environmentally-mediated mechanism of dormancy regulation (e.g., secondary dormancy). To begin to reconcile these differences, the drivers of state transitions need to be examined in light of the new understanding of the chilling response presented here, namely that temperature determines the duration of dormancy.

Past studies of endogenous circannual rhythmicity have subjected test populations of $A$. catenella cysts to continuous cold storage conditions (either 2 or $4^{\circ} \mathrm{C}$ ) in designs that are quite similar to the experiments described here. Unlike our experiment, however, these storage conditions were maintained for multiple years and lacked an explicit focus on the transition from dormancy to quiescence. Another important difference is that the analysis reported here considers cold temperature as a variable environmental signal. The most basic finding - that cysts stored at warmer temperatures take longer to attain quiescence - has immediate implications for cysts in 
both shallow and deep water habitats. Warmer wintertime temperatures would be expected to extend the duration of $A$. catenella cyst dormancy. In a similar way, temperature may play a role in modulating the overall period of dormancy-quiescence cycling by deep water cysts and/or determine the proportion of time that cysts spend in dormant and quiescent states.

It is noteworthy that the reported periods of endogenous germination rhythmicity in cysts from the Gulf of Maine are less than one full year - instead just 11 months (Anderson and Keafer 1987; Matrai et al. 2005). In situ, such a short period would pose a substantial ecological disadvantage to older year classes, especially considering that the lifetime of a cyst in sediment can be several decades or more (Keafer et al. 1992; Miyazono et al. 2012; Feifel et al. 2012). A resolution to this apparent defect is provided by considering the effect of chilling on dormancy as described through this study. Both past descriptions of endogenous rhythmicity have used $2{ }^{\circ} \mathrm{C}$ as a storage temperature, somewhat colder than the average bottom temperatures most likely experienced by GOM cysts $\left(7.4^{\circ} \mathrm{C} \pm 2.6 ; 2009-2016\right.$; http://www.neracoos.org/datatools). If the $T_{\max }$ and chilling requirement of the GOM cysts are the same as those for Nauset cysts $\left(15^{\circ} \mathrm{C}\right.$ and $800 \mathrm{CU}$ ), the choice of storage temperature would have shortened the dormancy period by a little over a month. Replication of these endogenous rhythmicity experiments using slightly higher storage temperatures might therefore be expected to prolong the period of germination rhythmicity to a full year.

\section{Effects of dormancy breaking by chilling in shallow water systems}

Using records of environmental temperature, the transition of the cyst seedbed from recurrent dormancy to quiescence can be calculated and compared to the appearance of new germling cells. In the laboratory, the onset of quiescence occurred at $500 \mathrm{CU}$, the $G^{*}{ }_{50}$ was attained at $800 \mathrm{CU}$, and all cysts had fully transitioned to quiescence by $1200 \mathrm{CU}$. In the context of the Nauset system, chilling begins in late October, and the 500, 800, and $1200 C U$ thresholds were attained between January and early March in both study years (Fig. 10b). Remarkably, this prediction is in agreement with the monthly observations of the seasonal dormancy status of the Nauset cyst seedbed (Fig. 3), where cysts first became quiescent in January, demonstrating the power of the chilling-based model for predicting dormancy-quiescence transitions by A. catenella cysts. 
The onset of quiescence is not synonymous with bloom inoculation in Nauset, as A. catenella blooms do not typically develop until April and May (Ralston et al. 2014). Instead, upon attainment of quiescence in the preceding months, cysts remain in the sediments, poised to respond to favorable conditions (Fig. 3). In Nauset, the primary factor limiting the germination of quiescent cysts is temperature. Instead of hastening the bloom inoculation, attainment of the chilling requirement ensures that a cyst will not germinate until conditions become progressively more favorable. Because the chilling requirement is achieved relatively early, pulses of germling cells can appear quite synchronously when favorable conditions arise. This is especially the case in shallow temperate systems like Nauset that are highly responsive to changing air temperatures. Such synchronous germling pulses may be ecologically advantageous in habitats with short growing seasons or where $A$. catenella must outcompete other phytoplankton species to establish itself. At the same time, a chilling requirement that is less than what might typically be achieved in a particular habitat ( 1700-2000 CU total is accumulated in Nauset; Fig 10b) may provide some resilience in the face of anomalously warm years. For example, an anomalously warm December and January would delay attainment of the chilling requirement (and quiescence), but still not substantially change the timing of bloom inoculation the subsequent spring so long as the chilling requirement is attained prior to the onset of conditions conducive to fast germination.

The function of the chilling response in cysts may be similar to that of many plant seeds and bulbs. Chilling winter temperatures help prevent precocious emergence during short spells of favorable conditions in an otherwise unfavorable season for plants (e.g. Arora et al. 2003; Horvath et al. 2003; Rohde and Bhalerao 2007). If this same logic is applied to A. catenella cysts, a short warm spell in December that might otherwise lead to precocious germination of cysts, would have little effect because cysts are dormant. Under a life cycle without recurrent dormancy, germling cells would be released into waters where their growth potential is limited by cold temperatures and short light periods. By quantifying the duration and severity of cold, $A$. catenella are able to track the passage of winter just like many plants, delaying quiescence until spring when conditions are more favorable for establishment of dense blooms.

The same chilling response may also produce different effects in the context of other shallow, inshore habitats. The amplitude of seasonal temperature oscillations in Nauset is quite strong (- 
$2-27^{\circ} \mathrm{C}$; Fig. 10a) relative to other areas that are also chronically impacted by $A$. catenella blooms (e.g. Puget Sound where bottom water temperatures vary seasonally from $8-13^{\circ} \mathrm{C}$; http:/green2.kingcounty.gov/marine-buoy/). If the chilling accumulation rates and thresholds established in Nauset are universal for all of $A$. catenella populations, milder seasonal temperature swings are likely to produce less-synchronous, more-dispersed inoculum for new blooms. In turn, this might translate to multiple small-scale blooms throughout a year or could represent an alternative bloom strategy whereby development of blooms is controlled to a larger degree on other abiotic and biotic factors (e.g., day length, light intensity, or the presence/absence of other competing species, grazers and parasites).

\section{Biogeographic and climactic implications}

Shallow coastal waters and estuaries that have little thermal inertia will be some of the first to reflect climate change-induced warming. Results from well-studied representative habitats for $A$. catenella like Nauset are therefore highly informative in testing how temperature thresholds will govern bloom phenology in the present and future. In regions where blooms already exist, the winters of the future will have different rates of chilling accumulation, and in others, the chilling requirement may no longer be attained. In Nauset, warmer bottom water temperatures will cause attainment of the chilling requirement to be delayed. Despite this effect, I anticipate that the initial consequences of warmer water temperatures will be apparent in higher rates of germination and cell division because of the current lag between attainment of quiescence and the onset of high rates of germination.

If all $A$. catenella cysts have similar chilling responses, the chilling requirement will likely have more immediate importance for determining the southernmost latitudes at which these blooms occur. In warmer, southern areas, A. catenella cysts may fail to attain their chilling threshold and remain dormant indefinitely. Alternatively, these warmer conditions may select for the minority of cysts on the lower spectrum of the chilling requirement (e.g. cysts that germinated with only $500 \mathrm{CU}$ ), as they are capable of leveraging favorable environmental conditions. In contrast, in colder regions, dormancy has a minimal effect on restraining the occurrence of blooms at present because the chilling requirement would be achieved so quickly. While dormancy may be 
prolonged due to warming in some cases, the most dramatic effects of warming on A. catenella phenology are likely to be observed through earlier bloom initiation and development.

More generally, rising ocean temperatures have obvious importance to the spread and retraction of Alexandrium populations in the future. The northern extent of these blooms is likely to increase in response to warming water temperatures (earlier germination and faster growth). Thus far, abundant cyst distributions of the toxic Alexandrium tamaranse complex have been reported in the continental shelves of the eastern Bering Sea and Chukchi Sea (Gu et al. 2012; Natsuike et al. 2013), and in Greenland and Iceland (Richlen et al. 2016). Further, vegetative cells of A. tamarense have been observed in the Chukchi Sea and the Bering Sea at concentrations on the order of $10^{3}$ cells L ${ }^{-1}$ and as far north as $73^{\circ} \mathrm{N}$ (Natsuike et al. 2017b). Laboratory studies demonstrate evidence of local physiological adaptations of these northern $A$. tamarense populations: they can grow at temperatures as low as $5^{\circ} \mathrm{C}$, can germinate at temperatures as low as $1^{\circ} \mathrm{C}$, and are dormant from the late summer through early spring (Natsuike et al. 2017a). Given these unique adaptations to higher latitudes, it is plausible that the regulation of dormancy in these northernmost populations would be adapted to different chilling parameters. Comparative studies of $T_{\max }$ and chilling thresholds in Alexandrium cysts are needed across different habitats to understand their role in this species' biogeography. 


\section{REFERENCES}

Anderson, D. M. 1980. Effects of Temperature Conditioning on Development and Germination of Gonyaulax tamarensis (Dinophyceae) Hypnozygotes. Journal of Phycology 16: 166-172.

Anderson, D. M. 1998. Physiology and Bloom Dynamics of Toxic Alexandrium Species, with Emphasis on Life Cycle Transitions, p. 29-48. In D.M. Anderson, A.D. Cembella, and G.M. Hallegraeff [eds.], Physiological Ecology of Harmful Algal Blooms. NATO ASI Series. NATO ASI Series.

Anderson, D. M., and B. Keafer. 1987. An endogenous annual clock in the toxic marine dinoflagellate Gonyaulax tamarensis. Nature 325: 616-617.

Anderson, D. M., and F. M. M. Morel. 1979. The Seeding of two Red Tide Blooms by the Germination of Benthic Gonyaulax tamarensis Hypnocysts. Estuarine and Coastal Marine Science 8: 279-293. doi:10.1016/0302-3524(79)90098-7

Anderson, D. M., and K. D. Stolzenbach. 1985. Selective retention of two dinoflagellates in a well-mixed estuarine embayment: The importance of diel vertical migration and surface avoidance. Marine Ecology Progress Series 25: 39-50.

Anderson, D. M., and K. Rengefors. 2006. Community assembly and seasonal succession of marine dinoflagellates in a temperate estuary: The importance of life cycle events. Limnology and Oceanography 51: 860-873.

Anderson, D. M., C. A. Stock, B. Keafer, and others. 2005. Alexandrium fundyense cyst dynamics in the Gulf of Maine. Deep Sea Research II 52: 2522-2542. doi:10.1016/j.dsr2.2005.06.014

Anderson, D. M., C. D. Taylor, and E. V. Armbrust. 1987. The effects of darkness and anaerobiosis on dinoflagellate cyst germination. Limnology and Oceanography 32: 340-351.

Anderson, D. M., S. W. Chisholm, and C. J. Watras. 1983. Importance of life cycle events in the population dynamics of Gonyaulax tamarensis. Marine Biology 76: 179-189. doi:10.1007/BF00392734

Anderson, D. M., T. J. Alpermann, A. D. Cembella, Y. Collos, E. Masseret, and M. Montresor. 2012. The globally distributed genus Alexandrium: Multifaceted roles in marine ecosystems and impacts on human health. Harmful Algae 14: 10-35. doi:10.1016/j.hal.2011.10.012

Anderson, D. M., Y. Fukuyo, and K. Matsuoka. 2003. Cyst Methodologies, p. 165-190. In G.M. Hallegraeff, D.M. Anderson, and A.D. Cembella [eds.], Manual on Harmful Marine Microalgae.

Arora, R., L. J. Rowland, and K. Tanino. 2003. Induction and release of bud dormancy in woody perennials: a science comes of age. HortScience.

Bewley, D. J., K. J. Bradford, H. Hilhorst, and H. Nonogaki. 2013. Seeds: Physiology of Development, Germination and Dormancy, 3rd ed. Springer.

Binder, B. J., and D. M. Anderson. 1986. Green light-mediated photomorphogenesis in a dinoflagellate resting cyst. Nature 322: 659-661. doi:10.1038/322659a0

Bravo, I., and D. M. Anderson. 1994. The effects of temperature, growth medium and darkness 
on excystment and growth of the toxic dinoflagellate Gymnodinium catenatum from northwest Spain. Journal of Plankton Research 16: 513-525. doi:10.1093/plankt/16.5.513

Cannon, J. 1993. Germination of the toxic dinoflagellate, Alexandrium minutum from sediments of the Port River, South Australia, p. 103-112. In T. Smayda and Y. Shimizu [eds.], Toxic Phytoplankton Blooms in the Sea.

Crespo, B. G., B. A. Keafer, D. K. Ralston, H. Lind, D. Farber, and D. M. Anderson. 2011. Dynamics of Alexandrium fundyense blooms and shellfish toxicity in the Nauset Marsh System of Cape Cod (Massachusetts, USA). Harmful Algae 12: 26-38. doi:10.1016/j.hal.2011.08.009

Dale, B. 1983. Dinoflagellate Resting Cysts, p. 69-136. In G.A. Fryxell [ed.], Survival Strategies of the Algae. Survival strategies of the algae.

Feifel, K. M., S. K. Moore, and R. A. Horner. 2012. An Alexandrium Spp. Cyst Record from Sequim Bay, Washington State, USA, and its Relation to Past Climate Variability. Journal of Phycology 48: 550-558. doi:10.1111/j.1529-8817.2012.01175.x

Gu, H., N. Zeng, Z. Xie, D. Wang, W. Wang, and W. Yang. 2012. Morphology, phylogeny, and toxicity of Atama complex (Dinophyceae) from the Chukchi Sea. Polar Biol 36: 427-436. doi:10.1007/s00300-012-1273-5

Guillard, R. L., and J. H. Ryther. 1962. Studies of Marine Planktonic Diatoms. Canadian Journal of Microbiology 8: 229-239.

Horvath, D. P., J. V. Anderson, W. S. Chao, and M. E. Foley. 2003. Knowing when to grow: signals regulating bud dormancy. Trends in Plant Science 8: 534-540. doi:10.1016/j.tplants.2003.09.013

Huber, G., and F. Nipkow. 1923. Experimentelle Untersuchungen über die Entwicklung und form bildung von Ceratium hirundinella O. F. Müller. Flora 116: 114-215.

Ji, R., M. Edwards, D. L. Mackas, J. A. Runge, and A. C. Thomas. 2010. Marine plankton phenology and life history in a changing climate: current research and future directions. Journal of Plankton Research 32: 1355-1368. doi:10.1093/plankt/fbq062

John, U., R. W. Litaker, M. Montresor, S. Murray, M. L. Brosnahan, and D. M. Anderson. 2014. Formal Revision of the Alexandrium tamarense Species Complex (Dinophyceae) Taxonomy: The Introduction of Five Species with Emphasis on Molecular-based (rDNA) Classification. Protist 165: 779-804. doi:10.1016/j.protis.2014.10.001

Karssen, C. M. 1982. Seasonal patterns of dormancy in weed seeds, p. 243-270. In A.A. Khan [ed.], The physiology and biochemistry of seed development, dormancy and germination.

Keafer, B. A., K. O. Buesseler, and D. M. Anderson. 1992. Burial of living dinoflagellate cysts in estuarine and nearshore sediments. Marine Micropaleontology 20: 147-161. doi:10.1016/0377-8398(92)90004-4

Kremp, A., and D. M. Anderson. 2000. Factors regulating germination of resting cysts of the spring bloom dinoflagellate Scrippsiella hangoei from the northern Baltic Sea. Journal of Plankton Research 22: 1311-1327. doi:10.1093/plankt/22.7.1311

Luedeling, E., M. Zhang, and E. H. Girvetz. 2009. Climatic Changes Lead to Declining Winter 
Chill for Fruit and Nut Trees in California during 1950-2099. PLoS ONE 4: 1-9. doi:10.1371/journal.pone.0006166

Matrai, P., B. Thompson, and M. Keller. 2005. Circannual excystment of resting cysts of Alexandrium spp. from eastern Gulf of Maine populations. Deep Sea Research Part II 52: 2560-2568. doi:10.1016/j.dsr2.2005.06.013

Miyazono, A., S. Nagai, I. Kudo, and K. Tanizawa. 2012. Viability of Alexandrium tamarense cysts in the sediment of Funka Bay, Hokkaido, Japan: Over a hundred year survival times for cysts. Harmful Algae 16: 81-88. doi:10.1016/j.hal.2012.02.001

Montresor, M., and D. Marino. 1996. Modulating effect of cold-dark storage on excystment in Alexandrium pseudogonyaulax (Dinophyceae). Marine Biology 127: 55-60. doi:10.1007/BF00993643

Moore, S. K., B. D. Bill, L. R. Hay, J. Emenegger, K. C. Eldred, C. L. Greengrove, J. E. Masura, and D. M. Anderson. 2015. Factors regulating excystment of Alexandrium in Puget Sound, WA, USA. Harmful Algae 43: 103-110. doi:10.1016/j.hal.2015.01.005

Natsuike, M., H. Oikawa, K. Matsuno, A. Yamaguchi, and I. Imai. 2017a. The physiological adaptations and toxin profiles of the toxic Alexandrium fundyense on the eastern Bering Sea and Chukchi Sea shelves. Harmful Algae 63: 13-22. doi:10.1016/j.hal.2017.01.001

Natsuike, M., K. Matsuno, T. Hirawake, A. Yamaguchi, S. Nishino, and I. Imai. 2017b. Possible spreading of toxic Alexandrium tamarense blooms on the Chukchi Sea shelf with the inflow of Pacific summer water due to climatic warming. Harmful Algae 61: 80-86. doi:10.1016/j.hal.2016.11.019

Natsuike, M., S. Nagai, K. Matsuno, R. Saito, C. Tsukazaki, A. Yamaguchi, and I. Imai. 2013. Abundance and distribution of toxic Alexandrium tamarense resting cysts in the sediments of the Chukchi Sea and the eastern Bering Sea. Harmful Algae 27: 52-59. doi:10.1016/j.hal.2013.04.006

Penfield, S., and V. Springthorpe. 2012. Understanding chilling responses in Arabidopsis seeds and their contribution to life history. Philosophical Transactions of the Royal Society B: Biological Sciences 367: 291-297. doi:10.1098/rstb.2011.0186

Perez, C. C., S. Roy, M. Levasseur, and D. M. Anderson. 1998. Control of germination of Alexandrium tamarense (Dinophyceae) cysts from the lower St. Lawrence Estuary (Canada). Journal of Phycology 34: 242-249. doi:10.1046/j.1529-8817.1998.340242.x

Pfiester, L. A. 1977. Sexual reproduction of Peridinium gatuense (Dinophyceae). Journal of Phycology 13: 92-95.

Pfiester, L. A., and D. M. Anderson. 1987. Dinoflagellate Reproduction, p. 611-648. In F.J.R. Taylor [ed.], The Biology of Dinoflagellates.

Prud'homme van Reine, W. 2017. Report of the Nomenclature Committee for Algae: 15. Taxon 66: $191-192$. doi:10.12705/661.16

Ralston, D. K., B. A. Keafer, M. L. Brosnahan, and D. M. Anderson. 2014. Temperature dependence of an estuarine harmful algal bloom: Resolving interannual variability in bloom dynamics using a degree-day approach. Limnology and Oceanography 59: 1112-1126. doi:10.4319/lo.2014.59.4.1112 
Ralston, D. K., M. L. Brosnahan, S. E. Fox, K. Lee, and D. M. Anderson. 2015. Temperature and Residence Time Controls on an Estuarine Harmful Algal Bloom: Modeling Hydrodynamics and Alexandrium fundyense in Nauset Estuary. Estuaries and Coasts 38: 2240-2258. doi:10.1007/s12237-015-9949-z

Rathaille, A. N., and R. Raine. 2011. Seasonality in the excystment of Alexandrium minutum and Alexandrium tamarense in Irish coastal waters. Harmful Algae 10: 629-635. doi:10.1016/j.hal.2011.04.015

Rengefors, K., and D. M. Anderson. 1998. Environmental and endogenous regulation of cyst germination in two freshwater dinoflagellates. Journal of Phycology 568-577. doi:10.2307/2839001?ref=no-X-route:7191c230a3ac0bdf2bdd6c36fbd9e0d1

Richlen, M. L., O. Zielinski, L. Holinde, U. Tillmann, A. Cembella, Y. Lyu, and D. M. Anderson. 2016. Distribution of Alexandrium fundyense (Dinophyceae) cysts in Greenland and Iceland, with an emphasis on viability and growth in the Arctic. Marine Ecology Progress Series 547: 33-46. doi:10.3354/meps 11660

Rohde, A., and R. P. Bhalerao. 2007. Plant dormancy in the perennial context. Trends in Plant Science 12: 217-223. doi:10.1016/j.tplants.2007.03.012

Schwinghamer, P., D. M. Anderson, and D. M. Kulis. 1991. Separation and concentration of living dinoflagellate resting cysts from marine sediments via density-gradient centrifugation. Limnology and Oceanography 36: 588-592. doi:10.4319/1o.1991.36.3.0588

Stosch, H. A., von. 1967. Haptophyceae, p. 646-656. In W. Ruhland [ed.], Encyclopedia of Plant Physiology. Gottingen and Heidelberg.

Stosch, H. A., von. 1973. Observations on vegetative reproduction and sexual life cycles of two freshwater dinoflagellates, Gymondinium pseudopalustre Schiller and Woloszynskia apiculata sp. nov. British Phycological Journal 8: 105-134. doi:10.1080/00071617300650141

Tang, Y. Z., and F. C. Dobbs. 2007. Green autofluorescence in dinoflagellates, diatoms, and other microalgae and its implications for vital staining and morphological studies. Applied and Environmental Microbiology 73: 2306-2313. doi:10.1128/AEM.01741-06

Vegis, A. 1964. Dormancy in higher plants. Annual Review of Plant Physiology 15: 185-224. doi:10.1146/annurev.pp.15.060164.001153

Vleeshouwers, L. M., H. J. Bouwmeester, and C. M. Karssen. 1995. Redefining seed dormancy: an attempt to integrate physiology and ecology. The Journal of Ecology 83: 1031-1037. doi: $10.2307 / 2261184$

Wall, D. 1971. Biological problems concerning fossilizable dinoflagellates. Geoscience and Man 3: 1-15. doi:10.1080/00721395.1971.9989704 


\section{FIGURES}

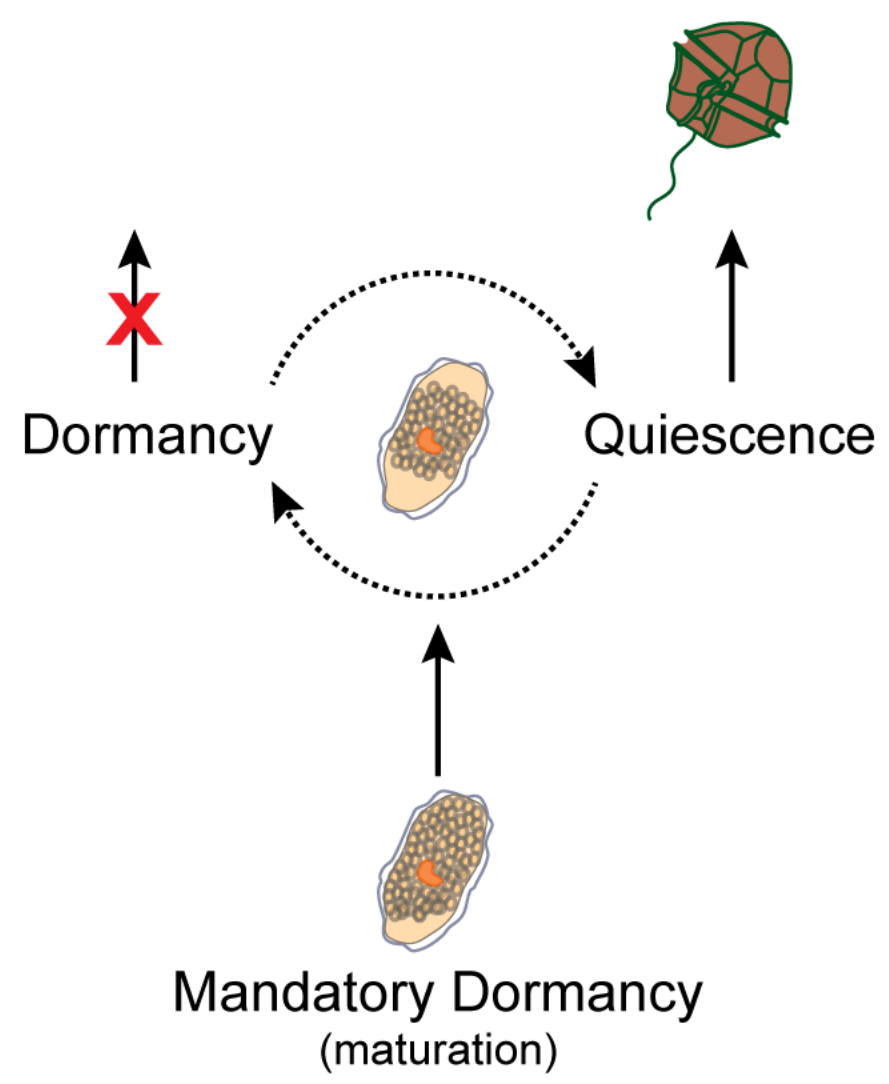

Fig. 1. Schematic of dormancy-quiescence transitions. Immediately after formation, mandatory dormancy prevents germination so cysts can complete maturation. Mandatory dormancy is alleviated by factors within the cyst. At this point, cysts become quiescent or enter dormancy due to environmental and/or internal factors (e.g. endogenous clock). Once quiescent, cysts can germinate under favorable environmental conditions. The quantity of starch granules within the cartoon cysts reflects the starch being utilized as a cyst matures and ages. 


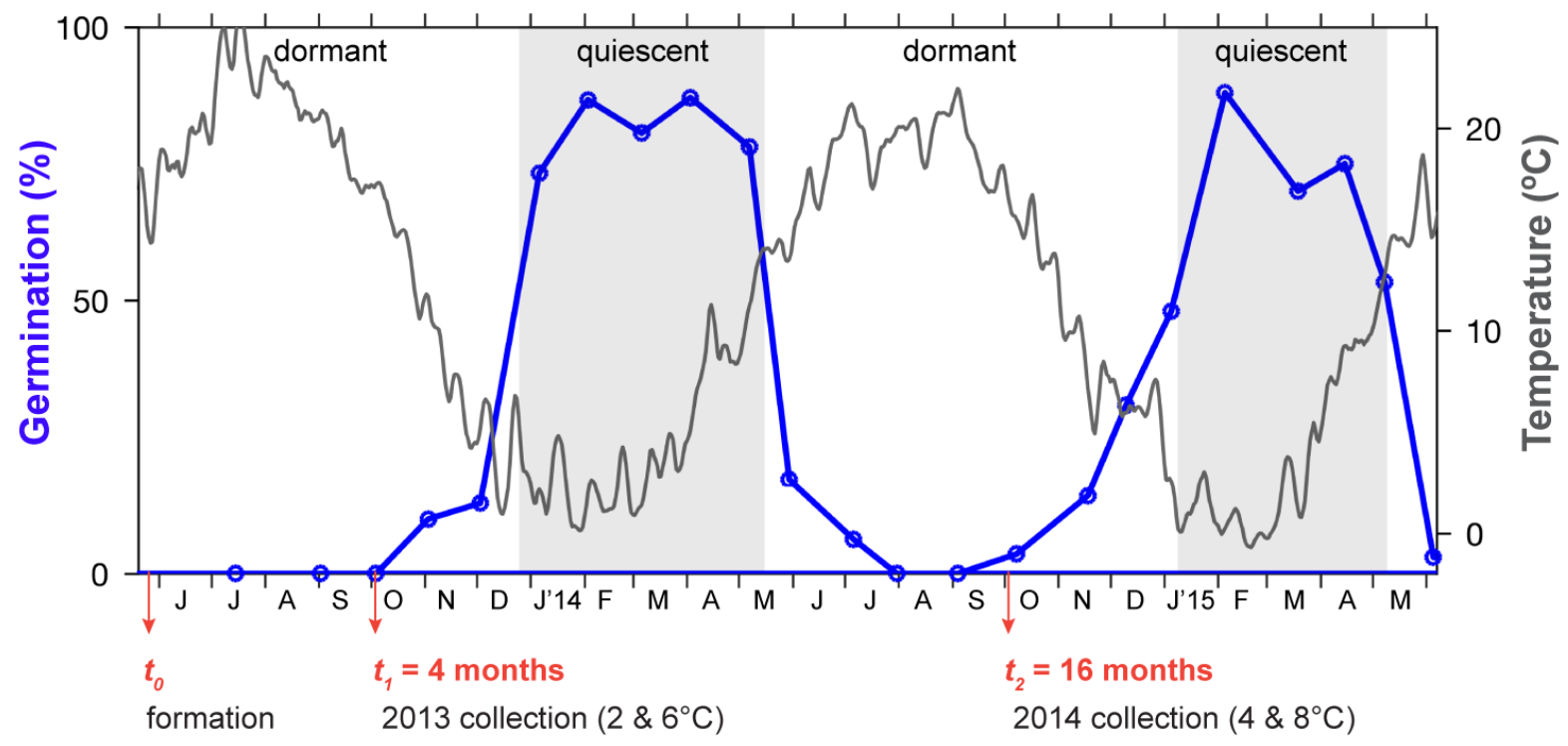

Fig. 2. Seasonal dormancy status of the Nauset cyst seedbed from July 2013 to June 2015. Each blue data point is the cumulative germination of a cohort of freshly-collected cysts incubated under optimal conditions $\left(15^{\circ} \mathrm{C}\right.$, light, and oxygen $)$ for one week. Periods of majority quiescence (when cumulative germination exceeds $50 \%$ ) are demarcated by grey shading. Red arrows highlight the timing of cyst formation $\left(t_{0}\right)$ following the 2013 spring bloom, and the 2013 and 2014 collections. The grey line represents the bottom water temperature conditioning that cysts experienced prior to laboratory manipulation. 


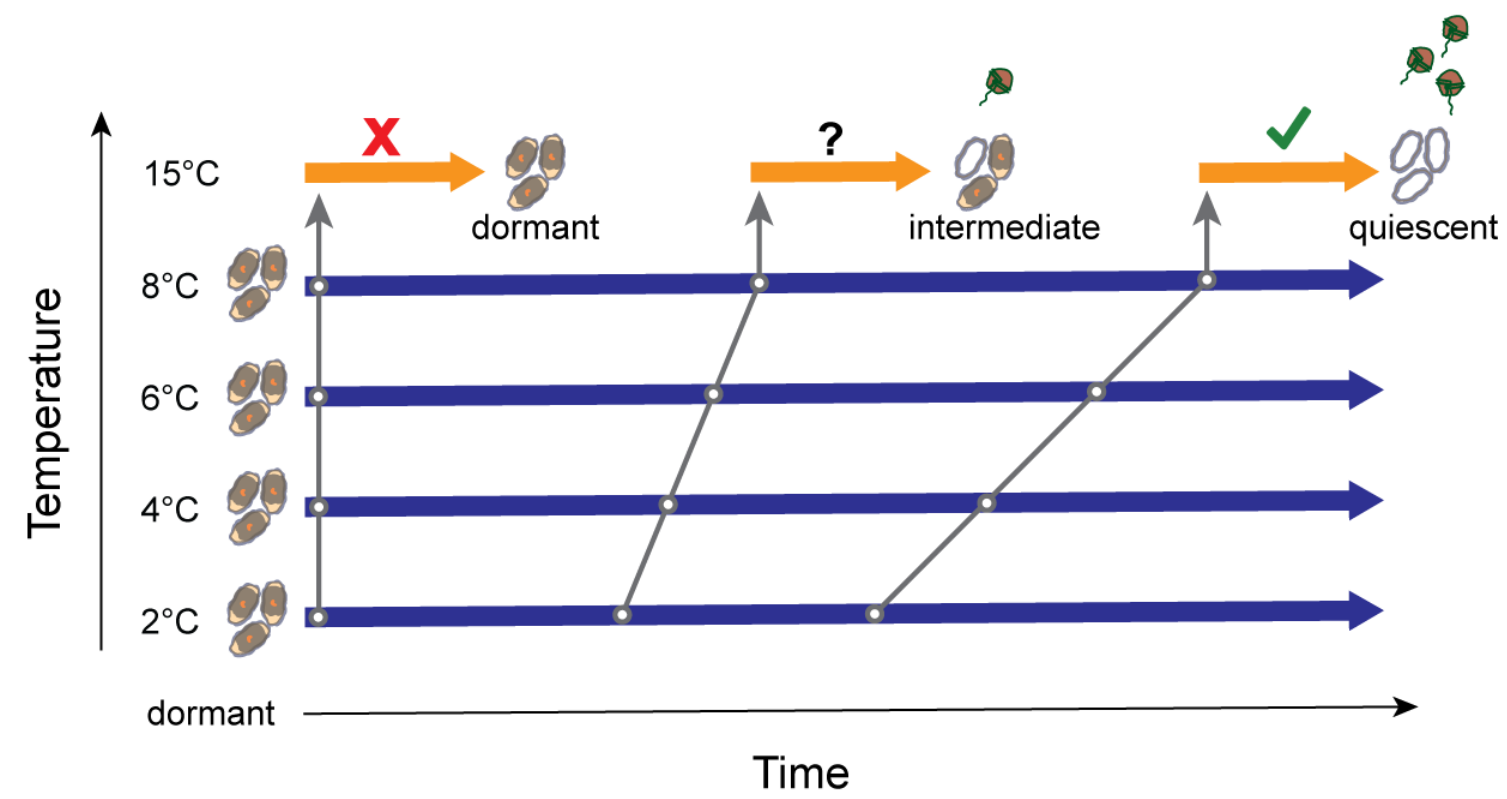

Fig. 3. Germination assay of dormancy state. Cyst cohorts were stored in anoxic, dark storage at $2,4,6$, and $8^{\circ} \mathrm{C}$ and removed after different durations to examine their dormancy status. The linked points on the four storage temperature timelines are equivalent steps of chilling accumulation - i.e., different durations at different storage temperatures are required to reach comparable levels of chilling. 

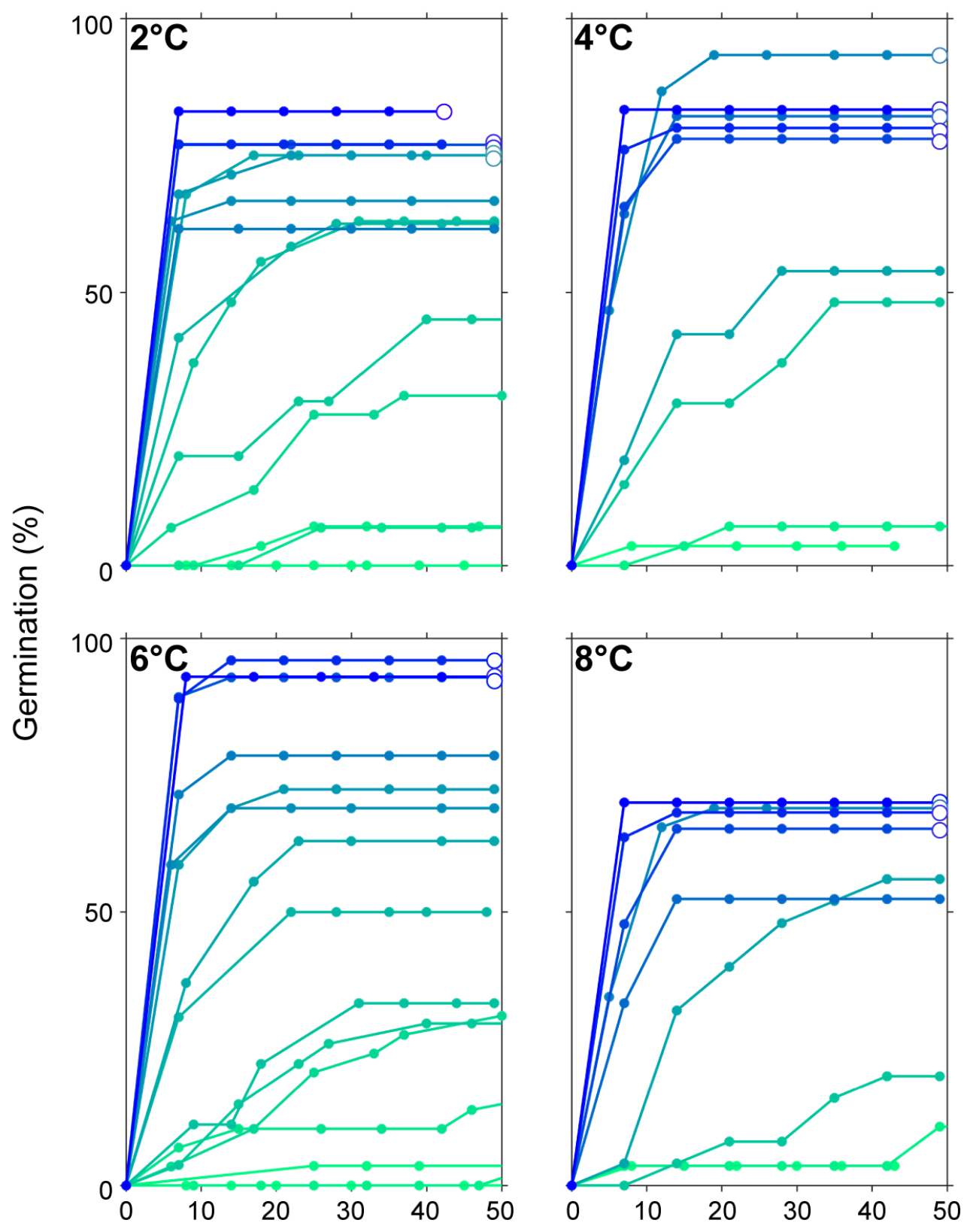

constant

storage

(days)
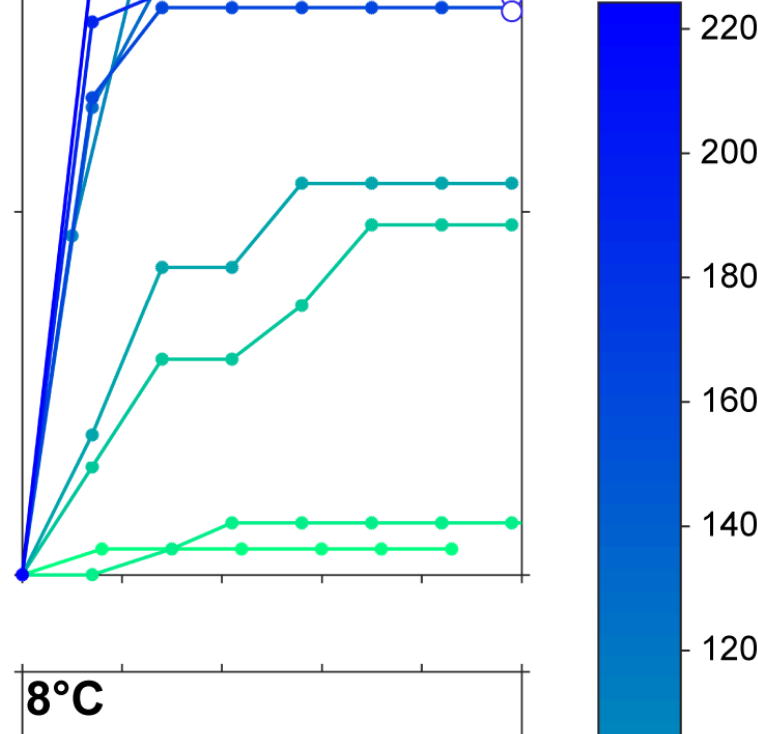

120

100

80
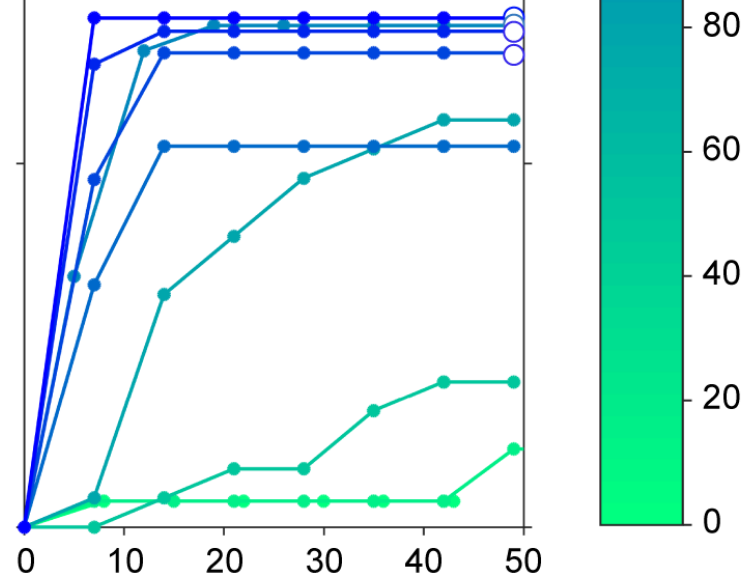

Incubation time (days)

Fig. 4. Germination time-course curves for A. catenella cyst cohorts exhumed from 2, 4, 6, and $8^{\circ} \mathrm{C}$ storage treatments of different durations. The colorbar indicates the duration of constant cold storage for each cohort - the bluer the color, the longer the duration. The open circles indicate $G_{\max }$ values of cohorts that exceeded $85 \%$ of the maximum germination of each treatment - these were averaged to calculate the $\bar{G}_{\max }$ for each treatment. 


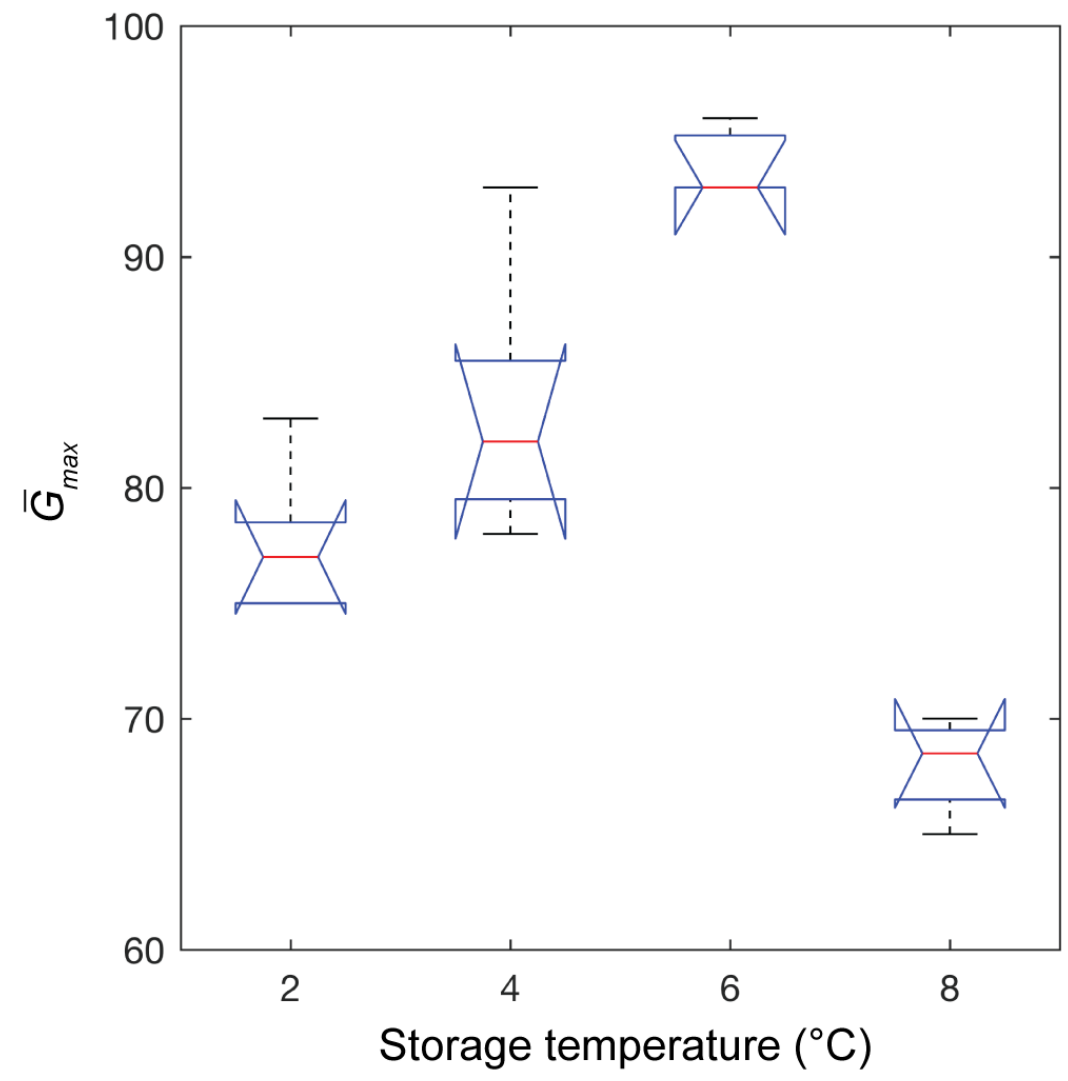

Fig. 5. Mean maximum germination $\left(\bar{G}_{\max }\right)$ of cyst cohorts exhumed from different cold storage treatments and durations. The data presented here are of cyst cohorts that exceeded $85 \%$ of the maximum germination of the treatment within the first week of incubation under optimal conditions $\left(15^{\circ} \mathrm{C}\right.$, light, and oxygen) (open circles from Fig. 4). 


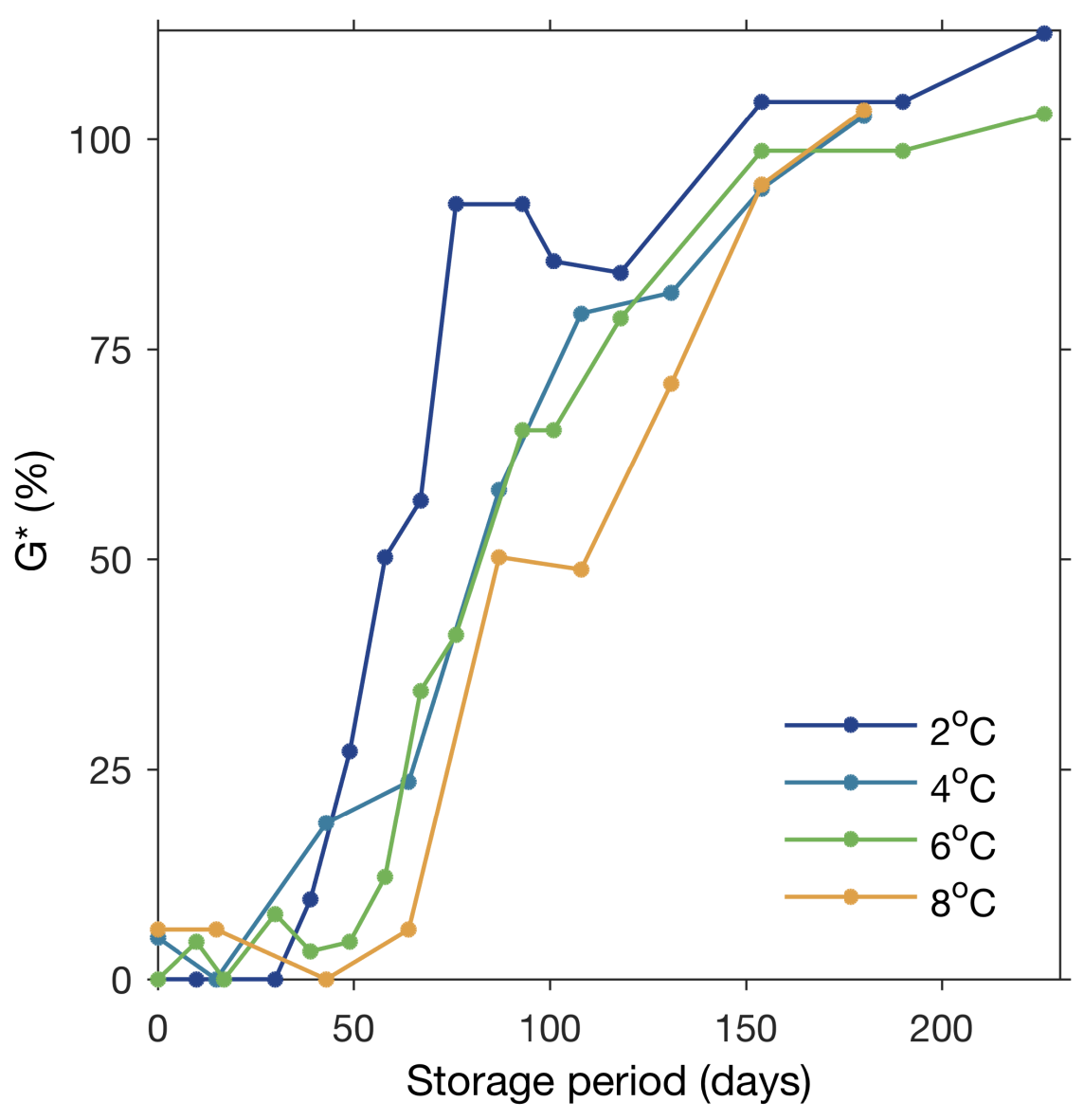

Fig. 6. Cumulative percent germination of cyst cohorts exhumed from different cold storage treatments and durations and incubated under optimal conditions $\left(15^{\circ} \mathrm{C}\right.$, light, and oxygen) for one week. Data are normalized to the $\bar{G}_{\max }$ of each cold storage treatment. 

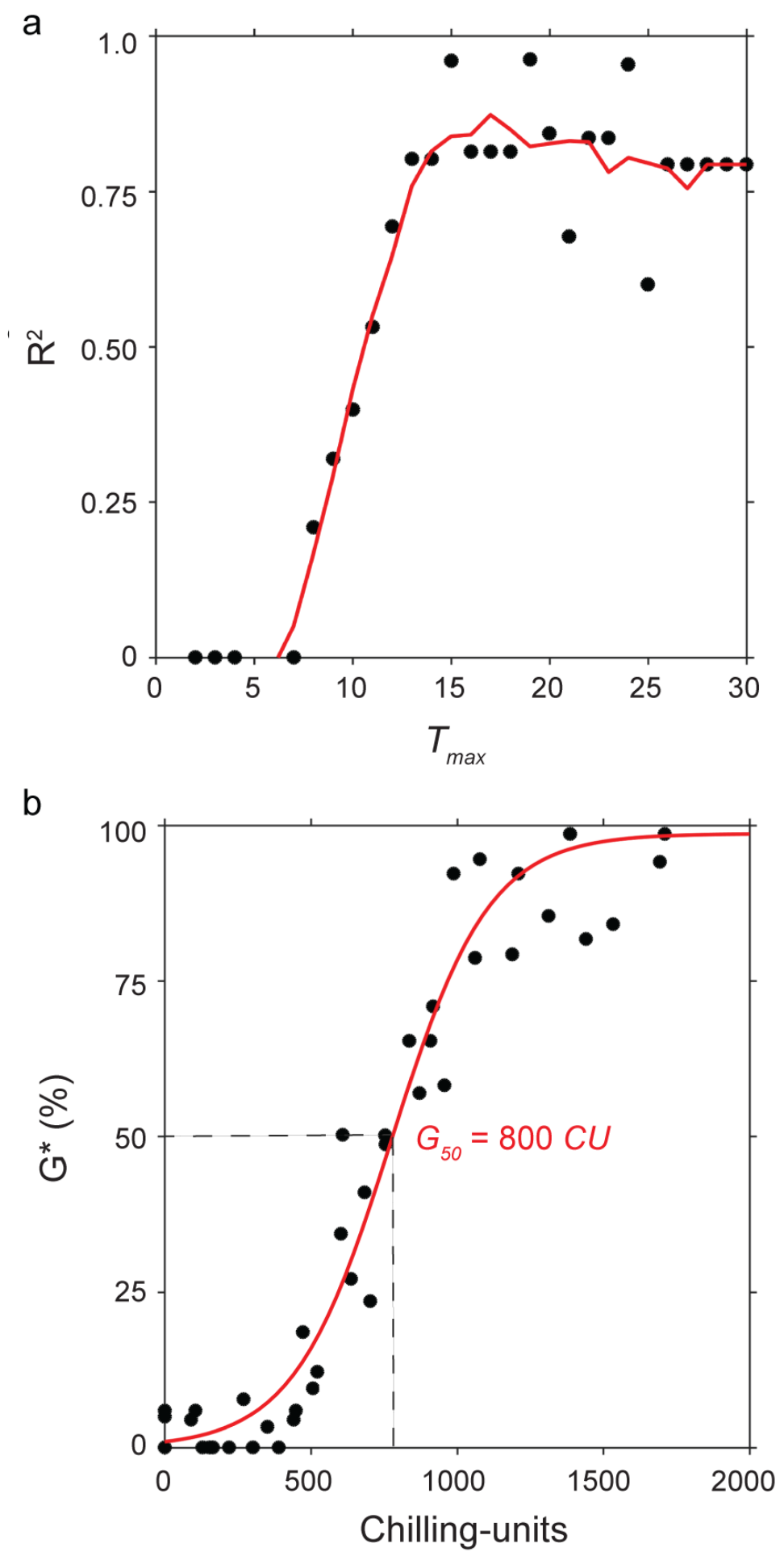

Fig. 7. (a) Optimizing the $T_{\max }$ below which chilling is perceived by $A$. catenella. (b) Sigmoid curve fit of cumulative percent germination of cyst cohorts with different accumulated amounts of chilling calculated using $T_{\max }=15^{\circ} \mathrm{C}$. 

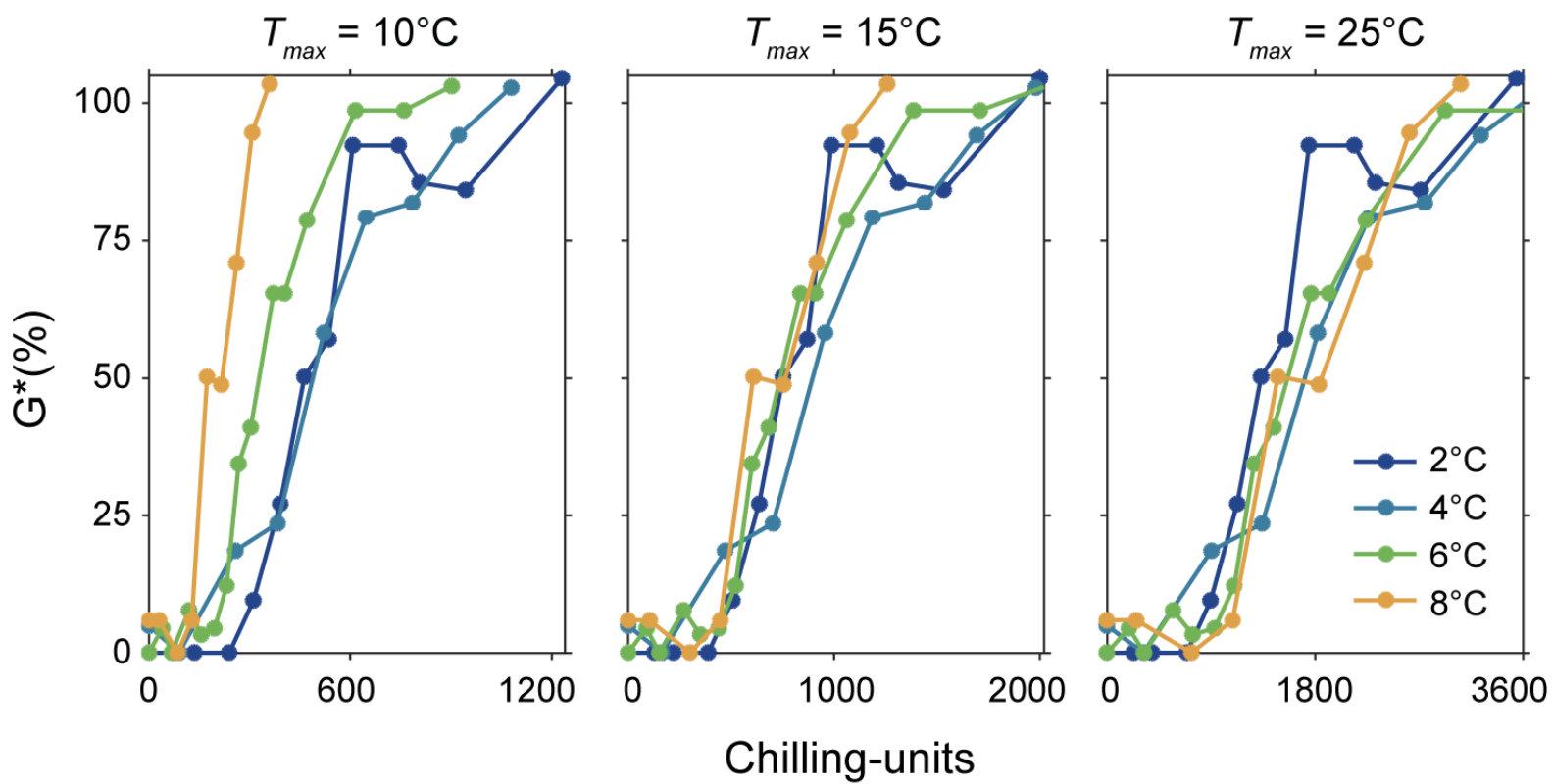

Fig. 8. Testing the rigor with the $T_{\max }$ needs to be defined to quantify $A$. catenella cyst germination responses to chilling accumulation. Data are the cumulative percent germination after one week of incubation under optimal conditions $\left(15^{\circ} \mathrm{C}\right.$, light, and oxygen) replotted as a function of chilling-units. 


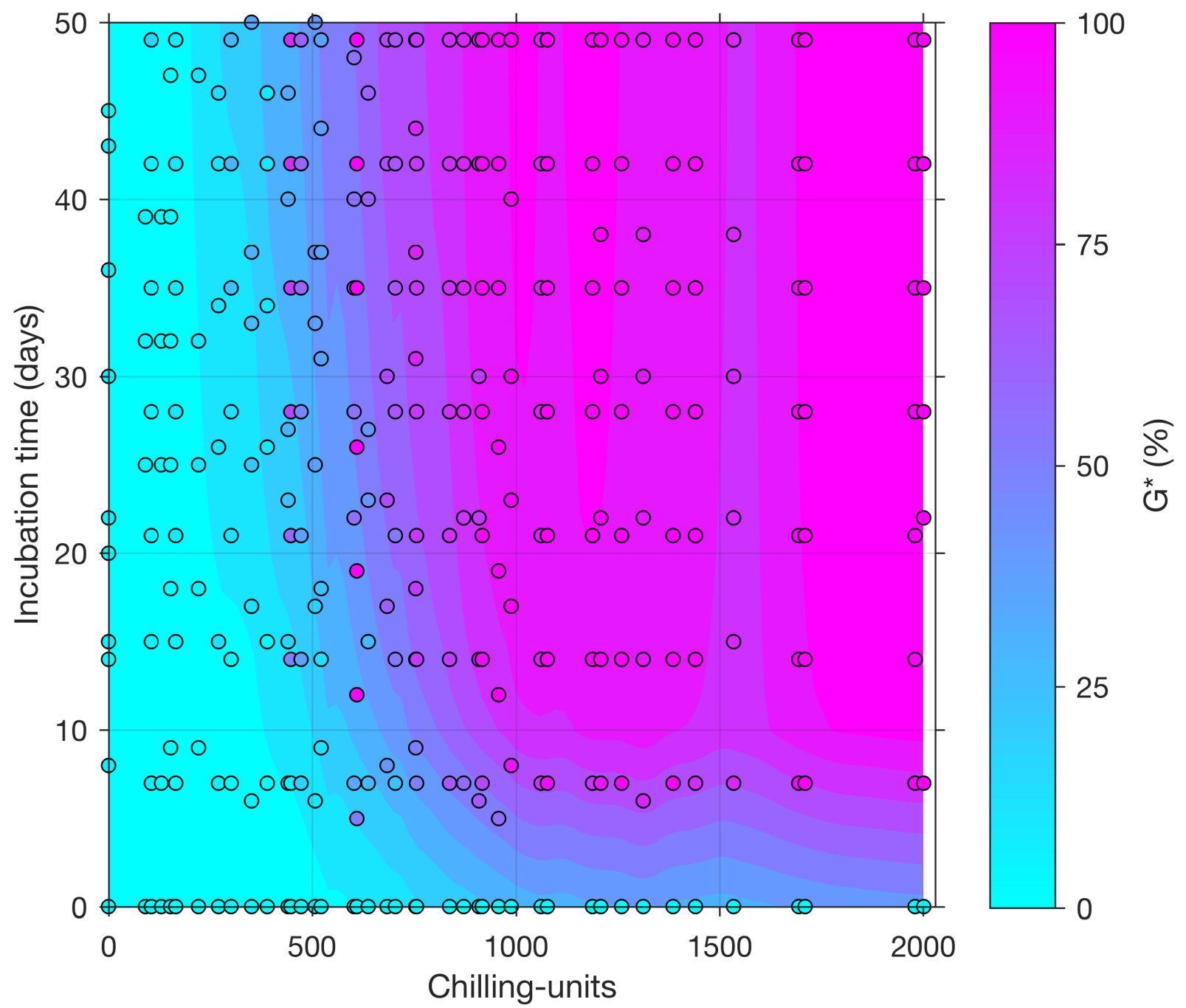

Fig. 9. Relationship between the chilling accumulation of $A$. catenella cyst cohorts and the incubation time needed to reach various germination percentages. The shading of each region corresponds to the cumulative germination percentage given the accumulated chilling-units and incubation time - cool colors indicate low cumulative percent germination and warm colors indicate high cumulative percent germination. The open circles show the sampling resolution. 

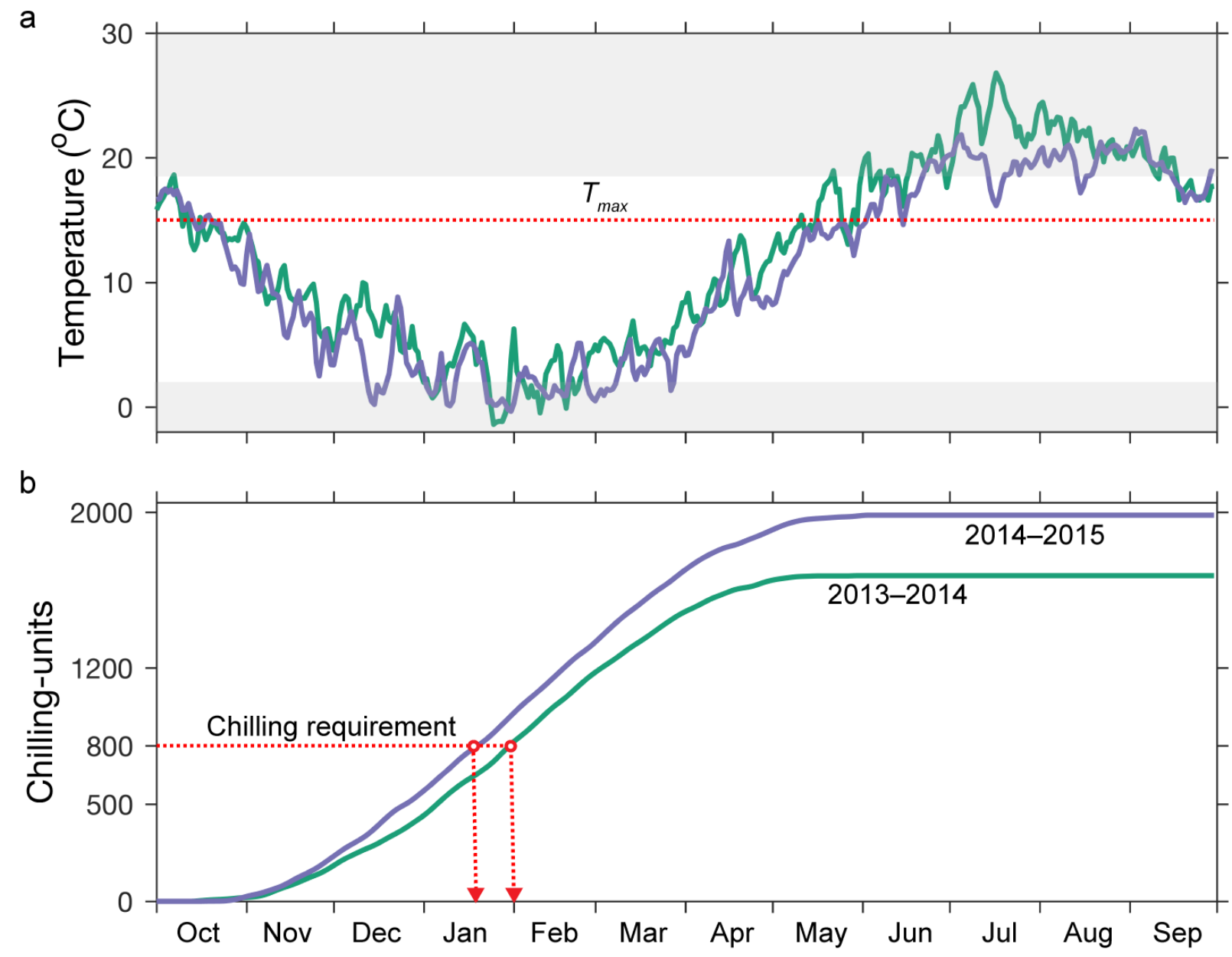

Fig. 10. (a) Temperature and (b) chilling-unit accumulation in the Nauset Marsh system from October 2013 to 2015 . Grey shaded areas indicate temperatures outside the 2 to $18.5^{\circ} \mathrm{C}$ window for $A$. catenella cyst germination (Anderson and Rengefors 2006 ). The $15^{\circ} \mathrm{C} T_{\max }$ is delineated to demonstrate the possible window of chilling accumulation in Nauset. The attainment of the chilling requirement in 2013-2014 and 2014-2015 is demarcated and predicts the transition from dormancy to quiescence for the majority of the cyst seedbed. 


\title{
Chapter 3
}

\section{Field emergence and laboratory germination of cysts of the toxic dinoflagellate Alexandrium catenella in response to vernal warming}

\begin{abstract}
Excystment of toxic Alexandrium dinoflagellates from the benthos is driven by internal and environmental factors, most importantly temperature. Our knowledge of cyst ecophysiology stems predominantly from laboratory studies using constant temperatures, oxygen, and irradiance - all of which are highly variable and not always at favorable levels in the natural benthos. The emergence flux of germling cells inoculates the annual $A$. catenella spring bloom in Nauset Marsh (Cape Cod, MA) and in many other systems, and therefore is a vital parameter for bloom prediction. The suitability of laboratory-derived germination rates and percentages to predict field emergence of $A$. catenella in the spring were evaluated in 2013, 2014, and 2015 in Nauset Marsh. In situ emergence from natural sediments in plankton emergence traps was measured alongside germination from laboratory incubations of individual cysts and sediment slurries at different temperatures. Emergence and germination rates had a clear positive linear relationship with temperature between 1 and $7^{\circ} \mathrm{C}$. Interestingly, at temperatures higher than $7^{\circ} \mathrm{C}$, emergence rates began to decrease for all study years. These decreasing rates are hypothesized to be from reduction in the oxygen penetration depth in the sediments with vernal warming (increased respiration), which would reduce the number of cysts exposed to oxygen and thus able to germinate. Total germination in excess of $98 \%$ was attained in the sediment slurries, whereas a very low percentage of $A$. catenella emerged from the surface $1 \mathrm{~cm}$ sediment layer of the PETs $(0.3-1.2 \%)$. The equivalent relationship between temperature and the rates of germination and emergence, indicates that this difference is predominantly constrained by the steep gradients of oxygen and light in natural sediments and the effect of tortuosity. This amount of emergence is
\end{abstract}


much less than has often been assumed in the past, thereby greatly reducing the potential cyst inoculum from the surface layer of sediments.

\section{INTRODUCTION}

The emergence of cells from the benthos to the plankton is the first step in bloom initiation for many cyst-forming dinoflagellates, including those that cause harmful algal blooms (HABs). Resting cysts form during blooms and accumulate in the sediments (Anderson and Wall 1978; Anderson et al. 2005) and near-bottom waters (Kirn et al. 2005; Pilskaln et al. 2014; Butman et al. 2014), where they remain until conditions are suitable for germination. The timing of germination has implications for whether a germling cell survives, divides, and reproduces in the given environment, and if it is part of the bloom inoculum. Temperature is a key regulator of cyst germination, and it acts in at least two ways: (1) by removing dormancy (Anderson and Morel 1979; Anderson 1980; Chapter 2) and (2) by controlling the rate of germination for quiescent cysts (Huber and Nipkow 1923; Anderson and Wall 1978; Dale 1983; Anderson 1998; Anderson et al. 2005). However, the physiological response of cysts to temperature has been studied almost exclusively under constant laboratory conditions. Given the key role that cysts play in inoculating blooms, estimates of the emergence flux in response to natural temperature variability are needed.

Laboratory studies on excystment of toxic Alexandrium species abound due to their role in causing paralytic shellfish poisoning (PSP), a potentially fatal seafood poisoning syndrome. These studies are primarily conducted via two methodologies. The first approach isolates individual cysts from natural populations, incubates them under various conditions, and assesses germination from an empty cyst or presence of a swimming cell (e.g. Anderson 1980; Anderson and Keafer 1987; Chapter 2). The second approach creates resuspended slurries from natural sediments and assesses germination from the intact cysts remaining after different durations (e.g. Anderson et al. 2005). Therefore, the question underlying this study is whether laboratory germination rates can satisfactorily predict field emergence. A related question is whether the total extent of germination measured in the laboratory is ever realized under natural conditions. 
Cyst accumulations in the natural environment are buried well below the sediment surface by factors, which include bioturbation and sedimentation (Anderson et al. 1982). Thus, the temperature, oxygen, and light conditions experienced in the benthos are very different from the laboratory (Fig. 1). Water temperatures vary on diurnal and daily scales in natural systems, whereas constant temperatures are used in laboratory experiments. Oxygen is required for germination of Alexandrium spp. (Anderson et al. 1987; Rengefors and Anderson 1998; Kremp and Anderson 2000) so it can only proceed in oxygenated sediment layers, the thickness of which varies seasonally and across habitats. For example, in Aarhus Bay, Denmark, a coastal embayment with similar silty sediments and seasonal temperature variation to Nauset, oxygen penetration varies seasonally from $4 \mathrm{~mm}$ in winter, to $\sim 2 \mathrm{~mm}$ in the spring and summer, to $<1$ $\mathrm{mm}$ in fall (Rasmussen and Jorgensen 1992). In contrast, laboratory conditions are oxygen replete. Lastly, light is not essential, but it expedites the germination rate of Alexandrium species (Anderson et al. 1987; Bravo and Anderson 1994; Anderson et al. 2005; Genovesi et al. 2009; Vahtera et al. 2014). Below $1 \mathrm{~mm}$, light attenuates exponentially with depth in all sediments (Kuhl et al. 1994). In Nauset sediments, cysts are buried as deep as $5 \mathrm{~cm}$ (Appendix), so the majority are in complete darkness - in contrast to the constant high levels of irradiance in laboratory studies. Given these differences, the germination rate and extent measured under laboratory conditions may be different in the natural benthos.

Measurements of the in situ emergence flux have been greatly facilitated by new techniques. The most sophisticated are the plankton emergence trap (PET) chambers designed by Ishikawa (2007), which were deployed on the seafloor of Ago Bay, Japan to measure the emergence flux of $A$. catenella. Each PET chamber consists of a base cylinder plugged with natural sediment and a top cylinder covered by a $10 \mu \mathrm{m}$ mesh to keep the plankton inside but allow water exchange with the in situ environment. Natsuike (2017a) measured the emergence flux of $A$. catenella and A. pacificum in Kesennuma Bay, Japan by deploying sediment core tubes containing filtered seawater that were capped. The objective of both of these studies was to document the seasonality of the in situ emergence flux, so sampling vessels were deployed every 2- to 6-weeks for 24-hr intervals over the course of at least a year. However, this multi-week sampling 
frequency was insufficient resolution to assess the relationship between the daily emergence rate and temperature.

The aim of this research was to determine if laboratory germination rates can predict the $A$. catenella emergence flux in response to the natural vernal warming that precedes the annual bloom in Nauset Marsh in Cape Cod, MA. Common laboratory methods - incubations of isolated cysts and sediment slurries - were used in tandem with PETs deployed in situ to measure germination and emergence, respectively. To account for variability in vernal warming and bloom formation, the study was conducted over three years (2013, 2014, and 2015). The link between laboratory germination and field emergence investigated here has applications to blooms of Alexandrium in other habitats, as well as other cyst-forming dinoflagellates.

\section{METHODS}

\section{Study area}

The Nauset Marsh is a shallow estuary consisting of tidal channels within a central marsh area that connect three drowned kettle ponds - Salt Pond, Mill Pond, Town Cove - each of which hosts independent, localized populations of A. catenella (Crespo et al. 2011; Ralston et al. 2015) (Fig. 2). Localization of blooms within the ponds occurs through an interaction between $A$. catenella swimming behavior, in conjunction with water stratification within the ponds and the shallow central marsh area which acts as a sill - blocking passage of cells from one pond to the other and promoting population retention within the salt pond (Anderson et al. 1983; Anderson and Stolzenbach 1985; Ralston et al. 2015). In turn, retention promotes the local deposition of cysts that then inoculate new blooms each spring, leading to PSP shellfishing closures on a nearannual basis. Blooms in Nauset occurred in all of the study years, but the maximum cell concentrations were two orders of magnitude higher in 2013 and 2015, than in 2014 (Fig. 3).

\section{Sediment sampling}

Cysts used in this study's germination experiments were collected from Roberts Cove and Salt Pond, both within the Nauset estuary. These sites were selected due to their accessibility and 
high mean concentrations of $A$. catenella cysts in the surficial sediments $\left(>10^{3}\right.$ cysts $\left.\mathrm{cm}^{-3}\right)$. Different methods were used to collected undisturbed sediment cores due to differences in the water depth at each of the sites: a hand corer was used in Roberts Cove and a gravity corer from a boat was used in Salt Pond. All cores had a light-colored, oxygenated surface layer of a few millimeters overlaying anoxic sediment, which was identified by its black coloration and odor. Temperature was monitored at the collection sites for the duration of the study by moored, internally-recording HOBO loggers (Onset Computer Corporation). All sediment cores were transported back to the laboratory for extrusion and sediment processing, with the exception of those for the 2013 PET experiment which was conducted at Roberts Cove. During transportation, sediment cores were kept upright in a bucket filled with water maintained at the in situ water temperature. A key component of the experimental design was using only quiescent cysts, so sediment sampling was restricted to a period when the cyst seedbed was known to be quiescent: February-May (Chapter 2).

\section{Germination of isolated cysts}

This experiment measures germination from cysts isolated from natural sediments (Fig. 4a). Sediment was sampled monthly from Roberts Cove from February through May, as these months would be expected to produce the inoculum for the annual spring bloom. Sampling was carried out in 2013, 2014, and 2015 to capture natural variability of the germination response. Once cores were in the laboratory, the overlying water was aspirated away and the surface $1 \mathrm{~cm}$ layer of sediment was sub-sampled and placed into a beaker. The sample was sonicated with a Branson Sonifier 250 at a constant 40-W output for $1 \mathrm{~min}$, and sieved to yield a clean, 20-100 $\mu \mathrm{m}$ size fraction (Anderson et al. 2003). Next, cysts were separated from same size particles with higher specific densities using density cushion centrifugation as described by Schwinghamer et al. (1991). The density of $A$. catenella cysts range from 1.15 to $1.30 \mathrm{~g} \mathrm{~cm}^{-3}$, so heavy solutions of colloidal silica were adjusted to $1.40 \mathrm{~g} \mathrm{~cm}^{-3}$ through addition of sucrose to ensure complete retention of cysts at the cushion interface. Round-bottom step gradient tubes were centrifuged for $15 \mathrm{~min}$ at $200 \mathrm{rcf}$, and then cysts and other organic material were removed from the cushion interface and overlaying suspension by Pasteur pipette. Cysts and other light debris were then concentrated and thoroughly rinsed with filtered seawater over a $20 \mu \mathrm{m}$ sieve. Sieve contents 
were then backwashed into a Sedgewick-Rafter counting chamber from which cysts could be easily identified and isolated under a Zeiss Axioskop upright microscope.

Each month, $\sim 30$ healthy-looking cysts (starch granules present, golden to brown coloration) were individually isolated by micropipette and subjected to the in situ temperature of Nauset. The in situ temperature in Nauset differed somewhat between years, thus each cyst collection had a different temperature history (Fig. 3b). To assess if the different temperature histories had an impact, the incubation temperature of each month was kept consistent: $2^{\circ} \mathrm{C}$ in February, $3.5^{\circ} \mathrm{C}$ in March, $7.5^{\circ} \mathrm{C}$ in April, and $11^{\circ} \mathrm{C}$ in May. Isolated cysts were placed in wells of a 96-well tissue culture plate, each pre-loaded with $200 \mu \mathrm{L}$ of f/2 medium (Guillard and Ryther 1962). The plates were then sealed to limit evaporative loss of medium and incubated at the in situ temperature on a 14:10 h L:D cycle $\left(250 \mu \mathrm{mol} \mathrm{m} \mathrm{m}^{-2} \mathrm{~s}^{-1}\right.$ photon flux density). Individual cysts were checked for germination on a weekly basis using an inverted Olympus IX-70 microscope until germination reached a maximum percentage or 17 weeks had elapsed. In this study, only the cumulative germination after the first week of incubation was analyzed to measure the instantaneous germination response of the cyst seedbed for that month. Germination rates (\% day $^{-1}$ ) were calculated by dividing this percent germination measurement by 7 days. As a control to demonstrate the total germination potential of the cyst seedbed at each monthly timepoint, an additional $\sim 30$ cysts were isolated and incubated at $15^{\circ} \mathrm{C}$ under the same light conditions. These cysts were monitored weekly for four weeks but no further germination occurred beyond the first week.

\section{Germination of cysts in sediment slurry}

This experiment measures germination from cysts in resuspended slurries of natural sediments (Fig. 4b). Sediment cores were collected from Roberts Cove on 05 March 2014. Once in the laboratory, headwater from each core was carefully aspirated before extrusion of sediment. To target the cysts deposited from the 2013 spring bloom, the surface $1 \mathrm{~cm}$ layer of sediment was sub-sampled. This sediment was combined with $\mathrm{f} / 2$ medium in a 1:7 ratio to make a slurry. Homogenous 10-ml aliquots of this slurry were delivered to 250-ml glass flasks (106 total), each containing 50-mL of f/2 medium, for a final dilution of _, as detailed in Anderson et al. (2005). The 60-ml content of each flask was gently swirled, thoroughly mixing the added slurry with the 
medium. All manipulations were carried out inside a walk-in refrigerator at $4^{\circ} \mathrm{C}$, approximately the temperature at the time of collection.

The flasks were randomly separated into five different incubation conditions with 20 flasks per treatment and placed into incubators at $2,4,6,8$, and $10^{\circ} \mathrm{C}$ on a $14: 10-\mathrm{h} \mathrm{L}: \mathrm{D}$ cycle. The chosen temperatures reflect the annual temperature range of Roberts Cove in the spring (Fig. 5b). The six remaining flasks were processed to determine the average initial cyst count. All flasks were thoroughly mixed weekly to ensure a consistent exposure to light and oxygenated media. The flasks were harvested at specific intervals, which ranged from every 2 to 14 days to ensure adequate coverage of the germination time course. Most of the flasks were harvested in duplicate but individual flasks were occasionally harvested to conserve samples. Harvested flasks were processed as described in the methods of Anderson (2005). Flasks were thoroughly rinsed and their contents were sonicated and sieved as detailed in the cyst isolation experiment.

To easily visualize $A$. catenella cysts under a microscope, they were stained with primulin (Yamaguchi et al. 1995) according to standard methods for cyst identification and enumeration (Anderson et al. 2003). Seawater was used to bring the volume of processed sediment to $9 \mathrm{~mL}$ and then $1 \mathrm{~mL}$ of $10 \%$ paraformaldehyde was added to preserve the sample. The sample was then incubated at $4^{\circ} \mathrm{C}$ for at least $30 \mathrm{~min}$. Thereafter, the sample was centrifuged for $10 \mathrm{~min}$ and then its overlying water was decanted, it was brought up to $10 \mathrm{ml}$ with methanol, and it was incubated at $4^{\circ} \mathrm{C}$ for at least $48 \mathrm{~h}$. The sample was centrifuged and decanted as before, brought up to $9 \mathrm{ml}$ with deionized water, plus $1 \mathrm{ml}$ of primulin stain $\left(2 \mathrm{mg} \mathrm{ml}^{-1}\right)$. After staining for 30 min, the sample was centrifuged and decanted for the final time and brought up to $5 \mathrm{ml}$ with deionized water. Finally, A. catenella cysts were counted in $1 \mathrm{ml}$ Sedgewick Rafter slides. Two 1 $\mathrm{ml}$ counts of each final, stained subsample were made on a Zeiss Axioskop microscope under blue light epifluorescence at 160X with a chlorophyll filter set (band pass 450-490 nm, long pass $520 \mathrm{~nm}$ ). Stained cysts were easily and rapidly counted at low magnification.

Cumulative germination percentages $(\%)$ and germination rates $\left(\%\right.$ day $\left.^{-1}\right)$ were calculated as follows. The initial cyst concentration $\left(\right.$ cysts $\mathrm{cm}^{-3}$ ) was first determined by averaging the cyst concentrations of the six initial flasks: $6614( \pm 551)$ cysts $\mathrm{cm}^{-3}$. The difference between the initial 
cyst concentration and that after each harvest interval was used to calculate the percentage of cysts that germinated over each time interval. To determine the germination rate $\left(\% \mathrm{day}^{-1}\right)$ at each temperature, the slope of the linear fit was used as in Anderson et al. 2005. The fitting procedure was complicated by the asymptotic behavior of the data points as $100 \%$ cumulative germination was approached. To capture the slope during the period over which the majority of cysts germinated, only points prior to the attainment of $80 \%$ cumulative germination were included in the fit. The fitted lines were not forced through the origin to minimize the influence of any necessary acclimation to experimental conditions after transfer from the field. For all temperatures, at least five points in the linear region were used to determine the germination rate.

\section{In situ Emergence}

The emergence flux of $A$. catenella from natural sediments was measured using plankton emergence trap (PET) chambers (Ishikawa et al. 2007) (Fig. 4c). The PET method quantifies 'emergence' from the sediment, which is different from the cyst isolation and sediment slurry experiments that quantify absent cysts and thus measure 'germination'. Germling cells may temporarily remain in the sediments before emerging, thus measurements of 'germination' may differ from 'emergence' (Fig. 1).

To measure the emergence flux in response to vernal warming, PETs observations began midMarch and concluded at the peak of the A. catenella Mill in Salt Pond in 2013 and after bloom termination in Salt Pond for years 2014 and 2015 (Fig. 3). Accordingly, the observation period varied each year: 41 days in 2013 (16 March - 26 April), 72 days in 2014 (15 March - 26 May), and 59 days in 2015 (24 March - 22 May). PETs were sampled at near daily intervals, with the longest sampling gap of 2 days. The percentage of days in the observation period sampled in 2013,2014 , and 2015 were, $73 \%, 70 \%$, and $81 \%$, respectively. There was not an obvious difference between the germling cells measured on the first day after the sampling gap from the observations on the days before and after the gap. Gap days were accounted for by dividing the emergence measurement on the first day after the gap by the duration of the gap.

Cores were collected from Roberts Cove for the 2013 experiment and from Salt Pond for the 2014 and 2015 experiments. The original experimental setup included 2 cores in 2013, and 4 
cores in the 2014 and 2015. Due to significant number of harpacticoid copepods in two of the cores in 2015, and the possibility that these copepods might have grazed on A. catenella germlings, only data from the 2 non-contaminated cores in 2015 were used. Cores were directly collected in the lower portion of the PET chamber, and the core was carefully pushed to the top of the core tube. The upper chamber of the PET was then affixed to the lower chamber as described by Ishikawa (2007).

In 2013, each sediment core PET was immediately placed inside a $15 \mu \mathrm{m}$ Nitex bag, the bag was sealed, and positioned on an incubation platform in Mill Pond. To be sure that the PETs were submerged during the tidal cycle, incubations were conducted at a depth of $\sim 2 \mathrm{~m}$ at mean low tide. In 2014 and 2015, the cores were maintained in a large tank outside the Woods Hole Oceanographic Institution that was continuously exchanged with water from neighboring Eel Pond (Fig. 2). Eel Pond was selected as the site for the 2014 and 2015 experiments because water temperatures were very similar to those in Salt Pond in Nauset and because daily sampling was significantly facilitated (a 3-hr roundtrip drive was no longer required). The temperature in Roberts Cove in 2013 and in the Eel Pond tanks in 2014 and 2015 were monitored for the duration of the study by internally-recording HOBO loggers (Onset Computer Corporation) (Fig. 7c). Over the observation periods, the cysts in the sediments of the PET chambers were exposed to temperatures ranging from 3.3 to $13.7^{\circ} \mathrm{C}$ in 2013 , from 0 to $16.8^{\circ} \mathrm{C}$ in 2014 , and from 0.1 to $15.3^{\circ} \mathrm{C}$ in 2015 .

Prior to sample collection, each PET within the Nitex bag was carefully removed, attached to a ring stand, and rinsed with freshwater and thoroughly scrubbed. This effort ensured removal of any contaminating vegetative cells, which may have attached to the outside of the PET chamber from the surrounding seawater. The contents of the upper chamber were collected in a $1 \mathrm{~L}$ beaker and the chamber was thoroughly rinsed $3 \mathrm{x}$ with filtered seawater, which was added to the sample. The sample was then concentrated using a $15 \mu \mathrm{m}$ Nitex sieve and backwashed with filtered seawater to a $14 \mathrm{~mL}$ volume. Samples were fixed with $5 \% \mathrm{v} / \mathrm{v}$ formalin, stored on ice and centrifuged at $3000 \mathrm{x}$ g for 5 minutes. The supernatant was aspirated and replaced with $100 \%$ cold methanol and stored at $-20^{\circ} \mathrm{C}$ until analysis using a FISH technique as described in Anderson (1995) where 50\% of the sample was hybridized. Sample filters were enumerated for 
A. catenella cells at 100x magnification using a compound epifluorescence microscope. Some of the concentrated samples contained sediment particles resulting from minor sediment resuspension that occurred during the PET sampling process. In the samples, germling cells (planomeiocytes) were distinguished from vegetative cells based on their large size (ca. $60 \mu \mathrm{m}$ length) and elongated shape. Smaller cells $(<50 \mu \mathrm{m})$ with a more rounded shape were assumed to be vegetative cells resulting from division, so every two vegetative cells were counted as one planomeiocyte. Finally, as noted, a small amount of resuspension of the surficial sediments often occurred when the PETs were sampled. This may have increased the supply of oxygen to the surface sediments, however, this amount of resuspension was estimated to be similar to that which occurs in the natural benthos from bioturbation and currents, both wind- and tidal- driven.

The total percent of $A$. catenella emerged from the surface $1 \mathrm{~cm}$ of sediment each year (total $\%$ emerged) was calculated by dividing the total emerged germling cells by the initial number of cysts in the $1 \mathrm{~cm}$ thick layer. The emerged cells in the PET chambers were first summed to provide a total emergence number per chamber (total cells chamber ${ }^{-1}$ ). These values were averaged for 2013, 2014, and 2015 study years. To avoid disruption of the PET cores, the initial concentrations of cysts were not sampled, however the final concentrations in the surface $1 \mathrm{~cm}$ later were sampled (cysts cm$\left.{ }^{-3}\right): 2013(M=4327, S D=2219, n=2), 2014(M=1147, S D=374$, $n=4)$, and $2015(M=2861, S D=2669, n=2)$. The initial number of cysts in the surface $1 \mathrm{~cm}$ layer of each of the PET cores was estimated by calculating the final number of cysts from the cyst densities and the surface area of the core $\left(31.17 \mathrm{~cm}^{2}\right)$, and adding that value to the total emerged cells.

The emergence flux (cells $\mathrm{m}^{-2}$ day $\left.^{-1}\right)$, rate $\left(\%\right.$ day $\left.^{-1}\right)$, and total $(\%)$ were calculated as follows. The emerged cells in the PET chambers were first averaged to provide a daily emergence number per chamber (cells chamber ${ }^{-1}$ day $^{-1}$ ) and then these were converted into the daily emergence flux per $\mathrm{m}^{-2}$ (cells $\mathrm{m}^{-2}$ day $^{-1}$ ) by using the sediment surface of the PET core. Each of the study years had different initial concentrations of cysts, thus to permit interannual comparison, the cumulative emergence (\%) was normalized by dividing each daily emergence flux by the summed total germling cells that emerged each year. To determine the relationship 
between the emergence rate and temperature, rates $\left(\%\right.$ day $\left.^{-1}\right)$ were calculated from the normalized cumulative emergence and binned at $1^{\circ} \mathrm{C}$ temperature intervals.

\section{Data analysis}

Germination rates (i.e., the inverse of time needed to attain a specific germination percentage) generally increase with temperature to an optimum. It is well established for many quiescent plant seeds that germination rates increase linearly with temperature between a specific range and several mathematical models were developed to describe this relationship (e.g. Bewley and Black 1982; Garcia-Huidobro et al. 1982; Roberts 1988). Thus, given known similarities between seed and A. catenella cyst dormancy (Chapter 2), the present study employs a linear model from the plant seed literature. In this model, the rate of germination $(G R)$ increases linearly with temperature $(T)$ from a base temperature $\left(T_{\mathrm{b}}\right)$, at which the rate is zero, up to an optimum $\left(T_{\mathrm{o}}\right)$, beyond which the rate decreases. The thermal response of germination can be expressed as:

$$
\begin{array}{lll}
\mathrm{GR}=\frac{1}{t}=\frac{\left(T-T_{b}\right)}{\theta} & \text { if } \quad T_{o} \geq T \geq T_{b} \\
\mathrm{GR}=0 & \text { if } T<T_{b}
\end{array}
$$

The reciprocal of the slope in this equation is the thermal time for germination $\left(\theta\right.$, units $\left.{ }^{\circ} \mathrm{Cd}\right)$. Different cyst populations would be expected to have different $T_{\mathrm{b}}$ and $\theta$ parameters, which affect their germination response to temperature.

This linear model was used to regress the rates of germination and emergence as a function of temperature for each of the experimental methods used in this study. The coefficients of determination $\left(r^{2}\right)$ were calculated to test how well the model predicted the data. Generalized linear models (GLM) were used to determine if there was an interaction effect on $T_{\mathrm{b}}$ and $\theta$ from differences in: (1) the study year $(2013,2014,2015)$, (2) the method (cyst isolations, sediment slurries, PETs), and (3) the location of the cyst population. The sediment slurry experiment in this study was also conducted using cysts from the Gulf of Maine (GOM) by Anderson et al. (2005), thus the germination results from Nauset and GOM cyst populations will be compared. For this GLM analyses, the rates of germination and emergence were used as the dependent 
variable and temperature was the predictor variable. Significance was assessed using analysis of variance (ANOVA).

\section{RESULTS}

\section{Germination of isolated cysts}

The cyst isolation experiment assessed the germination response to temperature during the spring months in 2013, 2014, and 2015 (Fig. 4a). Freshly-collected Nauset cysts were isolated and incubated at approximately the in situ temperature $-2^{\circ} \mathrm{C}$ in February, $3.5^{\circ} \mathrm{C}$ in March, $7.5^{\circ} \mathrm{C}$ in April, and $11^{\circ} \mathrm{C}$ in May - and the percent germination was recorded after one week (Fig. 5). The percent germination observed in February and March was low, averaging 3.8\% ( \pm 3.3$)$ and 3.3\% $( \pm 5.8)$, respectively. As temperatures in Nauset warmed, the mean cumulative germination increased to $30.7 \%( \pm 10)$ in April, and then to $67.2 \%( \pm 15)$ in May. In contrast, the mean cumulative germination of the control cysts that were incubated at $15^{\circ} \mathrm{C}$ each month was consistently high: 74.7\% ( \pm 11$)$ (Fig. 5a). These control cysts were monitored for an additional three weeks, but the cumulative germination did not increase, so this value is considered the total germination for this experiment. Germination rates were derived for each of the in situ incubation temperatures and years (Table 1). The rate of germination increased linearly with temperature $\left(r^{2}=0.91\right)$ above a base temperature $\left(T_{\mathrm{b}}\right)$ of $2^{\circ} \mathrm{C}$ (Table 2 ; Fig. 8$)$.

\section{Germination of cysts in a sediment slurry}

This test measured germination from natural sediments in resuspended slurries (Fig. 4b). Flasks filled with approximately equivalent numbers of cysts in sediment slurries were incubated at temperatures characteristic of vernal warming in Nauset: $2,4,6,8$, and $10^{\circ} \mathrm{C}$ (Fig. 5b). The total cumulative germination attained for all temperatures was in excess of $98 \%$. One explanation for why the total germination percentage in the sediment slurries is higher than for isolated cysts is because the washing steps used to isolate each cyst can on occasion remove the protective mucilaginous layer surrounding each cyst. The germination rate increased with increasing temperatures (Fig. 6). For example, to attain 50\% cumulative germination, either $\sim 7$ days of $10^{\circ} \mathrm{C}$ incubation were required or $\sim 50$ days of $2^{\circ} \mathrm{C}$ incubation were required. The linear portion 
of the germination time course for each temperature was used to calculate the corresponding rate of germination (Table 1). The rate of germination had a near perfect linear relationship $\left(r^{2}=\right.$ 0.98 ) above a $T_{\mathrm{b}}$ of $0.3^{\circ} \mathrm{C}$ and a thermal time constant $(\theta)$ of $1.11^{\circ} \mathrm{Cd}$ (Table 2; Fig. 8).

These thermal germination parameters were compared with those derived from eastern and western Gulf of Maine (GOM) cysts by Anderson (2005) using the same experimental approach

(Table 1). The rates from the GOM cysts were fit to the linear germination model $\left(r^{2}=0.60\right)$ and had a $T_{\mathrm{b}}$ of $0.8^{\circ} \mathrm{C}$ and a $\theta$ of $1.67^{\circ} \mathrm{Cd}$. The fitted GLM highlighted a statistically significant interaction of the source of cysts on the $T_{\mathrm{b}},(F(2,9)=9.08, p=<.02)$, but no effect on $\theta,(F(2,9)$ $=1.56, p=$ n.s.). Finally, the goodness of fit of the linear germination model was excellent for cysts from the western GOM $\left(r^{2}=0.77\right)$, but less so for cysts from the eastern GOM $\left(r^{2}=0.55\right)$.

\section{In situ Emergence}

Emergence of $A$. catenella germling cells from the sediments was measured using PET chambers in 2013, 2014, and 2015 (Fig. 4c). Within the surface $1 \mathrm{~cm}$ layer of the PET cores, the average total percentage of $A$. catenella that emerged over the duration of the experiment was very low: $1.2 \%$ in $2013(S D=0.4 \%), 0.3 \%$ in $2014(S D=0.2 \%)$, and $0.8 \%(S D=0.2 \%)$ in 2015 . The daily emergence fluxes differed interannually, which is due in part to different initial cyst densities in the PET cores. The maximum raw emergence rates attained were an order of magnitude higher in $2013\left(0.046 \% \mathrm{~d}^{-1}\right)$ and $2015\left(0.029 \% \mathrm{~d}^{-1}\right)$ than in $2014\left(0.0082 \% \mathrm{~d}^{-1}\right)($ Fig. $7 \mathrm{a})$. Thus to permit comparison among years, emergence rates were normalized to the total number of $A$. catenella that emerged in each of the study years (Fig. 7d).

For all study years, there was a positive, linear relationship between the emergence rate and temperature until $7^{\circ} \mathrm{C}$. However, at temperatures above $7^{\circ} \mathrm{C}$, rates decreased, which was unexpected given that rates clearly increased at equivalent temperatures in the germination experiments. This decrease in the rate occurred in 2013 on 6 April when $84 \%$ cumulative emergence had been attained (Fig. 7b). In 2014 and 2015, this occurred around 15 April when the normalized cumulative emergence was $32 \%$ and $35 \%$, respectively. Slower emergence rates later in the spring season may have been a result of fewer cysts remaining in the oxygen and light-replete surface veneer of sediment. Cysts under conditions of lower oxygen and darkness in 
deeper sediments would have slower germination rates. Thus, to assess the relationship between temperature and emergence rates under ideal natural oxygen and light conditions, only temperatures between 0 and $7^{\circ} \mathrm{C}$ were considered (Table 1). These emergence rates increased linearly with temperature $\left(r^{2}=0.67\right)$ above a $T_{\mathrm{b}}$ of $1^{\circ} \mathrm{C}$ (Table 2 ; Fig. 8).

\section{Comparison between germination and emergence rates}

A GLM approach was used to compare the responsivity of the germination and emergence rates derived from different methodological approaches and years to temperature. Year $(2013,2014$, 2015) and method (cyst isolations, sediment slurries, PETs) were investigated as interaction terms. The year did not have a significant effect on the $\theta(F(2,32)=2.20, p=$ n.s. $)$ or the $T_{\mathrm{b}}$ $(F(2,32)=2.20, p=$ n.s. $)$. The methodological approach had a significant effect on the $T_{\mathrm{b}}(F(2$, $32)=6.62, p<.004)$, but not the $\theta(F(2,32)=0.48, p=$ n.s. $)$.

Next, these linear germination and emergence rate functions were tested to see how well they could predict the timing of in situ emergence. Linear rate functions were applied to the temperature regimes experienced by cysts in the PETs to yield a daily prediction of the emergence (Fig. 9), which permits identification of periods in Nauset during which observed emergence was nonlinear. Generally, the linear rate approximations from both laboratory germination tests predicted the average in situ timing of germling cell emergence well. In 2015, the predicted emergence using the linear rate from cyst isolation experiment matched the in situ emergence nearly perfectly, which demonstrates that germination and emergence had the same relationship with temperature. In 2013 and 2014, there was more noise in the observed emergence in comparison to the predicted emergence, which could be due to a variety of factors that will be detailed in the discussion.

\section{DISCUSSION}

A. catenella cyst germination rates from laboratory incubations successfully predicted the timing of in situ emergence in response to vernal warming over three spring seasons (Fig. 9).

Germination was measured via common laboratory techniques - individual cyst isolations and 
bulk sediment slurries - and germling cell emergence from natural sediments was measured using PETs. Rates of germination and emergence had a strong linear relationship with temperature between a specific range of $1-7^{\circ} \mathrm{C}$. Moreover, the rate parameters derived from the laboratory germination experiments were comparable with those derived from in situ PET emergence observations. The rates from the PET emergence observations were, however, more variable. Finally, the total germination measured under laboratory conditions was higher than the total emergence measured from the PETs, which reveals insights into the proportion of the $A$. catenella cyst seedbed in Nauset that germinates each spring and connections to bloom formation. These findings are discussed in more detail below.

\section{Linear approximation of the in situ emergence timing}

Germination rates measured under laboratory conditions and emergence rates measured in situ with PETs increased linearly within a specific temperature range of $1-7^{\circ} \mathrm{C}$ (Fig. 8; Table 2). Although the thermal time constant $\theta$ did not significantly differ between the methods, the base temperature $T_{\mathrm{b}}$ did. The parameter $T_{\mathrm{b}}$ is important to the biogeography of $A$. catenella because it determines the lowest possible temperature at which germination is possible. The $T_{\mathrm{b}}$ was highest in the cyst isolations $\left(2^{\circ} \mathrm{C}\right)$, followed by the PETs $\left(1^{\circ} \mathrm{C}\right)$, and lowest in the sediment slurries $\left(0.3^{\circ} \mathrm{C}\right)$. Despite the low $T_{\mathrm{b}}$ in the sediment slurries, this experiment did not test temperatures below $2^{\circ} \mathrm{C}$. However, the PETs did observe emergence at temperatures $0-2^{\circ} \mathrm{C}$ and a clear $T_{\mathrm{b}}$ of $1^{\circ} \mathrm{C}$ (Fig. 7d, 7). One caveat with the PET measurements is that it is not possible to determine if observed germling cells had germinated in the days prior under different (e.g. warmer or colder) temperatures and just remained in the sediments. These results combined from multiple methodologies suggest that $1^{\circ} \mathrm{C}$ is a reasonable estimate for the $T_{\mathrm{b}}$ of this Nauset population. Further, this base temperature is shared by A. catenella populations from the Bering Sea and Chukchi Sea that were observed to excyst at temperatures as low as $1^{\circ} \mathrm{C}$ (Natsuike et al. 2017a).

Notably, at temperatures above $7^{\circ} \mathrm{C}$, the rate of emergence decreased in 2013, 2014, and 2015 (Fig 6d). This consistency in this temperature among years, despite occurring over at different times and with different numbers of cysts remaining, suggests that this temperature is coincident with changes in the sediment. One explanation, is that increased microbial respiration from warming temperatures resulted in increased anoxia in the sediments. For example, in a coastal 
embayment with similar silty sediments and seasonal temperature variation to Nauset, Aarhus Bay, Denmark, oxygen penetration varies seasonally from $4 \mathrm{~mm}$ in winter, to $\sim 2 \mathrm{~mm}$ in the spring and summer, to $<1 \mathrm{~mm}$ in fall (Rasmussen and Jorgensen 1992). Oxygen is necessary for germination to proceed, so this would have reduced the number of cysts in the PET chamber that were able to germinate. To fully investigate the relationship between the oxygen consumption in Nauset sediments and seasonally warming temperatures and the apparent $8^{\circ} \mathrm{C}$ threshold, an oxygen microelectrode study would need to be conducted.

Another factor that likely contributed to reduced emergence rates was that cysts in the surface layers of sediment became depleted, with subsequent germination representing cysts in deeper layers. This hypothesis is likely not the primary reason for the rate decrease because once temperatures reached $8^{\circ} \mathrm{C}$ in each year of the PET experiment, the cumulative emergence percentage up to that point differed (84\%, 32\%, and 35\%, in 2013, 2014, and 2015, respectively). The deeper in the sediments that germination occurs, the lower the light and greater the effect of tortuosity. For fine sediments like Nauset, the light extinction depth can be estimated at about 1 $\mathrm{mm}$ (Kuhl et al. 1994). Light is not necessary for germination to proceed, but rates in the light are about twice as fast as those in the dark (Anderson et al. 2005; Vahtera et al. 2014). Additionally, cells that germinate in deeper layers of sediment experience a greater effect of tortuosity - meaning they must travel through a larger matrix of sediment and detrital particles in order to emerge into the PET chamber - which could depress the rate of emergence.

The linear approximated rates from the laboratory germination methods effectively predicted the timing of the in situ emergence flux in the PETs (Fig. 9). The 2015 observed emergence flux had a nearly perfect linear relationship with temperature, whereas there was more noise in the 2013 and 2014 observed emergence fluxes. This variability is also visualized in the goodness of fit of the linear relationship between germination rate and temperature for the PET cysts $\left(r^{2}=0.67\right.$; Fig. 7d), in comparison to the controlled laboratory studies of the sediment incubations $\left(r^{2}=\right.$ 0.98 ) and the monthly isolations $\left(r^{2}=0.91\right)$ (Table 2). One source of this variability is how $A$. catenella responds to the diurnal and daily temperature fluctuations of the natural environment. Periods of alternating temperatures are known to stimulate germination in many plant seeds (Roberts et al. 1988), and so this may have a similar effect on cysts. This could be an explanation 
for the anomalously high rates of emergence that occurred around 5 and $6^{\circ} \mathrm{C}$ in $2013-$ temperatures hovered at $5.2^{\circ} \mathrm{C}( \pm 1.3)$ for 16 days (Fig. 7c). In contrast, the temperatures of 2014 and 2015 spent only 6 days at $5.6^{\circ} \mathrm{C}( \pm 0.7)$ in 2014 and 7 days at $5.5^{\circ} \mathrm{C}( \pm 0.4)$ in 2015 . An alternative explanation for difference of rates at $5^{\circ} \mathrm{C}$ among the 2013, 2014, and 2015 PETs could simply be the number of datapoints. Yet another source of variability is that exposure to near freezing temperatures might have a negative effect on quiescent cysts. In March, two excursions to freezing temperatures occurred in 2014 and one occurred in 2015, and emergence was suppressed in the days following, despite favorable temperatures (Fig. 7c, d). Further studies are needed to quantitatively investigate the effect of alternating temperatures and cold damage on A. catenella germination. These predictions demonstrate that natural variability can have some effect on the emergence, but a linear model can predict the average emergence timing with good skill.

\section{Applications to other A. catenella populations}

The linearity of the relationship between the germination and emergence rates and temperature for all methods used in this study strengthens the case for expressing $A$. catenella germination in thermal time $\left({ }^{\circ} \mathrm{Cd}\right)$ - which is how germination is described for many plant seeds (e.g. GarciaHuidobro et al. 1982). Further, a previous study used the reverse of thermal time, "chillingunits", to describe changes in A. catenella cyst dormancy - which is also an analog to dormancy breaking in plant seeds (Chapter 2). Other populations of Alexandrium would be expected to have different $\theta$ and $T_{\mathrm{b}}$ parameters. Once these parameters are defined, it should be possible to use the temperature regimes of different habitats (e.g. the Gulf of Maine) to estimate the fraction of non-dormant cysts that may germinate. For example, the thermal time needed for $50 \%$ of the Nauset cyst population to germinate can be estimated by multiplying 50 by $\theta$. This would result in $69^{\circ} \mathrm{Cd}, 56^{\circ} \mathrm{Cd}$, and $58^{\circ} \mathrm{Cd}$ (equivalent to $\sim 12$ days, $\sim 9$ days, and $\sim 10$ days incubated at $6^{\circ} \mathrm{C}$ ) for the cyst isolations, sediment slurries, and the PETs, respectively.

To evaluate if the linearity of the germination response to temperature and the associated thermal parameters were comparable among $A$. catenella cysts, these relationships were compared to cysts from the GOM. Anderson et al. (2005) conducted a similar sediment slurry experiment using western and eastern GOM cysts and determined rates with regard to temperature (Fig. 8; 
Table 1). The goodness of fit to the linear germination model was significant for cysts from the eastern GOM $\left(r^{2}=0.55\right)$ and western $\operatorname{GOM}\left(r^{2}=0.77\right)$, but the fit was not as good as cysts from Nauset $\left(r^{2}=0.98\right)$. Interestingly, the more southern the cyst population, the better the linear fit: the eastern GOM is the northernmost, the western GOM is central, and Nauset is the southernmost. Thus the linearity of the relationship between germination and temperature may vary with latitudinal gradients and reflect different strategies among $A$. catenella populations that inhabit different physical and chemical regimes. Further studies are needed to explore this hypothesis.

\section{The germinable fraction of the cyst seedbed}

Differences in total germination percentages between the sediment slurry $(>98 \%)$ and cyst isolation (>70\%) techniques may be due to the isolation technique. Cysts must undergo several washing steps, which on occasion can remove their mucilaginous coating, which provides protection from microbes. During weekly monitoring, cysts were occasionally observed to be covered in a layer of microbes, and they never germinated. In contrast, the sediment slurry method has the benefit of keeping cysts untouched in their natural sediments. Thus the high total germination percentage from the sediment slurry method better reflects the germination potential of cysts in the natural benthos.

The difference between the near $100 \%$ germination attained in the sediment slurries and the incredibly low percentage of $A$. catenella that emerged from the surface $1 \mathrm{~cm}$ sediment layer of the PETs $(0.3-1.2 \%)$ is informative with respect to the factors that limit the total germination potential in natural sediments. Temperature affected rates of germination and emergence similarly, so the majority of differences were caused by physical and chemical factors, most importantly oxygen, light, and tortuosity.

Oxygen is a germination requirement, so the oxygen gradients in natural sediments are of utmost importance. Unlike the oxygen replete cysts in the germination experiments, cysts in the PETs remained unmoved from natural sediments, which would have had variable oxygen levels. A number of factors can affect the oxygen penetration depth in natural sediments including the seasonal progression, bioturbation, and resuspension. In temperate shallow embayments, oxygen 
reaches a maximum depth in the winter and a minimum depth at the end of summer (Rasmussen and Jorgensen 1992). Bioturbation by macro- and meiofaunal can produce spatially heterogeneous oxygen microgradients in the sediments (e.g. Aller 1982). Although not obvious signs of bioturbation were present in the PET cores, bioturbation has been observed in other sediment cores from Nauset. Resuspension by waves and currents would also extend the depth to which cysts can access oxygen. A resuspension depth of $1 \mathrm{~mm}$ is estimated to occur over the winter and spring in the GOM sediments with cyst accumulations (Butman et al. 2014). The water column depth of the Nauset cyst seedbed $(\sim 4 \mathrm{~m})$ is much shallower than the GOM cyst seedbed $(\sim 100 \mathrm{~m})$, which would suggest more resuspension, but salt ponds are small which makes it difficult for large waves to form. The oxygen penetration depth in similar coastal sediments (non-vegetated, fine-grained, some bioturbation by benthic organisms) in shallow embayments and estuaries has been estimated to be an average of 2-5mm (Revsbech et al. 1980; Jørgensen and Revsbech 1985; Berg et al. 1998; Thibault de Chanvalon et al. 2015).

Other factors that may have reduced the total germination percentages from the PET sediment cores were light levels and tortuosity in the sediment matrix. Below $1 \mathrm{~mm}$, light attenuates exponentially with depth in all sediments (Kuhl et al. 1994). Thus once cysts in the sunlit surface layer had germinated, all germination would occur in the dark deeper sediment layers.

Germination rates of $A$. catenella in the darkness are approximately half those in light (Anderson et al. 1987; Bravo and Anderson 1994; Anderson et al. 2005; Genovesi et al. 2009; Vahtera et al. 2014), and thus would limit the total emergence that could occur over a defined period. Further, the deeper in the sediment that cyst germination occurs, the greater the effect of tortuosity on the ability of a planomeiocyte to successfully emerge into the water column.

It has been suggested that only a small fraction of the cyst seedbed germinates (Anderson et al 2012), but this is the first study to document just how small: only 0.3 to $1.2 \%$ of cysts in the surface $1 \mathrm{~cm}$ layer in Nauset. Assuming 100\% germination in the surficial sediments, these percentages would translate to germination of cysts in only a fraction of $1 \mathrm{~mm}$. Despite this, high densities of cysts are present in Nauset sediments to as deep as $5 \mathrm{~cm}$ (Appendix). These low percent emergence results are similar to the results obtained from a similar in situ emergence study in a different $A$. catenella habitat, Kesennuma Bay, Japan (Natsuike et al. 2017b). Natsuike 
et al. (2017b) found that the percentage of cysts emerged from the surface $1 \mathrm{~cm}$ layer of sediment ranged from 0.15 to $2.5 \%$ during the periods April-May, June-July, and November-April. In contrast to the near-daily observations in Nauset, the Natsuike et al. (2017b) study and a similar study in Ago Bay, Japan, by Ishikawa et al. (2014) had observation frequencies of every 2-6 weeks so it was not possible to directly measure the emergence rate in response to temperature, however rates could be estimated. The maximum rates obtained for in these studies $\left(0.054 \%\right.$ day $^{-}$ ${ }^{1}$ in Kesennuma Bay; 0.147\% day ${ }^{-1}$ and $0.337 \%$ day $^{-1}$ in Ago Bay) are in line with those obtained in this study. This consistency across these studies of the low total percentage of $A$. catenella emerged from the surface $1 \mathrm{~cm}$ layer demonstrates that the fraction of the cyst seedbed that is able to respond to temperature is severely restricted by the steep gradients of oxygen and light in natural sediments and the effect of tortuosity.

The total emergence percentages measured from the PET sediments permit assessment of the contribution of germling cells to the bloom inoculum in Nauset. To estimate the total germling cells that emerged in Salt Pond, the depth in the sediments to which cysts are physically able to germinate was generously estimated as $1 \mathrm{~mm}$. Surface sediment surveys of Salt Pond in the autumn-winter in 2008 through 2016 demonstrate that there is some interannual variation in the initial size of the cyst seedbed (Crespo et al. 2011; Ralston et al. 2015; A. Fischer, unpublished), but a reasonable estimate is 2000 cysts $\mathrm{cm}^{-3}$ in the surface $1 \mathrm{~cm}$ layer. This density estimated was multiplied by the estimated sediment depth of germination, and by the average area of the Salt Pond cyst seedbed $\left(9.46 \times 10^{4} \mathrm{~m}\right)$ to determine the number of germling cells emerged. Lastly, this value was divided by the average volume of Salt Pond $\left(2.79 \times 10^{8} \mathrm{~L}\right)$ to yield the resulting concentration of germling cells in the water column: 678 cells $\mathrm{L}^{-1}$. The timing of this emergence flux on bloom initiation is explored in Chapter 4 .

\section{Bridging laboratory germination measurements with the natural environment}

There are many laboratory studies of dinoflagellate cyst germination in the literature, but in situ emergence has not previously been measured with the same temporal and annual resolution as in the present study. The detailed approach used here demonstrates that if the oxygen and light penetration depths are accounted for, in situ emergence rates of $A$. catenella from Nauset have the same relationship with temperature as germination rates measured under laboratory 
conditions. There was no significant difference between the rate of germination recorded by the laboratory methods employed in this study - cyst isolations and sediment slurries. Thus, if the oxygen and light penetration depths can be accounted for, laboratory germination measurements can be used to predict the general emergence flux for cyst seedbeds in benthic habitats with different oxygen and light penetration depths.

Germination and emergence rates show a positive, linear relationship with temperature for Nauset. This means that specific germination fractions could be anticipated using a thermal time approach, which is commonly used for plant seeds. This relationship may be applicable to $A$. catenella populations in other habitats and perhaps other cyst-forming dinoflagellates. Understanding how temperature controls the $A$. catenella emergence flux in the natural environment and how that impacts bloom initiation is critical to predictions of toxic spring blooms in Nauset and in other habitats. This also has considerable importance in the context of weather variability and a changing climate. The linear relationship between temperature and the rates of germination and emergence suggests that under the milder winters anticipated with climate change, the emergence flux would begin soon after winter dormancy is alleviated (Chapter 2). The pattern of emergence might also be faster in a warmer climate, yielding a more synchronized pulse of germling cells as an inoculum. This could lead to earlier blooms in Nauset. Understanding the degree to which the timing and size of the emergence flux can impact bloom development is investigated in Chapter 4. 


\section{REFERENCES}

Aller, R. C. 1982. The Effects of Macrobenthos on Chemical Properties of Marine Sediment and Overlying Water, p. 53-102. In P.L. McCall and M.J.S. Tevesz [eds.], Animal-Sediment Relations.

Anderson, D. 1995. Identification of Harmful Algal Species Using Molecular Probes: An Emerging Perspective, p. 3-13. In P. Lassus, G. Arzul, E. Erard, P. Gentien, and C. Marcaillou [eds.], Harmful Marine Algal Blooms.

Anderson, D. M. 1980. Effects of Temperature Conditioning on Development and Germination of Gonyaulax tamarensis (Dinophyceae) Hypnozygotes. Journal of Phycology 16: 166-172.

Anderson, D. M. 1998. Physiology and Bloom Dynamics of Toxic Alexandrium Species, with Emphasis on Life Cycle Transitions, p. 29-48. In D.M. Anderson, A.D. Cembella, and G.M. Hallegraeff [eds.], Physiological Ecology of Harmful Algal Blooms. NATO ASI Series. NATO ASI Series.

Anderson, D. M., and B. Keafer. 1987. An endogenous annual clock in the toxic marine dinoflagellate Gonyaulax tamarensis. Nature 325: 616-617.

Anderson, D. M., and D. Wall. 1978. Potential Importance of Benthic Cysts of Gonyaulax tamarensis and G. excavata in Initiating Toxic Dinoflagellate Blooms. Journal of Phycology 14: 224-234.

Anderson, D. M., and F. M. M. Morel. 1979. The Seeding of two Red Tide Blooms by the Germination of Benthic Gonyaulax tamarensis Hypnocysts. Estuarine and Coastal Marine Science 8: 279-293. doi:10.1016/0302-3524(79)90098-7

Anderson, D. M., and K. D. Stolzenbach. 1985. Selective retention of two dinoflagellates in a well-mixed estuarine embayment: The importance of diel vertical migration and surface avoidance. Marine Ecology Progress Series 25: 39-50.

Anderson, D. M., C. A. Stock, B. Keafer, and others. 2005. Alexandrium fundyense cyst dynamics in the Gulf of Maine. Deep Sea Research II 52: 2522-2542.

doi:10.1016/j.dsr2.2005.06.014

Anderson, D. M., C. D. Taylor, and E. V. Armbrust. 1987. The effects of darkness and anaerobiosis on dinoflagellate cyst germination. Limnology and Oceanography 32: 340-351.

Anderson, D. M., D. G. Aubrey, M. Tyler, and D. W. Coats. 1982. Vertical and horizontal distributions of dinoflagellate cysts in sediments. Limnology and Oceanography 27: 757765. doi:10.4319/1o.1982.27.4.0757

Anderson, D. M., S. W. Chisholm, and C. J. Watras. 1983. Importance of life cycle events in the population dynamics of Gonyaulax tamarensis. Marine Biology 76: 179-189. doi:10.1007/BF00392734

Anderson, D. M., Y. Fukuyo, and K. Matsuoka. 2003. Cyst Methodologies, p. 165-190. In G.M. Hallegraeff, D.M. Anderson, and A.D. Cembella [eds.], Manual on Harmful Marine Microalgae.

Berg, P., N. Risgaard Petersen, and S. Rysgaard. 1998. Interpretation of measured concentration 
profiles in sediment pore water. Limnology and Oceanography 43: 1500-1510. doi:10.4319/lo.1998.43.7.1500

Bewley, J. D., and M. Black. 1982. Physiology and Biochemistry of Seeds in Relation to Germination, Springer-Verlag.

Bravo, I., and D. M. Anderson. 1994. The effects of temperature, growth medium and darkness on excystment and growth of the toxic dinoflagellate Gymnodinium catenatum from northwest Spain. Journal of Plankton Research 16: 513-525. doi:10.1093/plankt/16.5.513

Butman, B., A. L. Aretxabaleta, P. J. Dickhudt, P. S. Dalyander, C. R. Sherwood, D. M. Anderson, B. A. Keafer, and R. P. Signell. 2014. Investigating the importance of sediment resuspension in Alexandrium fundyense cyst population dynamics in the Gulf of Maine. Deep Sea Research Part II 103: 79-95. doi:10.1016/j.dsr2.2013.10.011

Crespo, B. G., B. A. Keafer, D. K. Ralston, H. Lind, D. Farber, and D. M. Anderson. 2011. Dynamics of Alexandrium fundyense blooms and shellfish toxicity in the Nauset Marsh System of Cape Cod (Massachusetts, USA). Harmful Algae 12: 26-38. doi:10.1016/j.hal.2011.08.009

Dale, B. 1983. Dinoflagellate Resting Cysts, p. 69-136. In G.A. Fryxell [ed.], Survival Strategies of the Algae. Survival strategies of the algae.

Garcia-Huidobro, J., J. L. Monteith, and G. R. Squire. 1982. Time, Temperature and Germination of Pearl Millet (Pennisetum typhoides S. \& H.). Journal of Experimental Botany 33: 288-296.

Genovesi, B., M. Laabir, E. Masseret, A. Vaquer, and D. Grzebyk. 2009. Dormancy and germination features in resting cysts of Alexandrium tamarense species complex (Dinophyceae) can facilitate bloom formation in a shallow lagoon (Thau, southern France). Journal of Plankton Research 31: 1209-1224. doi:10.1093/plankt/fbp066

Guillard, R. L., and J. H. Ryther. 1962. Studies of Marine Planktonic Diatoms. Canadian Journal of Microbiology 8: 229-239.

Huber, G., and F. Nipkow. 1923. Experimentelle Untersuchungen über die Entwicklung und form bildung von Ceratium hirundinella O. F. Müller. Flora 116: 114-215.

Ishikawa, A., M. Hattori, and I. Imai. 2007. Development of the "plankton emergence trap/chamber (PET Chamber)," a new sampling device to collect in situ germinating cells from cysts of microalgae in surface sediments of coastal waters. Harmful Algae 6: 301-307. doi:10.1016/j.hal.2006.04.005

Jørgensen, B. B., and N. P. Revsbech. 1985. Diffusive boundary layers and the oxygen uptake of sediments and detritus. Limnology and Oceanography 111-122.

Kirn, S. L., D. W. Townsend, and N. R. Pettigrew. 2005. Suspended Alexandrium spp. hypnozygote cysts in the Gulf of Maine. Deep Sea Research Part II 52: 2543-2559. doi:10.1016/j.dsr2.2005.06.009

Kremp, A., and D. M. Anderson. 2000. Factors regulating germination of resting cysts of the spring bloom dinoflagellate Scrippsiella hangoei from the northern Baltic Sea. Journal of Plankton Research 22: 1311-1327. doi:10.1093/plankt/22.7.1311 
Kuhl, M., C. Lassen, and B. B. Jørgensen. 1994. Light penetration and light-intensity in sandy marine sediments measured with irradiance and scalar irradiance fiberoptic microprobes. Marine Ecology Progress Series 105: 139-148.

Natsuike, M., H. Oikawa, K. Matsuno, A. Yamaguchi, and I. Imai. 2017a. The physiological adaptations and toxin profiles of the toxic Alexandrium fundyense on the eastern Bering Sea and Chukchi Sea shelves. Harmful Algae 63: 13-22. doi:10.1016/j.hal.2017.01.001

Natsuike, M., K. Yokoyama, G. Nishitani, Y. Yamada, I. Yoshinaga, and A. Ishikawa. 2017 b. Germination fluctuation of toxic Alexandrium fundyense and A. pacificum cysts and the relationship with bloom occurrences in Kesennuma Bay, Japan. Harmful Algae 62: 52-59. doi:10.1016/j.hal.2016.11.018

Pilskaln, C. H., D. M. Anderson, D. J. McGillicuddy, B. A. Keafer, K. Hayashi, and K. Norton. 2014. Spatial and temporal variability of Alexandrium cyst fluxes in the Gulf of Maine: Relationship to seasonal particle export and resuspension. Deep Sea Research Part II 103: 40-54. doi:10.1016/j.dsr2.2012.11.001

Ralston, D. K., M. L. Brosnahan, S. E. Fox, K. Lee, and D. M. Anderson. 2015. Temperature and Residence Time Controls on an Estuarine Harmful Algal Bloom: Modeling Hydrodynamics and Alexandrium fundyense in Nauset Estuary. Estuaries and Coasts 38: 2240-2258. doi:10.1007/s12237-015-9949-z

Rasmussen, H., and B. B. Jorgensen. 1992. Microelectrode studies of seasonal oxygen uptake in a coastal sediment: Role of molecular diffusion. Marine Ecology Progress Series 81: 289303.

Rengefors, K., and D. M. Anderson. 1998. Environmental and endogenous regulation of cyst germination in two freshwater dinoflagellates. Journal of Phycology 34: 568-577.

Revsbech, N. P., J. Sorensen, T. H. Blackburn, and J. P. Lomholt. 1980. Distribution of oxygen in marine sediments measured with microelectrodes. Limnology and Oceanography 25: 403411.

Roberts, E. H. 1988. Temperature and Seed Germination. Society for Experimental Biology 42: 109-132.

Schwinghamer, P., D. M. Anderson, and D. M. Kulis. 1991. Separation and concentration of living dinoflagellate resting cysts from marine sediments via density-gradient centrifugation. Limnology and Oceanography 36: 588-592. doi:10.4319/1o.1991.36.3.0588

Thibault de Chanvalon, A., E. Metzger, A. Mouret, and others. 2015. Two-dimensional distribution of living benthic foraminifera in anoxic sediment layers of an estuarine mudflat (Loire Estuary, France). Biogeosciences Discussions 12: 10311-10358. doi:10.5194/bgd-1210311-2015

Vahtera, E., B. G. Crespo, D. J. McGillicuddy, K. Olli, and D. M. Anderson. 2014. Alexandrium fundyense cyst viability and germling survival in light vs. dark at a constant low temperature. Deep-Sea Research Part II 103: 112-119. doi:10.1016/j.dsr2.2013.05.010

Yamaguchi, M., S. Itakura, I. Imai, and Y. Ishida. 1995. A rapid and precise technique for enumeration of resting cysts of Alexandrium spp. (Dinophyceae) in natural sediments. Phycologia 34: 207-214. doi:10.2216/i0031-8884-34-3-207.1 


\section{TABLES AND FIGURES}

Table 1

Germination and emergence rate estimates $\left(\% \mathrm{~d}^{-1}\right)$ for $A$. catenella cysts at different temperatures measured via cyst isolations, sediment slurries, and plankton emergence traps. Western and eastern Gulf of Maine (WGOM, EGOM) rates from (Anderson et al. 2005) are shown for comparison. A dash indicates that no data are available.

\begin{tabular}{|c|c|c|c|c|c|c|c|c|c|}
\hline & \multicolumn{3}{|c|}{$\begin{array}{c}\text { Cyst Isolation } \\
\text { Germination Test }\end{array}$} & \multicolumn{3}{|c|}{$\begin{array}{l}\text { Sediment Slurry } \\
\text { Germination Test }\end{array}$} & \multicolumn{3}{|c|}{$\begin{array}{c}\text { Plankton Emergence } \\
\text { Trap Method }\end{array}$} \\
\hline & 2013 & 2014 & 2015 & Nauset & WGOM & EGOM & 2013 & 2014 & 2015 \\
\hline $0^{\circ} \mathrm{C}$ & - & - & - & - & - & - & - & 0 & 0 \\
\hline $1.0^{\circ} \mathrm{C}$ & - & - & - & - & - & - & - & 0.24 & 0 \\
\hline $2.0^{\circ} \mathrm{C}$ & 0.71 & 0 & 0.90 & 1.28 & 0.89 & 1.74 & - & 0 & 0.50 \\
\hline $3.0^{\circ} \mathrm{C}$ & - & - & - & - & - & - & 1.34 & 0.29 & 0.67 \\
\hline $3.5^{\circ} \mathrm{C}$ & 1.36 & 0 & 0 & - & - & - & - & - & - \\
\hline $4.0^{\circ} \mathrm{C}$ & - & - & - & 3.38 & 1.69 & 1.74 & 2.36 & 0 & 4.18 \\
\hline $5.0^{\circ} \mathrm{C}$ & - & - & - & - & - & - & 6.88 & 2.56 & 2.76 \\
\hline $6.0^{\circ} \mathrm{C}$ & - & - & - & 5.80 & 2.03 & 1.58 & 6.60 & 4.90 & 2.56 \\
\hline $7.0^{\circ} \mathrm{C}$ & - & - & - & - & - & - & 5.09 & 5.39 & 4.33 \\
\hline $7.5^{\circ} \mathrm{C}$ & 5.17 & 4.61 & 2.86 & - & - & - & - & - & - \\
\hline $8.0^{\circ} \mathrm{C}$ & - & - & - & 6.72 & 6.55 & 4.03 & - & - & - \\
\hline $10.0^{\circ} \mathrm{C}$ & - & - & - & 8.61 & - & - & - & - & - \\
\hline $11.0^{\circ} \mathrm{C}$ & 7.05 & 7.17 & 5.71 & - & - & - & - & - & - \\
\hline
\end{tabular}


Table 2. Parameters of linear regressions of the germination and emergence rate $\left(G R ; \% \mathrm{~d}^{-1}\right)$ on temperature $\left(T ;{ }^{\circ} \mathrm{C}\right)$, from different measurement approaches. The equation was $G R=\left(T-T_{\mathrm{b}}\right) / \theta$, where $T_{\mathrm{b}}$ defines a base temperature at which the rate is zero and $\theta$ is the thermal time constant.

\begin{tabular}{lcccc}
\hline Method & $\begin{array}{c}T_{\mathrm{b}} \\
\left({ }^{\circ} \mathrm{C}\right)\end{array}$ & $\begin{array}{c}\theta \\
\left({ }^{\circ} \mathrm{Cd}\right)\end{array}$ & $r^{2}$ & $n$ \\
\hline Cyst Isolation Germination Test & $2.0^{\circ} \mathrm{C}$ & 1.37 & 0.91 & 12 \\
Sediment Slurry Germination Test & $0.3^{\circ} \mathrm{C}$ & 1.11 & 0.98 & 5 \\
Plankton Emergence Trap Method & $1.0^{\circ} \mathrm{C}$ & 1.16 & 0.67 & 19 \\
\hline
\end{tabular}

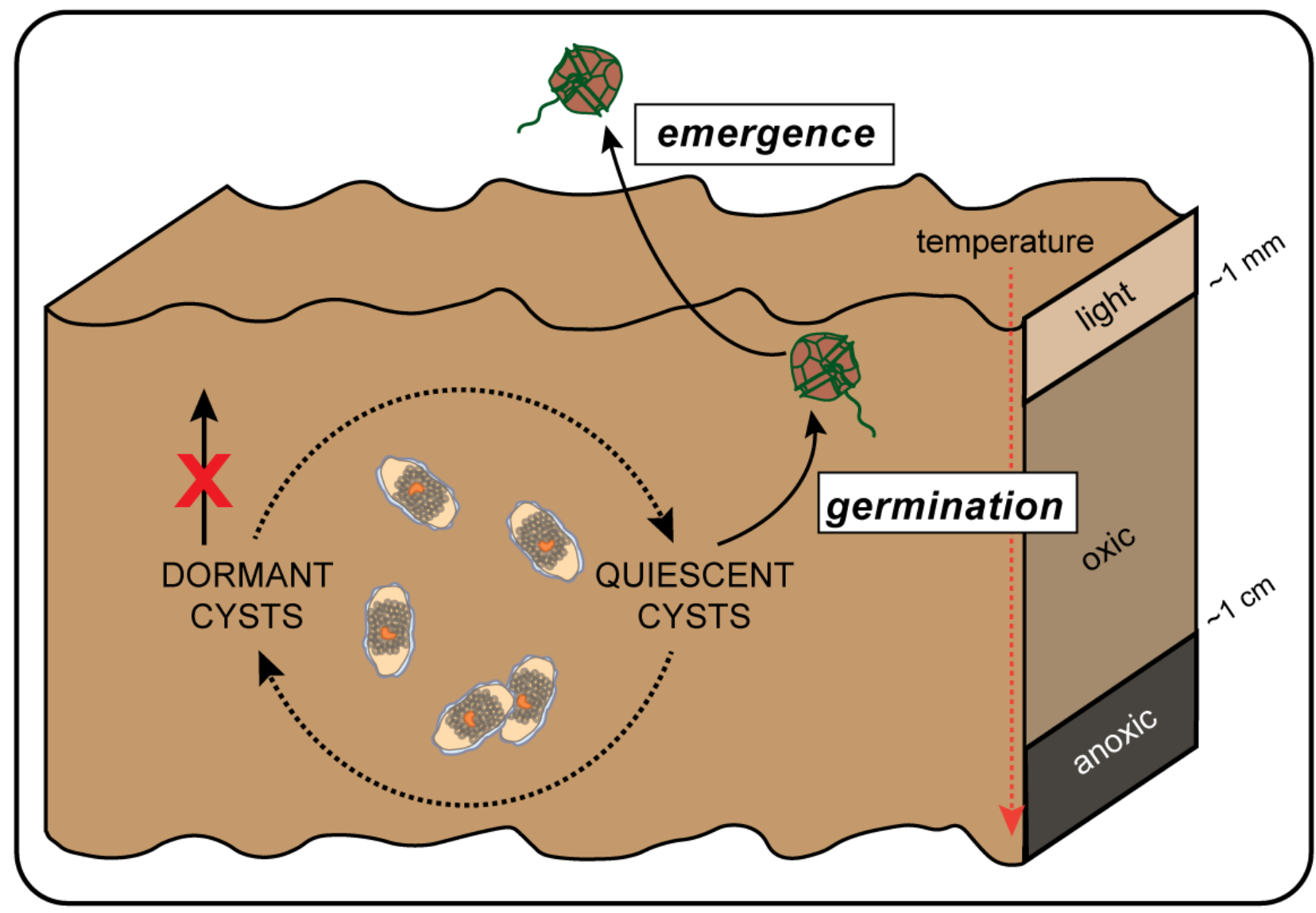

Fig. 1. Factors affecting germination and emergence of $A$. catenella from natural sediments. 

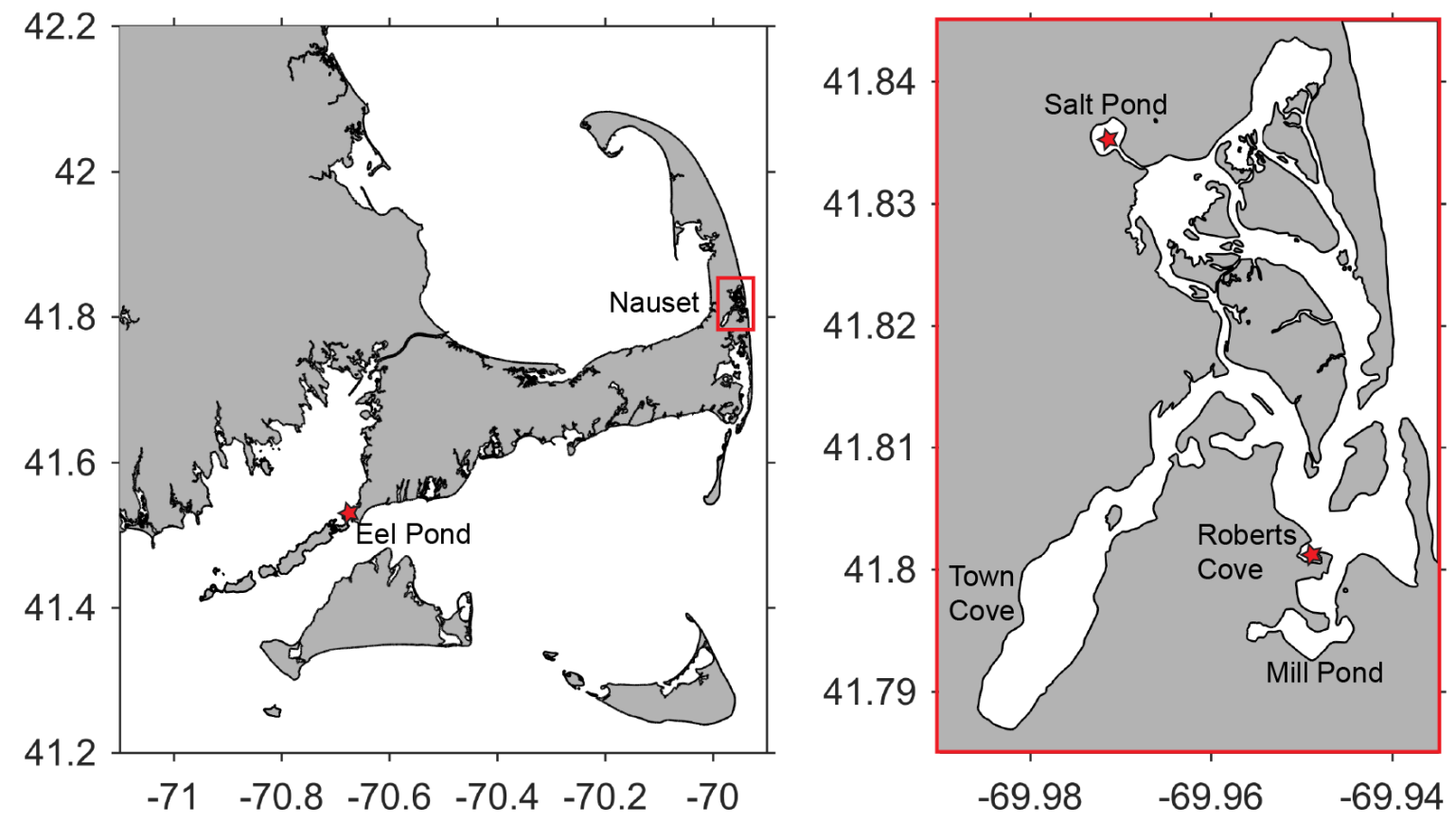

Fig. 2. Locations of Nauset Marsh and Eel Pond on Cape Cod, MA. Sediments were collected from Salt Pond and Roberts Cove within Nauset. Plankton emergence traps were submerged in Roberts Cove in 2013, and in Eel Pond water in 2014 and 2015.

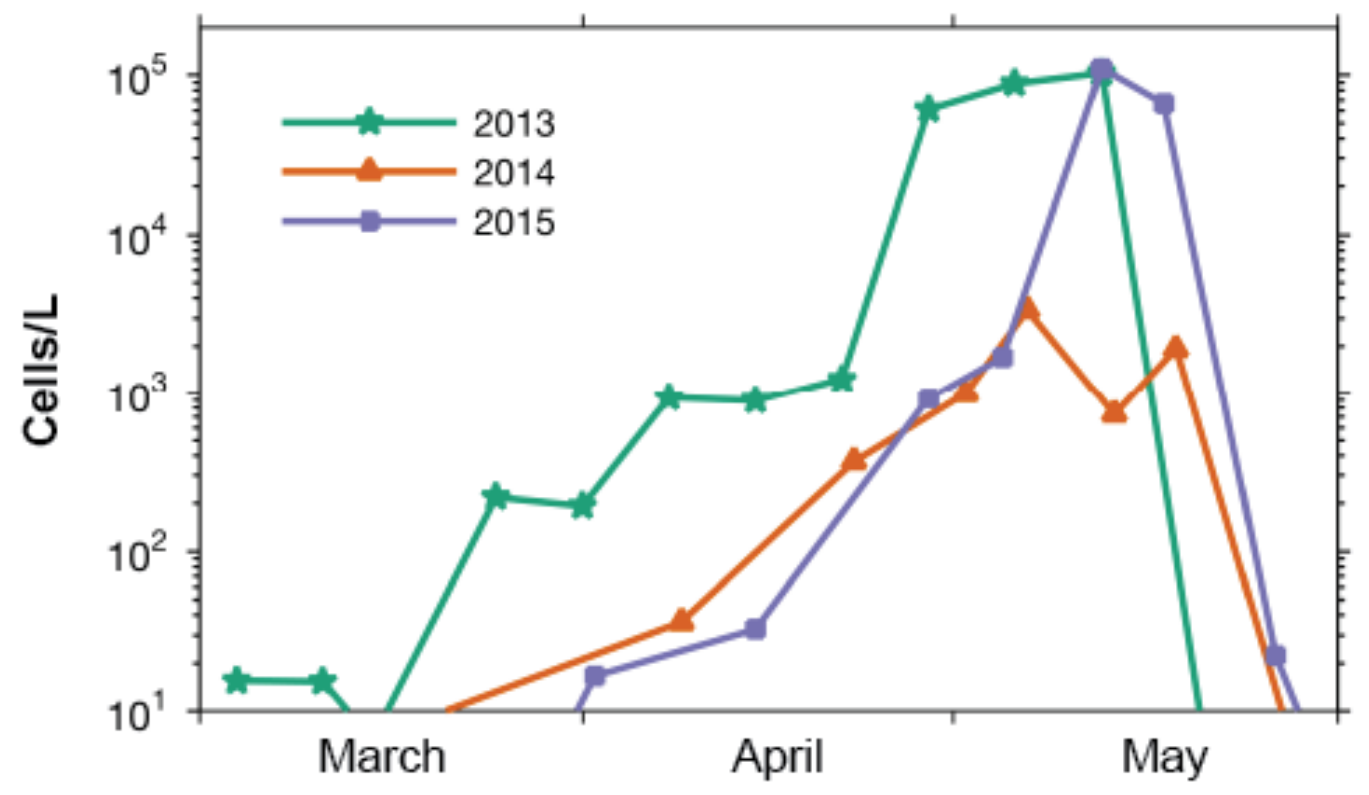

Fig. 3. Mean A. catenella concentration from weekly surveys in Salt Pond in 2013, 2014, 2015. 


\section{a) Cyst Isolation Germination Test}

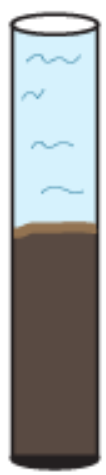

\section{February-May:}

collect sediment, isolate cysts, and incubate at the in situ temperature

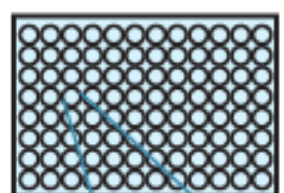

monitor for germination weekly
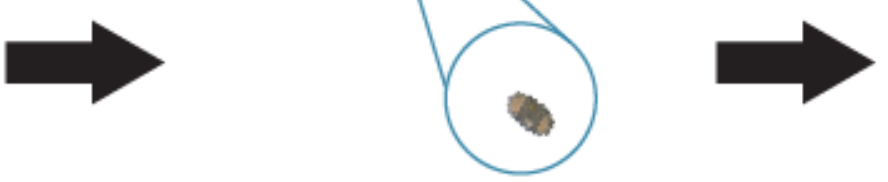

\section{b) Sediment Slurry Germination Test}

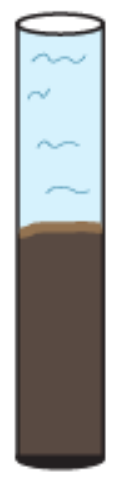

March: collect

sediment, fill flasks, and incubate at $2,4,6,8,10^{\circ} \mathrm{C}$

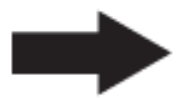

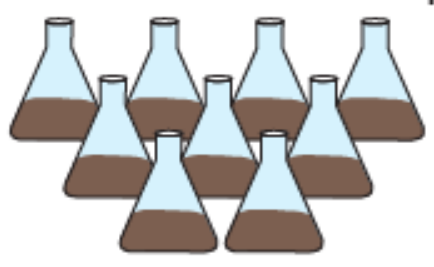

harvest flasks at $2-7$ day intervals to count the remaining cysts

\section{c) Plankton Emergence Trap Method}

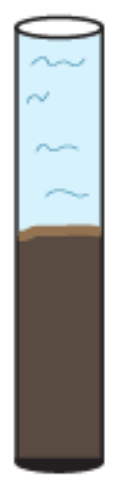

March: collect sediment, initialize and submerge PETs in situ

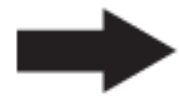

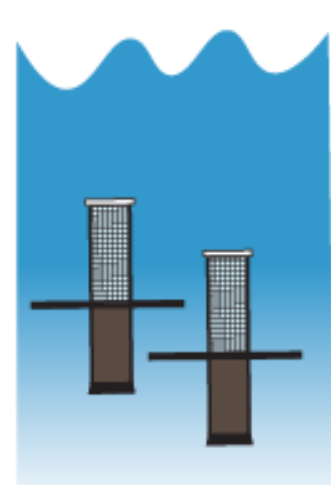

retrieve and resubmerge PETs $\sim$ daily to count germling cells

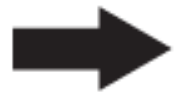

Fig. 4. Experimental design of (a) cyst isolation and (b) sediment slurry tests to measure germination under laboratory conditions and (c) plankton emergence trap (PET) method to measure emergence under natural conditions. 

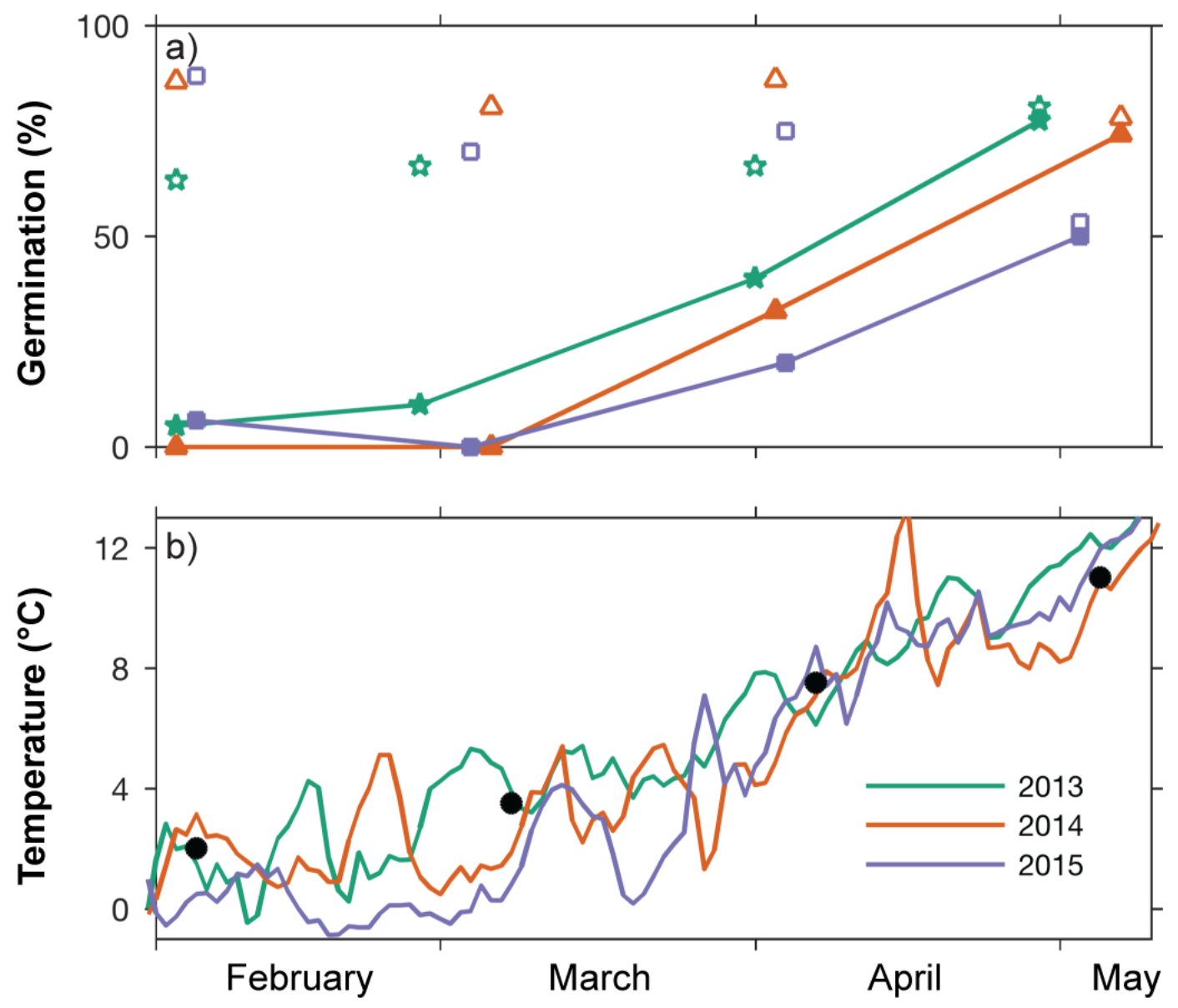

Fig. 5. (a) Germination success of freshly-collected A. catenella cysts. Monthly, from February through May, cysts were collected from Nauset, isolated, and incubated at the in situ temperature (closed symbols with line) and at $15^{\circ} \mathrm{C}$ (open symbols) for one week. (b) Vernal warming of the bottom water temperatures in Roberts Cove in Nauset. The in situ incubation temperatures used were $2^{\circ} \mathrm{C}$ for February, $3.5^{\circ} \mathrm{C}$ for March, $7.5^{\circ} \mathrm{C}$ for April, and $11^{\circ} \mathrm{C}$ for May (black dots). 


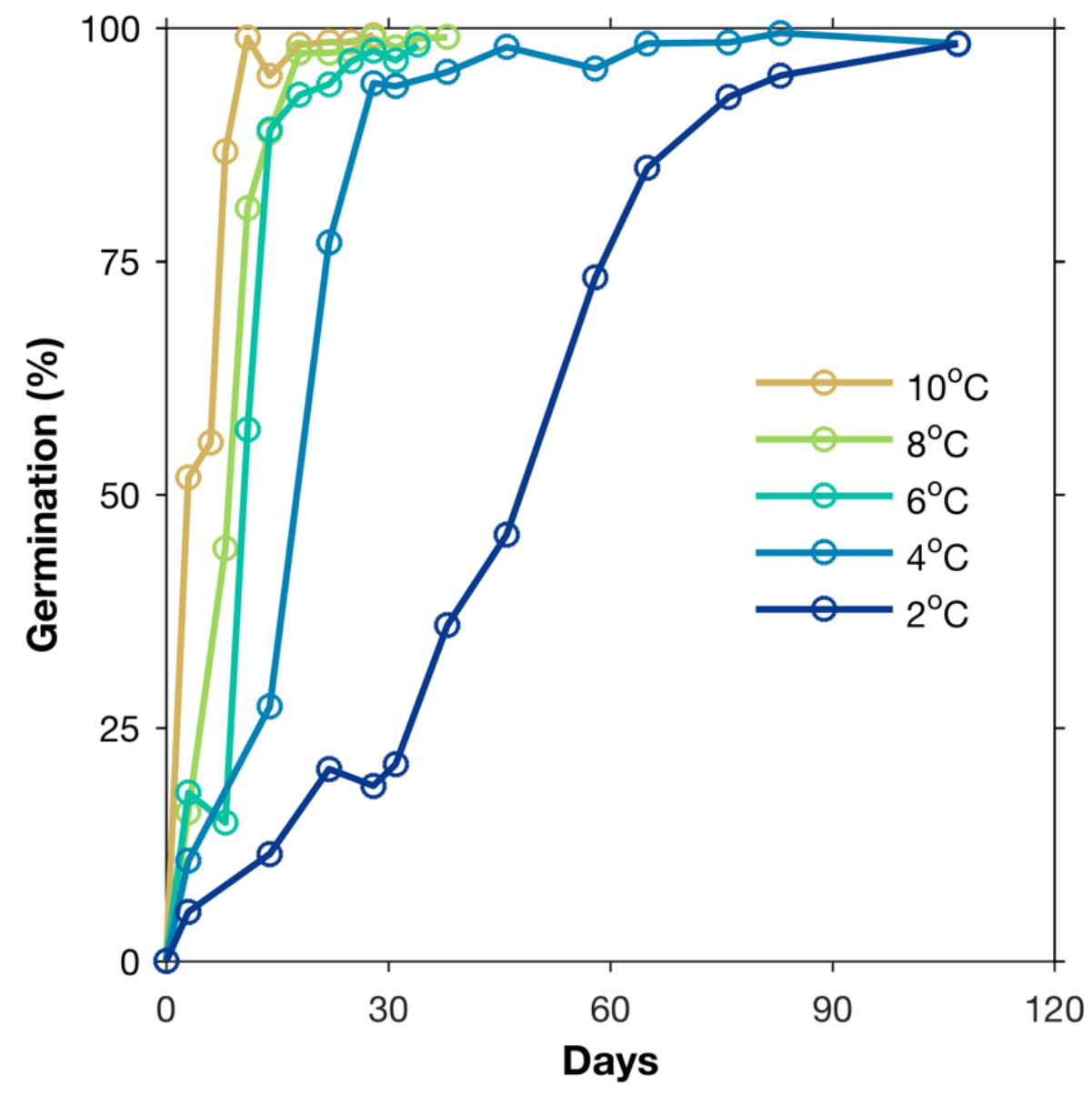

Fig. 6. Time course of $A$. catenella cyst germination in sediment slurries incubated at different temperatures. Cyst-rich sediments were collected from Nauset in March 2014 and equally divided among flasks. Flasks were incubated at $2,4,6,8$, and $10^{\circ} \mathrm{C}$ and harvested at different intervals, which are indicated by the points. 

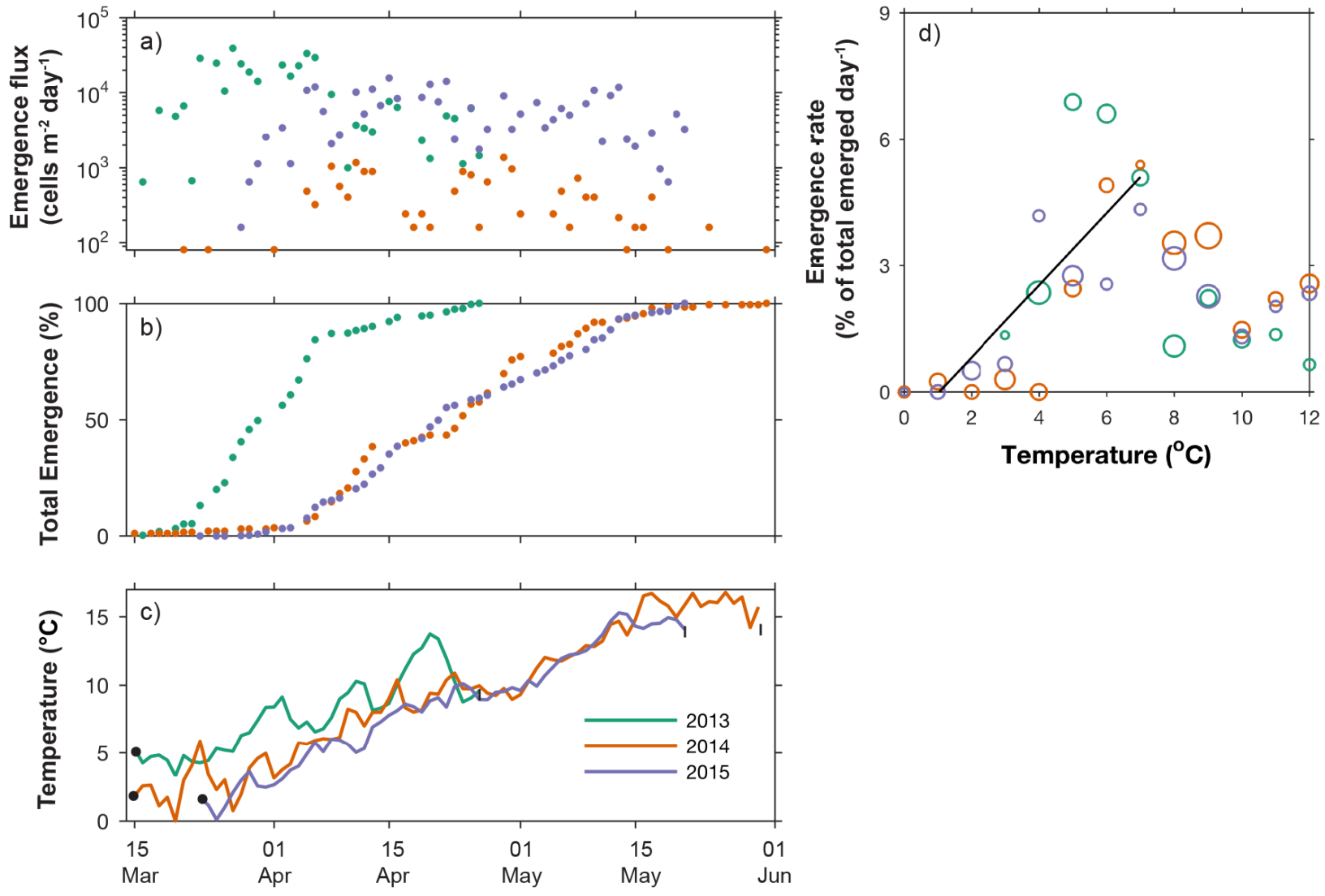

Fig. 7. (a) The emergence flux of $A$. catenella cysts from the surface $1 \mathrm{~cm}$ of sediment. Germling cells were counted on a near-daily basis from plankton emergence trap (PET) chambers. (b) The cumulative emergence was normalized to the total emerged germling cells in each year of the experiment. (c) The in situ water temperatures surrounding the PET chambers in Nauset in 2013 and in Eel Pond in 2014 and 2015. The black dot and vertical tick indicates the start and stop of the observation period each year. (d) Emergence rates were calculated from the total germling cells emerged over the course of the experiment, and binned at $1{ }^{\circ} \mathrm{C}$ intervals. Datapoint sizes are proportional to the number of values in each bin interval (the smallest has 1 and the largest has 8). 


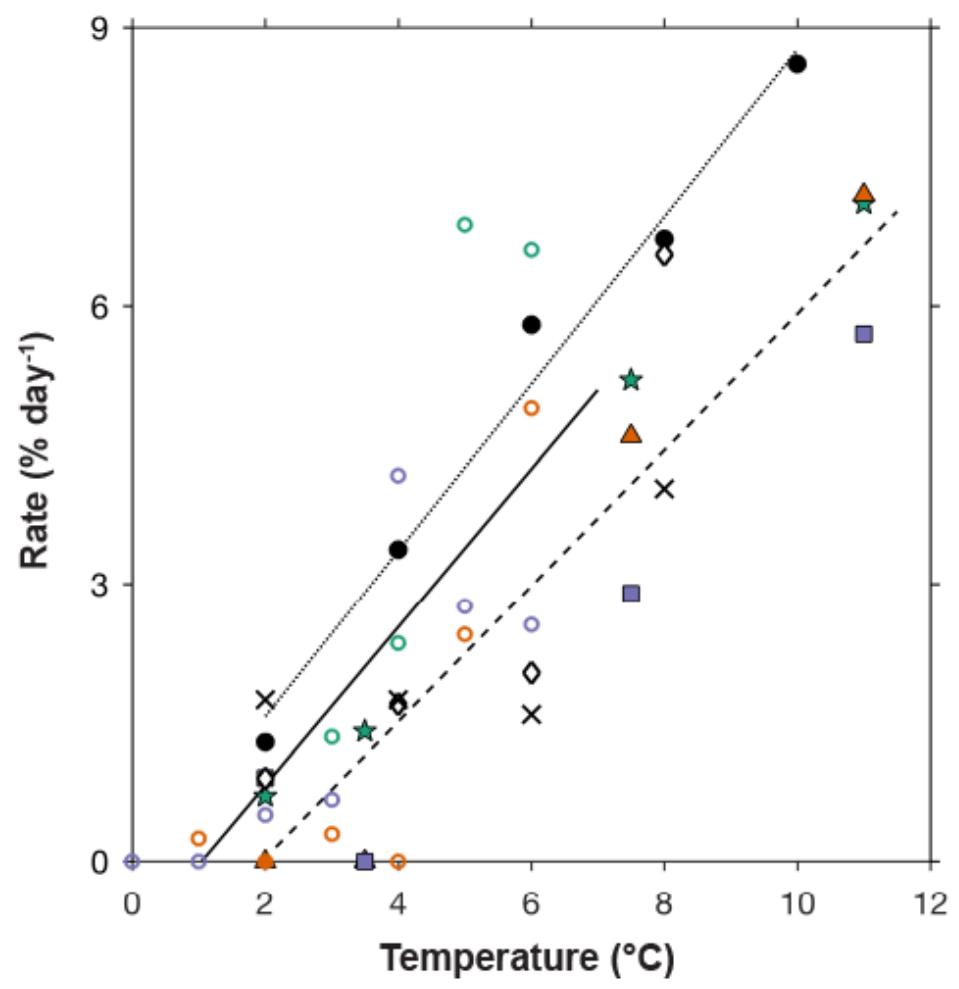

Cyst Isolation Germination Test

2013

$\Delta \quad 2014$

- 2015

- - Linear regression

Sediment Slurry Germination Test

- Nauset

.......... Linear regression

$\diamond \quad$ WGOM

$x$ EGOM

Plankton Emergence Trap Method

○ 2013

- 2014

- 2015

- Linear regression

Fig. 8. Germination and emergence rates of $A$. catenella cysts derived from cyst isolations, sediment slurries, and plankton emergence traps. Rates from each method were fit to linear regressions. Western and eastern Gulf of Maine (WGOM, EGOM) rates from a sediment slurry germination test in (Anderson et al. 2005) are shown for comparison. 

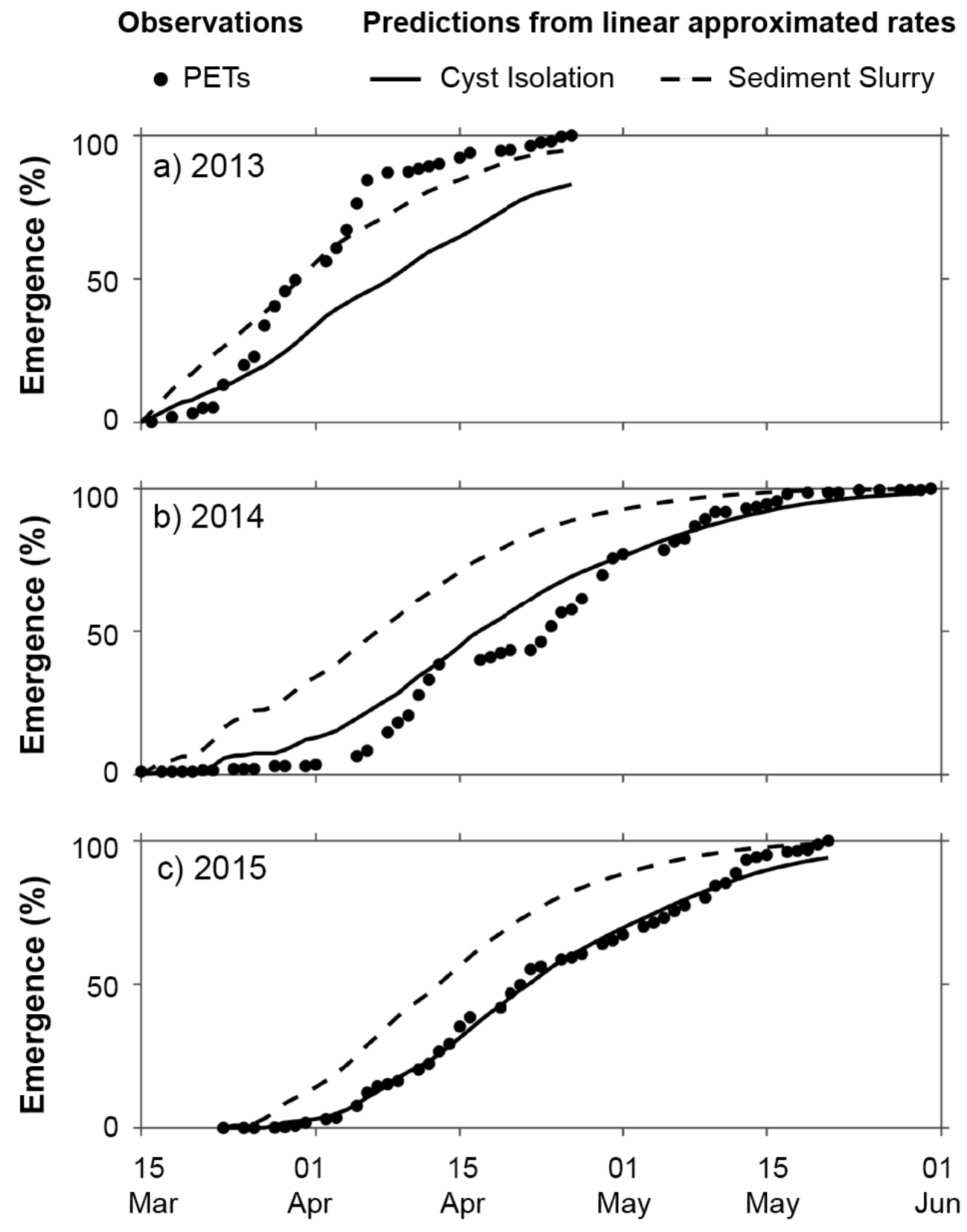

Fig. 9. Comparison of emergence observations to predictions in (a) 2013, (b) 2014, and (c) 2015. In situ emergence was observed using plankton emergence traps (PETs). The germination rates derived from the cyst isolation and sediment slurry methods were applied to the in situ temperature regime to predict the timing of emergence. 


\title{
Chapter 4
}

\section{Temperature modulation of dormancy transitions, germination, and division as a determinant of Alexandrium catenella bloom initiation}

\begin{abstract}
Cysts of the toxic dinoflagellate Alexandrium catenella were recently discovered to require a quantifiable amount of chilling to exit dormancy and become quiescent (i.e. become germinable). Here, a simple temperature-dependent model of $A$. catenella was developed to investigate the sensitivity of bloom phenology to dormancy breaking by winter chilling in an estuarine embayment. Nauset Marsh on Cape Cod (MA, USA) consists of three salt ponds, each with recurrent springtime blooms that are initiated by local cyst seedbeds and cause near annual shellfishing closures due to paralytic shellfish poisoning. In the model, the transition between cyst dormancy and quiescence is regulated by accumulation of a chilling threshold using a sigmoid function and the relationship between temperature and rates of germination and division are derived from field populations. Model bloom predictions were evaluated against observations of $A$. catenella over eight bloom years (2009-2016), during which winter and spring temperatures varied considerably $\left( \pm 2.0^{\circ} \mathrm{C}\right)$ from climatological averages. Notably, the chillingalleviated dormancy model accurately predicted the timing of quiescence (January) and the variable bloom phenology from multiple blooms in Nauset. Once cysts became quiescent and began to germinate, however, temperatures were typically too cold for growth to exceed losses so there was a several-week lag until bloom development. Years with warmer winters and springs, like 2012 and 2016, had shorter lag periods and thus significantly earlier blooms, even though it took longer to achieve the chilling threshold to break dormancy. Thus, in Nauset, it is not the chilling requirement that regulates the timing of blooms, since this is achieved in the middle of winter every year. Rather, the temperature conditions that control vegetative growth following germination determine bloom timing and magnitude. Nevertheless, dormancy breaking
\end{abstract}


by a chilling threshold is advantageous because it prevents the mismatch between conditions that are favorable for germination but not for bloom formation, that occur in the autumn and early winter in Nauset. Synchronized germination after winter chilling also promotes efficient conversion from the cyst seedbed to the spring bloom inoculum. The dormancy mechanism characterized here may be present in other A. catenella strains, as well as other cyst-forming dinoflagellates, but there is likely plasticity in this trait that reflects the temperature regime of each habitat. In another A. catenella habitat with warmer temperatures that support a high growth rate year round, dormancy breaking by chilling could have a more dominant role in bloom initiation.

\section{INTRODUCTION}

The dinoflagellate species Alexandrium catenella presents an expanding public health threat through its association with the paralytic shellfish poisoning (PSP) syndrome (Anderson et al. 2014). PSP is the most geographically widespread of harmful algal bloom (HAB)-associated poisoning syndromes (e.g. Hallegraeff 1993; Anderson et al. 2012). A major concern is the extent to which HABs and their human health impacts will be altered by a changing climate, but realistic forecasts remain challenging. This is due in part to the heteromorphic life cycle of many HAB species, including A. catenella. During its life cycle, A. catenella must complete sexual recombination, which is intertwined with the production of benthic resting cysts - a stage that can lie dormant for years to decades in the sediments. Cysts may inoculate new blooms through germination, but only if they are not in a state of dormancy. Despite these life cycle complexities, prevailing paradigms of how HABs will respond to climate change focus on the "growth window" of planktonic, swimming stages (e.g. Moore et al. 2008; Paerl and Huisman 2008; Tester et al. 2014). Because growth rates increase with temperature within a specific range, one hypothesis is that warming water temperatures will cause earlier, longer-lasting, and more toxic blooms of $A$. catenella (Moore et al. 2008), though these authors acknowledge that biotic factors can also regulate bloom phenology. Further, most predictions are based on extrapolations from laboratory cultures, which have behaviors that are very different from those in natural ecosystems (Brosnahan et al., in revision). 
Interannual variability in environmental forcing (e.g., different weather patterns) can provide a useful proxy to explore how natural populations of $A$. catenella may respond to future climate scenarios. This study focused on Nauset Marsh, a shallow coastal estuary subject to recurrent springtime blooms A. catenella blooms that cause near annual shellfishing closures due to PSP, that experiences an average temperature variation of $\pm 2.0^{\circ} \mathrm{C}$. Over many years of study in Nauset, warmer winters have tended to produce earlier blooms, but the duration and intensity have remained fixed (Ralston et al. 2014). Further, Nauset's three terminal salt ponds host independent, localized populations of A. catenella each spring (Crespo et al. 2011; Ralston et al. 2015), which facilitate studies of the species' complete life cycle under different temperature scenarios within the same year. Localization of blooms within each of the ponds occurs through an interaction between the swimming behavior of $A$. catenella cells, stratification within the ponds, and restricted outflow to the central marsh area as a barrier to transport (Anderson et al. 1983; Anderson and Stolzenbach 1985; Ralston et al. 2015). Thus, the Nauset system is an ideal location to assess the effects of interannual temperature variability that may be representative of climate change scenarios on the timing of life cycle transitions and bloom development.

The timing of cyst germination determines whether a cell divides and reproduces in a given environment. Both internal and external factors influence the timing of $A$. catenella germination (Anderson and Keafer 1987; Pfiester and Anderson 1987; Matrai et al. 2005). Immediately after formation, cysts enter mandatory dormancy which prevents germination so cysts can complete physiological maturation (Anderson and Morel 1979; Anderson 1980). Mandatory dormancy only occurs once in a cyst's lifetime and is alleviated by internal factors (Jann and Amen 1977). Once the barrier imposed by dormancy is broken, cysts remain in an internal resting state, termed quiescence, until external factors are favorable for germination. Temperature is considered a primary regulatory factor and must be within an optimal range for germination to occur (e.g. Anderson and Morel 1979; Bravo and Anderson 1994; Chapter 3). Oxygen is a germination requirement for this species (Anderson et al. 1987; Rengefors and Anderson 1998; Kremp and Anderson 2000). Finally, light increases the rate of Alexandrium germination, although it is not a requirement (Bravo and Anderson 1994; Anderson et al. 2005; Genovesi et al. 2009; Vahtera et al. 2014). Mature cysts that are otherwise competent to germinate can enter another type of 
dormancy ('recurrent dormancy') multiple times during their lifetime (Anderson and Keafer 1987; Matrai et al. 2005; Rathaille and Raine 2011; Chapter 2). In A. catenella cysts from Nauset, this dormancy was discovered to be broken once cysts had attained a quantifiable amount of chilling (a period of low but above freezing temperatures) (Chapter 2). A simple function with only two parameters collapses observed variability in dormancy duration: a threshold temperature $T_{\max }$ below which chilling accumulates, and a chilling requirement that must be met for $50 \%$ of a cyst population to achieve quiescence (termed $G_{50}$ ). As a consequence, cysts would be expected to remain dormant longer during warmer winters, a counterintuitive finding that has obvious importance for the climate response of this species. The present study assesses the implications of a chilling requirement on bloom phenology under different temperature regimes.

Dormancy breaking by a chilling requirement is fundamentally important for predicting the timing and supply of new A. catenella cells to initiate blooms now and under climate-warming scenarios. Thus, the first objective of this study was to incorporate this dormancy breaking mechanism, as well as rates of germination and division from natural populations, into a simple temperature-dependent model. Model predictions were generated for several dormancy parameterizations and for a case without dormancy. These model results were compared to observations of cell abundance over multiple years in Nauset. The second objective was to use this model to determine how interannual differences in temperature (e.g. a warm anomaly year) shift the supply of new $A$. catenella cells to initiate blooms. A final objective was to assess the presence of chilling-alleviated dormancy in a different $A$. catenella population in a shallow coastal embayment with a completely different temperature regime. This study permits environmental windows for germination and growth to be better defined and demonstrates the ecological advantages of chilling-alleviated dormancy.

\section{METHODS}

\section{Study area}


The focus of this study is Nauset Marsh, a complex series of marsh and submerged kettle ponds on Cape Cod, Massachusetts connected by an inlet through a dynamic barrier beach to the Atlantic Ocean (Fig. 1). A network of tidal channels through a vegetated marsh platform connect three drowned kettle ponds - Salt Pond, Mill Pond, Town Cove - each of which hosts independent, localized populations of A. catenella (Crespo et al. 2011; Ralston et al. 2015). Localization of blooms within the ponds occurs through an interaction between the swimming behavior of A. catenella cells (surface avoidance), stratification within the ponds, and the narrow and shallow channel connecting to the central marsh area which restricts transport of cells from the ponds to the central marsh (Anderson et al. 1983; Anderson and Stolzenbach 1985; Ralston et al. 2015). In turn, retention promotes the local deposition of cysts that then inoculate new blooms each spring, leading to PSP shellfishing closures on a near-annual basis. In studies spanning from 1980 through present (e.g. Anderson et al. 1983; Crespo et al. 2011; Ralston et al. 2014; Brosnahan et al., in revision) large A. catenella blooms have not been observed in Nauset in seasons other than the spring. Further, Massachusetts Department of National Resources PSP toxicity measurements have been taken nearly weekly from around March through December back to 1980. PSP toxicity has only ever been reported in the spring months.

\section{Observations}

Weekly surveys in Salt Pond

Approximately weekly during the spring months of 2009 through 2016, large-scale surveys of physical and biological conditions were conducted in Nauset as described elsewhere (Crespo et al. 2011; Ralston et al. 2014; Brosnahan et al. 2015). The weekly surveys capture the seasonal trends in Salt Pond across multiple years. Here we summarize those methods, extend the observations to additional years, and focus on data collection in Salt Pond. Surveys occurred around daytime high tides and began in the late winter and finished about 2 weeks after bloom demise: 12 surveys from 24 March to 17 June 2009, 13 surveys from 23 March to 16 June 2011, 11 surveys from 14 February to 8 May 2012, 12 surveys from 04 March to 22 May 2013, 9 surveys from 19 March to 12 June 2014, 10 surveys from 17 March to 03 June 2015, and 23 surveys from 17 February to 21 May 2016. A. catenella cells may have been present in Salt Pond earlier than the first sampling date. Survey stations varied from 2009 to 2016 but annual measurements were always made in the center of Salt Pond (Station 21), and thus will be the 
focus of our analyses for this study. During each survey, water samples for $A$. catenella abundance and nutrient measurements were collected with 2.5 liter Niskin bottles at multiple depths: $1 \mathrm{~m}, 3 \mathrm{~m}, 5 \mathrm{~m}$, and $1 \mathrm{~m}$ above the bottom $(7-8 \mathrm{~m})$. Vertical profiles of salinity and temperature were also taken using a Sea-Bird 19plus CTD (Sea-Bird Electronics, Bellevue, Washington). Details on sample processing and quantification of $A$. catenella abundance are provided in Crespo et al. (2011), Ralston et al. (2014), and Brosnahan et al. (2015).

\section{Dormancy status of the cyst seedbed}

Experiments to assess the seasonal dormancy status of the cyst seedbed were originally described in Chapter 2, but the results are of great utility here so those methods will be summarized. Monthly from July 2013 through June 2015, cysts were collected from intertidal sediment within Roberts Cove, an area immediately outside of Mill Pond in the southern branch of Nauset (Fig. 1). Undisturbed sediment cores were collected with a hand corer and transported back to the laboratory for extrusion and sediment processing. During transportation, sediment cores were kept upright in a bucket filled with water maintained at the ambient temperature of Roberts Cove. Once in the laboratory, the sediment sample was subsampled, sonicated, and sieved and cysts were separated from same size particles with higher specific densities using density cushion centrifugation. The sample was aliquoted into a Sedgewick-Rafter counting chamber and cysts were identified and isolated using a Zeiss Axioskop upright microscope. For each monthly dormancy test, approximately 30 healthy-looking cysts (starch granules present, golden to brown coloration) were individually isolated by micropipette and subjected to conditions known to induce rapid germination of quiescent cysts. Isolated cysts were placed in wells of a 96-well tissue culture plate, each pre-loaded with $200 \mu \mathrm{L}$ of $\mathrm{f} / 2$ medium (Guillard and Ryther 1962). The plates were then sealed to limit evaporative loss of medium and incubated at $15^{\circ} \mathrm{C}$ on a $14: 10 \mathrm{~h}$ L:D cycle $\left(250 \mu \mathrm{mol} \mathrm{m}^{-2} \mathrm{~s}^{-1}\right.$ photon flux density). Individual cysts were checked for germination on a weekly basis using an inverted Olympus IX-70 microscope. If the germination percentage of total cysts after the first week was less than $50 \%$, the majority of the cyst seedbed was deemed dormant, and if the germination percentage exceeded $50 \%$, the majority of the cyst seedbed was deemed quiescent.

\section{Continuous temperature measurements}


Moored, internally recording $\mathrm{HOBO}$ temperature loggers (Onset Computer Corporation) were deployed in Salt Pond in August 2012 through 2016 to provide continuous records of the surface and bottom water temperature over the course of the year. As a proxy for temperature during periods when loggers were not deployed in Salt Pond, additional data were retrieved from sensors maintained at the nearby Waquoit Bay National Estuarine Research Reserve (http://cdmo.baruch.sc.edu/), in accordance with the approach established by Ralston et al. (2014). Waquoit Bay is also a tidal embayment on Cape Cod, connecting several small rivers to Nantucket Sound. The Waquoit Bay stations that most closely tracked the observed temperatures in Salt Pond were selected as representative proxies: Menauhant, which tended to be slightly cooler and Metoxit Point, which was slightly warmer during the spring bloom period. The average temperature from these two stations was used to represent water temperatures prior to August 2012, when instruments were not deployed in Salt Pond. To assess the degree of interannual temperature variability, temperature anomalies were calculated. The mean daily temperature was calculated for October 2008 through 2016 (Fig. 2c). Daily temperature anomalies were calculated by finding the daily difference between each bloom year's temperature and the mean (Fig. 3).

\section{Bloom Initiation Model}

A simple model was developed to assess the effect of temperature seasonality on development of the A. catenella bloom inoculum in Salt Pond. In this model, attainment of the chilling requirement breaks dormancy for a population of $A$. catenella cysts. These newly-quiescent cysts germinate and divide according to rates measured in natural populations. Model parameters are listed in Table 1. Bloom initiation in the model is defined as the time when the net cells from germination (total germling cells minus losses) is exceeded by net cells from division (total cells from division minus losses). The bloom inoculum in the model is the net cells (total cells from both germination and division minus losses) at bloom initiation. The pre-bloom period is defined as the time from when $10 \%$ of the cyst seedbed has germinated until bloom initiation occurs.

Temperature dependence of cyst dormancy control and the onset of germination is a distinguishing feature between this model and other A. catenella models previously developed for the Gulf of Maine (Stock et al. 2005) and Nauset (Ralston et al. 2015). The Gulf of Maine 
model uses an empirically determined endogenous clock function, which places a rigid constraint on the timing of germination from March through June (Anderson and Keafer 1987; Matrai et al. 2005). The Nauset model of the 2011 bloom uses the spring tide preceding the earliest survey as the starting point. In contrast, the present study's model incorporates the recent discovery that the transition from dormancy to quiescence is dependent upon surpassing a chilling threshold (Chapter 2).

\section{Chilling-alleviated dormancy transition}

Chilling-units $(C U)$ are a measurement of winter severity commonly used in horticulture studies. A common model assigns one $C U$ for each degree below $T_{\max }$, a temperature below which an organism perceives chilling (Luedeling et al. 2009; Penfield and Springthorpe 2012). For $A$. catenella cysts from Nauset, this $T_{\max }$ is $15^{\circ} \mathrm{C}$ (Chapter 2). Daily chilling-units were calculated for the average daily bottom temperature $\left(T_{i}\right)$ that the cyst seedbed experienced in Salt Pond:

$$
C U(t)=\Delta t \sum_{i=t o}^{t}\left\{\begin{array}{ccc}
T_{\max }-T_{i} & \text { if } & T_{\max } \geq T_{i} \geq 0 \\
0 & \text { if otherwise }
\end{array}\right.
$$

Chilling-unit calculations applied a start date in June, which approximates the timing of new cyst formation in Salt Pond. Further, at this time of year, temperatures already exceed the $T_{\max }$ and continue to do so until October, so chilling is not accumulated until the autumn. The maximum chilling possible in each bloom year was calculated using this formulation.

The transition from dormancy to quiescence for the $A$. catenella cyst population is represented by a sigmoidal function. Sigmoidal responses are commonly observed in terrestrial plant studies and reflect the normally-distributed variance of germination times among cyst populations. For the present study, the well-known logistic sigmoid function was used to constrain the fraction of the cyst seedbed that is quiescent $(Q)$ :

$$
Q(C U)=\frac{1}{1+e^{-\mathrm{k}(C U-R)}}
$$


where $k$ is a constant that determines the curvature of the quiescence pattern, and $R$, the chilling requirement, is the inflection point of the curve. This function transitions the cyst seedbed from complete dormancy (0) to quiescence (1). For cysts from Nauset, laboratory experiments found that the parameters $R=800 C U$ and $k=0.004$ could successfully predict when half of a cyst population was quiescent and could therefore germinate (Chapter 2). Due to the nature of a sigmoid relationship, a very small number of cysts will germinate earlier and later, so here the predicted onset of quiescence is defined as $Q=5 \%$ and complete quiescence as $Q=95 \%$, and the duration of the dormancy-quiescence transition as the time between these two points. Under this definition, the slope $k$, results in the onset of quiescence at $\sim 300 C U$ before $R$ is attained and complete quiescence at $\sim 300 C U$ after $R$ is attained. For example, using the laboratory-derived $R$ of $800 \mathrm{CU}$, the onset of quiescence would be 500 and complete quiescence at $1100 \mathrm{CU}$ respectively.

\section{Germination rate}

The germination rate is a function of oxygen, light, and most importantly, temperature. Another key difference between this model and previous $A$. catenella models is that it incorporates temperature-dependent emergence rates from field observations (Chapter 3). The germination rate $(G R)$ model used here increases linearly with temperature $(t)$ up to an optimum, beyond which the rate decreases. When the rate is linear, extrapolation defines a base temperature $\left(T_{\mathrm{b}}\right)$, at which the rate is zero so the thermal response of the germination can be expressed as:

$$
\begin{array}{ll}
\mathrm{GR}=\frac{1}{t}=\frac{\left(T-T_{b}\right)}{\theta} & \text { if } T_{o} \geq T \geq T_{b} \\
\mathrm{GR}=0 & \text { if } T<T_{b}
\end{array}
$$

The denominator in this equation is the thermal time needed for germination $\left(\theta\right.$, units ${ }^{\circ} \mathrm{Cd}$, 'degree-days'). Cyst distributions from surface sediment surveys of the Salt Pond in the autumnwinter in 2008 through 2016 were used to set the initial size of the cyst seedbed (Crespo et al. 2011; Ralston et al. 2015; A. Fischer, unpublished). An average estimate of the Salt Pond cyst seedbed from the surface $1 \mathrm{~cm}$ layer was used: 1000 cysts $\mathrm{cm}^{-3}$. To focus explicitly on the effect of dormancy-quiescence transitions on formation of the bloom inoculum, the size of the cyst seedbed was kept constant in all years. Due to oxygen limitation, germination was estimated to 
only occur in a sediment thickness of $2 \mathrm{~mm}$ in Nauset (Chapter 3). Irradiance was not found to have a clear impact on emergence rates at temperatures below $7^{\circ} \mathrm{C}$ (Chapter 3) and because division was the dominant source of cells at this temperature in Nauset, the influence of light was not considered in this model. Thus the initial size of the cyst seedbed used in this model was $20 \%$ of the average cyst concentration of the $0-1 \mathrm{~cm}$ layer of sediment, over the area of Salt Pond. Resuspension, which would refresh the surface sediment layers with new cysts, presumably occurs in Nauset (Butman et al. 2014). To keep this model as simple as possible, the resuspension physical forcing was not included, so the surface cyst seedbed is not replenished. Thus, the interplay of the dormancy and germination functions release new germling cells into the model. The net new cells generated from germination each day (new germling cells minus losses per day) will be termed the "germination pulse".

\section{Division rate}

As the water column is seeded by germling cells, $A$. catenella cell abundance increases via vegetative cell division. Division rates for this species depend on water temperature, irradiance and nutrient availability. Nauset is nutrient replete due to significant anthropogenic inputs (Giblin and Gaines 1999; Colman and Masterson 2008). Nutrients and irradiance are not dominant drivers of the A. catenella bloom in Nauset (Ralston et al. 2015), so they were not considered for the purposes of this model. Investigations using an Imaging Flow Cytobot (IFCB) in Nauset revealed that daily rates of $A$. catenella division during bloom development were more than twice those from batch cultures grown in replete medium at the same temperatures within the temperature range of $7-9^{\circ} \mathrm{C}$ (Brosnahan et al. 2015). Thus, this model used a conservative daily division rate $(\mu)$ measured by the IFCB during the 2016 bloom following the methods of Brosnahan et al. (2015).

$$
\mu(t)=0.041 t-0.1034
$$

Temperature gradient bar studies have demonstrated that $A$. catenella division does not occur at temperatures below $2^{\circ} \mathrm{C}$ (Watras et al. 1982; Ralston et al. 2014; A. Fischer, unpublished), thus $2^{\circ} \mathrm{C}$ was used as the lower bound in this model. 
Loss rate

In many cases, IFCB-estimates of $A$. catenella growth rates in Salt Pond were greater than the overall rates of accumulation, which suggests that cell loss rates are quite low (Brosnahan et al. 2015). The dominant factor controlling the loss of cells in Salt Pond is the efficient retention of cells, which is affected by bathymetric constraints, stratification, and cell behavior (diel vertical migration) (Ralston et al. 2015). Daily loss rates are estimated to alternate between approximately $0.1 \mathrm{~d}^{-1}$ and $0.3 \mathrm{~d}^{-1}$ during neap and spring tide cycles, respectively, and there is interannual variability depending on the stratification and swimming behavior (Ralston et al. 2015; Brosnahan et al.). Specific loss rates due to grazing are unknown but their impact has not been shown to be a major factor in bloom development or decline (Petitpas et al. 2015; Ralston et al. 2015). Unlike the model of Ralston et al. (2015), this study's model begins many months earlier in the year when loss rates have not been estimated. Due to unknown rates in the fall and winter and minimal grazing impact, constant daily loss rates within the range estimated for advective losses $(0.05,0.1,0.2$, and 0.3$)$ were evaluated (Ralston et al. 2015), with the goal of determining an average loss rate for bloom initiation and development. To assess the goodness of fit between cell abundance observations and model predictions with different loss rates, the normalized mean square error (NMSE) was calculated. NMSE costs range between -infinity (bad fit) to 1 (perfect fit). Finally, to determine the upper bound of the loss rate, the extinguishing loss rate was calculated; this is the average loss rate over the pre-bloom period needed to extinguish the bloom inoculum (total cells from germination and division minus losses at bloom initiation).

\section{Evaluating the parameterization and function of chilling-alleviated dormancy in Nauset}

To assess the sensitivity of this Salt Pond bloom initiation model to the laboratory-derived chilling requirement $(R=800 C U)$, three additional parameterizations at intervals of $400 \mathrm{CU}$ were tested: Zero, Low, and High. The Zero $(R=0 C U)$ parameterization allowed germination to proceed once temperatures fell below the upper temperature bound for $A$. catenella germination, $18.5^{\circ} \mathrm{C}$ (Anderson and Rengefors 2006). The Low parameterization had $R=400 C U$ and the High parameterization had $R=1200 C U$. These model predictions were compared to the observed cell abundance data to assess the best fit. 
Next, chilling-alleviated dormancy was evaluated as an ecological strategy by determining the efficiency of the conversion between the cyst seedbed and the bloom inoculum. A more efficient conversion indicates that when germling cells emerged, water temperatures were warm enough to support bloom formation, thus these cells had higher odds of surviving, dividing, and reproducing - which would be advantageous for $A$. catenella. In contrast, an inefficient conversion would be characterized by a lot of precocious germination in which cells emerged when temperatures were too cold for bloom formation - which would not be a good strategy. A model diagnostic to evaluate efficiency is the fraction of the cyst seedbed remaining at bloom initiation - the greater the fraction remaining, the more efficient the conversion. The fraction of the cyst seedbed remaining will be assessed for all the dormancy parameterizations.

\section{Application of chilling-alleviated dormancy to Puget Sound}

To evaluate if chilling-alleviated dormancy was conserved for $A$. catenella in a different shallow coastal embayment, the model was applied to an $A$. catenella habitat with a different temperature regime and bloom timing - Quartermaster Harbor (QMH) in Puget Sound. Since cysts were first measured in surface sediments in Puget Sound in 2005, QMH has been the most persistent seedbed with the highest concentrations, ranging from $10^{3}$ (Greengrove et al. 2014) to $10^{4}$ cysts $\mathrm{cm}^{-3}$ (Horner et al. 2011). QMH has a shallow inner bay with an average depth of $6 \mathrm{~m}$ that is connected to an outer bay with an average depth of $12 \mathrm{~m}$. The mechanisms regulating excystment in cysts in QMH are not well understood (Moore et al. 2015). It is also unknown if the $A$. catenella blooms in QMH are self-seeding like Nauset, but given the frequent occurrence of PSP, it is considered a toxicity hot spot (Moore et al. 2009). Cell abundance data was obtained for this site from the SoundToxins program from October 2010 through 2013 (https://soundtoxins.org/). During this time period, bottom water temperature data from QMH had large gaps (http://green2.kingcounty.gov/marine-buoy/); however, bottom water temperature data from the nearby Seattle Aquarium were found to be nearly the same $\left(r^{2}=92\right)$, so these data were used instead.

To apply the Nauset model to QMH, a few assumptions were made due to uncertainties in the system. In QMH, there is no obvious start date for chilling accumulation because the timing of cyst formation is unknown and temperatures always exceed the $T_{\max }$ determined for Nauset cysts 
$\left(15^{\circ} \mathrm{C}\right)$. Thus, for this model, 01 October was selected as the start date because this was when water temperatures were at a seasonal maximum and cell abundance was decreasing. The second assumption made was that $A$. catenella blooms in QMH are seeded by the local cyst seedbed, which could very well be true, but is convenient for the model set-up. Under these terms, QMH temperature from October 2010 through 2013 was input into the model to generate predicted cell abundances for each of the different $R$ parameterizations.

\section{RESULTS}

\section{Observed interannual variability in temperatures and spring blooms}

From October 2008 through 2016 in Salt Pond, the average bottom water temperatures experienced by the cyst seedbed ranged from 1 to $24^{\circ} \mathrm{C}$ and differed interannually by an average of $\pm 2.0^{\circ} \mathrm{C}$ (Fig. 2c). The warmest bloom years were 2012 and 2016, and the coldest bloom years were 2011, 2014, and 2015 (Fig. 3). The implications of these temperature differences will be examined in subsequent sections. From October 2013 through July 2015, the dormancy status of the cyst seedbed was documented. The cyst seedbed was quiescent (defined as the time when the percent germination after one week exceeded 50\%) from January to May (Fig. 2b). From 2009 through 2016, an A. catenella bloom was observed every spring in Salt Pond, attaining a peak concentration on the order of $10^{5}$ cells L ${ }^{-1}$, with the exception of a small bloom in 2014 that only reached $10^{3}$ cells L ${ }^{-1}$ (Fig. 2a; Table 2). The peak of the bloom differed interannually by 6 weeks, ranging from early April in 2016 to mid-May in 2015.

\section{Determination of the average loss rate}

Constant loss rates were tested to determine the best fit for the period leading to the bloom peak (Fig. 4). A loss rate of $0.1 \mathrm{~d}^{-1}$ best predicted the majority of blooms: 2012, 2013, 2014, and 2015. This loss rate underestimated the 2016 bloom, but overestimated the 2009, 2010, and 2011 blooms - there were no obvious shared temperature patterns among these years. The fit of the 0.1 loss rate was the best (NMSE $=0.32)($ Fig. 5$)$, followed by the 0.05 loss rate $(\mathrm{NMSE}=0.11)$, the 0.2 loss rate $(\mathrm{NMSE}=-3.11)$, and lastly the 0.3 loss rate $(\mathrm{NMSE}=-55.04)$. 
To better understand the rage of loss rates in Salt Pond, the loss rate that would be needed to extinguish the bloom inoculum was determined. The time from the first germination pulse to bloom initiation is the pre-bloom period so the extinguishing loss rate was calculated over this period. Extinguishing loss rates were significantly higher in years with pre-bloom periods that were colder $(F(7,1)=16.96, p<.006$; Fig. 6a) and longer $(F(7,1)=32.62, p<.001$; Fig. $6 \mathrm{~b})$. This is because in years with colder pre-bloom periods, temperatures were too cold for growth to effectively counter losses, so only a small loss rate would be needed to eliminate the population. For example, the bloom year 2014 had the longest and one of the coldest pre-bloom periods, and the lowest extinguishing loss rate: 0.16 . Thus, given that 0.16 was the lowest extinguishing loss rate and 0.1 was the overall best fit to the observed bloom timing, 0.1 was determined to be a suitable estimate of a constant loss rate for $A$. catenella in Salt Pond and was used in all further analysis.

\section{Sensitivity of seasonal cell abundance to parameterization of the chilling requirement}

To determine the sensitivity of $A$. catenella bloom phenology to dormancy breaking by winter chilling, four chilling-requirement $(R)$ parameterizations were examined, including the value derived from laboratory experiments in Chapter 2: Zero $(R=0)$, Low $(R=400 C U)$, Laboratory ( $R=800 C U$ ), and High $(R=1200 C U)$. Among the 2009-2016 blooms, the average maximum chilling possible in Salt Pond was $1731( \pm 210) C U$ and was attained on 24 May ( \pm 9 days) (Fig. 7; Table 2). By the time maximum chilling had been reached, complete quiescence of the cyst seedbed had been attained for nearly all the $R$ parameterizations. The only exception was the High parameterization in 2010 and 2012 because the maximum chilling possible those years was only $1479 C U$ and $1367 C U$, respectively, which is less than the $1500 C U$ needed to attain $100 \%$ quiescence of the cyst seedbed.

The predicted onset of quiescence differed among the $R$ parameterizations. The average onset was 19 November ( \pm 3 days) for the Low, 4 January ( \pm 7 days) for the Laboratory, and 4 February ( \pm 9 days) for the High (Fig. 7). Notably, the onset of quiescence predicted by the Laboratory was consistent with the experimentally observed timing of quiescence in early January 2014 and 2015 in Salt Pond (Fig. 2b). The laboratory experiments that led to the $R=800 C U$ 
parameterization were completely independent of these field observations, which demonstrates the validity of this parameterization in the natural environment.

The phenology of predicted $A$. catenella cell abundance differed considerably among the $R$ parameterizations (Fig. 7). The Zero model formulation predicted autumn and winter blooms of extremely high magnitudes that persisted through the spring. The Low formulation predicted late autumn and winter blooms of small magnitudes that in some cases, persisted through the spring. The predicted timing of the spring bloom by the Low, Laboratory, and High parameterizations was generally similar and in line with the observed cell abundance. However, the Low and High predictions were inconsistent with spring bloom initiation observations in the warm anomaly years 2012 and 2016; the Low predicted cells too early and the High predicted cells too late in these years.

The ecological advantage of each of the dormancy parameterizations was investigated by assessing how efficient the conversion from the cyst seedbed to the spring inoculum was. The model diagnostic used to determine this was the size of the cyst seedbed at spring bloom initiation. The Laboratory and the High parameterizations were most efficient, with $45 \%( \pm 10 \%)$ and $54 \%( \pm 8 \%)$ of the cyst seedbed remaining at bloom initiation (Fig. 8). In contrast, the Low parameterization was very inefficient and only had $12 \%( \pm 9 \%)$ of the cyst seedbed remaining.

\section{Effect of interannual temperature variability on development of the bloom inoculum}

Given that the Laboratory $R$ prediction best represented the onset of quiescence and seasonal presence of A. catenella cells, this parameterization was used to explore the effect of interannual temperature variability on the bloom inoculum. The temperature anomaly for each bloom year from 01 October - right before when chilling is typically first accumulated in Nauset - through 01 February - after the onset of quiescence is observed - was determined to assess its impact on the predicted onset of quiescence. In years with warm temperature anomalies during this period, the onset of quiescence occurred later: $F(7,1)=76.11, p<1.3 \times 10^{-4}$ (Fig. 9a). For example, in the warm year 2016, the onset of quiescence began on 13 January, whereas in the cold year 2011, the transition began on 30 December. Although quiescence was attained later in warm anomaly years, the first germination pulse occurred earlier and faster division rates became possible 
sooner. To assess this, the average temperature anomaly during the period most relevant for bloom inoculum development - 01 February through 01 April - was determined for each bloom year. The average timing of when net cells from division exceeded cells from germination (bloom initiation) was 16 March ( \pm 15 days), and this occurred significantly earlier in years with warmer spring periods: $F(7,1)=37.43, p<8.7 \times 10^{-4}$ (Fig. 9b; Table 2).

Here, the effect of accumulated and current temperature conditions on the processes leading to bloom initiation in representative warm and cold winter-spring anomaly years are summarized. In the warm bloom year 2016, the onset of quiescence occurred last: 13 January. During this dormancy transition, temperatures were favorable for both germination and division to occur. However, the rate of division was slow because the average temperature during the pre-bloom period was cold, although variable: $4.0^{\circ} \mathrm{C}( \pm 1.8)$. Thus the time from the first germination pulse to bloom initiation was 26 days (Fig. 6b). Warm winter temperatures in 2016 produced higher rates of division earlier in the season than any other bloom year, so net cells from division outnumbered those from germination the earliest: 26 February (Fig. 10).

For comparison, 2011 and 2014 were both representative cold years but the former produced a large bloom and the latter produced a small bloom (Table 2). These bloom years had the earliest onsets of quiescence (26 December 2014 and 30 December 2011) but the ensuing winter temperatures resulted in the bloom inoculum developing differently. In 2011, temperatures were extremely cold and did not become favorable for germination until about 2 months later in early March (Fig. 10). At this point, temperatures were rapidly increasing and supported high rates of both germination and division. This pre-bloom period had the warmest average temperature $4.6^{\circ} \mathrm{C}( \pm 0.5)$ - so only 14 days of germination were needed to seed the bloom inoculum. Even though 2011 was a cold anomaly year, the predicted date of bloom initiation (when net cells from division exceed net cells from germination) was 20 March, approximately the average timing among the study years. In contrast, the cold temperatures that occurred from 01 February through 01 April in 2014 were highly variable: $2.6^{\circ} \mathrm{C} \pm 1.5$. This resulted in 80 days of dispersed pulses of precocious germination in which germling cells were met with temperatures unfavorable for division. Ultimately, this resulted in 2014 having the latest predicted timing of bloom initiation on 06 April. 


\section{Potential implications of chilling-alleviated dormancy for bloom phenology in a different}

shallow $A$. catenella habitat

The potential of chilling-alleviated dormancy was evaluated for $A$. catenella in a different shallow coastal embayment: Quartermaster Harbor (QMH) in Puget Sound. Over the period of October 2010 to 2013, A. catenella cells were observed from late March through late November (Fig. 11a). During this time period, the mean temperature oscillated seasonally from 8 to $12.5^{\circ} \mathrm{C}$ and was consistent interannually $\left( \pm 0.3^{\circ} \mathrm{C}\right)$ (Fig. 11b). Using the same chilling requirement parameterizations as the Nauset bloom development model, predicted cell abundances were generated from the mean bottom water temperature in QMH. The cell abundance predicted by the High parameterization best matched the observed timing of bloom initiation in late March (Fig. 11a). In contrast, the Zero, Low, and Laboratory parameterizations predicted blooms occurring in October, November, and January, respectively, which were all inconsistent with the observations. Further, unlike Nauset, there was no buffer between the onset of quiescence and bloom initiation in $\mathrm{QMH}$, because temperatures were consistently favorable for germination and division (Fig. 11a).

\section{DISCUSSION}

This study characterizes the temperature-dependence of dormancy, germination, and division, and relates these processes to the phenology of $A$. catenella blooms in an estuarine embayment. A. catenella cysts from Nauset require a threshold amount of chilling to break dormancy and become quiescent (germinable) (Chapter 2). The sensitivity of bloom phenology to the chilling requirement was evaluated using several parameterizations. Model predictions generated with the laboratory-derived parameterization accurately predicted the onset of quiescence and variable bloom phenology from multiple independent blooms in Nauset. Once cysts became quiescent, however, temperatures were typically too cold to support high rates of division so there was a several-week lag until bloom initiation occurred. Years with warmer winters and springs had shorter lag periods and thus significantly earlier blooms. Results here suggest that the role of dormancy breaking by chilling is to prevent precocious germination in the autumn and winter, 
thereby ensuring that the cyst seedbed is efficiently converted into the spring bloom inoculum. These results and their implications are discussed in detail below.

\section{Chilling-alleviated dormancy prevents precocious germination}

The dormancy status of the $A$. catenella cyst seedbed in Nauset was assessed experimentally and observed to be quiescent (and therefore physiologically able to germinate) from early January through May in both 2014 and 2015 (Fig. 2b). The onset of quiescence predicted by the model parameterization using the laboratory-derived chilling requirement (Laboratory, $R=800 \mathrm{CU}$ ) was highly consistent with observations: 4 January ( \pm 7 days) (Fig. 7; Table 2$)$. In contrast, the model parameterizations with lower and higher chilling thresholds to attain quiescence (Low, $R$ $=400 C U$; High, $R=1200 C U$ ) predicted different results. The Low parameterization predicted quiescence over a month earlier (19 November \pm 3 days) and the High parameterization predicted quiescence a month later (4 February \pm 9 days), respectively. An advantage of quiescence beginning later was a more efficient conversion of the cyst seedbed into the bloom inoculum. A larger cyst seedbed remaining upon bloom initiation indicates that a greater number of germling cells emerged into environmental conditions favorable for bloom formation, so each cyst has a higher probability of reproducing - thus an advantageous ecological strategy for a species. The cyst seedbed remaining at the time of bloom initiation was highest for the High prediction (54\% $\pm 8)$, followed by the Laboratory prediction $(45 \% \pm 10)$, and then the Low predictions $(12 \% \pm 9)$ (Fig. 8). Notably, the severity of cyst seedbed depletion predicted by the Low parameterizations was not observed during the winters and springs of the 2014 and 2015 bloom years in Salt Pond (Appendix).

A. catenella has been studied in Nauset since 1980 but large blooms have only been observed in the late winter and spring (e.g. Anderson et al. 1983; Crespo et al. 2011; Ralston et al. 2014; Brosnahan et al., in revision) and PSP toxicity has only been reported in the spring by the Massachusetts Department of National Resources. Due to winter and spring sampling bias for $A$. catenella cell abundance, it is conceivable that cells could be present at other times of the year but high abundances would be extremely unlikely due to the absence of toxicity. Observations of large, toxic spring blooms was consistent with the predictions by the Laboratory and High parameterizations, but inconsistent with the autumn and winter blooms predicted by the Zero and 
Low parameterizations (Fig. 7). This suggests that a non-existent or low chilling requirement would not be realistic as otherwise high $A$. catenella vegetative cell abundances and toxicity would be observed in the autumn and winter in Salt Pond. Even though the High parameterization had the most efficient conversion of cysts to cells in the bloom, which would seem to be a good ecological strategy, its predictions did not line up well with observations in the warm anomaly years, 2012 and 2016. Because the High parameterization required more accumulated chilling to attain quiescence, warmer winters and springs resulted in a delayed onset of quiescence which caused the initial germination pulse to be delayed - thus missing the initial observed cells. In 2012 and 2016, the first survey in Salt Pond was in mid-February and $A$. catenella cell concentrations on the order of $10^{2}$ were observed, which suggests that cells were present even earlier. Thus, a high chilling requirement is also not realistic because it cannot account for early bloom years. This confirms that the Laboratory model parameterization was the best fit to the observed bloom phenology.

Despite obvious flaws in the predictions of the Low, Laboratory, and High parameterizations, they all predicted approximately the same timing of the spring bloom, which matched the observed $A$. catenella cell abundance. The fact that spring bloom development was relatively insensitive to how the chilling requirement was parameterized between 400 and $1200 \mathrm{CU}$ demonstrates that temperatures favoring vegetative cell division were overwhelmingly the most important determinant of bloom initiation, as shown in Fig. 9b. This finding that division is the key driver of the Nauset spring bloom was originally demonstrated by Ralston et al. $(2014 ; 2015)$ for 2009-2012, thus the present study extends this finding to additional years.

Comparison of the bloom phenology predicted by all parameterizations provides insight into the ecological strategy of chilling-alleviated dormancy for $A$. catenella. This mechanism prevents precocious emergence in the autumn and early winter when there are brief periods of favorable conditions (that would trigger germination) but the decreasing daylight and cooling temperatures render the establishment of dense blooms difficult at that time of year in Nauset. By quantifying the duration and severity of cold, A. catenella cysts track the passage of winter and delay their quiescence until temperatures are at a seasonal minimum: January. Once germination-favorable temperatures begin, germling cells are met with increasing daylight and warming temperatures 
which will soon be able to support bloom development. Thus, chilling-alleviated dormancy helps avoid the mismatch between conditions that are favorable for germination but not for bloom formation that occur in the autumn and early winter in Nauset. Analogous to this dormancy mechanism, is the chilling requirement that many plant seeds and bulbs have to ensure emergence after winter has passed (e.g. Arora et al. 2003; Horvath et al. 2003; Rohde and Bhalerao 2007). The breaking of plant and A. catenella dormancy by chilling is likely an example of convergent evolution. They have separate evolutionary origins, but are superficially similar because they have both experienced natural selection that shaped their emergence timing to be in the spring.

This new understanding of chilling-alleviated dormancy's role in A. catenella phenology in Nauset provides a biologically-relevant start date for the bloom development model of Ralston et al. (2014; 2015). In Ralston et al. 2014, the start date selected for heat accumulation was 1 January because it was one of the coldest points in the year and statistically it produced the best result - it is lucky in its proximity to the onset of quiescence both observed and derived in this study. Further, in Ralston et al. 2015, the date of the full model simulation was set to the spring tide preceding the earliest survey. These fixed time-points may vary as climate changes and for different $A$. catenella habitats. Thus, incorporating the chilling-alleviated dormancy transition confers greater flexibility to bloom development model of Nauset (Ralston et al. 2014; 2015), including extension to other shallow coastal embayments with different temperature regimes.

\section{Low loss rates in Salt Pond}

The best overall prediction of the observed $A$. catenella cell abundance was using a constant loss rate of $0.1 \mathrm{~d}^{-1}$, encompassing mortality, advection, and grazing (Fig. 4). However, this value causes the model to underestimate growth in the 2016 bloom year and overestimate growth in 2009, 2010, and 2011, which have no apparent temperature trend among them (Fig. 2). These interannual differences could derive from a range of loss processes in Nauset. Our ability to parameterize loss processes in this system is hindered by uncertainty in the implications of ice cover, localization of pre-bloom populations, growth rates at low temperatures, and grazing rates. 
In all bloom years except for the anomalously warm 2012 and 2016, Salt Pond was covered with ice and sometimes snow during part of the winter. Detailed records of ice and snow cover are not maintained, but this was observed on numerous occasions during sampling trips and historically by National Park Service rangers who are stationed at Salt Pond (Sophia Fox, personal communication). For example, during monthly sediment collections for the cyst germination experiments, Salt Pond was completely covered in ice and snow in February and March of 2015, and partly covered during these months in 2014. Light does not penetrate ice covered with snow, which would have prevented cell division during these periods. If an ice and snow cover mortality term was included, the bloom prediction model results would be shifted a bit later in many of the bloom years. This could explain the slightly premature bloom predictions in 2009, 2010, and 2011 (Fig. 7).

Survey observations in February and March reported localization of A. catenella populations at the bottom of Salt Pond (>5 m) (A. Fischer, unpublished). This suggests that after germling cells emerge in the sediments, they remain near the sediment-water interface for some amount of time. Ralston et al. (2015) estimated that the residence time in Salt Pond for cells that vertically migrated to the surface was shorter than for those that migrated to a higher light level because most losses from tidal advection occur in the surface layer. For cells that vertically migrated to the fixed light level (not the surface), loss rates derived from residence time estimates in Ralston et al. (2015) ranged from 0.1 in neap tides to 0.3 in spring tides. Given that bottom-localized $A$. catenella populations would completely avoid the surface layers, they would be expected to experience loss rates at the lower bound of the estimates.

Constraining losses in the late winter and early spring is challenging because of uncertainty in growth rates. Model results demonstrate that $A$. catenella cells were present in the water column as early as mid-January in some years, but this cannot be verified because survey measurements did not typically begin until March (Fig. 9). Additionally, A. catenella division rates measured by an IFCB in Salt Pond were recently found to be twice as high as those measured in laboratory cultures at equivalent temperatures (Brosnahan et al. 2015). Rate measurements in Salt Pond prior to 15 March or at temperatures less than $8^{\circ} \mathrm{C}$ are not available, so it is unknown if elevated rates also occurred during the pre-bloom period. Thus, a conservative division rate estimate was 
used in the present study. This indicates that if the division rate used is an underestimate of prebloom $A$. catenella populations, the loss rate would also be an underestimate.

Finally, perhaps the greatest uncertainty is the lack of understanding of grazing rates and the environmental factors or population dynamics that control them (Petitpas et al. 2015). The work of Ralston (2015) demonstrated that the net accumulation rates during the bloom were similar to the upper limit of laboratory growth rates of $A$. catenella. However, if the growth rates were higher, as shown by Brosnahan (2015), the losses due to grazing could also be higher. The influence of grazers typically increases with temperature so the fact that a constant loss rate of 0.1 was able to successfully represent bloom initiation and development in this study's model suggests that the pre- and early-bloom grazing pressure was negligible. Thus, to confidently parameterize loss rates during the pre-bloom period in Salt Pond, high temporal observations of A. catenella cell accumulation and grazing are needed. An IFCB would need to be deployed in January (after cysts are quiescent) and measure cell abundance at different depths in the water column, especially near the sediment water interface to capture germling cells. Ideally, these observations would be paired with vertical profiles of salinity and temperature using a CTD to determine the depth of mixing early in the year.

\section{The bloom inoculum develops differently in warm and cold anomaly years}

The temperatures during the 2009-2016 bloom seasons in Nauset varied considerably from climatological averages $\left( \pm 2.0^{\circ} \mathrm{C}\right)$ and elicited different responses in the predicted development of the $A$. catenella bloom inoculum (Fig. 10). Most prominently, the bloom inoculum in the warm anomaly years 2012 and 2016 developed differently from representative cold anomaly years 2011 and 2014.

The warmer temperatures in 2012 and 2016 during the autumn and early winter resulted in the slowest chilling accumulation and thus the latest predicted onset of quiescence: 15 and 13 January, respectively (Fig. 9a). While the cyst seedbed was transitioning from dormancy to quiescence, temperatures were warm enough for cysts that had just attained quiescence to germinate. However, the time from the first germination pulse to bloom initiation was several weeks because temperatures were not yet warm enough to support high rates of division; the pre- 
bloom periods in 2012 and 2016 had average temperatures of $4.0^{\circ} \mathrm{C}( \pm 0.4)$ and $4.0^{\circ} \mathrm{C}( \pm 1.8)$, respectively, and lasted 30 and 26 days, respectively (Fig. 6b). Temperatures in these warm years could support high rates of division the earliest, which resulted in the earliest bloom initiations: 28 February 2012 and 26 February 2016. The observed peak of the 2016 bloom in Salt Pond preceded the predicted bloom (Fig. 7), which suggests that other factors helped expedite bloom development in this year. Extra warming would lead to stronger stratification and greater retention in Salt Pond, as demonstrated in the model results of Ralston et al. (2015). In general, years with warmer temperatures in the winter and spring would be expected to have earlier blooms of high magnitude in Salt Pond.

In the cold-anomaly years 2011 and 2014 (Fig. 3), the development of the bloom inoculum occurred in two ways that depended on how cold temperatures were after quiescence was attained. Rapid accumulation of chilling in each of these years predicted the earliest onsets of quiescence: 30 December 2011 and 26 December 2014 (Fig. 9a). In 2011, after that stage was achieved, temperatures were so cold that germination did not occur until approximately 2 months later in March (Fig. 10). Once germling cells did emerge, however, water temperatures were warming rapidly and growth could exceed loss - the average temperature of the pre-bloom period was $4.6^{\circ} \mathrm{C}( \pm 0.5)$ (Fig. $\left.6 \mathrm{~b}\right)$. Thus, the system was dominated by new cells from germination for only 14 days before being overtaken by net cells from division on 20 March 2011 (Fig. 9b). Despite 2011 being a cold anomaly year, the timing of bloom initiation was only slightly later than the average and the bloom reached a high magnitude (Table 2).

In contrast, in 2014, the temperature regime following the onset of quiescence was punctuated by brief warm temperature excursions (Fig. 10). This pre-bloom period had an average temperature of $2.7^{\circ} \mathrm{C}( \pm 1.6)$ and lasted a full 80 days (Fig. $\left.6 \mathrm{~b}\right)$. During this time, there were dispersed germination pulses where germling cells were met with temperatures unfavorable for division. Thus growth was unable to counter losses for a long period of time, which resulted in the latest predicted bloom initiation: 6 April. Further, temperatures remained anomalously cold through April and May $\left(-1.7^{\circ} \mathrm{C} \pm 1.5\right)$ (Fig. 3), which would have slowed bloom development. This may be a reason for why the observed bloom timing in 2014 in Salt Pond had the smallest magnitude of any of the other blooms in this study $\left(3.35 \times 10^{3}\right.$ cells $\left.\mathrm{L}^{-1}\right)$. 
These results demonstrate that in Nauset, the onset of quiescence has no bearing on when bloom initiation occurs. Instead, the timing of bloom development hinges on how rapidly temperatures are warming once germling cells emerge so that growth exceeds loss quickly. Thus, the ideal conditions for an early bloom of high magnitude in Nauset would occur as follows. The late fall and early winter would be particularly cold, which would lead to an early onset of quiescence for the cyst seedbed (e.g. late December). This would be followed by rapidly warming temperatures, so that once germling cells emerged, growth could exceed loss quickly. Complications that would impede extremely early blooms (e.g. February), would include lack of water column stratification and high losses due to advection from winter storms, as well as low light levels. The earliest blooms documented in this study reached their peaks in early April in 2012 and 2016 (Fig. 2), but it is possible that blooms could occur even earlier with earlier seasonally warming temperatures. Further, a cold winter and spring does not necessarily mean that a bloom will be small, although it will likely occur later. In a winter with particularly cold temperatures that inhibit germination for a few months following the onset of quiescence, as long as germling cells emerge into rapidly warming temperature conditions (allowing growth to rapidly overtake loss), the bloom will still reach a high magnitude (e.g. 2011 and 2015). However, if temperature conditions in the spring do not ever reach a point of rapid warming, bloom development would be expected to be stunted, much like what occurred in 2014.

\section{Possible role of dormancy on bloom phenology in a habitat with warmer temperatures}

The presence of chilling-alleviated dormancy in an A. catenella cyst population in a coastal embayment with a milder temperature regime was assessed through a modeling experiment with Quartermaster Harbor (QMH) in Puget Sound. QMH has a dampened temperature seasonality with minimal interannual temperature variability (Fig. 11b). A. catenella bloom phenology in QMH is very different from Nauset in that vegetative cells are present in the water column from April through November, which suggests the presence of multiple blooms (Fig. 11a). The model was initiated in October as this is when cell abundances decrease and when temperatures are at a seasonal maximum, so chilling accumulation would be slowest. Unlike Nauset, in QMH, there was no buffer between the predicted onset of quiescence and bloom initiation for any of the model parameterizations. Instead, immediately after cysts became quiescent, they germinated, 
and rapidly divided because temperatures were very warm (Fig. 11a). A higher loss rate than the one used in this model may yield a slight gap between the onset of quiescence and bloom initiation. Even so, the temperatures that support high rates of germination and division yearround, suggest that cyst quiescence has a more important role in the timing of bloom initiation in this habitat.

The observed A. catenella cell abundance in QMH was best predicted by the model parameterization with the highest chilling requirement (Fig. 11a). Additionally, the High parameterization's predicted onset of quiescence in late March appeared to roughly coincide with the results of a germination study using natural $A$. catenella cysts from QMH. Moore et al. (2015) documented the highest germination percentages from April through September. The consistency between the timing of germination and cell abundance from observations and predictions suggests that $A$. catenella cysts in Puget Sound may have a similar mechanism of chilling dormancy control but it is likely parameterized differently.

Similarly, it is likely that $A$. catenella across habitats with unique temperature regimes would be adapted to different chilling thresholds. For example, QMH cysts would be expected to have a different chilling requirement and threshold temperature below which cold is sensed $\left(T_{\max }\right)$. The maximum average temperature attained in the bottom waters of QMH is $12^{\circ} \mathrm{C}$ (Fig. $11 \mathrm{~b}$ ), so the ability to respond to temperatures above this would not necessarily be ecologically advantageous. Additionally, the $T_{\max }$ plays a significant role in synchronizing the cyst seedbed which is important because the presence of $A$. catenella cells in the water column from April through November suggests the presence of multiple blooms, which all may produce cysts at different times (Fig. 11a). Thus, if QMH A. catenella had the same $15^{\circ} \mathrm{C} T_{\max }$ as Nauset $A$. catenella, each new cyst cohort would accumulate chilling and transition from dormancy to quiescence at different times. In contrast, a lower $T_{\max }$ of $10^{\circ} \mathrm{C}$ for example, would result in all new cysts beginning to accumulate chilling at the point when this $T_{\max }$ is reached in QMH - this would allow cysts to better synchronize their germination until after winter has passed. To evaluate if dormancy in QMH A. catenella cysts can be alleviated by chilling and if there is plasticity in this response, germination assays similar to those in Chapter 2 are needed. 


\section{Plasticity of chilling-alleviated dormancy and climate change implications}

This study demonstrates that the parameterization of the chilling requirement derived from laboratory studies (Chapter 2) accurately predicted the onset of quiescence and variable bloom phenology from multiple years of blooms in Nauset. Both accumulated and instantaneous environmental temperature conditions determine whether and what fraction of $A$. catenella cysts in the seedbed will germinate at a given time. Ecologically, dormancy-breaking by chilling is significant because it prevents precocious emergence in the autumn and early winter when conditions cannot support dense blooms. Synchronized germination after winter chilling promotes an efficient conversion from the cyst seedbed to the spring bloom inoculum.

Chilling-alleviated dormancy elucidates a mechanism by which A. catenella and other dinoflagellates from different temperature regimes and habitats match excystment timing to their environment, thereby maximizing bloom potential. To examine if $A$. catenella from the deep cyst seedbeds of the Gulf of Maine - a colder habitat than Nauset and with different bloom timing also respond to chilling, I exposed clutches of cysts to long-term storage at $2^{\circ} \mathrm{C}, 6^{\circ} \mathrm{C}$, and $11^{\circ} \mathrm{C}$ (the ambient temperature when samples were collected in the GOM). Excitingly, the colder the treatment, the earlier that dormancy was broken, demonstrating that this GOM A. catenella also have a chilling requirement (see Chapter 5 for complete experiment). Importantly, GOM cysts transitioned from dormancy to quiescence approximately 1 month later than Nauset cysts and seem to have a different threshold temperature below which chilling is accumulated $\left(T_{\max }\right)$. Thus there is likely plasticity in the parameterization of the chilling requirement that reflects the temperature regime of each habitat.

The mechanism of dormancy control described in this study may also be present in other dinoflagellate species, including those in warmer climates. One example is Pyrodinium bahamase, which also causes PSP outbreaks but occurs predominantly at low latitudes in the tropics (e.g. Usup et al. 2012). I hypothesize that dormancy transitions in P. bahamase cysts may also be sensitive to chilling, but the threshold temperature $\left(T_{\max }\right)$ below which chilling would be accumulated, would be warmer to reflect their habitat. One example is the population of $P$. bahamase in Old Tampa Bay Florida. Given that $15^{\circ} \mathrm{C}$ is the coldest seasonal temperature there, $P$. bahamase in this habitat may have a higher $T_{\max }$, such as $20^{\circ} \mathrm{C}$. Unpublished results from a 
long-term storage experiment by Cary Lopez (Florida Fish and Wildlife Conservation Commission) found that dormancy was broken faster for $P$. bahamase cysts exposed to $15^{\circ} \mathrm{C}$ compared to $30^{\circ} \mathrm{C}$. This ability to sense "winter" (an extended period of seasonally low temperatures), would enable $P$. bahamase to track the time of year, and thus ensure germination only occurs during periods with the greatest potential for bloom formation. This result suggests that chilling-alleviated dormancy may be universal for many dinoflagellates across habitats.

In Nauset, when germling cells emerge, temperatures are typically too cold to support division. Thus, the timing of bloom initiation is driven by the occurrence of warm temperatures that allow growth to overtake loss; therefore, in years with warmer winters and springs, bloom development will begin earlier. Climate change will likely lead to more anomalously warm years like 2012 and 2016. This suggests that the Nauset cyst seedbed will have a delayed onset of quiescence ( $\sim$ mid-January), but shortly after, germling cells will emerge and grow rapidly, leading to earlier blooms. Net cells from division exceeded those from germination the earliest in 2012 and 2016: late February. In a climate warming scenario, warmer temperatures could occur even earlier, which would lead to growth overtaking loss earlier and thus even earlier blooms.

Chilling-alleviated dormancy may also have more influence on bloom initiation in habitats with warmer year-round temperatures than Nauset because immediately after cysts become quiescent they could germinate and rapidly divide. A possible response to climate warming in this situation would be slower chilling accumulation, which would delay quiescence and bloom initiation. Notably, this hypothesis is at odds with the climate warming hypothesis posed by Moore et al. (2008) which predicts longer windows of $A$. catenella growth opportunities (an extrapolation from growth rates increasing linearly with temperatures), and therefore earlier blooms. The authors do however acknowledge that other biotic factors can override this concept.

One such factor is that the chilling requirement will be unaffected by a warming climate due to the heterogeneity of the cyst seedbed. This is because the seedbed constitutes a species reservoir of genetic diversity (e.g. Alpermann et al. 2009) and may contain viable cysts up to 100 years old (Miyazono et al. 2012). Germination behavior of cyst populations is normally distributed so there are cysts that germinate much earlier and much later. An important assumption underlying 
this alternative hypothesis is that only a few cysts need to germinate to yield a bloom. Cysts that are eventually formed from blooms derived from these early and late germinations may have new thermal requirements, allowing the regional populations to adapt. Therefore, to make predictions of how $A$. catenella and other cyst-forming HABs may respond to climate changeinduced warming, it is important to consider life cycle transitions in the context of the natural environment and the relationship each stage has with temperature.

\section{REFERENCES}

Alpermann, T. J., B. Beszteri, U. John, U. Tillmann, and A. D. Cembella. 2009. Implications of life-history transitions on the population genetic structure of the toxigenic marine dinoflagellate Alexandrium tamarense. Molecular Ecology 18: 2122-2133. doi:10.1111/j.1365-294X.2009.04165.x

Anderson, D. M. 1980. Effects of Temperature Conditioning on Development and Germination of Gonyaulax tamarensis (Dinophyceae) Hypnozygotes. Journal of Phycology 16: 166-172.

Anderson, D. M., A. D. Cembella, and G. M. Hallegraeff. 2014. Progress in Understanding Harmful Algal Blooms: Paradigm Shifts and New Technologies for Research, Monitoring, and Management. Annual Review of Marine Science 4: 143-176. doi:10.1146/annurevmarine-120308-081121

Anderson, D. M., and B. Keafer. 1987. An endogenous annual clock in the toxic marine dinoflagellate Gonyaulax tamarensis. Nature 325: 616-617.

Anderson, D. M., and F. M. M. Morel. 1979. The Seeding of two Red Tide Blooms by the Germination of Benthic Gonyaulax tamarensis Hypnocysts. Estuarine and Coastal Marine Science 8: 279-293. doi:10.1016/0302-3524(79)90098-7

Anderson, D. M., and K. D. Stolzenbach. 1985. Selective retention of two dinoflagellates in a well-mixed estuarine embayment: The importance of diel vertical migration and surface avoidance. Marine Ecology Progress Series 25: 39-50.

Anderson, D. M., and K. Rengefors. 2006. Community assembly and seasonal succession of marine dinoflagellates in a temperate estuary: The importance of life cycle events. Limnology and Oceanography 51: 860-873.

Anderson, D. M., C. A. Stock, B. Keafer, and others. 2005. Alexandrium fundyense cyst dynamics in the Gulf of Maine. Deep Sea Research II 52: 2522-2542. doi:10.1016/j.dsr2.2005.06.014

Anderson, D. M., C. D. Taylor, and E. V. Armbrust. 1987. The effects of darkness and anaerobiosis on dinoflagellate cyst germination. Limnology and Oceanography 32: 340-351.

Anderson, D. M., S. W. Chisholm, and C. J. Watras. 1983. Importance of life cycle events in the population dynamics of Gonyaulax tamarensis. Marine Biology 76: 179-189. 
doi:10.1007/BF00392734

Anderson, D. M., T. J. Alpermann, A. D. Cembella, Y. Collos, E. Masseret, and M. Montresor. 2012. The globally distributed genus Alexandrium: Multifaceted roles in marine ecosystems and impacts on human health. Harmful Algae 14: 10-35. doi:10.1016/j.hal.2011.10.012

Arora, R., L. J. Rowland, and K. Tanino. 2003. Induction and release of bud dormancy in woody perennials: a science comes of age. HortScience.

Bravo, I., and D. M. Anderson. 1994. The effects of temperature, growth medium and darkness on excystment and growth of the toxic dinoflagellate Gymnodinium catenatum from northwest Spain. Journal of Plankton Research 16: 513-525. doi:10.1093/plankt/16.5.513

Brosnahan, M. L., D. K. Ralston, A. D. Fischer, A. R. Solow, and D. M. Anderson. Estimation of benthic cyst yield from a bloom of the toxic dinoflagellate Alexandrium catenella reveals shoaling of diel vertical migration and sediment infiltration by its cyst precursor stage. Limnology and Oceanography. In revision.

Brosnahan, M. L., L. V. Suárez, D. K. Ralston, and others. 2015. Rapid growth and concerted sexual transitions by a bloom of the harmful dinoflagellate Alexandrium fundyense (Dinophyceae). Limnology and Oceanography 60: 2059-2078. doi:10.1002/lno.10155

Butman, B., A. L. Aretxabaleta, P. J. Dickhudt, P. S. Dalyander, C. R. Sherwood, D. M. Anderson, B. A. Keafer, and R. P. Signell. 2014. Investigating the importance of sediment resuspension in Alexandrium fundyense cyst population dynamics in the Gulf of Maine. Deep Sea Research Part II 103: 79-95. doi:10.1016/j.dsr2.2013.10.011

Colman, J. A., and J. P. Masterson. 2008. Transient Simulations of Nitrogen Load for a Coastal Aquifer and Embayment, Cape Cod, MA. Environ. Sci. Technol. 42: 207-213. doi:10.1021/es070638b

Crespo, B. G., B. A. Keafer, D. K. Ralston, H. Lind, D. Farber, and D. M. Anderson. 2011. Dynamics of Alexandrium fundyense blooms and shellfish toxicity in the Nauset Marsh System of Cape Cod (Massachusetts, USA). Harmful Algae 12: 26-38. doi:10.1016/j.hal.2011.08.009

Genovesi, B., M. Laabir, E. Masseret, A. Vaquer, and D. Grzebyk. 2009. Dormancy and germination features in resting cysts of Alexandrium tamarense species complex (Dinophyceae) can facilitate bloom formation in a shallow lagoon (Thau, southern France). Journal of Plankton Research 31: 1209-1224. doi:10.1093/plankt/fbp066

Giblin, A. E., and A. G. Gaines. 1999. Nitrogen inputs to a marine embayment: the importance of groundwater. Biogeochemistry 10: 309-328.

Greengrove, C. L., J. E. Masura, S. K. Moore, and others. 2014. Alexandrium catenella cyst distribution and germination in Puget Sound, WA USA. Proceedings of the 15 th International Conference on Harmful Algae. Harmful Algae.

Guillard, R. L., and J. H. Ryther. 1962. Studies of Marine Planktonic Diatoms. Canadian Journal of Microbiology 8: 229-239.

Hallegraeff, G. M. 1993. A review of harmful algal blooms and their apparent increase. Phycologia 32: 79-99. 
Horner, R. A., C. L. Greengrove, K. S. Davies-Vollum, J. E. Gawel, J. R. Postel, and A. M. Cox. 2011. Spatial distribution of benthic cysts of Alexandrium catenella in surface sediments of Puget Sound, Washington, USA. Harmful Algae 11: 96-105. doi:10.1016/j.hal.2011.08.004

Horvath, D. P., J. V. Anderson, W. S. Chao, and M. E. Foley. 2003. Knowing when to grow: signals regulating bud dormancy. Trends in Plant Science 8: 534-540.

doi:10.1016/j.tplants.2003.09.013

Jann, R. C., and R. D. Amen. 1977. What is germination? p. 157-178. In A.A. Khan [ed.], The Physiology and Biochemistry of Seed Dormancy and Germination.

Kremp, A., and D. M. Anderson. 2000. Factors regulating germination of resting cysts of the spring bloom dinoflagellate Scrippsiella hangoei from the northern Baltic Sea. Journal of Plankton Research 22: 1311-1327. doi:10.1093/plankt/22.7.1311

Luedeling, E., M. Zhang, and E. H. Girvetz. 2009. Climatic Changes Lead to Declining Winter Chill for Fruit and Nut Trees in California during 1950-2099. PLoS ONE 4: 1-9. doi:10.1371/journal.pone.0006166

Matrai, P., B. Thompson, and M. Keller. 2005. Circannual excystment of resting cysts of Alexandrium spp. from eastern Gulf of Maine populations. Deep Sea Research Part II 52: 2560-2568. doi:10.1016/j.dsr2.2005.06.013

Miyazono, A., S. Nagai, I. Kudo, and K. Tanizawa. 2012. Viability of Alexandrium tamarense cysts in the sediment of Funka Bay, Hokkaido, Japan: Over a hundred year survival times for cysts. Harmful Algae 16: 81-88. doi:10.1016/j.hal.2012.02.001

Moore, S. K., B. D. Bill, L. R. Hay, J. Emenegger, K. C. Eldred, C. L. Greengrove, J. E. Masura, and D. M. Anderson. 2015. Factors regulating excystment of Alexandrium in Puget Sound, WA, USA. Harmful Algae 43: 103-110. doi:10.1016/j.hal.2015.01.005

Moore, S. K., N. J. Mantua, B. M. Hickey, and V. L. Trainer. 2009. Recent trends in paralytic shellfish toxins in Puget Sound, relationships to climate, and capacity for prediction of toxic events. Harmful Algae 8: 463-477. doi:10.1016/j.hal.2008.10.003

Moore, S. K., V. L. Trainer, N. J. Mantua, M. S. Parker, E. A. Laws, L. C. Backer, and L. E. Fleming. 2008. Impacts of climate variability and future climate change on harmful algal blooms and human health. Environ Health 7: 24-27. doi:10.1186/1476-069X-7-S2-S4

Paerl, H. W., and J. Huisman. 2008. Blooms Like It Hot. Science 320: 57-58. doi:10.1126/science. 1155398

Penfield, S., and V. Springthorpe. 2012. Understanding chilling responses in Arabidopsis seeds and their contribution to life history. Philosophical Transactions of the Royal Society B: Biological Sciences 367: 291-297. doi:10.1098/rstb.2011.0186

Petitpas, C. M., J. T. Turner, B. A. Keafer, D. J. McGillicuddy, and D. M. Anderson. 2015. Zooplankton community grazing impact on a toxic bloom of Alexandrium fundyense in the Nauset Marsh System, Cape Cod, Massachusetts, USA. Harmful Algae 47: 42-55. doi:10.1016/j.hal.2015.05.010

Ralston, D. K., B. A. Keafer, M. L. Brosnahan, and D. M. Anderson. 2014. Temperature dependence of an estuarine harmful algal bloom: Resolving interannual variability in bloom dynamics using a degree-day approach. Limnology and Oceanography 59: 1112-1126. 
doi:10.4319/1o.2014.59.4.1112

Ralston, D. K., M. L. Brosnahan, S. E. Fox, K. Lee, and D. M. Anderson. 2015. Temperature and Residence Time Controls on an Estuarine Harmful Algal Bloom: Modeling Hydrodynamics and Alexandrium fundyense in Nauset Estuary. Estuaries and Coasts 38: 2240-2258. doi:10.1007/s12237-015-9949-z

Rathaille, A. N., and R. Raine. 2011. Seasonality in the excystment of Alexandrium minutum and Alexandrium tamarense in Irish coastal waters. Harmful Algae 10: 629-635. doi:10.1016/j.hal.2011.04.015

Rengefors, K., and D. M. Anderson. 1998. Environmental and endogenous regulation of cyst germination in two freshwater dinoflagellates. Journal of Phycology 34: 568-577.

Rohde, A., and R. P. Bhalerao. 2007. Plant dormancy in the perennial context. Trends in Plant Science 12: 217-223. doi:10.1016/j.tplants.2007.03.012

Stock, C. A., D. J. McGillicuddy Jr, A. R. Solow, and D. M. Anderson. 2005. Evaluating hypotheses for the initiation and development of Alexandrium fundyense blooms in the western Gulf of Maine using a coupled physical-biological model. Deep Sea Research Part II 52: 2715-2744. doi:10.1016/j.dsr2.2005.06.022

Tester, P. A., R. L. Feldman, A. W. Nau, S. R. Kibler, and R. W. Litaker. 2014. Ciguatera fish poisoning and sea surface temperatures in the Caribbean Sea and the West Indies. Toxicon 56: 698-710. doi:10.1016/j.toxicon.2010.02.026

Usup, G., A. Ahmad, K. Matsuoka, P. T. Lim, and C. P. Leaw. 2012. Biology, ecology and bloom dynamics of the toxic marine dinoflagellate Pyrodinium bahamense. Harmful Algae 14: 301-312. doi:10.1016/j.hal.2011.10.026

Vahtera, E., B. G. Crespo, D. J. McGillicuddy, K. Olli, and D. M. Anderson. 2014. Alexandrium fundyense cyst viability and germling survival in light vs. dark at a constant low temperature. Deep-Sea Research Part II 103: 112-119. doi:10.1016/j.dsr2.2013.05.010

Watras, C. J., S. W. Chisholm, and D. M. Anderson. 1982. Regulation of Growth in an Estuarine Clone of Gonyaulax tamarensis Lebour: Salinity-Dependent Temperature Responses. Journal of Experimental Marine Biology and Ecology 62: 25-37. doi:10.1016/00220981(82)90214-3 


\section{TABLES AND FIGURES}

Table 1. Bloom initiation model parameters.

\begin{tabular}{|c|c|c|c|}
\hline $\begin{array}{l}\text { Paramete } \\
\mathrm{r}\end{array}$ & Units & Values & Description \\
\hline$T_{\max }$ & ${ }^{\circ} \mathrm{C}$ & 15 & $\begin{array}{l}\text { Upper threshold temperature for chilling } \\
\text { accumulation }\end{array}$ \\
\hline$R$ & $C U$ & $\begin{array}{l}0,400,800 \\
1200\end{array}$ & Chilling requirement \\
\hline$k$ & $\% C U^{-1}$ & 0.004 & Slope of the dormancy-quiescence function \\
\hline$G R$ & $\%$ day $^{-1}$ & $0-0.07$ & Germination rate \\
\hline$T_{b}$ & ${ }^{\circ} \mathrm{C}$ & 2 & $\begin{array}{l}\text { Base temperature at which the germination rate is } \\
\text { zero }\end{array}$ \\
\hline$\theta$ & ${ }^{\circ} \mathrm{Cd}$ & 1.16 & Thermal time constant of the germination rate \\
\hline$\mu$ & day $^{-1}$ & $0-0.5$ & Division rate \\
\hline$l$ & day $^{-1}$ & 0.1 & Loss rate \\
\hline
\end{tabular}


Table 2. Relationship between the winter-spring temperature anomaly, the maximum chilling possible, the predicted timing of quiescence and bloom initiation, and the observed maximum cell concentration for bloom seasons 2009 through 2016. The model predictions using the laboratory-derived chilling requirement $(R=800 \mathrm{CU})$ are shown here. The date of bloom initiation was determined as when the net cumulative cells from division exceeds the net cumulative cells from germination. Observed maximum cell abundance are depth-averaged from weekly surveys.

\begin{tabular}{ccccc}
\hline & $\begin{array}{c}\text { Maximum } \\
\text { Chilling } \\
\text { Possible }(C U)\end{array}$ & $\begin{array}{c}\text { Predicted } \\
\text { Quiescence } \\
\text { Onset (date) }\end{array}$ & $\begin{array}{c}\text { Predicted } \\
\text { Bloom } \\
\text { Initiation } \\
\text { (date) }\end{array}$ & $\begin{array}{c}\text { Observed } \\
\text { Maximum } \\
\text { Cells L }\end{array}$ \\
\hline $\mathbf{2 0 0 9}$ & 1809 & 31 Dec. & 17 Mar. & $1.09 \times 10^{5}$ \\
$\mathbf{2 0 1 0}$ & 1479 & 03 Jan. & 07 Mar. & $5.63 \times 10^{5}$ \\
$\mathbf{2 0 1 1}$ & 1894 & 30 Dec. & 20 Mar. & $9.30 \times 10^{4}$ \\
$\mathbf{2 0 1 2}$ & 1367 & 15 Jan. & 28 Feb. & $1.04 \times 10^{5}$ \\
$\mathbf{2 0 1 3}$ & 1773 & 05 Jan. & 19 Mar. & $1.03 \times 10^{5}$ \\
$\mathbf{2 0 1 4}$ & 1985 & 26 Dec. & 06 Apr. & $3.35 \times 10^{3}$ \\
$\mathbf{2 0 1 5}$ & 1929 & 05 Jan. & 06 Apr. & $1.10 \times 10^{5}$ \\
$\mathbf{2 0 1 6}$ & 1559 & 13 Jan. & 26 Feb. & $6.94 \times 10^{5}$ \\
\hline
\end{tabular}



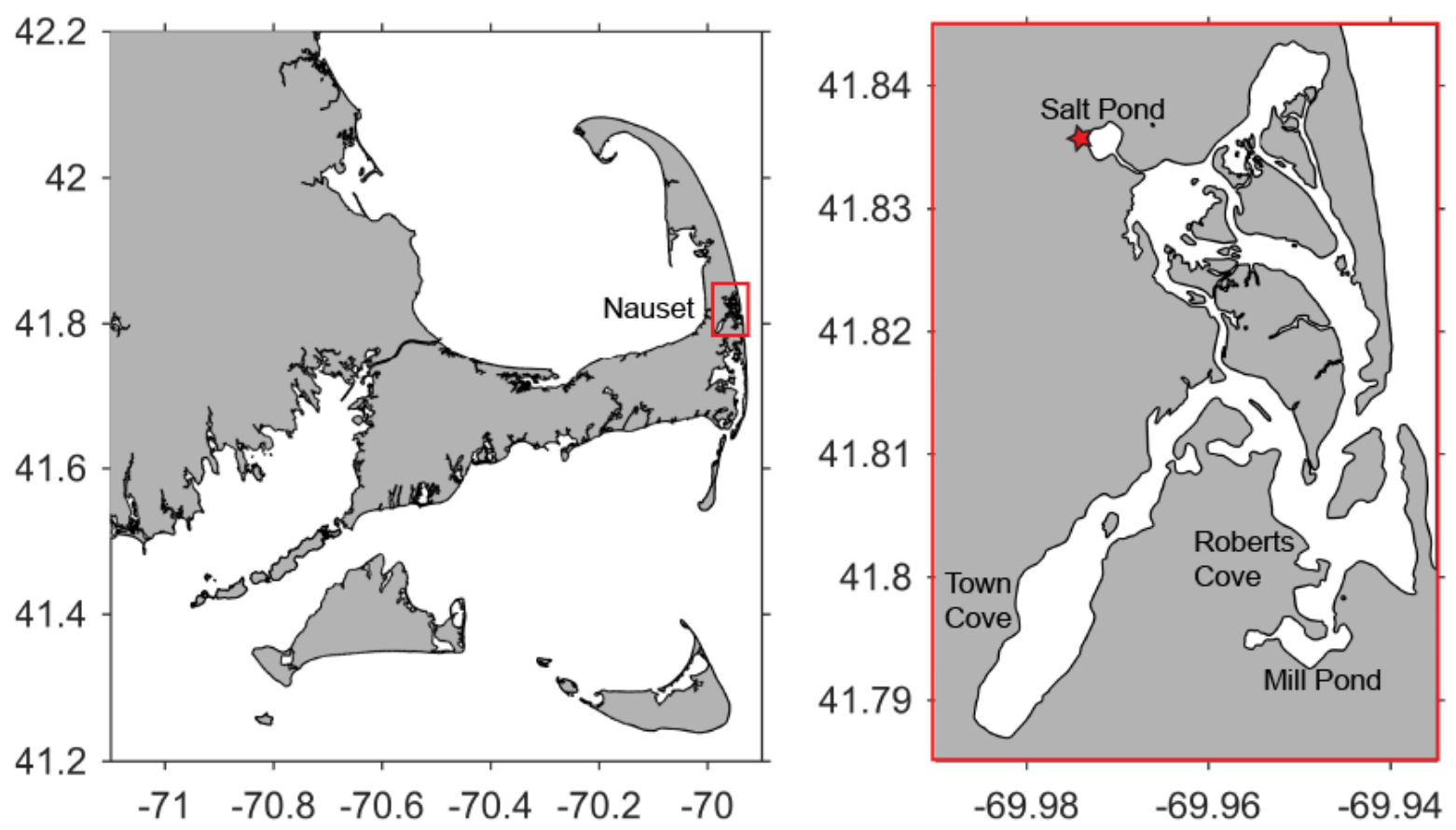

Fig. 1. Location of the Nauset Marsh on Cape Cod, MA. A shallow central marsh area connects Salt Pond to the Atlantic Ocean via a narrow inlet while also isolating its $A$. catenella blooms. 

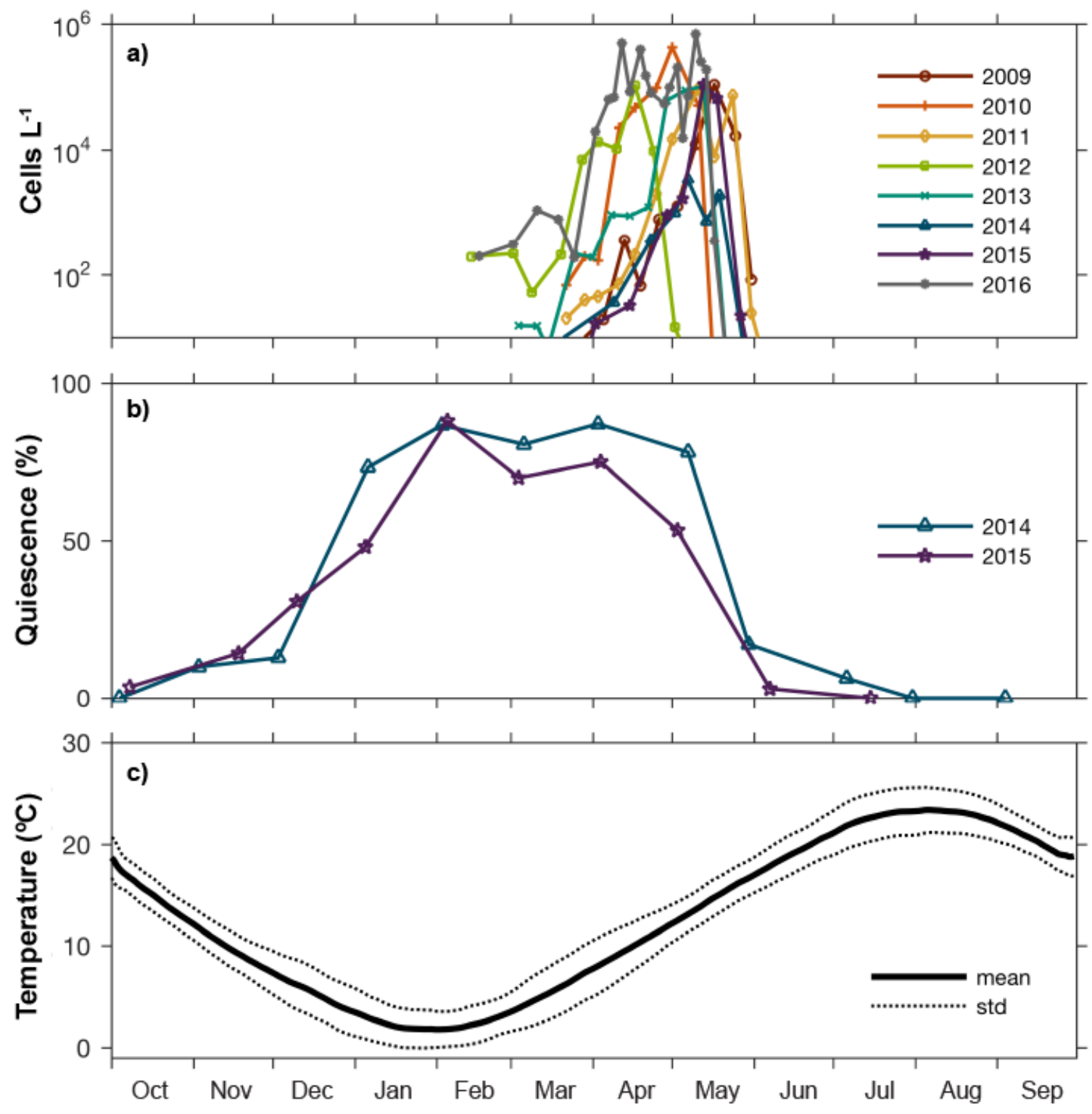

Fig. 2. Observed annual variation in Nauset of (a) A. catenella blooms, (b) cyst quiescence, and (c) temperature. A. catenella cell concentrations are depth-averaged and from weekly surveys each spring from 2009 through 2016 - large blooms do not occur at other times of the year. The seasonal quiescence status of the cyst seedbed was determined from October 2013 through July 2015 by collecting natural cyst populations monthly and measuring the percentage germination after one week under favorable conditions. The smoothed mean and standard deviation of bottom water temperatures are from October 2008 through September 2016. 


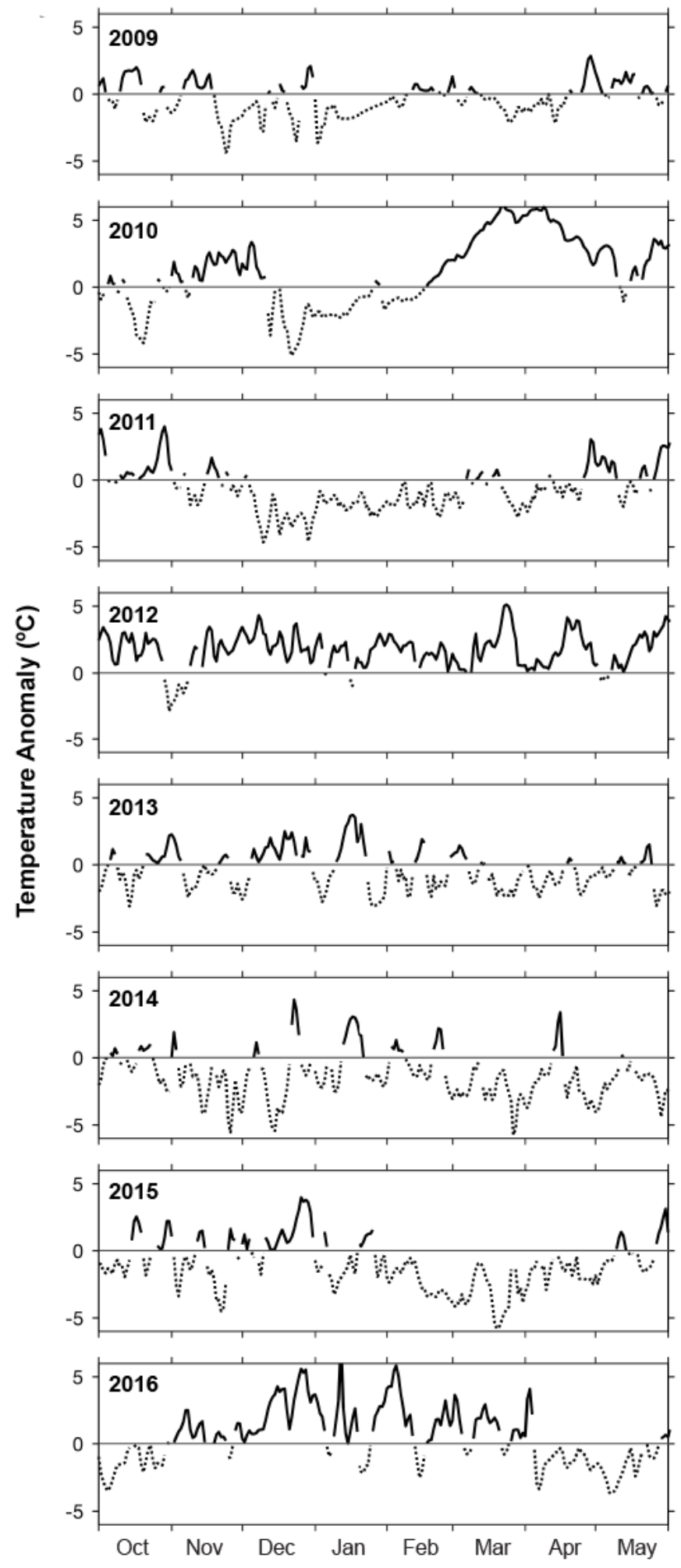

Fig. 3. Daily temperature anomaly for the period preceding and during the spring blooms of 2009-2016. The daily anomaly was determined from the deviation from the daily mean temperature for each of the study years. 

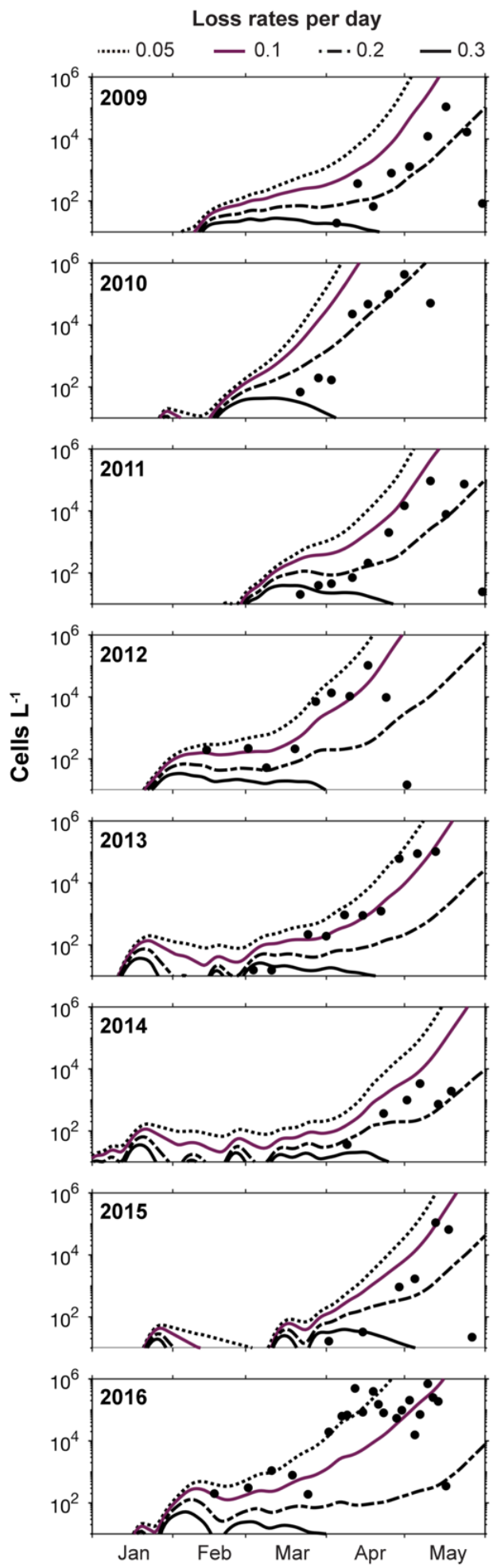

Fig. 4. Testing the effect of constant daily loss rates on the predicted $A$. catenella cell abundance (solid lines) in comparison to the observed (filled circles) for the 2009-2016 spring blooms in Salt Pond. The formulation of the model here is with the laboratory-derived dormancy parameterization $(R=800 C U)$. Both observed and predicted cell abundances are depthaveraged. 


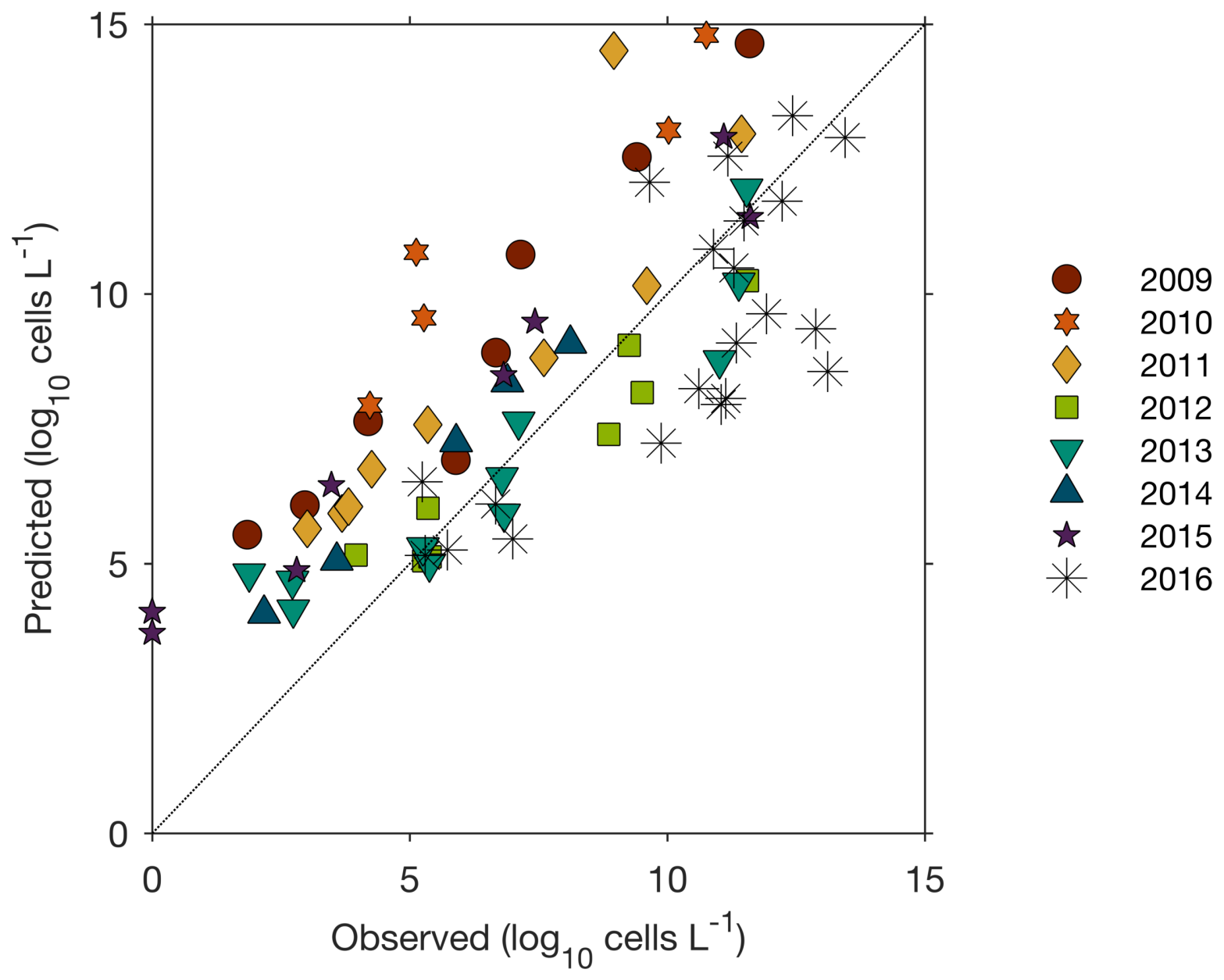

Fig. 5. Comparison of depth-averaged A. catenella cell abundance from observations and predictions using the laboratory-derived dormancy parameterization $(R=800 C U)$ with a loss rate of 0.1 day $^{-1}$. 

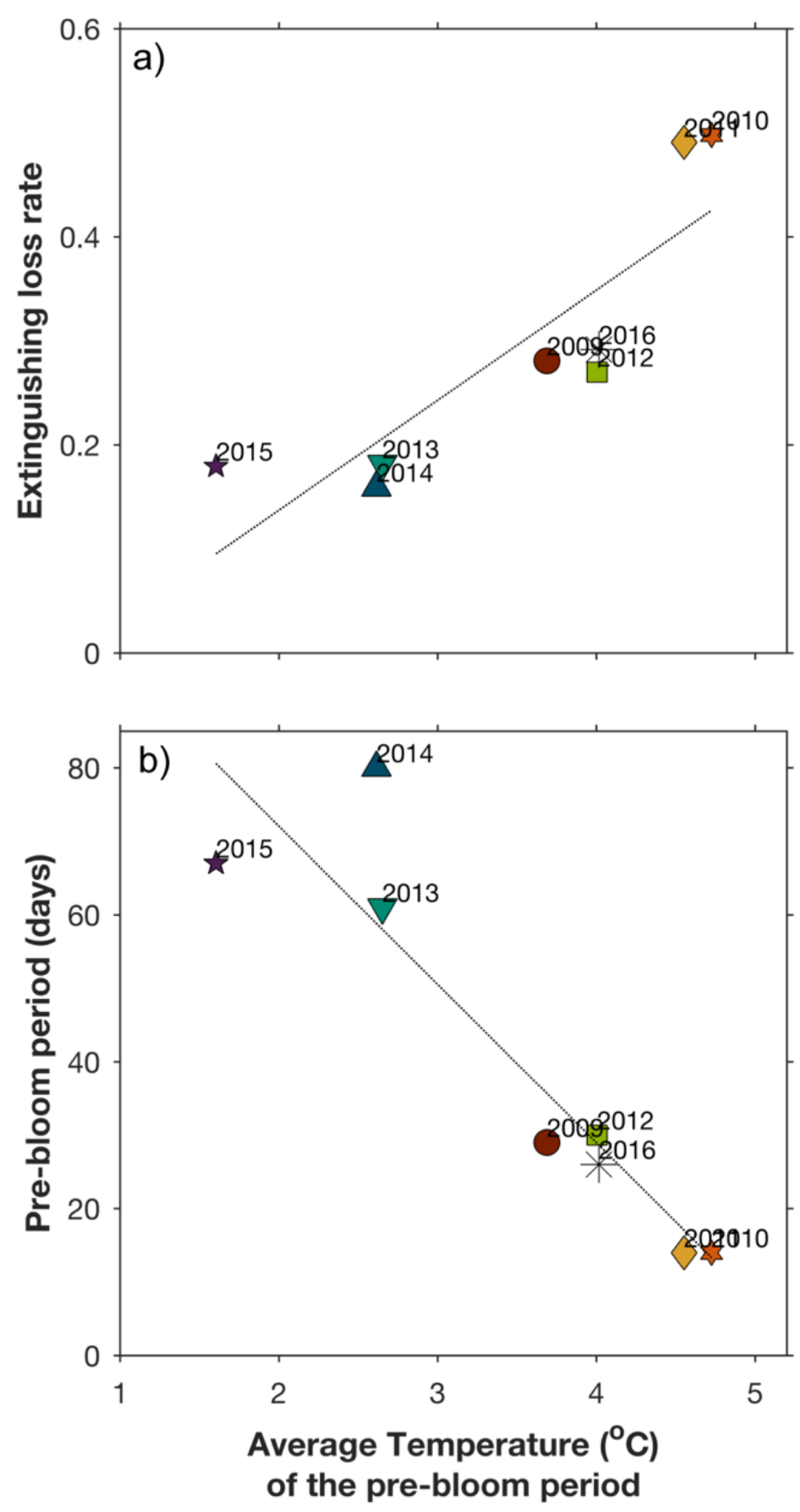

Fig. 6. Effect of the average temperature of the pre-bloom period on (a) its extinguishing loss rate and (b) its duration. The pre-bloom period is defined as the time between the first germination pulse and bloom initiation. The formulation of the model here is with the laboratoryderived dormancy parameterization $(R=800 C U)$. 


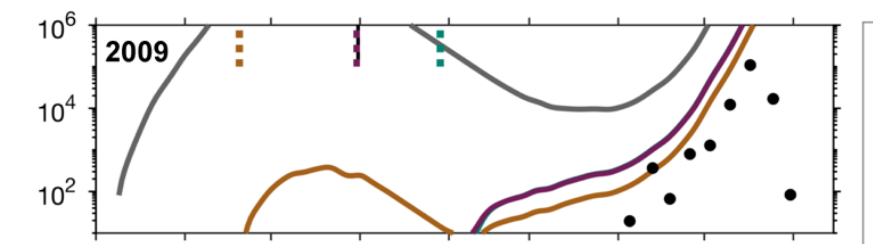

Chilling Requirement parameterizations

Zero - $0 \mathrm{CU}$

Low - $400 \mathrm{CU}$

Laboratory - $800 \mathrm{CU}$

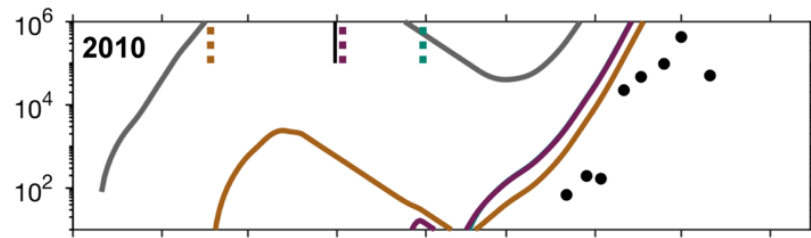

High - $1200 \mathrm{CU}$

$\square \quad$ Max chilling

Onset of Quiescence

:i: predicted

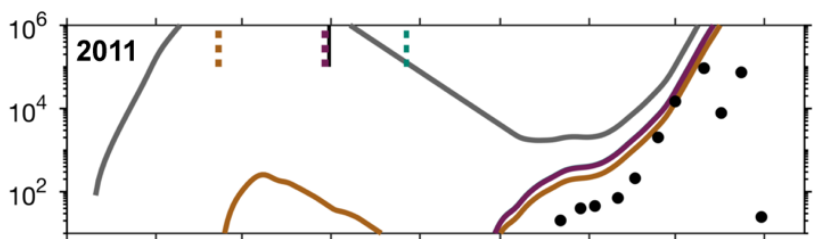

observed

Cells $\mathrm{L}^{-1}$

를 predicted

- observed
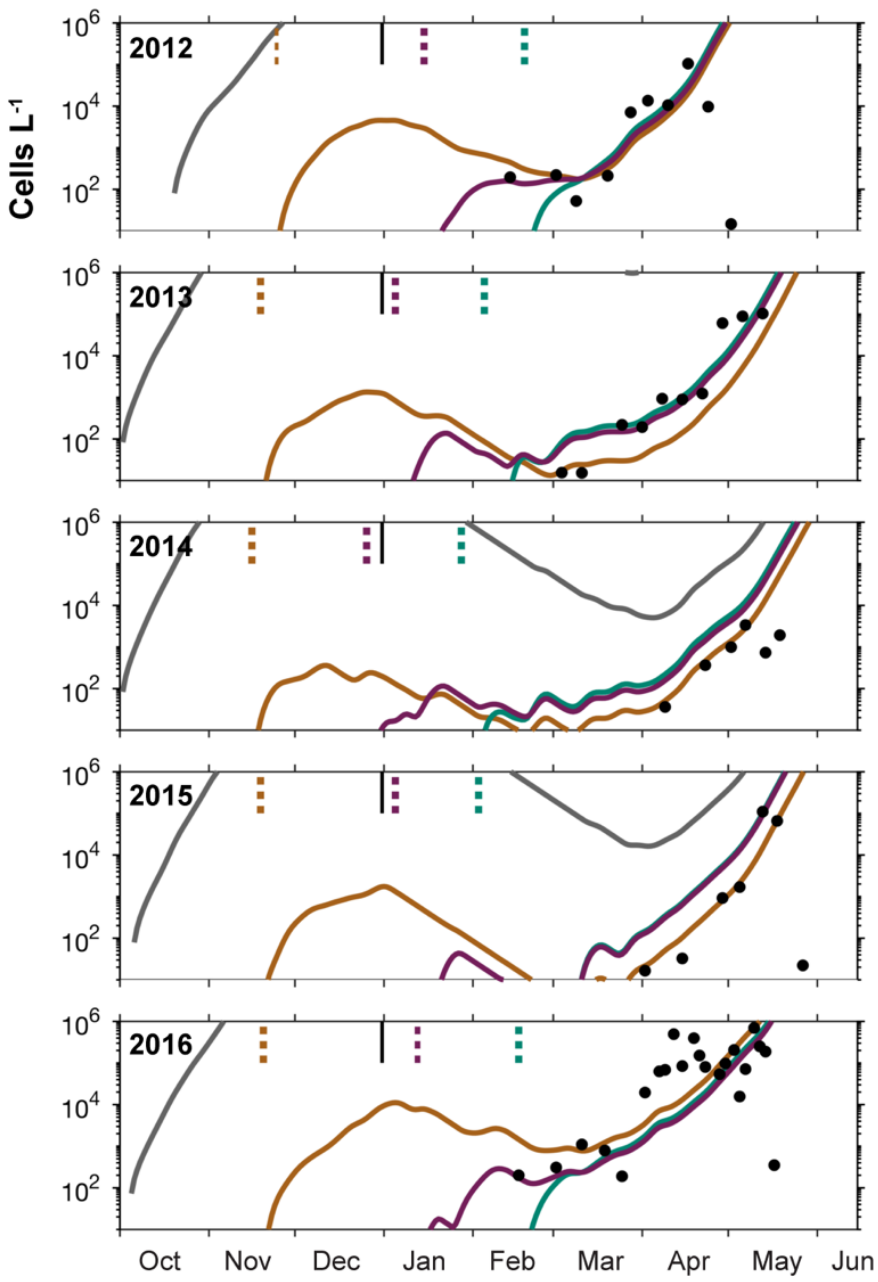

Fig. 7. Predicted depth-averaged A. catenella cell concentrations in Salt Pond for the 2009-2016 bloom seasons using different parameterizations of the chilling requirement in the dormancy transition function. Observations are depth-averaged $A$. catenella cell concentrations from weekly surveys each year. 


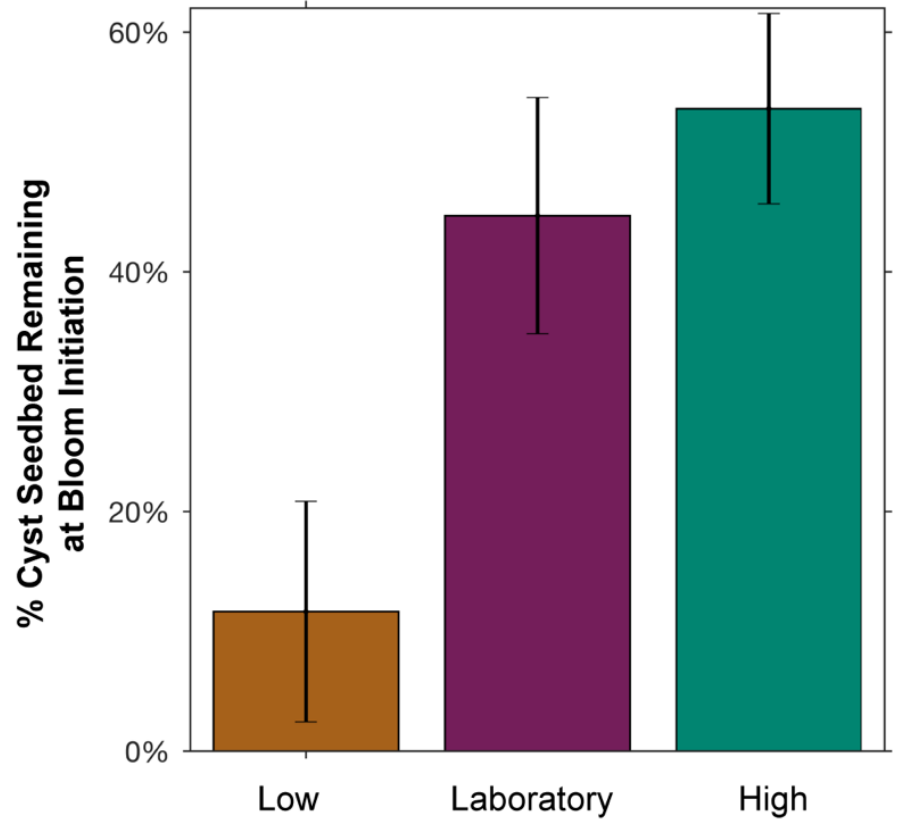

Fig. 8. Fraction of the cyst seedbed remaining at spring bloom initiation under different parameterizations of the chilling requirement. The date of bloom initiation is defined as the point at which net cumulative cells from division exceed net cumulative cells from germination.
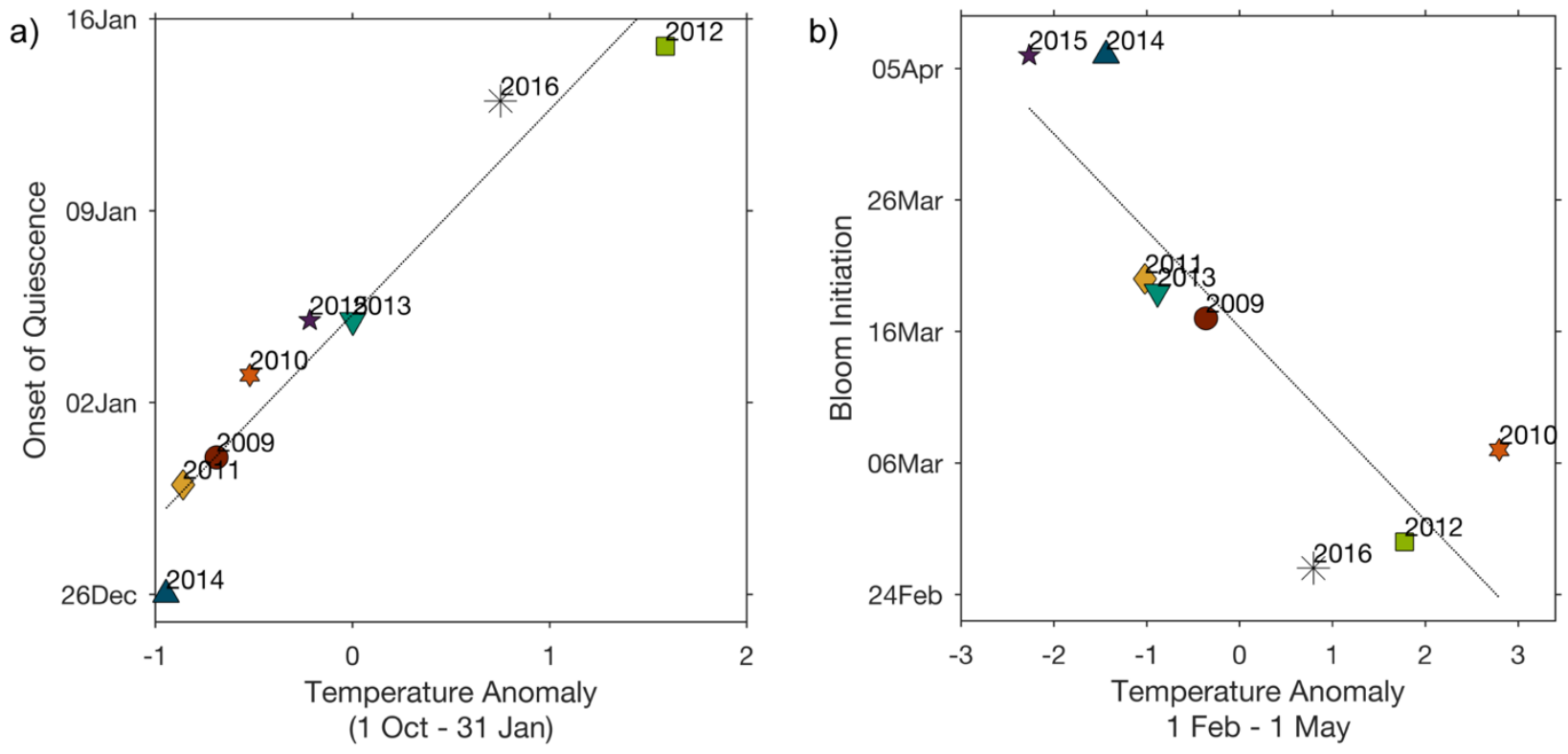

Fig. 9. Effect of temperature on (a) the onset of quiescence and (b) bloom initiation. The formulation of the model here is with the laboratory-derived dormancy parameterization $(R=$ $800 C U)$. 

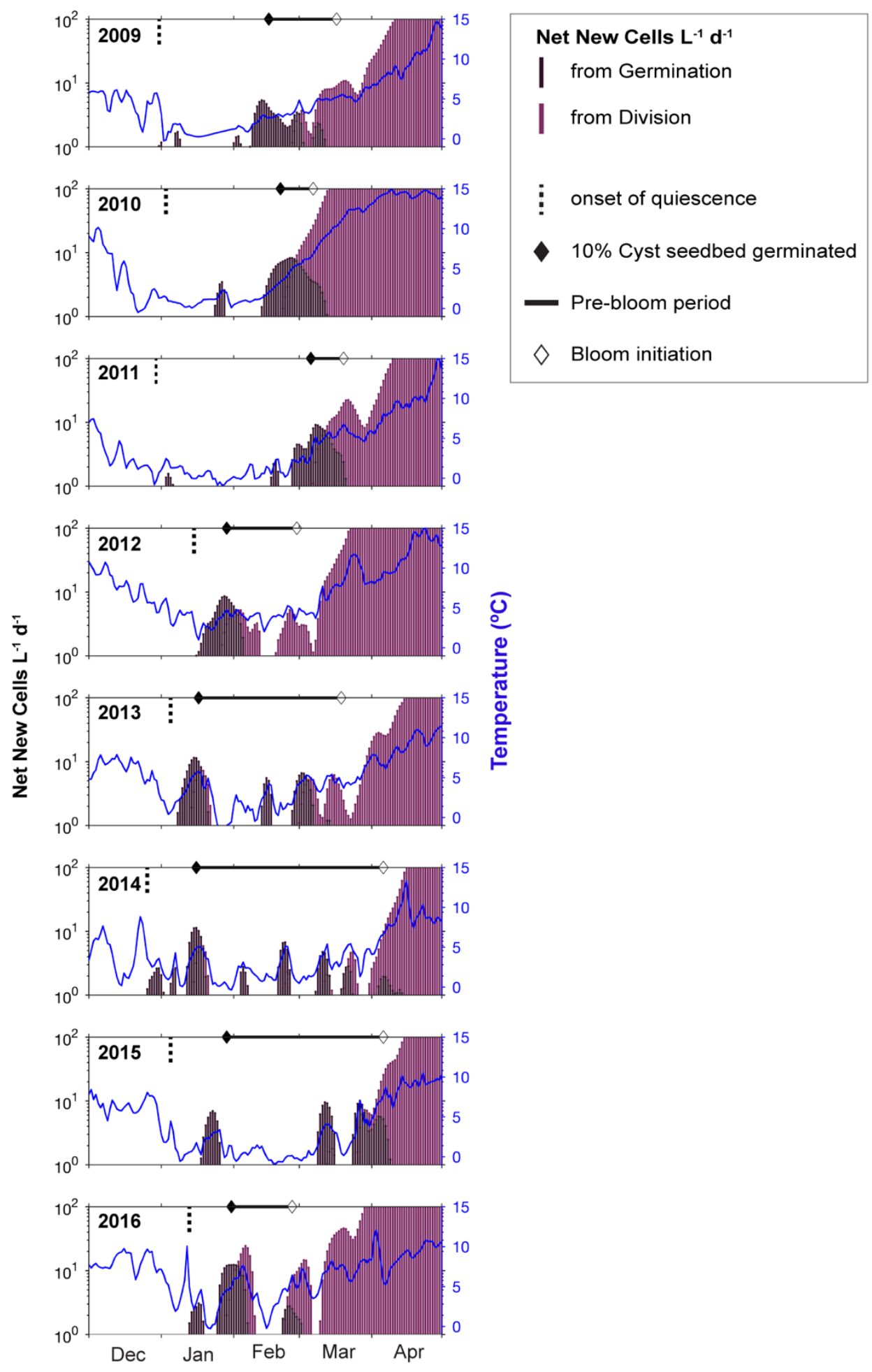

Fig. 10. Net new cells per day from germination and division for the 2009-2016 spring blooms in Salt Pond. Predicted depth-averaged cell concentrations are shown using the Laboratory parameterization $(R=800 C U)$. Bottom water temperature is overlaid to demonstrate its influence on the onset of quiescence, when $10 \%$ of the cyst seedbed germinates, and the timing of bloom initiation (when net cells from division exceeds net cells from germination). 


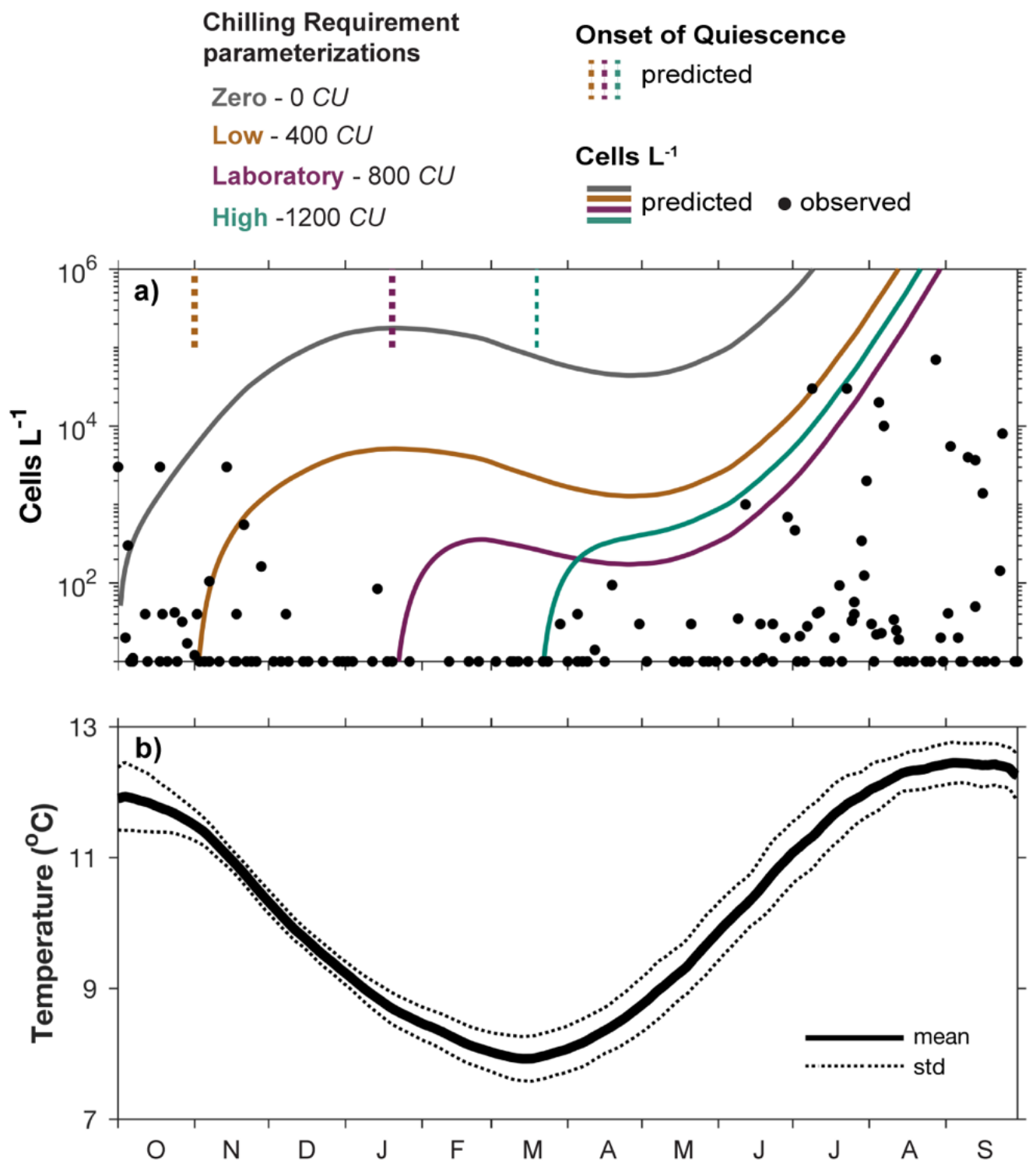

Fig. 11. Observed and predicted monthly variation from October 2010 to 2013 in Puget Sound of (a) A. catenella cell abundance and (b) mean bottom water temperature. Observed cell abundance data are provided by the SoundToxins program and all data during October 20102013 are displayed. Predicted cell abundance data are generated using the Nauset model parameterizations and the mean bottom water temperature. 


\section{Chapter 5}

\section{Summary and conclusions}

The resting cyst stage of dinoflagellates allows for the survival of individual species, as well as populations, over long periods of time (Wall 1971; Dale 1983). The defining feature of the cyst stage is dormancy: an internal state that impedes germination under otherwise adequate environmental conditions. Once the barrier imposed by dormancy is removed, germination can proceed under a wide range of environmental conditions in an internal state known as quiescence (Pfiester and Anderson 1987). The environmental factors that induce the transition from dormancy to quiescence in natural populations were previously not well understood. This thesis demonstrates that cysts of the dinoflagellate Alexandrium catenella, which causes paralytic shellfish poisoning syndrome (PSP), synchronize transitions from dormancy to quiescence with the seasons in a small estuarine embayment. Nauset Marsh on Cape Cod (MA, USA) consists of three salt ponds, each with recurrent springtime blooms that are initiated by local cyst seedbeds and cause near annual shellfishing closures due to PSP. By quantifying the duration and severity of cold, A. catenella cysts track the passage of winter and delay their quiescence until temperatures are at a seasonal minimum: January. Once germination-favorable temperatures begin, germling cells are met with increasing daylight and warming temperatures which will soon be able to support bloom development. Thus, chilling-alleviated dormancy helps avoid the mismatch between conditions that are favorable for germination but not for bloom formation that occur in the autumn and early winter in Nauset. This conceptual model of the environmental windows for A. catenella dormancy and germination significantly enriches our understanding of bloom phenology. Due to the expanding public health threat that these toxic blooms represent, there is a practical need for a quantitative understanding of these environmental controls to improve bloom prediction at present and as the climate changes. The key findings in Chapter 2, Chapter 3, and Chapter 4 leading to this conceptual model are summarized next.

Chapter 2 characterizes the mechanism underlying the seasonality of $A$. catenella cyst germination in an estuarine embayment: cysts require conditioning by chilling to become 
germinable (quiescent). Experiments were conducted to document the natural dormancy rhythm and to determine how cysts respond to the severe temperatures in the winter. The A. catenella cyst seedbed in Nauset was dormant from June through January. Much like the seeds of terrestrial plant seeds, cysts quantitatively respond to chilling, and need to surpass a chilling threshold, to transition from dormancy to quiescence. This discovery of chilling-alleviated dormancy is significant because it elucidates a mechanism by which $A$. catenella populations from different temperature regimes and habitats match excystment timing to their environment, thereby maximizing bloom potential. For decades, dinoflagellate studies in the literature have reported that chilling (often referred to as cold conditioning) improves viability and shortens the incubation time until germination for Ceratium spp. (Stosch 1967), Gymnodinium spp., Woloszynskia spp., (Stosch 1973), and Alexandrium pseudogonyaulax (Montresor and Marino 1996), but the mechanism and reason for this was unknown. Therefore, the present study's discovery of chilling as a seasonal dormancy-breaking agent represents a significant advancement in the ecophysiology of dinoflagellate cysts.

Once dormancy has been alleviated, sensitivity to the current environment, particularly to temperature, light, and oxygen, determine the rate and extent of germination of quiescent cysts; this is the focus of Chapter 3. Our knowledge of cyst ecophysiology stems predominantly from laboratory studies using constant temperatures, oxygen, and irradiance - all of which are highly variable and not always at favorable levels in the natural benthos. The emergence flux of germling cells inoculates the annual A. catenella spring bloom in Nauset Marsh (Cape Cod, MA) and in many other systems, and therefore is a vital parameter for bloom prediction. This chapter therefore asks the critical question: how representative are laboratory-derived germination rates and percentages of field emergence of $A$. catenella? The suitability of laboratory-derived germination rates and percentages to predict field emergence of $A$. catenella in the spring were evaluated in 2013, 2014, and 2015 in Nauset Marsh. Emergence and germination rates had a clear positive linear relationship with temperature between 1 and $7^{\circ} \mathrm{C}$. An interesting finding was that at temperatures higher than $7^{\circ} \mathrm{C}$, emergence rates began to decrease for all study years. These decreasing rates are hypothesized to be from reduction in the oxygen penetration depth in the sediments with vernal warming (increased respiration), which would reduce the number of cysts exposed to oxygen and thus able to germinate. Total germination in excess of $98 \%$ was 
attained in the sediment slurries, whereas a very low percentage of $A$. catenella emerged from the surface $1 \mathrm{~cm}$ sediment layer of the PETs $(0.3-1.2 \%)$. The equivalent relationship between temperature and the rates of germination and emergence, indicates that this difference is predominantly constrained by the steep gradients of oxygen and light in natural sediments and the effect of tortuosity. This amount of emergence is much less than has often been assumed in the past, thereby greatly reducing the potential cyst inoculum from the surface layer of sediments. Thus, if the oxygen and light penetration depths can be accounted for, laboratory germination measurements can be used to predict the emergence flux for cyst seedbeds in benthic habitats with different oxygen and light penetration depths.

The ability of the dormancy and germination mechanisms identified in Chapters 2 and 3 to ensure that germling cells emerge at the most advantageous time of year for survival was investigated in Chapter 4. This study developed a simple temperature-dependent model of $A$. catenella to investigate the sensitivity of bloom phenology to dormancy breaking by winter chilling in Nauset. In the model, the transition between cyst dormancy and quiescence is regulated by accumulation of a chilling threshold using a sigmoid function and the relationship between temperature and rates of germination and division are derived from field populations. Model bloom predictions were evaluated against observations of $A$. catenella over eight bloom years (2009-2016), during which winter and spring temperatures varied considerably $\left( \pm 2.0^{\circ} \mathrm{C}\right)$ from climatological averages. Notably, the chilling-alleviated dormancy model accurately predicted the timing of quiescence (January) and the variable bloom phenology from multiple blooms in Nauset. Once cysts became quiescent and began to germinate, however, temperatures were typically too cold for growth to exceed losses so there was a several-week lag until bloom development. Years with warmer winters and springs, like 2012 and 2016, had shorter lag periods and thus significantly earlier blooms, even though it took longer to achieve the chilling threshold to break dormancy. Thus, in Nauset, it is not the chilling requirement that regulates the timing of blooms, since this is achieved in the middle of winter every year. Rather, the temperature conditions that control vegetative growth following germination determine bloom timing and magnitude. Nevertheless, dormancy breaking by a chilling threshold is advantageous because it prevents the mismatch between conditions that are favorable for germination but not for bloom formation, that occur in the autumn and early winter in Nauset. Synchronized 
germination after winter chilling also promotes efficient conversion from the cyst seedbed to the spring bloom inoculum. The dormancy mechanism characterized here may be present in other $A$. catenella strains, as well as other cyst-forming dinoflagellates. There is plasticity in this trait as an adaptation to the temperature regime of each habitat. In another $A$. catenella habitat with warmer temperatures that support a high growth rate year round, dormancy breaking by chilling could have a more dominant role in bloom initiation.

The interactions of dormancy mechanisms with both accumulated and current environmental temperature conditions determine whether and what fraction of $A$. catenella cysts in the seedbed will germinate at a given time. This intensive look into temperature has revealed insights into the sensitivity of these processes to weather and climate variability, and if that has implications for bloom initiation in Nauset and other habitats. For shallow coastal habitats with pronounced temperature seasonality like Nauset, division-favorable temperatures are the driver of bloom initiation. Climate change predicts more anomalously warm years like 2012 and 2016 and the bloom inoculum developed differently in these years. In these years, chilling was accumulated slowly, which delayed the predicted onset of quiescence to mid-January but germling cells emerged soon after, which was earlier than other years. At this point, water temperatures were unable to support high rates of division, so there was a lag until bloom initiation occurred in early March. However, in an extreme climate warming scenario, warm temperatures supporting high division rates could occur even earlier, which could lead to even earlier blooms. This dormancy mechanism could have more influence on bloom initiation in habitats with warmer year-round temperatures than Nauset. In this type of habitat, immediately after cysts became quiescent they would be able germinate and rapidly divide. Thus, a possible response to climate warming would be slower chilling accumulation, which would delay quiescence and, counterintuitively, delay bloom initiation. Notably, this hypothesis is at odds with the climate warming hypothesis posed by Moore et al. (2008) which predicts longer windows of A. catenella growth opportunities (an extrapolation from growth rates increasing linearly with temperatures), and therefore earlier blooms. Therefore, to make predictions of how A. catenella and other cystforming HABs may respond to a warming climate, thus thesis has demonstrated the importance of understanding individual life cycle transitions in the context of the natural environment. 


\section{FUTURE RESEARCH DIRECTONS}

The work presented in this thesis has advanced our understanding of seasonal dormancy cycling of dinoflagellate cysts, opening the door to many new and exciting questions. One clear gap in our understanding is the molecular basis for chilling-alleviated dormancy. Further, the discovery of the chilling-modulated transition from dormancy to quiescence represents just half of the dormancy cycle, thus a fundamental question is: does temperature also induce dormancy in $A$. catenella cysts from Nauset? Another aspect that this work brings into focus is the paradigm that the factors controlling germination of deep water and shallow inshore A. catenella cyst populations are fundamentally different. These areas of research and proposed studies to address them will be discussed in depth below.

\section{Molecular control of dormancy}

A basic but challenging area of research is uncovering the molecular basis for chilling-alleviated dormancy. Dinoflagellates like A. catenella are known for their unique chromosomal structure and exceptionally large genomes (ca. $2 \times 10^{11}$ bases or approximately $70 \mathrm{x}$ the size of the human genome Hackett et al. 2005). Studying molecular pathways in dinoflagellates is difficult due to large size of these genomes that are mostly unannotated. Further, the extent to which dinoflagellates regulate transcription is currently unclear, because no recognizable promoter sequences promoter sequences (e.g. TATA boxes) have been identified in dinoflagellate genes. Instead, post-transcriptional gene regulation and post-translational modification are more common. Changes in protein phosphorylation levels have been tied with circadian changes in a different Alexandrium species (Schröder-Lorenz and Rensing 1987). Making the assumption that a circannual rhythm may have a similar mechanism of regulation as a circadian rhythm, I would propose an initial experiment to investigate protein phosphorylation levels in cysts with varying levels of dormancy. The identification of molecular markers for dormancy could lead to standardization of a dormancy assay for dinoflagellate cysts, which would greatly facilitate collaboration.

\section{Summer induction of dormancy}


The mechanism by which recurrent dormancy is induced in quiescent, mature $A$. catenella cysts in Nauset is not known, but is fundamental to understanding the seasonality of dormancy cycling and germination (Fig. 1). Chapter 2 demonstrated that re-induction of dormancy in natural cyst populations in Nauset coincides with warming temperatures in June. Thus, I hypothesize that dormancy can be induced by summer warming, specifically the accumulation of degree-days to a "heating threshold". Alternatively, dormancy could be induced by exceedance of a temperature threshold based on past work that showed temperatures $>18^{\circ} \mathrm{C}$ inhibit $A$. catenella germination (Anderson and Rengefors 2006).

The following experiment is planned to examine how summer warming induces recurrent dormancy. Nauset sediment samples containing newly quiescent $A$. catenella cysts (e.g. February) will be subdivided into vials for storage at 15,20 , and $25^{\circ} \mathrm{C}$ in anoxic, dark conditions that prevent germination. Cysts require oxygen for germination (Anderson et al. 1987), so anoxic storage will enable repeated assessments of cyst germinability in response to temperature treatments without risk of artifacts from unobserved germinations. Biweekly, single vials will be removed from each treatment and at least 30 cysts isolated into single wells of a tissue culture plate. Plates will be incubated under optimal conditions $\left(15^{\circ} \mathrm{C}, 14: 10 \mathrm{~h}\right.$ light:dark cycle, 250 $\mu \mathrm{mol} \mathrm{m} \mathrm{m}^{-2}$ photon flux density; (Anderson et al. 2005)), and germination will be monitored weekly. Testing of each treatment will continue until cysts become dormant (they have lost their ability to germinate). Then cysts will be chilled at $4^{\circ} \mathrm{C}$ to drive them back into quiescence and demonstrate viability. Storage conditions that both induce dormancy and preserve cyst viability will then be compared. If dormancy is induced by a heating threshold rather than a temperature boundary (e.g. $>18^{\circ} \mathrm{C}$ ), cysts in the warmest treatments will become dormant earliest. These experiments will also determine whether quiescence-to-dormancy transitions can be shifted by temperature, making onset of dormancy sensitive to weather and climate variability (as with dormancy-to-quiescence transitions).

\section{Environmental entrainment of the endogenous circannual clock}

One of the more puzzling aspects of dormancy regulation by A. catenella cysts has been the apparent conflict between the behavior of deep water and shallow, inshore populations. Dormancy cycling by cyst populations lying in the deep areas of the Gulf of Maine (GOM) have 
an endogenous circannual rhythmicity that causes quiescence to coincide with spring when conditions in overlying euphotic waters are favorable for blooms (Anderson and Keafer 1987; Matrai et al. 2005). Such endogenous rhythmicity is advantageous in these deep habitats because seasonal temperature variability at depth is greatly dampened relative to euphotic waters where blooms develop. In contrast, endogenous rhythmicity appears to be muted or absent in $A$. catenella cysts from shallow, inshore habitats in Puget Sound, WA (Moore et al. 2015) and Cork Harbour, Ireland (Rathaille and Raine 2011). However, there is one intriguing artifact of the original GOM endogenous rhythm experiment that suggests that the rhythm may not be as rigid as originally thought. The experiments by Anderson (1987) and Matrai (2005) both reported periods of approximately 11 months - less than a year. In situ, such a short period would pose a substantial ecological disadvantage to older year classes of cysts, especially considering that the lifetime of a cyst in sediment can be several decades or more (Keafer et al. 1992; Miyazono et al. 2012; Feifel et al. 2012). Notably, the experiments were performed under continuous cold storage at $2^{\circ} \mathrm{C}$, which is considerably lower than the average bottom temperature in the GOM, 7.4 ${ }^{\circ} \mathrm{C}$ ( \pm 2.6$)$ (2009-2016; http://www.neracoos.org/datatools; Fig. 2). If GOM cysts were adapted to the seasonal temperature regime and responsive to a chilling threshold like cysts from Nauset, they would accumulate chilling faster when conditioned at $2^{\circ} \mathrm{C}$, in comparison to their natural environment, which could be responsible for this 11-month period. Therefore, I hypothesize that (1) the annual dormancy cycling rhythm in GOM cysts can be entrained by chilling; and (2) temperature can shift its annual period. Experiments to address these hypotheses are currently underway.

GOM sediment samples containing dormant cysts were collected when seasonal temperatures were at a peak in November 2016. Samples were subdivided into vials for storage at $2^{\circ} \mathrm{C}, 6^{\circ} \mathrm{C}$, and $11^{\circ} \mathrm{C}$ in anoxic, dark conditions that prevent germination. $2^{\circ} \mathrm{C}$ was selected for consistency with the original GOM rhythm experiments, $6^{\circ} \mathrm{C}$ was selected because it is close to the average bottom water temperature, and $11^{\circ} \mathrm{C}$ was selected because this was the ambient bottom water temperature at the time of collection and for an additional treatment. To test this chilling response hypothesis, single vials were removed from the $2^{\circ} \mathrm{C}, 6^{\circ} \mathrm{C}$, and $11^{\circ} \mathrm{C}$ treatments biweekly and at least 30 cysts were isolated into single wells of a tissue culture plate. Plates were incubated under optimal conditions $\left(15^{\circ} \mathrm{C}, 14: 10 \mathrm{~h}\right.$ light:dark cycle, $250 \mu \mathrm{mol} \mathrm{m}^{-2} \mathrm{~s}^{-1}$ photon flux 
density; (Anderson et al. 2005), and germination was monitored weekly. Once cysts are fully quiescent, germinability tests decreased in frequency to monthly. These experiments are planned to continue for approximately one year to test the second hypothesis that temperature conditioning affects the period of the annual dormancy rhythm. If the $6^{\circ} \mathrm{C}$ treatment prolongs the period from 11 months to a full year, this indicates that the endogenous annual clock of GOM cysts is entrained to the temperature of its environment.

Preliminary comparisons reveal that the colder the treatment, the earlier that dormancy was broken (Fig. 3). The $2^{\circ} \mathrm{C}$ cysts germinated before the $6^{\circ} \mathrm{C}$ cysts, which germinated before the $11^{\circ} \mathrm{C}$ cysts. This demonstrates that GOM cysts also have a chilling requirement - however, it is parameterized differently than Nauset cysts. Importantly, GOM cysts transitioned from dormancy to quiescence approximately 1 month later than Nauset cysts. For example, in the $2^{\circ} \mathrm{C}$ storage treatment, half of the Nauset cysts became quiescent after $\sim 50$ days (Chapter 2), whereas half of the GOM cysts became quiescent after $\sim 80$ days (Fig. 3). Once the complete dataset has been attained, optimization tests will be performed to determine the most appropriate threshold temperature $\left(T_{\max }\right)$ below which GOM cysts sense chilling, and the chilling requirement that must be met for $50 \%$ of a cyst population to achieve quiescence $\left(G_{50}\right)$. These findings indicate that the endogenous clock is not as rigid as originally thought, and instead can be entrained by environmental temperature.

Of the three forms of seasonal rhythms defined by the field of chronobiology, the dormancy rhythm of GOM cysts would be classified as a Type II rhythm, or a "true" circannual rhythm (Gwinner 1986). Type II rhythms are fully endogenous, persist for two or more cycles with a period that is less than 12 months in individuals maintained in constant conditions. In nature, this rhythm is entrained to the seasonal cycle (e.g., temperature) and is a full 12 months. Thus, an environmentally-entrained endogenous clock in GOM cysts would be better able to respond to shifts in the natural environment than an inflexible rhythm. Although these data analyses and the periodicity experiment are still in progress, these preliminary results shift a long-standing paradigm. 


\section{CONCLUSION}

The ability of cold conditioning to improve viability and shorten the duration of cyst dormancy has been demonstrated in several other species of dinoflagellates but its ecological relevance and mechanism was never understood (Stosch 1967; 1973; Montresor and Marino 1996), until now. Together, these thesis chapters have constructed a conceptual model of how A. catenella dormancy and germination are synchronized to seasonal temperature cycles, and improve the odds of a germling cell surviving, dividing, and reproducing. Although the studies were conducted in Nauset, an estuarine embayment, the basic framework may be universal for $A$. catenella populations across habitats. Critical to further exploration across habitats and among dinoflagellate species will be an integrated experimental, observational, and modelling approach such as the employed here to identify the relevant environmental windows of opportunity.

\section{REFERENCES}

Anderson, D. M., and B. Keafer. 1987. An endogenous annual clock in the toxic marine dinoflagellate Gonyaulax tamarensis. Nature 325: 616-617.

Anderson, D. M., and K. Rengefors. 2006. Community assembly and seasonal succession of marine dinoflagellates in a temperate estuary: The importance of life cycle events. Limnology and Oceanography 51: 860-873.

Anderson, D. M., C. A. Stock, B. Keafer, and others. 2005. Alexandrium fundyense cyst dynamics in the Gulf of Maine. Deep Sea Research II 52: 2522-2542. doi:10.1016/j.dsr2.2005.06.014

Anderson, D. M., C. D. Taylor, and E. V. Armbrust. 1987. The effects of darkness and anaerobiosis on dinoflagellate cyst germination. Limnology and Oceanography 32: 340-351.

Feifel, K. M., S. K. Moore, and R. A. Horner. 2012. An Alexandrium Spp. Cyst Record from Sequim Bay, Washington State, USA, and its Relation to Past Climate Variability. Journal of Phycology 48: 550-558. doi:10.1111/j.1529-8817.2012.01175.x

Gwinner, E. 1986. Circannual Rhythms: Endogenous Annual Clocks in the Organization of Seasonal Processes, W. Burggren, S. Ishii, K. Johansen, H. Langer, G. Neuweiler, and D.J. Randell [eds.]. Springer-Verlag.

Hackett, J. D., T. E. Scheetz, H. S. Yoon, M. B. Soares, M. F. Bonaldo, T. L. Casavant, and D. Bhattacharya. 2005. Insights into a dinoflagellate genome through expressed sequence tag analysis. BMC Genomics 6: 1-13. doi:10.1186/1471-2164-6-80 
Keafer, B. A., K. O. Buesseler, and D. M. Anderson. 1992. Burial of living dinoflagellate cysts in estuarine and nearshore sediments. Marine Micropaleontology 20: 147-161.

doi:10.1016/0377-8398(92)90004-4

Matrai, P., B. Thompson, and M. Keller. 2005. Circannual excystment of resting cysts of Alexandrium spp. from eastern Gulf of Maine populations. Deep Sea Research Part II 52: 2560-2568. doi:10.1016/j.dsr2.2005.06.013

Miyazono, A., S. Nagai, I. Kudo, and K. Tanizawa. 2012. Viability of Alexandrium tamarense cysts in the sediment of Funka Bay, Hokkaido, Japan: Over a hundred year survival times for cysts. Harmful Algae 16: 81-88. doi:10.1016/j.hal.2012.02.001

Montresor, M., and D. Marino. 1996. Modulating effect of cold-dark storage on excystment in Alexandrium pseudogonyaulax (Dinophyceae). Marine Biology 127: 55-60. doi:10.1007/BF00993643

Moore, S. K., B. D. Bill, L. R. Hay, J. Emenegger, K. C. Eldred, C. L. Greengrove, J. E. Masura, and D. M. Anderson. 2015. Factors regulating excystment of Alexandrium in Puget Sound, WA, USA. Harmful Algae 43: 103-110. doi:10.1016/j.hal.2015.01.005

Rathaille, A. N., and R. Raine. 2011. Seasonality in the excystment of Alexandrium minutum and Alexandrium tamarense in Irish coastal waters. Harmful Algae 10: 629-635. doi:10.1016/j.hal.2011.04.015

Schröder-Lorenz, A., and L. Rensing. 1987. Circadian changes in protein-synthesis rate and protein phosphorylation in cell-free extracts of Gonyaulax polyedra. Planta 170: 7-13. doi:10.1007/BF00392374

Stosch, H. A., von. 1967. Haptophyceae, p. 646-656. In W. Ruhland [ed.], Encyclopedia of Plant Physiology. Gottingen and Heidelberg.

Stosch, H. A., von. 1973. Observations on vegetative reproduction and sexual life cycles of two freshwater dinoflagellates, Gymondinium pseudopalustre Schiller and Woloszynskia apiculata sp. nov. British Phycological Journal 8: 105-134. doi:10.1080/00071617300650141 
FIGURES

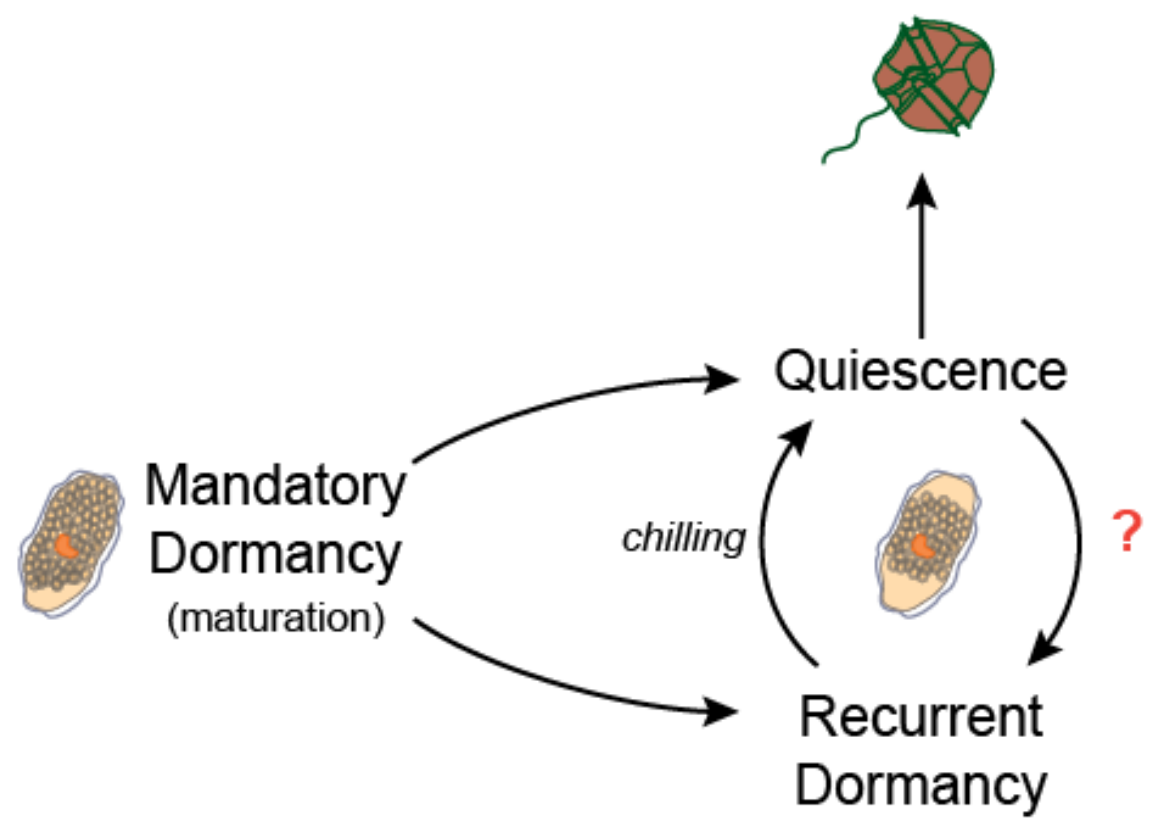

Fig. 1. Environmental modulation of dormancy-quiescence cycling of Alexandrium catenella cysts in Nauset. Immediately after formation, mandatory dormancy prevents germination so cysts can complete maturation. Mandatory dormancy is alleviated by factors within the cyst. At this point, cysts become quiescent or enter recurrent dormancy. Recurrent dormancy can be alleviated by conditioning with a specific amount of chilling. Once quiescent, cysts can germinate under favorable environmental conditions. The internal and environmental processes that induce recurrent dormancy in cysts are unknown and indicated by question marks. The quantity of starch granules within the cartoon cysts reflects the starch being utilized as a cyst matures and ages. 


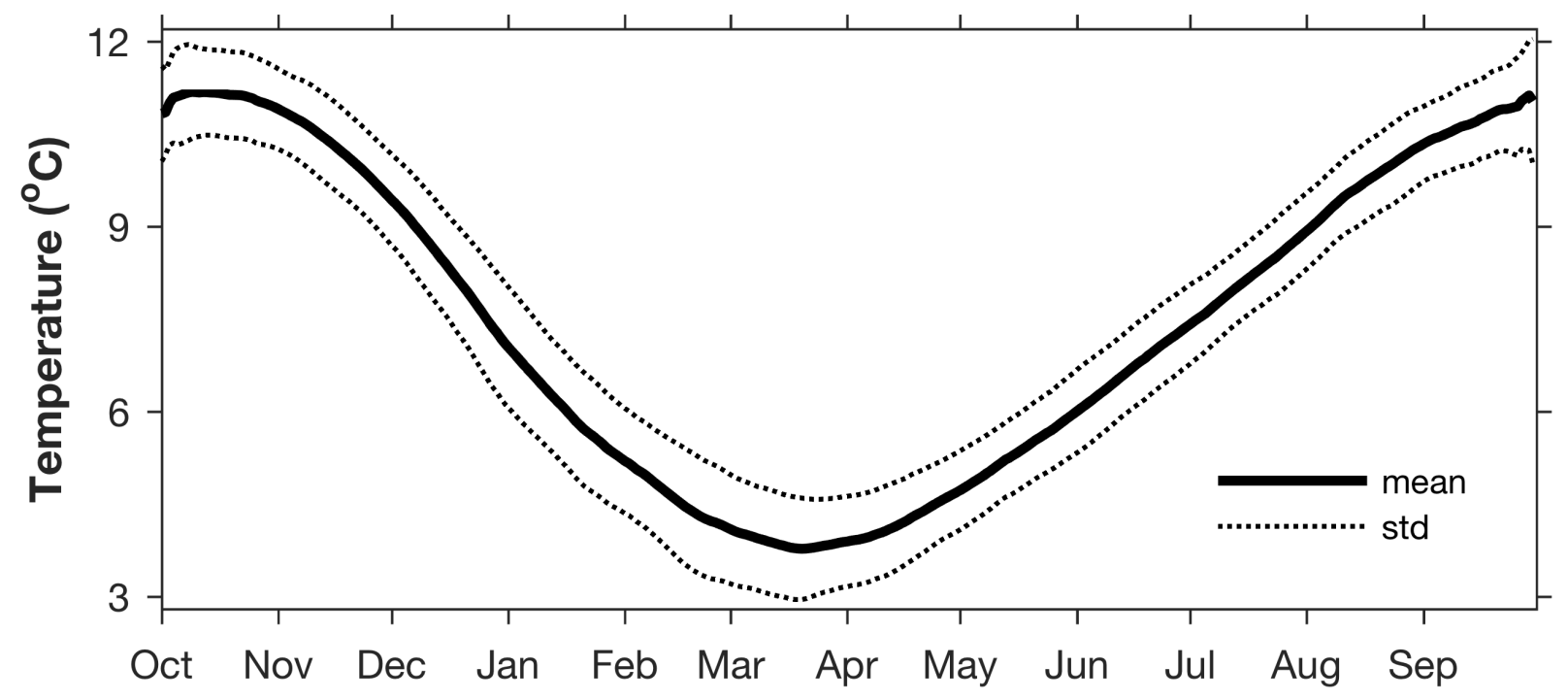

Fig. 2. Monthly variation in the bottom waters of the Central Gulf of Maine from October 2008 to 2015. Data are from the NERACOOS E buoy at $\sim 150 \mathrm{~m}$ depth. 


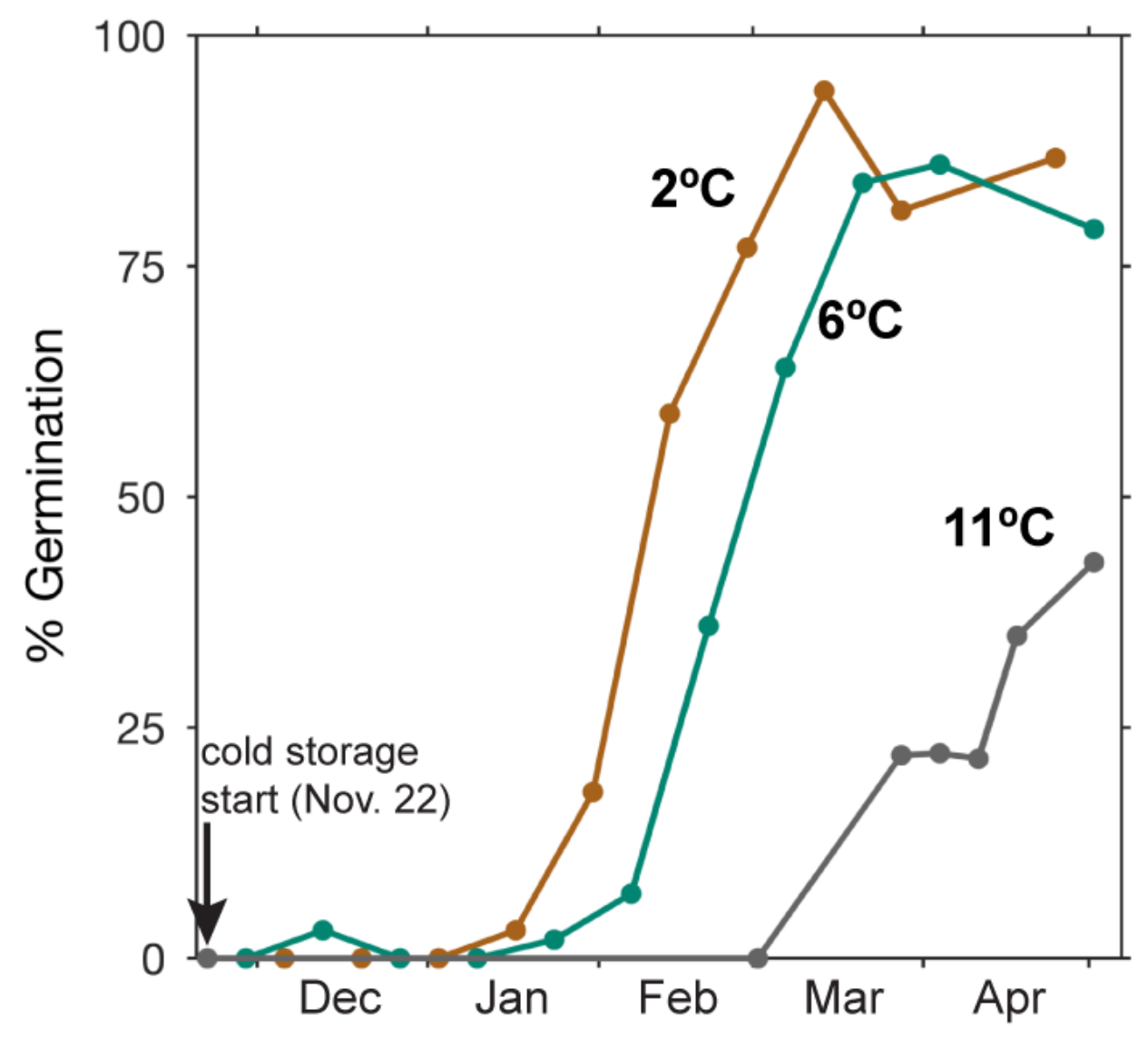

Fig. 3. Time course of percent germination of cyst cohorts exhumed from $2^{\circ} \mathrm{C}, 6^{\circ} \mathrm{C}$, and $11^{\circ} \mathrm{C}$ anoxic, dark storage. Germination success was measured after incubation for one week under optimal conditions $\left(15^{\circ} \mathrm{C}, 14: 10 \mathrm{~h}\right.$ light:dark cycle, $250 \mu \mathrm{mol} \mathrm{m} \mathrm{m}^{-2} \mathrm{~s}^{-1}$ photon flux density). 


\section{Appendix}

\section{The persistence of Alexandrium catenella cyst seedbeds in Nauset Marsh}

\section{INTRODUCTION}

The localization of Alexandrium catenella cyst accumulations in bottom sediments (termed "seedbeds") can be an important determinant for where blooms occur. In both estuarine systems and in deeper coastal waters, discrete cyst seedbeds have been shown to provide the inoculum for A. catenella blooms (Crespo et al. 2011; Ralston et al. 2015). In some habitats, the size of the cyst seedbed and the timing of an extent of excystment can directly affect the magnitude of blooms (Wall 1971; McGillicuddy 2011; Anderson et al. 2014). Cyst seedbeds have obvious implications for the persistence of $A$. catenella - thus understanding temporal dynamics is important.

Cyst seedbeds are dynamic environments affected by a number of biological and physical factors (Fig. 1). Dispersion and accumulation regulate the horizontal distribution of cysts, whereas burial, bioturbation by benthic organisms, and resuspension contribute to their vertical distribution (Anderson et al. 1982; Giangrande et al. 2002) (Anderson et al. 1982). In addition to these processes, biotic factors, including germination, natural mortality, and degradation, also determine cyst abundances in the sediment (e.g. Persson et al. 2000). The extent to which these factors affect the cyst seedbed depends on the nature of the habitat. In the open ocean, cyst abundance is a result of a complex combination of production, lateral transport, resuspension, and accumulation processes (Richter et al. 2007). This is contrasted with confined shallow water systems, which tend to have tighter connections between cysts and vegetative populations or particular environmental conditions (e.g. Garcés 2004). 
Here, the temporal variability of two A. catenella cyst seedbeds was assessed over multiple years in a shallow coastal embayment. Nauset Marsh (Cape Cod, MA) has three localized seedbeds at the extreme ends of the complex network of channels and kettle ponds that each host independent, localized A. catenella blooms (Crespo et al. 2011). Past surveys conducted in Nauset in the autumn of 2008 and 2009 suggest that cyst distributions vary temporally (Crespo et al. 2011), but whether these variations are of seasonal or annual nature is impossible to say given the scarcity of the data. The broad questions posed in this study are: (1) How variable is the size of the cyst seedbed over multiple years? (2) What are the key gain and loss processes affecting the size of the cyst seedbed and do they differ annually and seasonally? and (3) How are cysts dispersed vertically in the sediments? The work presented here is an incomplete investigation, however provides a fascinating preliminary dataset from which follow up studies can be launched.

\section{METHODS}

\section{Temporal surveys of resting cyst abundance in Salt Pond and Roberts Cove}

Monthly, sediment cores were collected in triplicate from a site in the northern shore of Salt Pond and a site in Roberts Cove. Different methods were used to collected undisturbed sediment cores due to differences in the water depth at each of the sites: a hand corer was used in Roberts Cove and a gravity corer from a boat was used in Salt Pond. All cores had a light-colored, oxygenated surface layer overlaying anoxic sediment, which was identified by its black coloration and odor. Cores were extruded for collection of the uppermost $0-1 \mathrm{~cm}$ surface and the 1-3 cm subsurface layers of sediment on site.

In Salt Pond the 0-1 cm layer was sampled from 04 March 2013 to 18 June 2015, and the 1-3 cm layer was sampled from 04 September 2013 to 30 May 2015. In Roberts Cove the 0-1 cm layer was sampled from 05 November 2012 to 30 May 2015, and the 1-3 cm layer was sampled from 04 September 2013 to 30 May 2015. In the month before and after the 2013, 2014, and 2015 blooms, sampling increased to near weekly. 
Once in the laboratory, the samples were sonicated with a Branson Sonifier 250 at a constant 40W output for $1 \mathrm{~min}$, and sieved to yield a clean, 20-100 $\mu \mathrm{m}$ size fraction (Anderson et al. 2003). These fractions were fixed in $10 \%$ unbuffered formalin in seawater $(\mathrm{v} / \mathrm{v})$ at $4^{\circ} \mathrm{C}$ for at least 30 min, then resuspended in $-20{ }^{\circ} \mathrm{C}$ methanol for pigment extraction for at least $48 \mathrm{~h}$. Cyst fractions were then resuspended in $200 \mu \mathrm{g} \mathrm{mL}^{-1}$ primulin in deionized water (Yamaguchi et al. 1995). After staining for $30 \mathrm{~min}$, the sample was centrifuged and decanted for the final time and brought up to $5 \mathrm{ml}$ with deionized water. Finally, A. catenella cysts were counted in a Sedgewick Rafter slide under a Zeiss Axioskop microscope with blue light excitation and a $520 \mathrm{~nm}$ long pass emission filter. A. catenella cysts were identified by positive staining and their characteristic pill shape, 55-60 $\mu \mathrm{m}$ long and 20-25 $\mu \mathrm{m}$ in diameter.

\section{Measurements of new cyst production}

In the weeks leading up to the the 2013, 2014, and 2015 blooms, triplicate sediment samples were taken at the northwest site in Salt Pond. Sediment was subsampled for primulin counts (described above) and live counts, which will be described here. Following sonication and sieving, the cysts in the 20-100 $\mu \mathrm{m}$ size fraction were separated from same size particles with higher specific densities using density cushion centrifugation as described by Schwinghamer et al. (1991). The density of $A$. catenella cysts range from 1.15 to $1.30 \mathrm{~g} \mathrm{~cm}^{-3}$, so heavy solutions of colloidal silica were adjusted to $1.40 \mathrm{~g} \mathrm{~cm}^{-3}$ through addition of sucrose to ensure complete retention of cysts at the cushion interface. Round-bottom step gradient tubes were centrifuged for $15 \mathrm{~min}$ at $1500 \mathrm{rpm}$ then cysts and other organic material were removed from the cushion interface and overlaying suspension by Pasteur pipette. Afterwards, cysts and other light debris were concentrated and thoroughly rinsed with filtered seawater over a $20 \mu \mathrm{m}$ sieve. Sieve contents were then backwashed to a Sedgewick-Rafter counting chamber from which cysts could be easily counted under $160 \mathrm{X}$ magnification.

The fraction of new cysts in each sample was determined by enumerating the number of "immature" and "mature" cysts. Immediately after their formation, the cytoplasm of new $A$. catenella cysts is filled with starch granules that are consumed and become concentrated around the cysts' mid-body or poles as cysts mature, a process that takes 1-3 months depending on storage temperature (Fig. 2; Anderson 1980). Using this morphological distinction, the 
abundance of new, immature cysts was recorded relative to the older mature ones. The fraction of immature cysts of the total (immature cysts + mature cysts) were determined from observation of no less than 449 cysts.

\section{Vertical distribution of cyst viability}

To assess the vertical distribution of viable cysts in the sediments, sediment cores were collected from a shallow and deep site in Salt Pond. The shallow site $(\sim 3 \mathrm{~m})$ was the same northern site used in the temporal study, and the deep site ( $7 \mathrm{~m})$ was from the center of Salt Pond. Triplicate cores were collected on 08 April 2015 as the pre-bloom time-point and on 01 September as the post-bloom time-point. Cores were processed as described in the temporal study, but the $3-5 \mathrm{~cm}$ layer, 5-7 cm layer, 7-9 $\mathrm{cm}$ layer, and the 9-11 $\mathrm{cm}$ layer were also sampled. Total cyst abundance was counted using the primulin staining. Additionally, a live count was performed to assess cyst viability. Here, "dead" cysts were counted, in addition to "immature" and "mature" cysts. Dead cysts have a darkened hue and internal starch that is more granular in appearance, and in some cases, internal vacuoles were present within the accumulation body.

\section{PRELIMINARY RESULTS \& DISCUSSION}

Cyst abundances in the surficial sediments were measured on weekly to monthly timescales from March 2013 to June 2015 in Salt Pond and from November 2012 to June 2015 in Roberts Cove. The size of the cyst seedbed in both locations shifted by orders of magnitude during the period of observation (Fig. 3). Within Salt Pond, the cyst seedbed concentration ranged from a maximum of 17,050 cysts cc $^{-1}$ to a minimum of 50 cysts cc$^{-1}$ in the $0-1 \mathrm{~cm}$ layer. The size of the Roberts Cove cyst seedbed was more constant and ranged from a maximum of $6,363 \mathrm{cysts} \mathrm{cc}^{-1}$ to a minimum of 715 cysts cc $^{-1}$. Despite differences in cyst abundance, both sites revealed similar temporal patterns of gains and losses to the cyst seedbed.

\section{New cyst production by natural blooms}

Gains to the cyst seedbed coincided with termination of the 2013, 2014, 2015 blooms in Salt Pond, and the 2013 and 2015 blooms in Roberts Cove. Despite the similar magnitudes of the 
2013 and 2015 blooms, the size of the cyst enrichment was larger following the 2013 bloom. This was most dramatic in Salt Pond, where the enrichment was about five times higher in 2013 than in 2015. In Salt Pond, this enhanced enrichment in 2013 is demonstrated through observations of new cyst production, by quantifying the proportion of cysts having the immature morphology (Fig. 2). In the 0-1 cm layer, the greatest proportion observed during the 2013 bloom was $88 \%$ (31 May), whereas the greatest proportion observed during the 2015 bloom was $64 \%$ (19 May) (Fig. 4). The proportion of new cysts in the 1-3 cm layer was also measured in 2015 , and reached its highest value, $40 \%$ new cysts, on 27 May. This short lag between the highest new cyst proportions in the $0-1 \mathrm{~cm}$ and $1-3 \mathrm{~cm}$ layers demonstrates the short timescale of sediment mixing in Nauset, or alternatively planozygotes swimming down into the sediment.

Differences between the size of the cyst enrichment among years could be due to the interaction of the swimming behavior of planozygotes, the immediate precursor to cysts in the life cycle, and advection. It was recently demonstrated that planozygotes vertically migrate nearer to the water surface, which significantly increases the physical dispersal of cysts (Brosnahan et al., in revision). A hydrodynamic modeling study found that these surface ambits reduces the residence time of cells within Salt Pond by half relative to the vertical migration behavior exhibited during bloom development (Ralston et al. 2015). Thus depending on the timing of the tides and the daily migrations, this behavior could result in a greater loss of planozygotes, and thus cysts, from the system.

In the blooms with the largest cyst depositions - both 2013 blooms and in the Salt Pond 2015 bloom - there was a notable time lag between the disappearance of planktonic stages and the appearance of new resting cysts (Fig. 3). Conversely, in the 2014 bloom in Salt Pond and the 2015 bloom in Roberts Cove, cyst enrichment coincided with the peak of the bloom. Another interesting feature of these blooms was that their 1-3 cm layer became enriched before the $0-1$ cm layer. In the 2013 bloom, Brosnahan et al. (in revision) determined that this lag was a result of planozygotes settling on the bottom and swimming in the sediment interstices prior to encystment. Differences between blooms with a time lag and without a time lag could be due to earlier cyst formation in the sediments. 


\section{Vertical distribution of viable cysts in the sediments}

Differences in the vertical distribution of cyst viability were examined before and after the 2015 bloom at a shallow site and a deep site in Salt Pond. Predictably, the surficial sediments of the shallow site were enriched with cysts following the bloom. Notably, no immature cysts were found in any of the samples in this study, demonstrating the brevity of this morphology. The concentration of cysts with mature morphology nearly quadrupled in the 0-3 layer of sediment

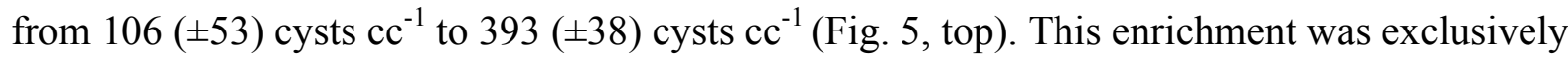
from new cysts that had become mature by the time these cores were taken in September. Below $3 \mathrm{~cm}$ in the sediments, the concentration of both mature and dead cysts decreased slightly in the post-bloom sample. A different response to the bloom was documented at the deep site. The total cyst concentration was smaller and the number of cysts in the 0-3 cm layer did not change with

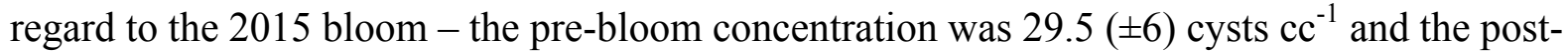
bloom concentration was $24( \pm 2)$ cysts cc $^{-1}$ (Fig. 5, bottom). However, just like the shallow site, very few cysts were observed below $3 \mathrm{~cm}$ depth, and this number decreased in the post-bloom sample. Notably, the number of cysts with dead morphology also decreased, which suggests decay over the summer occurred before the post-bloom sample was collected in September. One possible explanation for reduced dead cysts in these samples are accelerated disintegration over the summer due to warmer temperatures.

\section{Conclusions}

These results demonstrate that the cyst seeded is a dynamic system and is impacted by a number of gain and loss processes. Gains from cyst enrichment from the 2013, 2014, and 2015 blooms were documented. The size of enrichment from new cyst formation varied considerably and was not necessarily related to bloom magnitude. Specifically, there was more enrichment from the 2013 bloom than the 2015 bloom. It is unlikely this difference was a result of biases from a single sample site because this enrichment pattern was observed in both Salt Pond and Roberts Cove. A reasonable explanation for cyst enrichment differences between the 2013 and 2015 blooms is likely the interaction of the surface localization behavior and physical advection (Brosnahan et al. in revision). Of course, fewer cysts could have also been produced in the 2015 bloom. 
A general decrease in the cyst seedbed at both Salt Pond and Roberts Cove was observed between pulses of enrichment from cyst formation in blooms. Losses could be from a multitude of factors, including germination, sediment erosion, bioturbation, predation, death, and decay (Fig. 1). This study provides some indication as to the extent of processes of death and decay in natural sediments. Observations of the vertical distribution of cysts in the sediments revealed the maximum cyst abundances are concentrated in the $0-3 \mathrm{~cm}$ thickness of sediment. This is consistent with observations of new cysts in the 2015 bloom which were found in both the $0-1$ $\mathrm{cm}$ and 1-3 cm layers, and demonstrates the high amount of sediment mixing. Further, below 3 $\mathrm{cm}$, the number of cysts with both mature and dead morphology declined between the April and September 2015 samples, which suggests that decay from higher microbial respiration rates in the warm summer months could be the cause of this. This drop-off below $3 \mathrm{~cm}$ is interesting and further studies are needed to better understand why. Another important finding from this viability study was the abundance of cysts with dead morphology. Depending on the integrity of their cell wall, these dead cysts could be stained by the primulin method that is used to quantify cysts. This would bias our estimates of the viable cyst seedbed higher. Studies that more closely examine the seasonality of the fraction of dead cysts in the seedbed would be informative. Although preliminary, the observations and analyses presented in this Appendix have important implications for the persistence and dynamics of other $A$. catenella cyst seedbeds.

\section{REFERENCES}

Anderson, D. M. 1980. Effects of Temperature Conditioning on Development and Germination of Gonyaulax tamarensis (Dinophyceae) Hypnozygotes. Journal of Phycology 16: 166-172.

Anderson, D. M., B. A. Keafer, J. L. Kleindinst, and others. 2014. Alexandrium fundyense cysts in the Gulf of Maine: Long-term time series of abundance and distribution, and linkages to past and future blooms. Deep-Sea Research Part II 1-21. doi:10.1016/j.dsr2.2013.10.002

Anderson, D. M., D. G. Aubrey, M. Tyler, and D. W. Coats. 1982. Vertical and horizontal distributions of dinoflagellate cysts in sediments. Limnology and Oceanography 27: 757765. doi:10.4319/1o.1982.27.4.0757

Anderson, D. M., Y. Fukuyo, and K. Matsuoka. 2003. Cyst Methodologies, p. 165-190. In G.M. Hallegraeff, D.M. Anderson, and A.D. Cembella [eds.], Manual on Harmful Marine Microalgae.

Brosnahan, M. L., D. K. Ralston, A. D. Fischer, A. R. Solow, and D. M. Anderson. Estimation of 
benthic cyst yield from a bloom of the toxic dinoflagellate Alexandrium catenella reveals shoaling of diel vertical migration and sediment infiltration by its cyst precursor stage. Limnology and Oceanography.

Crespo, B. G., B. A. Keafer, D. K. Ralston, H. Lind, D. Farber, and D. M. Anderson. 2011. Dynamics of Alexandrium fundyense blooms and shellfish toxicity in the Nauset Marsh System of Cape Cod (Massachusetts, USA). Harmful Algae 12: 26-38. doi:10.1016/j.hal.2011.08.009

Garcés, E. 2004. Relationship between vegetative cells and cyst production during Alexandrium minutum bloom in Arenys de Mar harbour (NW Mediterranean). Journal of Plankton Research 26: 637-645. doi:10.1093/plankt/fbh065

Giangrande, A., M. Montresor, A. Cavallo, and M. Licciano. 2002. Influence of Naineris laevigata (Polychaeta: Orbiniidae) on vertical grain size distribution, and dinoflagellate resting stages in the sediment. Journal of Sea Research 47: 97-108. doi:10.1016/S13851101(01)00103-4

McGillicuddy, D. I., Jr. 2011. Suppression of the 2010 Alexandrium fundyense bloom by changes in physical, biological, and chemical properties of the Gulf of Maine. Limnology and Oceanography 56: 2411-2426. doi:10.4319/lo.2011.56.6.2411

Persson, A., A. Godhe, and B. S. O. Karlson. 2000. Dinoflagellate cysts in recent sediments from the west coast of Sweden. Botanica Marina 43: 69-79.

Ralston, D. K., M. L. Brosnahan, S. E. Fox, K. Lee, and D. M. Anderson. 2015. Temperature and Residence Time Controls on an Estuarine Harmful Algal Bloom: Modeling Hydrodynamics and Alexandrium fundyense in Nauset Estuary. Estuaries and Coasts 38: 2240-2258. doi:10.1007/s12237-015-9949-z

Richter, D., A. Vink, K. A. F. Zonneveld, H. Kuhlmann, and H. Willems. 2007. Calcareous dinoflagellate cyst distributions in surface sediments from upwelling areas off NW Africa, and their relationships with environmental parameters of the upper water column. Marine Micropaleontology 63: 201-228.

Schwinghamer, P., D. M. Anderson, and D. M. Kulis. 1991. Separation and concentration of living dinoflagellate resting cysts from marine sediments via density-gradient centrifugation. Limnology and Oceanography 36: 588-592. doi:10.4319/1o.1991.36.3.0588

Wall, D. 1971. Biological problems concerning fossilizable dinoflagellates. Geoscience and Man 3: 1-15. doi:10.1080/00721395.1971.9989704

Yamaguchi, M., S. Itakura, I. Imai, and Y. Ishida. 1995. A rapid and precise technique for enumeration of resting cysts of Alexandrium spp. (Dinophyceae) in natural sediments. Phycologia 34: 207-214. doi:10.2216/i0031-8884-34-3-207.1 


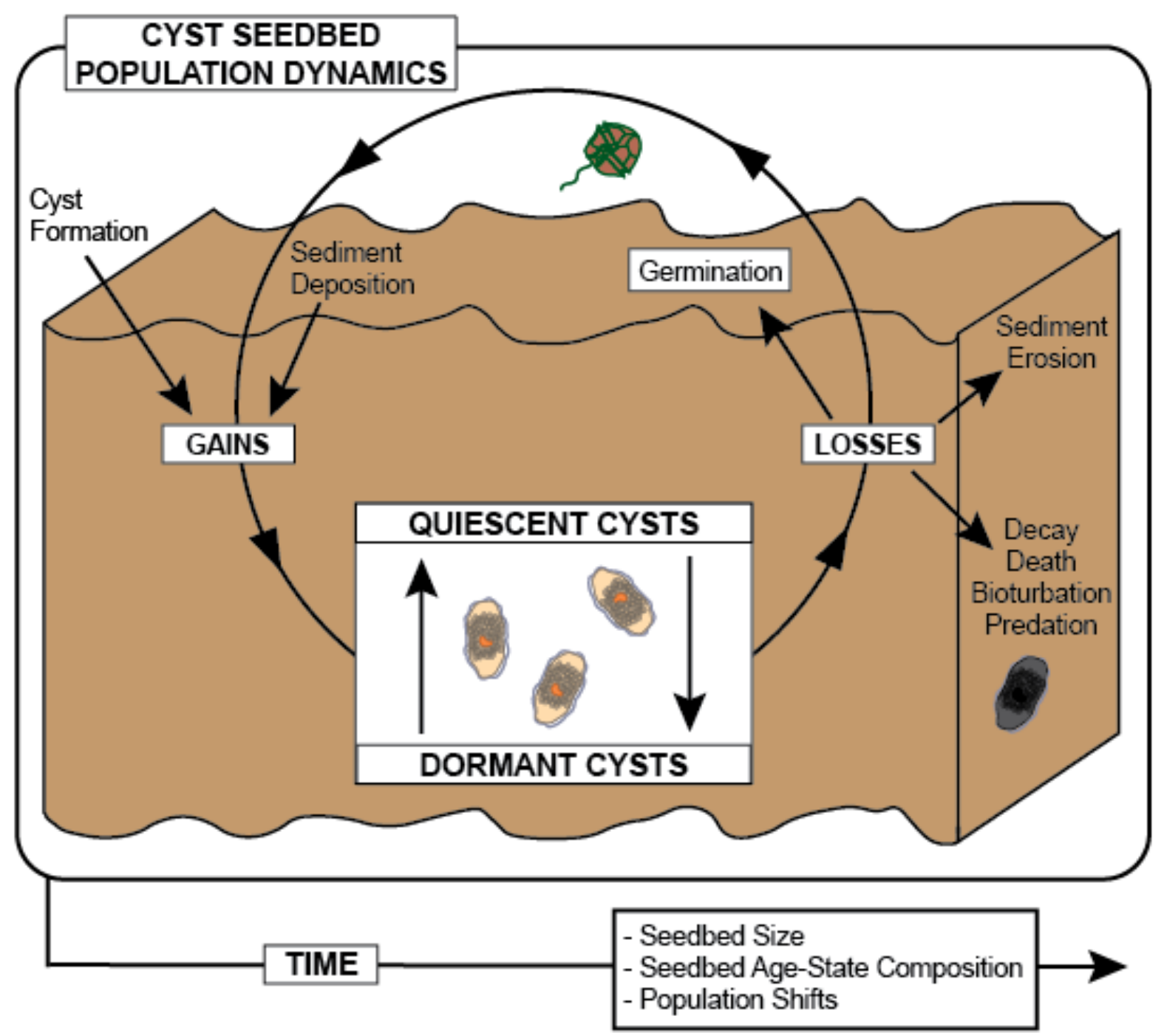

Fig 1 . Biological and physical factors affecting population dynamics of $A$. catenella cysts in the sediment. 

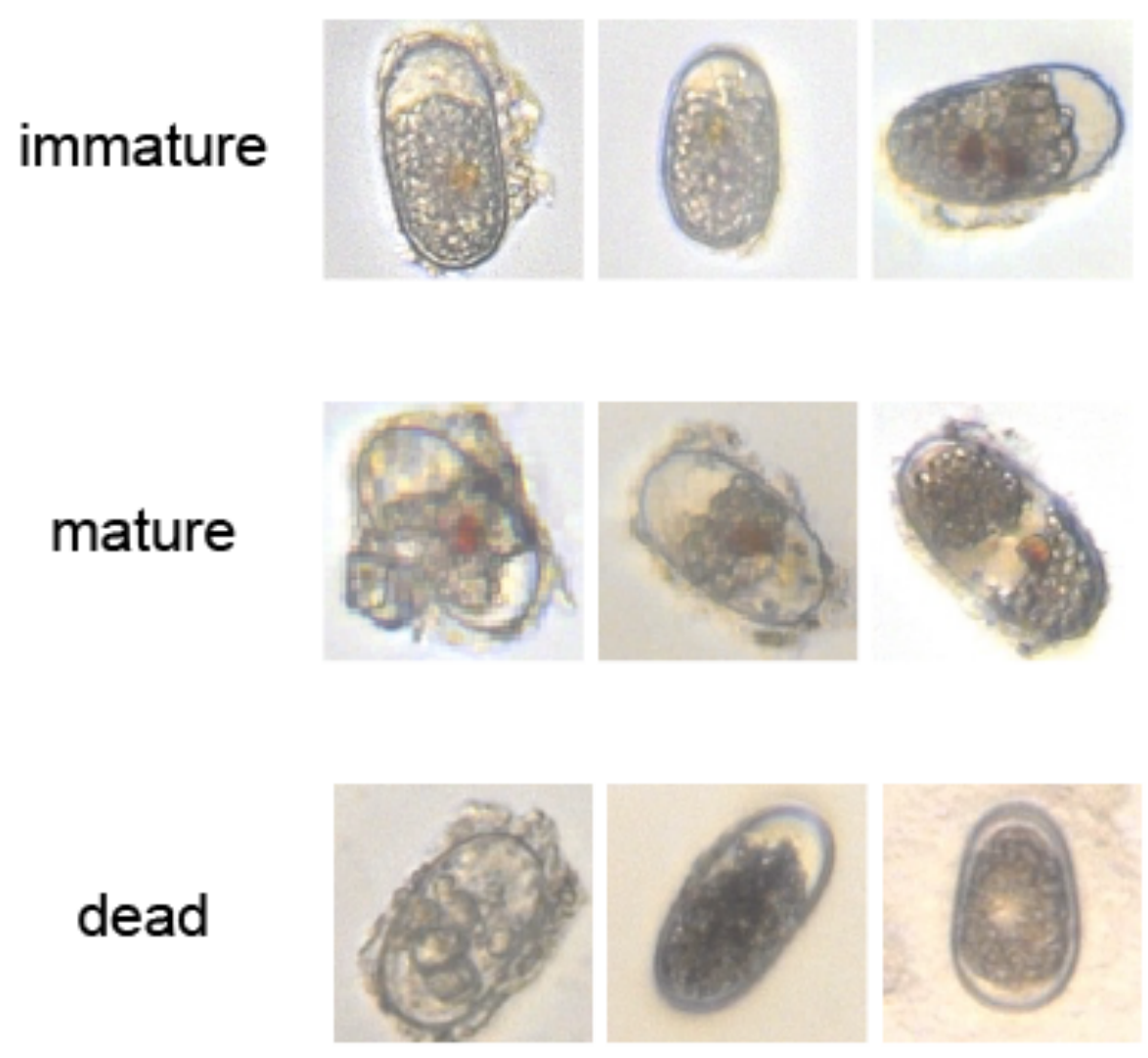

Fig. 2. Morphology of immature, mature, and dead cysts of A. catenella. The cysts classified as 'immature' were imaged within a week of bloom termination and so are also very new. 

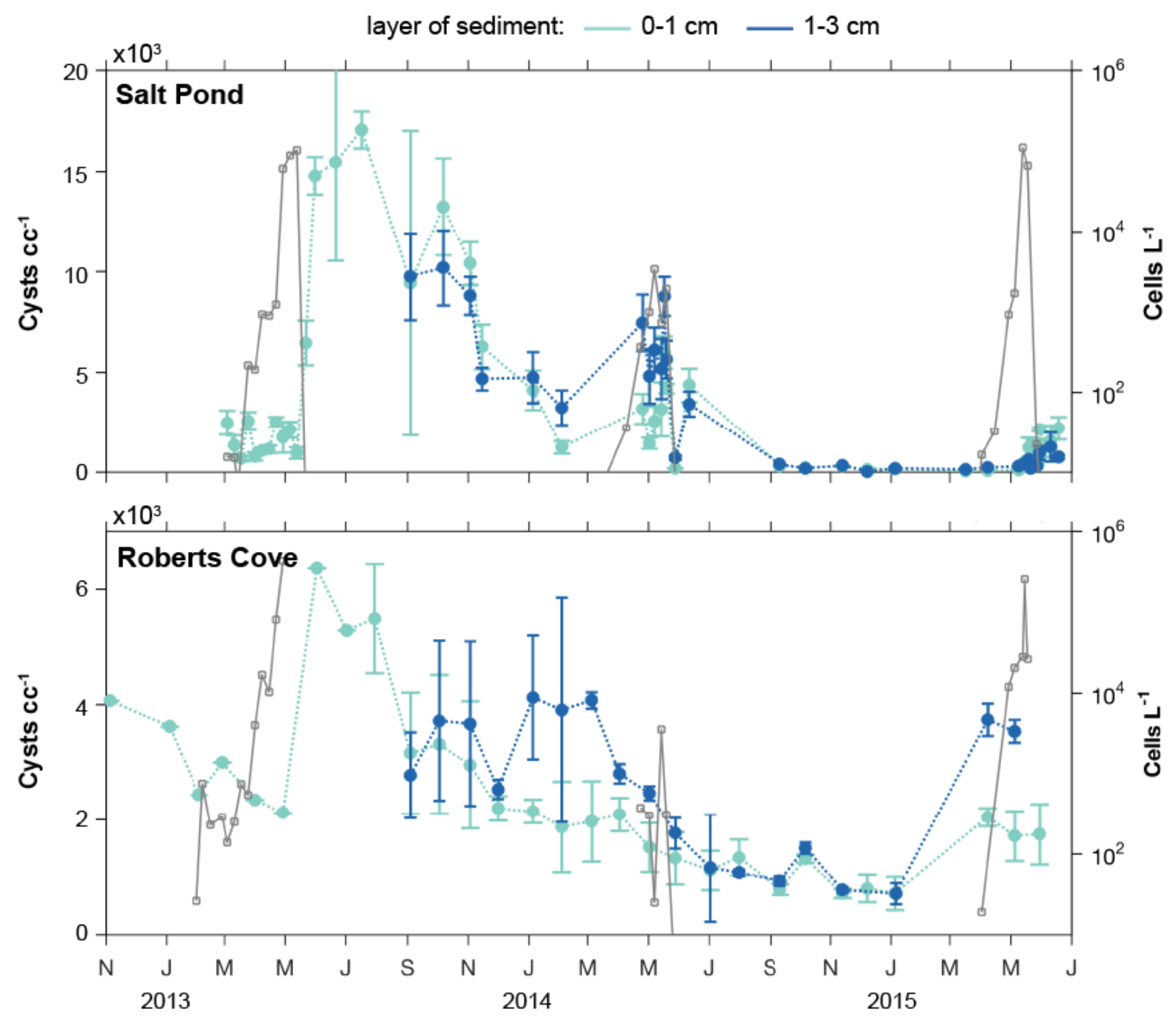

Fig. 3. Time series of $A$. catenella cyst abundance in the surface sediments of Salt Pond and Roberts Cove in relation to bloom timing in 2013, 2014, and 2015. 

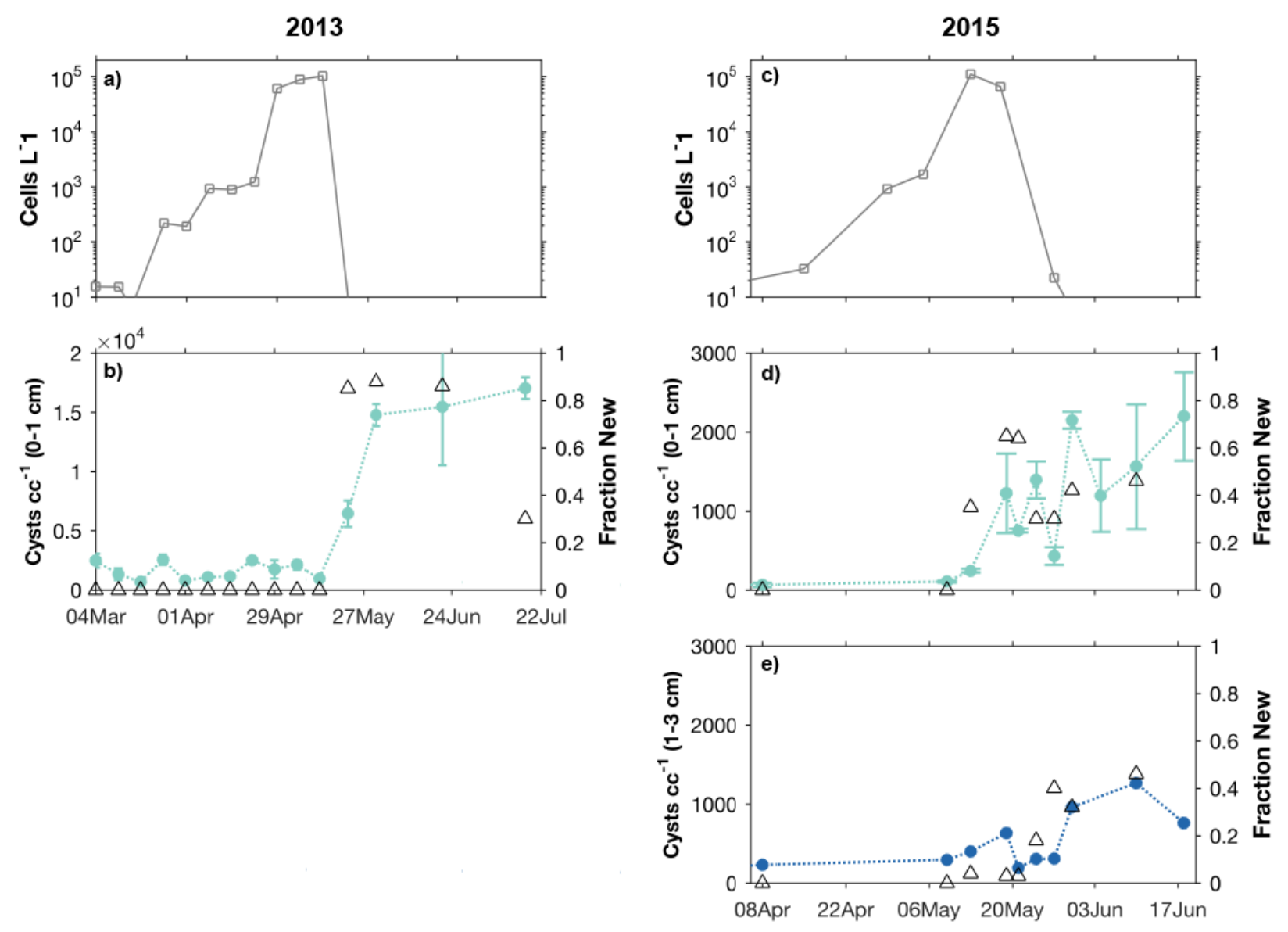

Fig. 4. Cyst seedbed enrichment from the 2013 and 2015 spring blooms in Salt Pond. Cell concentrations are means of weekly bottle samples collected at 1,3,5, and $7 \mathrm{~m}$. Cyst abundance (closed blue circles) and new cyst fractions (open black triangles) are means of weekly triplicate sampling of surficial sediment in the $0-1 \mathrm{~cm}$ and $1-3 \mathrm{~cm}$ layers near the northern shore of Salt Pond. The 1-3 cm layer was not sampled during the 2013 bloom. 

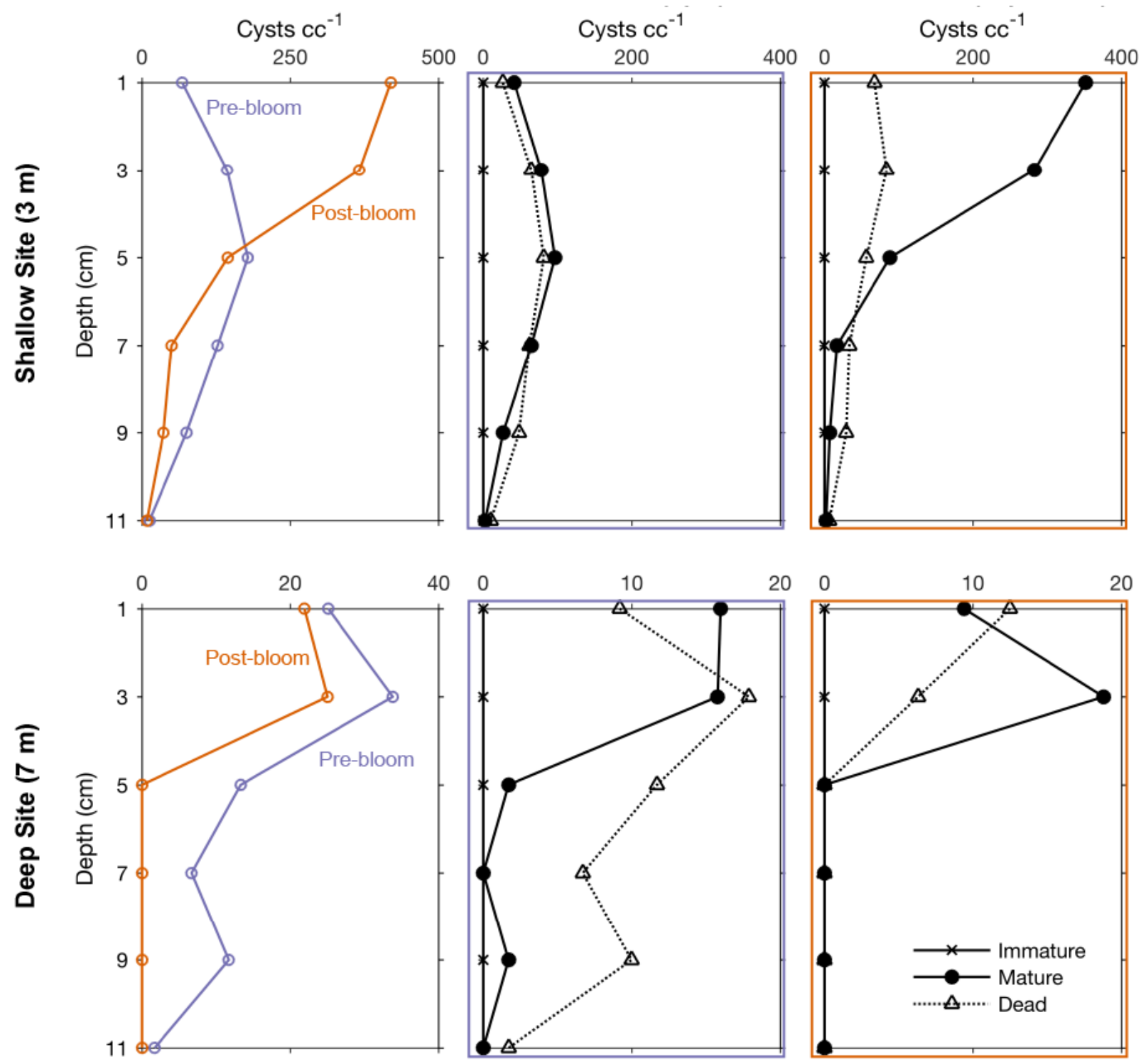

Fig. 5. Pre- and post-bloom cyst abundance at a shallow and deep site in Salt Pond. Pre-bloom cores were taken in April 2015 and post-bloom cores were taken in September 2015. The shallow site is near the northern shore and the deep site is in the center of Salt Pond. Cysts were counted as immature, mature, and dead. 
